\title{
Governing
}

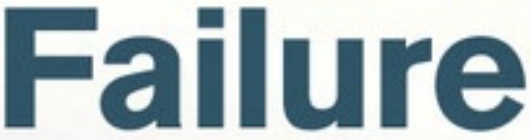

\section{Provisional Expertise and the Transformation of Global Development Finance}

\section{JACQUELINE BEST}

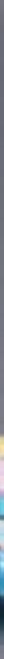




\section{Governing Failure}

Jacqueline Best argues that the changes in International Monetary Fund, World Bank and donor policies in the 1990s, towards what some have called the 'Post-Washington Consensus,' were driven by an erosion of expert authority and an increasing preoccupation with policy failure. Failures such as the Asian financial crisis and the decades of despair in sub-Saharan Africa led these institutions to develop governance strategies designed to avoid failure: fostering country ownership, developing global standards, managing risk and vulnerability, and measuring results. In contrast to the structural adjustment era when policymakers were confident that they had all the answers, the author argues that we are now in an era of provisional governance, in which key actors are aware of the possibility of failure even as they seek to inoculate themselves against it. This book considers the implications of this shift, asking if it is a positive change and whether it is sustainable.

JacQueline best is an Associate Professor in the School of Political Studies at the University of Ottawa. Her work focuses on the social, cultural and political underpinnings of the global economic system, which she studies by examining how organizations such as the International Monetary Fund and the World Bank work to govern the global economy. 


\section{Governing Failure}

Provisional Expertise and the Transformation of Global Development Finance

Jacqueline Best 


\section{CAMBRIDGE \\ UNIVERSITY PRESS}

University Printing House, Cambridge CB2 8BS, United Kingdom

Published in the United States of America by Cambridge University Press, New York

Cambridge University Press is part of the University of Cambridge.

It furthers the University's mission by disseminating knowledge in the pursuit of education, learning and research at the highest international levels of excellence.

www.cambridge.org

Information on this title: www.cambridge.org/9781107035041

(C) Jacqueline Best 2014

This publication is in copyright. Subject to statutory exception and to the provisions of relevant collective licensing agreements, no reproduction of any part may take place without the written permission of Cambridge University Press.

First published 2014

Printed in the United Kingdom by Clays, St Ives plc

A catalogue record for this publication is available from the British Library

Library of Congress Cataloguing in Publication data

Best, Jacqueline, 1970-

Governing failure : provisional expertise and the transformation of global development finance / Jacqueline Best.

pages $\mathrm{cm}$

Includes bibliographical references and index.

ISBN 978-1-107-03504-1 (Hardback)

1. Economic development-Finance. 2. Economic assistance. 3. Development banks. 4. Nongovernmental organizations. 5. Corporate governance. I. Title. HD75.B4965 2014

$332.1^{\prime} 53-\mathrm{dc} 23 \quad 2013028563$

ISBN 978-1-107-03504-1 Hardback

Cambridge University Press has no responsibility for the persistence or accuracy of URLs for external or third-party internet websites referred to in this publication, and does not guarantee that any content on such websites is, or will remain, accurate or appropriate. 


\section{Contents}

List of figures

page vi

Acknowledgements

vii

List of abbreviations

Part I Understanding how global governance works 1

1 Introduction 3

2 A meso-level analysis 20

Part II History 43

3 What came before 45

4 Transformations 66

$\begin{array}{ll}\text { Part III New governance strategies } & 89\end{array}$

5 Fostering ownership 91

6 Developing global standards 115

7 Managing risk and vulnerability 139

8 Measuring results 164

$\begin{array}{ll}\text { Part IV Conclusion } & 187\end{array}$

9 The politics of failure and the future of provisional
governance

Endnotes 209

List of people interviewed 263

Index 266 


\section{Figures}

8.1 The LOGFRAME

page 170

8.2 CIDA's results chain

173 


\section{Acknowledgements}

In the almost seven years that I have been working on this book in one form or another, I have collected a number of debts to colleagues, research assistants and friends.

I would like to start by thanking those colleagues who generously commented on one or more chapters of the final manuscript, including Michael Orsini, Paul Langley, Michael Best, Tony Porter, André Broome and William Walters. A number of others have commented over the years on earlier versions of these chapters, including Mat Paterson, Alexandra Gheciu, Iver Neumann, Lindsey McGoey, Stefano Guzzini, Arne Rückert, Ole Jacob Sending, Len Seabrooke, Rob Aitken, David Black, Rodney Bruce Hall, Kate Weaver, Mark Blyth, Charlotte Epstein, Eric Helleiner, Bessma Momani, Randall Germain and Susan Park.

Earlier versions of several chapters were presented at a number of workshops, conferences and talks. Many of these talks provided crucial feedback on the central theoretical and methodological arguments of this volume. I was particularly inspired by the discussions during workshops at the Copenhagen Business School on "The Business of International Organizations," and at the European Consortium for Political Research on "Diffusion of Authority," together with talks at the University of Queensland, the University of Oxford, the Norwegian Institute of International Affairs, the NorthSouth Institute, the University of Warwick and the University of Sydney.

I am fortunate to be working in an environment where I am surrounded by some excellent minds. Many of the ideas in this book are inspired by conversations with friends and colleagues at the University of Ottawa and Carleton University, including Kevin McMillan, Dalie Giroux, Stephen Brown, Nisha Shah, Paul Saurette, Susan Spronk, Patrick Leblond, Laura Macdonald, Hélène Pellerin, Kathryn Trevenen and Marie-Josée Massicotte. I am also indebted to the participants of the International Political Economy Network seminar at the University of Ottawa where I was able to present an overview of the project towards the end of the writing process.

I benefitted from some excellent research and editorial assistance in producing this volume. I would particularly like to thank Marie Langevin 
and Kailey Cannon for their superb research and editorial skills, without which this book would not have been possible. Phillipe Roseberry, Robert MacNeil, Maxime Ouellet and Dan Furukawa Marques also helped enormously through their research assistance.

The research for this book was supported financially by the Social Sciences and Humanities Research Council of Canada, together with the Faculty of Social Sciences at the University of Ottawa. I also benefitted from research leave spent at the University of Oxford - where I enjoyed support from the Global Economic Governance Centre, the Department of International Development and the Institute for Science, Innovation and Technology - and at the University of Queensland's School of Political Science and International Studies. I would like to thank Ngaire Woods, Rodney Bruce-Hall, Steve Woolgar and Roland Bleiker for making me welcome at these institutions.

I was also fortunate in being able to benefit from access to several archival collections in researching this book, including the International Monetary Fund (IMF) Archives, the World Bank Archives and the British National Archives. Premela Isaac and Jean Marcoyeux at the IMF Archives and Sherinne Thompson at the World Bank Archives provided invaluable assistance.

Parts of Chapter 5, "Fostering ownership," appeared in Third World Quarterly, 28 (3), 2007, and parts of Chapter 7, "Managing risk and vulnerability," appeared in Third World Quarterly, 34 (2), 2013. Both are reproduced here with the permission of Taylor and Francis, www.tandfonline.com.

Figure 8.1, "The LOGFRAME," is reproduced from a report prepared for the United States Agency for International Development (USAID): Project Analysis and Monitoring Company. 1980. "The Logical Framework." Prepared for the United States Agency for International Development, Document \# PN-AAR-443. Washington, DC. The report is available through the USAID Development Experience Clearinghouse: http://pdf.usaid.gov/pdf_docs/PNAAR443.pdf.

Figure 8.2, "CIDA results chain," is reproduced from a Government of Canada official document: CIDA. 2008. "Results-based Management 2008 Policy Statement: Amended Terms and Definitions." Gatineau: Canadian International Development Agency. Available from www.acdicida.gc.ca/acdi-cida/acdi-cida.nsf/eng/ANN-102094249-J4B. The reproduction has not been produced in affiliation with, or with the endorsement of, the Government of Canada.

Finally, I would like to thank my husband and partner, Paul Tyler, for his support and encouragement over the past years as I navigated the ups and downs of the research and writing process. 


\section{Abbreviations}

$\begin{array}{ll}\text { ANT } & \text { actor network theory } \\ \text { CAS } & \text { country assistance strategy } \\ \text { CCT } & \text { conditional cash transfer } \\ \text { CDF } & \text { comprehensive development framework } \\ \text { CIDA } & \text { Canadian International Development Agency } \\ \text { CGD } & \text { Centre for Global Development } \\ \text { COD } & \text { cash on delivery } \\ \text { CPIA } & \text { country policy and institutional assessment } \\ \text { DAC } & \text { Development Assistance Committee } \\ \text { DFID } & \text { United Kingdom Department for International } \\ & \text { Development } \\ \text { DFGG } & \text { demand for good governance } \\ \text { DSA } & \text { debt sustainability analysis } \\ \text { DSF } & \text { debt sustainability framework } \\ \text { ED } & \text { Executive Director } \\ \text { EFF } & \text { Extended Fund Facility } \\ \text { ESAF } & \text { Enhanced Structural Adjustment Fund } \\ \text { FSAP } & \text { Financial Sector Assessment Program } \\ \text { GAC } & \text { governance and corruption strategy } \\ \text { GDDS } & \text { general data dissemination standard } \\ \text { GDP } & \text { gross domestic product } \\ \text { HIPC } & \text { highly indebted poor country } \\ \text { IDA } & \text { International Development Association } \\ \text { IEO } & \text { Independent Evaluation Office } \\ \text { IFI } & \text { international financial institution } \\ \text { IMF } & \text { International Monetary Fund } \\ \text { IO } & \text { international organization } \\ \text { IPE } & \text { international political economy } \\ \text { IR } & \text { international relations } \\ \text { LIC } & \text { low-income country } \\ & \end{array}$




LOGFRAME
MCC
MGDs
NGO
ODI
OECD

OED

OPEC

P4R

PBA

PDR

PEFA

PFP

PRA

PREM

PRGF

PRSP

PSI

RBM

ROSC

RVA

SAF

SAL

SDDS

SDRM

SPS

STS

UK

US

USAID

VFM

WDR logical framework

Millennium Challenge Corporation

millennium development goals

non-governmental organization

Overseas Development Institute

Organization for Economic Co-operation and

Development

Operations Evaluation Department

Organization of Petroleum Exporting Countries

program for results lending

performance-based allocation

Policy Development and Review Department public expenditure and financial accountability policy framework paper participatory rural appraisals

poverty reduction and economic management poverty reduction and growth fund Poverty Reduction Strategy Paper policy support instrument results-based management reports on observance of standards and codes risk and vulnerability assessments Structural Adjustment Fund structural adjustment loan special data dissemination standard sovereign debt restructuring mechanism social protection strategy science and technology studies United Kingdom United States United States' Agency for International Development value for money World Development Report 
Part I

Understanding how global governance works 
Over the past two decades, the main organizations involved in financing international development have become preoccupied with the problem of failure. Whether we look back at Joseph Stiglitz's 1998 seminal lecture, when he was the World Bank's Chief Economist, on the need to move beyond the "failures of the Washington consensus," or consider the new Bank President, Kim Jong Kim's recent insistence that the institution not only acknowledges and learns from past failures but also develops a results-oriented "science of delivery" to avoid them in the future, we find the idea of failure everywhere. ${ }^{1}$ Even the International Monetary Fund (IMF), which has historically been loath to acknowledge the possibility of failure, has recognized its errors in estimating the economic effects of austerity policies in the context of the European financial crisis. ${ }^{2}$

This book looks at how this growing preoccupation with failure has changed the way that international financial institutions and major donors do the work of managing development finance. Although their basic objectives have not changed greatly from the days of structural adjustment, how they seek to achieve them has. To capture these changes we need to look at more than the usual analytic categories of interests, objectives and norms, and examine the concrete practices through which key institutional actors do the everyday work of managing finance for development.

What kinds of everyday practices are staff at the IMF and World Bank and donors like the UK's Department for International Development (DFID) involved in today? If we were to peer over the shoulder of staff members in these organizations, we would find that some are preparing consultation processes with affected groups in order to try to foster a greater sense of ownership for development policies. Others will be developing indicators for assessing countries' compliance with standards of best practice in areas ranging from good governance to accounting. Yet others will be busy analysing the risks and vulnerabilities of a given country, individual or program. And many others will be preparing 
results matrixes trying to link their organization's actions to specific development outcomes, such as an increase in the number of children in school.

Each of these practices is linked to one of four new and powerful governance strategies that I examine in this book: fostering ownership, developing global standards, managing risk and vulnerability, and measuring results. These strategies are common to almost all of the organizations involved in development finance. They are also very heterogeneous. Yet, if we look closely at how they do the work of governing development finance, we find some common patterns. Those engaged in these practices tackle the work of governing differently than they did during the structural adjustment era of the 1980s and early 1990s. ${ }^{3}$ They approach their ultimate object - changing low-income countries' (LICs) economic policies and outcomes - far less directly than in the past, working on the broader institutional context or through other intermediaries. They are also more proactive, even pre-emptive, playing the long game by, for example, trying to reduce underlying vulnerabilities or instil a set of best practices. Institutional actors also rely on more symbolic techniques - as conditions or results are used primarily for their value as signalling devices to communicate political commitment and economic soundness. Above all, those engaged in these new practices of governance are more preoccupied with the problem of failure: its ever-present possibility, its many sources in the form of risks or dysfunctional politics, and the need to avoid it at all costs.

In their efforts to confront the problem of failure, development organizations have begun to rely on what I am calling a provisional kind of governance. The Oxford English Dictionary defines "provisional" as temporary or tentative, and as characterized by foresight or anticipation. As I will elaborate throughout this book, the four new governance strategies discussed here are more anticipatory in their orientation to possible futures and more cautious in the face of possible failure, seeking to inoculate their policies against such dangers. This is a style of governance that does not control its objects directly or absolutely, but rather through a subtler, more indirect approach. It is also a style of governance that relies increasingly on a kind of expertise that can be revised after the fact. The sociologist Niklas Luhmann was among the first to point to the rise of this kind of provisional expertise, suggesting that in a world characterized by an uncertain future, experts seek to hedge their bets in order to leave room for unpleasant surprises. ${ }^{4}$

Although the idea of provisional governance may seem at first like a highly abstract and academic concept, this form of management is in fact increasingly a part of everyday life. It is perhaps most obvious in marketing, 
or what we might think of as the governance of desire: companies and politicians alike are increasingly anticipatory in their approach, trying to guess at or even foster trends before they become popular. They seek to achieve their objective through indirect methods, using social media to try to engineer bottom-up movements and fads. With the dominance of the brand, moreover, symbolic value has long eclipsed usefulness as the defining feature of the objects of our desire (be they cars, phones or national leaders). ${ }^{5}$ Each of these techniques is designed to maximize the chances of success - and minimize the risk of failure - in what is seen as an increasingly uncertain world. Yet the ever-present possibility of failure remains. This is where provisional forms of expertise become particularly useful: think of the number of food products that now contain the statement "may contain nuts," or how habituated we have become to hearing that there is a thirty per cent chance of rain this afternoon. Even seemingly definitive economic statistics like current growth and unemployment rates in major economies have become "estimates" that are frequently revised after the fact - sometimes dramatically, as was the case in the October 2012 unemployment figures that helped President Obama's re-election. ${ }^{6}$ These are all examples of a kind of provisional statement that leaves itself open to revision or contradiction without losing its claim to expert authority.

I am not suggesting, of course, that the IMF, World Bank and key donors have become as sophisticated as Apple, the Republican Party or the Weather Channel in their knowledge management techniques. What I am arguing is that their most recent policies are taking on a more proactive, indirect and symbolic character, and that they increasingly rely on more provisional forms of expertise. When World Bank growthoriented policies focus on influencing "the underlying institutions and policies that promote growth," underlying vulnerabilities that predispose countries to economic disruption" rather than predict crises, ${ }^{8}$ they are engaging in practices that are open to many such provisional claims: that this particular vulnerability may open a country to further difficulties (if another shock occurs), or that reforms to these legal institutions should increase the likelihood of better economic performance (in the longer term). Little by little, those involved in development finance are coming to rely on this kind of more provisional expertise as they try to manage ever more complex problems in an uncertain environment.

Why has this shift occurred? In answering this question, this book develops a second major theme focusing on the politics of failure. These changes in how development governance is done were precipitated by a significant erosion of international financial institutions' (IFIs) and aid 
agencies' expert authority in the 1990s. These organizations have been struggling to regain their authority over the past two decades after the Asian financial crisis and the apparent failure of development aid in sub-Saharan Africa. These events raised doubts about the very core of what organizations like the IMF and World Bank pride themselves on their role as the global experts in finance and development.

The Asian financial crisis and the "lost decade" in Africa were important not so much because they were objective failures, but rather because of the way that they produced a particular kind of debate about what counts as failure. They, together with the more recent global financial crisis, are examples of what I am calling contested failures: events on the public stage that engender major disagreements about whether they are failures and, if so, what kind of failure they represent, eventually precipitating debates about what counts as success and failure in a given policy area. Michel Callon has called such debates "hot negotiations," in which policymakers, critics and academics debate not just the content of policies but also the metrics through which they are assessed. ${ }^{9}$ These hot negotiations ultimately produced several key moments of problematization, a term I am borrowing from Michel Foucault's later work. ${ }^{10}$ In the process, new questions and concerns - such as the political sources of policy failure, and the problem of risk and contingency - became the subject of intense intellectual and practical preoccupation. The products of these debates were the four new governance strategies I mentioned above: fostering country ownership, developing global standards of good practice, managing risk and vulnerability, and measuring results. Each seeks to re-establish the eroded authority of the IFIs and donors through new governance practices, and each does so in a way that has become, particularly in the past few years, increasingly preoccupied with the possibility of future failures.

Starting from this awareness of the fragility of expert authority and the politics of failure, this book is organized around three key questions: (1) how and why did this erosion in expert authority occur? (2) How do these emerging practices seek to re-establish that authority and more generally do the work of governing, given the possibility of failure? And (3) what are the implications of that shift - for the IFIs and donors themselves, and for global governance more generally?

\section{How and why the shift occurred}

The first chapters of this book are concerned with uncovering what has changed since the structural adjustment era, and understanding how and why this change occurred. There are those who argue that there is in fact 
very little new in the global governance of development finance, and that any apparent changes are only at the level of rhetoric and not practice. ${ }^{11}$ Yet, as I show in Chapter 3, if we compare the earlier structural adjustment-era practices to those of the past decade and a half, it is evident that there have been significant shifts in how development finance is undertaken.

The structural adjustment era stands out even now as the high point of the power of the IFIs and Western donors, when their capacity to exert influence over low- and middle-income countries appeared incontestable. Why then did it not last? Ironically, those very aspects of structural adjustment policies that made them seem so stable, such as their consistent reliance on universal economic principles and efforts to separate or subordinate politics to economics, ultimately proved to be unable to address the increasingly complex problems that institutions were faced with. Of course, there were significant sources of conflict between donor organizations and borrowing states and civil society organizations, all of which helped erode the structural adjustment policies. But these conflicts combined with tensions that began to emerge within the practices of governance themselves. As the IMF and World Bank delved deeper into the structural aspects of borrower countries' economies, they found their policy tools ill-suited for the task and began to experiment with new criteria for evaluating success and failure. The difficult events of the 1990s, including the Mexican and Asian financial crises and the recognition of a failed decade of aid to sub-Saharan Africa, were viewed as signs of profound failure in the governance of development and finance. Debates about "aid effectiveness" in the 1990s not only sought to resolve the problem of failure, but, more significantly, to develop a new consensus on what constituted success and failure.

These organizations thus came face to face with what the political theorist Sheldon Wolin, in his interpretation of Max Weber's political and methodological writings, describes as one of the central paradoxes of expert authority: the need for expertise to ground itself on methodological foundations which themselves are fragile and prone to contestation. ${ }^{12}$ As I will discuss in later chapters, such moments of contestation often occur when the gap between a system of measurement and the complexity of its objects becomes too big - as the fluidity of the world overtakes our capacity to translate it. ${ }^{13}$ In the case examined here, key international organizations (IOs), and state and non-governmental organization (NGO) actors, challenged the grounds of governance expertise and sought to redefine it through a process of problematization - debating and developing new techniques and practices. What emerged over time were several new governance strategies. 


\section{How the new practices work}

How do we go about understanding this transformation, and mapping the contours of these emerging practices of governing in the context of failure? In other words, how do we study the how of global governance? One of the challenges of investigating the changes discussed in this book is that they cannot be readily witnessed through the study of any one individual institution, such as the IMF or the World Bank. Although IO scholars focusing on an individual institution gain crucial insights into the complexities of internal bureaucratic politics and the dynamics between internal and external pressures, they run the risk of ignoring the ways in which policies pursued at one institution are connected to and dependent on processes at others and within a broader community of practice including donor agencies, NGOs and IOs. ${ }^{14}$ At the same time, focusing only on the broadest level of analysis, examining macro-trends in global governance - in the transformations of advanced capitalism, for example, or in neoliberalism - runs the risk of over-generalizing the changes taking place and missing the complex particularities that are involved in each institution and policy. ${ }^{15}$

Many of the important changes taking place in global governance including the emerging strategies discussed in this book - occur at a meso-level that is between these two more common levels of analysis. In Chapter 2, I develop an analytic framework for studying these meso-level processes - a "how to" guide of sorts - to assist those who are interested in understanding these messy intermediary processes of global governance but are uncertain of how to go about doing so.

This framework focuses on three interrelated meso-levels of practice. The first level of analysis is made up of governance strategies such as managing risk and vulnerability or fostering country ownership. These are broad clusters of governance practices organized around a particular problem: how, for example, to address the political sources of policy failure (by fostering ownership). These strategies cut across a range of different institutions. They are developed, often piecemeal, by various policymakers, politicians, economists and critics through a process of debate and problematization, in which a new set of issues or concerns is defined and new techniques developed for making them governable.

Although there has been a myriad of individual policy initiatives, this book argues that it is possible to identify four broad trends in policy that most key development financing organizations and many NGOs have participated in over the past decade and a half. Put simply, these are strategies of fostering ownership, developing global standards, managing risk and vulnerability, and measuring results. The first of these strategies, 
most apparent in IFI efforts to streamline conditionality and to replace structural adjustment lending with Poverty Reduction Strategy Papers (PRSPs), places new emphasis on ensuring that policies are responsive to local contexts, and seeks to build local ownership of IFI and donor programs. The second strategy of standardization seeks to develop universal standards of good governance and best economic practice, and to disseminate them to developing and emerging market countries. The third strategy of managing risk and vulnerability reconceptualizes the objects of development assistance - such as poverty reduction or project success - as more contingent and prone to failure, and works to develop pre-emptive measures in response. The final strategy of resultsbased measurement seeks to catch up with the increasing complexity of finance and development policies by creating ever more sophisticated methods for measuring policy success and failure, and integrating the measurement and evaluation of results deeply into the process of policy management.

The second meso-level of analysis drills down to the building blocks, or factors of governance, that make up these governance strategies: these include the actors who govern, the techniques and knowledge that they use, and the forms of power and authority involved. By mapping shifts and continuities in these key factors, we can gain a nuanced appreciation of how the work of governance is being done.

The past two decades have witnessed significant shifts in the various factors involved in the work of governance. New, more engaged actors have become implicated in the processes of governance, most notably through the integration of various kinds of civil society actors as the source of "demand" for particular kinds of government policies and market services. Forms of knowledge have also evolved, as practical, small " $i$ " ideas, such as new public management and new institutionalist economics, have become the drivers of institutional change, replacing the more ambitious big "I" Ideas like the Keynesian and Neoclassical paradigms. The techniques have also shifted accordingly, relying on new forms of participation and the production of different kinds of documents, or inscriptions, to coordinate action. ${ }^{16}$ The forms of power and authority involved in the governance of finance and development have also undergone a transformation, as IFIs and donors have begun to rely on more popular and moral forms of authority, and as their expert authority has become more provisional in character. In the process, they have also begun to replace some of the more overt, instrumental forms of power used in the structural adjustment era with less direct, more productive (but still exclusionary) forms, such as scoring and ranking processes that sort countries based on their performance. 
The third and final level of analysis that I am undertaking in this book considers whether there are any broader underlying patterns apparent in the strategies and factors of governance at a given moment in time. As I will elaborate in the next chapter, some historical moments are characterized by a particular style of governance. Such styles are defined by the particular ways that institutional actors have found to resolve the tensions facing governance efforts - in particular, the methodological dilemmas that I discussed above, as they seek to maintain expert authority in the face of a slippery world that resists full comprehension. In Chapters 3 and 4, I suggest that the structural adjustment era and the present day are each defined by a different style of governance - the earlier era being characterized by a far more confident and direct style than the present-day provisional form of governance.

\section{Implications}

What are the implications of such changes in how governance is done? This is a potentially vast question, which could be answered on many different levels - focusing on the effects on domestic communities, on interstate dynamics, or on the IFIs and donor organizations themselves. This book seeks to answer the question of implications in the final chapter by focusing primarily on the last of these questions - examining the effects of these changes on organizations by asking what their implications are for the politics of global governance, and considering how sustainable these new strategies ultimately are.

What is the future of this provisional style of governance? If we look more closely at the different patterns that constitute it - the shift towards more proactive and indirect approaches to governance, the reliance on symbolic techniques, and the increasing awareness of the possibility of failure - we do not find a single coherent telos but rather two possible paths. On the one hand, many of the practices involved in these strategies are open-ended and even experimental. ${ }^{17}$ They respond to the uncertainty of the world through a trial-and-error approach and bring new actors, particularly local ones, together with local forms of knowledge into the process to better respond to the unknown and learn from past failures. Yet this more open-ended and inclusive form of expertise coexists with, and is often trumped by, a much more risk-averse one that responds to those same uncertainties by relying on the security of more traditional forms of expertise, trying to reduce everything to numbers - an approach best captured by the new emphasis on measurable results.

Each of these paths also has significant political implications. More experimental approaches to governance often cede some authority to a 
wider range of actors, such as civil society organizations, poor people and local governments. Yet, when caution wins out, these messy and less reliable forms of input have to be translated into traditional expert categories, often reducing genuine debate and deliberation with thin proceduralist forms of consultation. ${ }^{18}$ The repoliticization of these governance processes paradoxically turns into a kind of depoliticization, as various forms of political action are read through the lens of economic expertise and then reduced to quantitative indicators.

The effects of this approach to governing failure are paradoxical. Policymakers' caution is one of the key ways they attempt to hedge against the possibility of failure. Yet, despite such efforts, failures persist. These new strategies continually confront the limits of their efforts to make ownership and governance measurable, to draw tidy lines between policies and results, or to reduce the uncertainties of finance and development to algorithms of risk. These failures of performance can lead to failures of consensus. Although one might expect that IFI and donor staff would embrace these new techniques of governance and the forms of power and authority that they afford, my interviews reveal that many of them are ambivalent about these reforms, precisely because of their continued messiness and refusal to fit within bureaucratic norms of neutral and apolitical expertise. ${ }^{19}$

But do these failures actually matter? After all, as scholars like James Ferguson and Timothy Mitchell have noted, although global development policies frequently fail, such failures seem to have a negligible effect on the development machine. ${ }^{20}$ Indeed, I will suggest, some of these failures are benign or even constructive, doing no damage to the institutions involved in development governance. Yet some of these failures are destructive to them: when failures of performance combine with failures of consensus, the ground is fertile for further erosion of governance authority.

\section{Empirical contributions}

In empirical terms, this study contributes to our understanding of some key changes in the governance of finance for development, speaking to scholars and policymakers interested in global governance, international organizations and international development. The book is the culmination of seven years of research into the changes taking place in the policies of the IMF, the World Bank and several key donors. Most of the book's empirical material is drawn from the IMF and the World Bank, given their dominant role in governing development finance. I do, however, also examine the policies of certain donor agencies, particularly where their influence has been important in shaping the direction of development 
policy - for example DFID's movement to eliminate economic conditionality, the Canadian International Development Agency (CIDA) pioneering adoption of results-based measurement, and the American Millennium Challenge Corporation's (MCC) pass-fail approach to conditions. ${ }^{21}$ The research is based on extensive document analysis, archival research at the IMF, World Bank, Canadian and British National Archives, and over fifty interviews with staff and management at the IMF, the World Bank, the Organization for Economic Co-operation and Development (OECD), NGOs, and in certain donor countries.

Scholars of international political economy (IPE) and finance tend to study the IMF and to focus on the interactions of major industrialized states, while development scholars study the World Bank and donors and tend to ignore the IMF. This book cuts across these two solitudes and provides a synthetic analysis of the changes taking place in these various organizations, while at the same time remaining attuned to the important differences among them. In fact, as the evidence in this book makes clear, the common claim that the IMF is "not a development organization" is untrue: even if development is not a formal part of its Articles of Agreement, the organization's actions have profound developmental effects. ${ }^{22}$ In choosing to focus on the institutional side of recent changes in finance for development, I have of course downplayed the other side of the equation: the impact of these changes in developing countries. This book is ambitious enough without attempting to do justice to these important questions. However, as these changes in policy have begun to take hold, other scholars have begun to tackle these issues. ${ }^{23}$

\section{Methodological innovations}

This volume's approach and structure also constitute an important methodological innovation. How do we go about studying the how of global governance? Much of the literature to date has tended to focus either on individual IOs or on broad-level governance trends and patterns. Yet many of the important changes taking place in global governance including the emerging strategies discussed in this book - occur at a meso-level that is between these two more common levels of analysis.

This book argues for the value of a methodological approach that begins in the middle, focusing on the concrete policies, strategies and techniques through which various actors do the work of global governance. ${ }^{24}$ This kind of analysis is "meso" for several reasons. It is a kind of analysis that starts in the middle: looking at what is going on in the form of concrete policy practices, like the consultations to produce PRSPs or efforts to streamline conditionality, and seeking to understand them. The objects of this analysis also exist somewhere in a middle ground between materiality 
and discourse, linking the two without being resolved into either one: the documents and consultation processes that are key to the PRSP, for example, are both material and discursive - their power, in effect, derives from their capacity to translate ideas into material form. This book thus undertakes an analysis focused primarily on processes - how ownership is fostered, for example - rather than on outcomes or interests. Finally, this is a meso-level analysis because its level of analysis exists between and connects the macro, more structural level of global governance and the micro level of individual state, NGO, academic and bureaucratic actors: to understand the strategy of ownership, for example, we must look at how certain practices emerged in and circulate among these different actors and institutions.

\section{Theoretical insights}

In focusing on the "how" of global governance, this research seeks to make theoretical contributions to several key academic debates. My principal inspirations and interlocutors can be found in the literatures on global governance and IOs, critical IPE and social theory. My goal is to bring some of the underappreciated insights of social theory, particularly certain concepts from actor-network theory (ANT) and science and technology studies (STS), into the global governance and IPE literature. In so doing, I hope to enrich the sociological turn in international relations (IR) through a contribution to our understanding of how global governance works.

More specifically, this book makes four key contributions to theoretical debates. The book focuses on strategies and techniques that link the material and the discursive, thus contributing to the practice turn in social theory and IR. The book also seeks to provide an account of change not only of norms but also of governance practices. It seeks to advance our understanding of the centrality of expertise and its limits, in part by examining the politics of failure. Finally, my attention to the rise of provisional governance contributes to but also moves beyond existing work on risk in social theory.

\section{The importance of practice: between materiality and ideas}

To trace various processes of global governance, this volume focuses on the concrete practices through which governance occurs - the documents, metrics, assessments, debates and consultations that actors produce and engage in on a day-to-day basis, as well as the broader strategies that help give them shape and direction. I draw considerable inspiration from the 
work of IR scholars Michael Barnett and Martha Finnemore, who have been pioneers in bringing more sociological insights into the study of the cultural factors that help shape IOs' bureaucratic practices. ${ }^{25}$ At the same time, my work seeks to move beyond their focus on norms by paying more attention to the central role of practices, drawing on a wider range of social theorists to do so, particularly those working within the traditions of STS and ANT, as well as some of Foucault's later work and the recent literature on practices in social theory and IR. ${ }^{26}$

What these literatures have in common is an interest in the concrete practices that make up global politics. Such practices are partly material they involve actions, activities and objects. Yet they are also profoundly social, and are situated within a matrix of ideas, meanings and assumptions that give them shape and that they in turn help to produce. A focus on practices provides a useful middle ground between discursive and materialist accounts of international politics. As I discuss in the next chapter, my own particular brand of practice-oriented analysis is also somewhat different from most of the current work on practices in IR because of my reliance on insights from ANT scholars who have to date been underappreciated in the field of IR. ${ }^{27}$

Although I will provide a fuller discussion of the different kinds of practice I am looking at in the next chapter, it is worth spending a moment considering one kind of governance technique - inscription that I will be using regularly throughout this book. The concept of inscription is a creation of several ANT scholars, including Michel Callon, Bruno Latour and Steve Woolgar. ${ }^{28}$ In their efforts to make sense of the social character of scientific practice, they focused on the ways through which scientists translate the messiness of laboratory activities into inscriptions (graphs, formulae, scientific papers) that they can then take out into the wider community and use to gain support for their theories.

It may be tempting to see inscriptions simply as another variation of what other scholars have described as discourse or ideas. Yet, as William Walters has pointed out, these other concepts tend to focus largely, if not exclusively, on language, ideas and texts, neglecting the material manifestations of the work of conceptualization. ${ }^{29}$ An inscription, on the other hand, is necessarily a physical object or process, whether a piece of paper, an image on a screen, or a technique or procedure. At the same time, it is the product of an imaginative process, and through its representations also makes possible other kinds of conceptual work. It is material and ideational. Focusing on practices of inscription allows us to trace how the work of development is done - and how it changes over time. 


\section{Understanding change}

Of course, how to conceptualize change is a perennial challenge for those working in the social sciences. ${ }^{30}$ In Chapters 2 and 4, I develop a conceptual framework for understanding how not just norms but also governance practices and strategies change over time: why, for example, it can suddenly become essential for staff members in the development industry to learn how to prepare a results matrix or design a consultation process, practices that give shape to development financing.

Rather than assuming a linear trajectory shaped by structural factors or functional logics, this analysis emphasizes the sometimes-idiosyncratic character of certain policy decisions and applications. ${ }^{31}$ The concept of inscription is particularly useful here: inscriptions - such as reports, studies, checklists and evaluations - are developed by particular actors, whether IO staff, NGOs or state representatives, and are often used to support a specific conception of appropriate practice. Such inscriptions are therefore the subject of contestation and negotiation among key actors both while they are being developed and as they are being put into practice. Yet if particular inscriptions gain enough support and become integrated into institutional life, they can begin to be taken for granted, or "black-boxed" as part of the factual background of policy practice. ${ }^{32}$ Black-boxing is not irreversible, but once a set of ideas and practices have become entrenched enough it takes much more vigorous contestation - often in the form of a more fundamental debate about the metrics of success and failure - to unsettle them.

This book focuses on a period in the history of economic governance that witnessed significant changes to the ways in which economic development finance was talked about and practiced. It seeks to make sense of those changes by paying attention to the various debates and negotiations, both cold and hot, through which new kinds of governance practices emerged understanding not just what did occur but what might have happened otherwise, had factors been somewhat different.

\section{Expertise and failure}

In trying to make sense of changes in the governance of development financing, the central practices that this book examines are all intimately connected to the production of knowledge and expertise: both the kind of big-picture knowledge that helps to shape World Development Reports and other such institution-defining publications, and the kind of everyday expertise that makes possible the generation of countless project analyses, assessments and evaluations. These practices are important 
not only to the functioning of such institutions, but also to their authority. Because IOs and donor agencies are bureaucratic, they rely heavily on technical expertise to gain authority to govern. They are essentially asking their stakeholders and borrowers to allow them considerable power because of their sophisticated grasp of the highly technical matters of development and financial assistance.

In focusing on the centrality of expert authority in global governance, this book draws inspiration from a range of scholars from Barnett and Finnemore, to Nikolas Rose and other economic sociologists who have emphasized the power of technical expertise. ${ }^{33}$ I will also seek to complicate these studies in one crucial way: despite their considerable strengths, these theories all tend to overstate the capacity of social actors to make things technical - and to govern the world through such practices. ${ }^{34}$ My research does confirm the effectiveness of such technical strategies in many cases, but also reveals the limits of efforts to render the world calculable and manageable. This book also points towards the central and contested role of failure in the evolution of expertise - as some kinds of objective failures in policy can precipitate more complex debates about what counts as success and failure, eroding some of the markers on which expert authority is based.

This study of the recent history of development finance thus reveals the contested and often-contingent character of expert authority. It also suggests that the fragility of expert authority is becoming increasingly evident, as the straightforward certainties of the structural adjustment era have given way to a more cautious kind of expertise.

\section{Provisional governance beyond risk}

In pointing to the rise of this less confident, more provisional style of governance preoccupied with the problem of failure, my work speaks to a wider literature in social theory on the growth in risk-based thinking and practice. Niklas Luhmann, from whom I borrowed the term "provisional," saw risk management as the central example of this kind of expertise. Many other scholars, including Mitchell Dean, Henry Rothstein, Melinda Cooper and Jeremy Walker, although not using the language of provisional governance, have nonetheless pointed to how risk-based thinking allows for this kind of cautious, anticipatory relationship with the objects of governance. ${ }^{35}$ In one respect, this book therefore seeks to bring some of these insights from social theory into a community of global governance and IPE scholars who have yet to discover it. Yet at the same time, this book pushes beyond this risk-based literature by pointing to how much more pervasive and complex this provisional approach to governance is 
than a simple focus on risk management. This study reveals that the basic attributes of provisional governance - its indirectness, proactive focus, reliance on symbolic constructions and preoccupation with failure characterize a wide range of governance practices, not simply those that rely on risk-based metrics. Moreover, as the focus of many institutions has shifted from risks to underlying vulnerabilities, the grounds of their expert claims have become even less certain. If we want to understand the patterns shaping contemporary governance practices, we therefore need to look beyond risk to the complex ways in which institutional actors attempt to engage with an uncertain world. ${ }^{36}$

\section{The plan of the book}

This book is organized into four sections. Chapter 2 continues the discussion initiated in this Introduction on how we might go about studying the "how" of global governance. After a discussion of this book's relationship with the broader practice turn in IR and social theory, I provide a more substantial account of the main categories of analysis used in this book governance strategies, governance factors and styles of governance followed by a brief overview of how I will put them together to understand the transformation of global governance practices.

Chapters 3 and 4 then consider the historical context of the recent changes in IFI policy, tracking the changes underway in governance factors and tracing the reasons for the emergence of new governance strategies. In order to establish whether policy strategies such as ownership and risk management are in fact new, it is important to show how they differ from earlier governance practices. Chapter 3 does just that, taking a careful look at how the IMF and World Bank sought to govern development financing in the 1970s and 1980s, revealing a far more confident and direct style of governance. Chapter 4 traces the gradual erosion of that governance style, a process driven by debates about contested failures in finance and development and the problematization of new issues. Throughout this period, staff, critics and leaders sought to re-establish the basis of IFI authority, not just by developing new policies such as the PRSP and good governance agenda, but also by developing entirely new governance strategies and definitions of success and failure.

In Chapters 5 through 8, I examine the four new governance strategies that have emerged in response to this erosion. In Chapter 5, I begin by examining the strategy of country ownership, the chief means by which IFI and donor actors have sought to govern the political dimensions of economic policy. Through their development of the PRSP and their efforts to streamline conditionality, the IMF, the World Bank and many 
donors have begun to pay more attention to the local dynamics of adjustment and development, as well as to the importance of political will. Yet even as they have touted the increased transparency of these new policies, in practice these institutions have been gradually informalizing and obscuring power relations. In Chapter 6, I move from the particulars of country ownership to the universals of global standards, tracing the ways in which IMF and World Bank staff members have transformed the rigid economic universals of the structural adjustment era into more flexible and ambitious global standards covering everything from accounting practices to maternal health. As they have moved into this more contested terrain, standards have become increasingly preoccupied with fostering credibility, making them both more symbolic and more performative.

After the shocks of the Asian crisis, the AIDS crisis and the most recent global financial crisis, both IFIs and donors have begun to focus more on risk and vulnerability, the subject of Chapter 7. At the World Bank, key units have re-defined poverty as social risk, while the IMF has developed a ranking system to assess borrowing countries' vulnerability to excessive debt. As agencies have begun to conceptualize the objects of their governance through the lenses of risk and vulnerability, they have also developed new tools for pre-empting the things that might go wrong. At the same time, as decisions increasingly get filtered through a risk-reward matrix at these institutions, poor countries find themselves ranked and sorted in ways that significantly affect their capacity to borrow. How should these increasingly complex and dynamic objects and techniques of governance be measured and evaluated? This is the challenge at the heart of the fourth and final policy strategy, examined in Chapter 8: that of results measurement. In various ways and with varying degrees of success, the World Bank and donors have sought to define a new category of knowledge, called "results." By demonstrating results, IFIs and donors hope to re-establish some of their lost authority. Although this turn to demonstrable results appears to be the exception to the turn towards more provisional forms of expertise, I suggest that the often-heroic assumptions that make such claims about possible results leave considerable room for hedging against failure.

What then is the future of provisional governance? This is the central question examined in the Conclusion. As a mode of governance that is unusually preoccupied with avoiding failure, it is ironic (if perhaps unsurprising) that efforts to pursue these new more provisional strategies nonetheless face resistance, limits and failure. After assessing the implications of these failures, I examine the two possible directions that provisional governance might take - more open-ended and experimental, or cautious and risk-averse. I conclude by considering which is the more likely future path for global governance. 
In the wake of the 2008 financial crisis, we have witnessed both a decline in the volume of traditional donor assistance and the return of more explicitly political kinds of aid, particularly among those donors with new conservative governments. These two shifts have precipitated calls for hard, quantitative results-based forms of expertise to demonstrate the "value for money" of various aid initiatives. Such manoeuvres reinforce the trend towards a cautious, even cynical kind of provisional governance in which expertise is increasingly tied to political convenience. At the same time, efforts to develop ever more standardized forms of evaluation only intensify the difficulties of translating the complexity of development into tidy forms of expert knowledge. Recent trends thus only exacerbate the tensions faced by those trying to manage development finance, accentuating the fragility of their expert authority and the persistence of the politics of failure. 


\section{$2 \quad$ A meso-level analysis}

This book proposes to study changes in how international financial institutions (IFIs) and donors go about the work of governing finance for development. Yet how do we go about studying the how of global governance? This may sound like a straightforward question, but it is in fact a significant challenge: if we want to focus on the process of governance rather than on specific organizations, it is not obvious what level of analysis to focus on, what objects to study, or how to analyse them. This chapter provides an overview of how I have gone about the task of studying the how of governance, and develops a framework of analysis that can be applied to other issue areas.

This book, and the framework that it proposes for studying global governance, is the product of a long process of trial and error, as I have sought to find ways of studying emerging patterns in global economic governance. When I began this research, almost seven years ago, I was initially interested in understanding policy changes that I had noticed in the International Monetary Fund (IMF), particularly its decision after the Asian financial crisis to streamline conditionality and introduce the standards and codes initiative. As I began talking to people at the organization and in non-governmental organizations (NGOs), and reading through archival documents on past practices, it became clear to me that these changes were not simply about fewer or different kinds of conditions, but instead reflected a more profound reworking of the practices of conditionality. These policies drafted new actors, including market participants and civil society actors, into the process of implementing and evaluating conditions and developed new techniques to do so. They relied on different assumptions from those of the structural adjustment era, such as those underpinning new institutionalist economics, and involved less direct forms of power and more complex forms of authority.

Over time, it also became clear that what I was studying was not one or two new policies, but rather several clusters of policies and related practices that shared certain assumptions and orientations. Each cluster could be understood as a particular governance strategy. The strategy of 
fostering ownership, for example, linked several policies together: not just the streamlining of conditionality but also the development of Poverty Reduction Strategy Papers (PRSPs) and the move to general budget support among donors. The strategy of standardization in turn underpinned the development of the standards and codes initiative as well as the good governance agenda and the millennium development goals (MDGs). Eventually I came to identify two more recent strategies focused on managing risk and vulnerability, and measuring results.

Although this project began as a study of the IMF, it soon became clear that if I focused only on this one institution, I would miss the connections between changes in IMF conditionality policy and those in other organizations such as the World Bank and British Department for International Development (DFID) that were often the originators of key policies and strategies. I could instead have treated these shifts as epochal global governance changes, understanding them as the latest stage of advanced capitalism or another example of global governmentality or the risk society. ${ }^{1}$ This more global perspective does make it possible to see broader forces underlying some of these policy changes. Yet, it quickly became clear that by focusing only on the broadest level of analysis I would risk overgeneralizing the changes taking place and miss the complex particularities involved in each institution and policy.

Instead of focusing on a single organization or on macro-historical patterns in global governance, this book engages in what I described in the Introduction as a meso-level analysis: one that starts in the middle, focusing on processes and practices that cut across a range of different institutions and links various actors. For this reason, this is not a book organized around specific organizations - with chapters on the IMF, the World Bank and key donor organizations, for example; nor is it structured around an analysis of the logics of capitalism, neoliberalism or network-based governance. Instead, I am focusing on four key governance strategies - standardization, ownership, risk and vulnerability management, and results-measurement - which are shared by a variety of organizations and agencies, but take specific forms in each. In order to understand how the work of governance is being done, I trace the role of five key governance factors that make up these governance strategies: the actors involved in governing, the techniques used, the forms of knowledge implicated, and the forms of power and authority involved. Finally, I take a step backwards and ask whether there are any broader patterns underlying the shifts taking place in these various governance practices; through this process, I have identified the emergence of a particular style of governance in recent years - a more provisional approach to governing. 
This chapter begins by arguing for the importance of understanding global governance as a kind of practice - situating my theoretical framework relative to the broader practice turn in social theory and international relations (IR). I then go on to develop the key categories in my analytic framework, explaining how we might study global governance by focusing on governance strategies, examining governance factors and identifying particular governance styles. I conclude by putting these analytic categories into action, seeking to understand how governance patterns change over time. The goal of this book is not simply to understand what these new governance strategies do, but also to figure out how they came into existence and whether they will survive. By focusing on the meso-level of analysis, I argue, we can develop a more nuanced conception of how not just individual policies, but more complex strategies and styles of governance, change over time.

\section{Understanding governance as practice}

Over the past decades, a growing number of social theorists have begun to use the concept of practice in their work. They are an eclectic bunch, ranging from Pierre Bourdieu (who developed a "practice theory" based on the concepts of practice, habitus and field), to Michel Foucault (who focused on discursive practices and, in his later work, on embodiment), and Michel Callon and Bruno Latour (who have studied the practice of knowledge-creation in the sciences through actor network theory (ANT)). Most IR scholars who identify themselves as part of the practice turn have drawn primarily on the work of Bourdieu. ${ }^{2}$ My framework, in contrast, owes more to the insights of Callon, Latour and other scholars of science and technology studies (STS), as well as to some of the ideas of Foucault.

What then is a practice, and why is it useful for understanding global governance? In his introduction to a field-defining book on the subject, Theodore Schatzki defines practices as "embodied, materially mediated arrays of human activity organized around shared practical understandings." ${ }^{3}$ It is worth spending a moment unpacking some of the implications of this definition. Practice theorists' emphasis on the material character of human action differentiates them from constructivist and certain post-structuralist approaches, which tend to focus more narrowly on its discursive or ideational dimension. Yet practices are not just activities (e.g. whirling around in a circle), but meaningful ones, organized around common understandings (e.g. about the pirouette as a kind of dance movement). Practices are therefore both material and discursive, combining an action with a frame of reference. 
Because practices are socially situated but enacted by individuals and groups, a focus on practice provides one possible answer to the conundrum of the relationship between structure and agency. Agency is constituted in part through practice: we are defined in part by what we do (as dancers or paper-pushers), and in part by the social context that makes this action possible. At the same time, practices are modified through individual and collective action, and change over time. There is a wide array of meaningful activities that we might define as practices, ranging from pronouncing words, to writing a memo, to negotiating a loan with a low-income country. ${ }^{4}$ As these examples suggest, practices can be thought of as connected and nested in one another, with more complex practices relying on a whole range of more basic and often unnoticed ones.

In IR circles, a number of scholars have begun to make use of the idea of practice in their work. ${ }^{5}$ Emmanuel Adler and Vincent Pouliot, in particular, have provided an elegant and coherent pitch for the importance of practice in IR, building on Bourdieu's work to do so. Although my use of practice in this book shares much with their contribution, it also differs in several important respects - partly on theoretical grounds, but also on practical ones. Much of the recent work on Bourdieu in IR, Adler and Pouliot's included, has focused on empirical cases in the realm of security and diplomacy. In this particular realm, Bourdieu's ideas have proven to be very fruitful. Bourdieu's concepts of field, doxa and habitus are particularly useful for explaining the persistence of logics of practice. Pouliot, for example, examines the operation of the field of diplomacy which he defines as a relatively autonomous community of practice in which everyone agrees on the stakes, knows the rules (or doxa) and plays the same game. ${ }^{6}$ In this context, Pouliot puts considerable emphasis on the role of habitus, the tacit know-how and assumptions that various actors learn through their position in the wider social structure, and bring to the game of diplomacy. ${ }^{7}$

Although my theoretical framework shares much with these earlier contributions to the practice turn in IR, there are also a number of key areas in which it differs. In order to make the practice turn work for the study of global governance, I argue that we need to place more emphasis on knowledge-making practices, shift from fields to problems as the basis for communities of practice, and pay greater attention to the dynamics of change.

Practice-oriented IR scholars have tended to emphasize the importance of tacit or practical knowledge in international politics, and to differentiate it from more reflexive, self-conscious forms. Pouliot for example seeks to contrast "the abstract schemes produced by technocrats and social scientists" with the tacit, unverbalized knowledge that informs practice: 
it is this tacit, practical knowledge that he sees as crucial to international practice. ${ }^{8}$ Yet, those who study global governance would certainly want to question such a tidy distinction between the abstractions of bureaucrats and the concrete practices of governance. ${ }^{9}$ The main practitioners of global governance are in fact technocrats, and many of them are also social scientists (particularly economists). Their practical work involves translating the messiness of the world into useful abstractions (reports, tables, matrices, scores, indexes) that can then be deployed to govern their unruly objects. To grasp the dynamics of global governance, we therefore need to understand the production of expert knowledge as a kind of practice - a task, I will suggest below, that is particularly suited to the insights of ANT scholars like Callon and Latour.

The concept of field used by many IR practice theorists also needs to be used with caution when considering the processes of global governance. Fields have a kind of coherent logic that enables those operating within them to know the rules and to agree on the stakes involved, rather like playing a game. ${ }^{10}$ While it is possible to identify a number of fields within the realm of development finance, the closer we look at current practices of governance, the less clear it becomes where the fields begin and end. Actors working at the IMF, the World Bank, NGOs and aid agencies share many assumptions about the tacit rules of the game and the relative hierarchy of economics over other forms of intellectual capital. Yet they also have quite different cultures: the IMF is a centralized institution that focuses tightly on "hard" financial issues and concerns, whereas the World Bank is known for its diffuse structure and more heterogeneous intellectual culture. If we focus on who is actually engaged in the practices of governance, we see a very loose network of actors (including international organizations (IOs), NGOs, governments, the private sector and academia) playing a multitude of games, often using different rules, and seeking different stakes. ${ }^{11}$ Moreover, many of the recent changes in development finance are expanding the community of practice by including an ever-wider range of actors in the processes of governance, making the boundaries of that community subject to change and contestation. As I will discuss below, I have therefore found it more useful in this study to look at how actors and practices become connected around concrete problems and strategies rather than through predefined fields. ${ }^{12}$

It is also important that we pay attention to changes in governance practice. As social theorists like William Sewell, David Stern and Anthony King have pointed out, Bourdieu's concepts of field and habitus tend to push his analysis towards the structuralist, or objectivist, side of the balance, making it easier to explain the stability of practices than to understand their changes. ${ }^{13}$ Although it is important to be able to understand 
what does not change in IOs and other institutions over time, we also need conceptual tools to help us understand shifts in practices. ${ }^{14}$ Even mundane bureaucratic practices change significantly over time. Why is it that everyone working at a development agency or government-funded development NGO nowadays (at least in certain countries) knows how to prepare a results matrix when proposing or evaluating a program, whereas they had not even heard of the practice fifteen years ago? Why did various practices designed to foster ownership become ubiquitous in the early 2000s, but have become less so more recently? To answer these questions, we need an approach to practices that is attentive to their contingency as well as their sedimentation.

In the remainder of this chapter, I will elaborate the analytic framework that I propose to use for the rest of this book. This meso-level approach draws on some of the insights of other practice theorists in IR while being more attentive to the role of knowledge-making practices, focusing on problems rather than fields as the glue that links governance practices, and seeking to understand what drives the changes in governance strategies. As this brief discussion has probably already made clear, the concept of practice is a slippery one: because it includes everything from basic coping practices like pronouncing words to highly sophisticated ones like managing an IO, the concept can be difficult to use with precision. To avoid conceptual muddiness, it is useful to use more specific terms to designate the different kinds of practice that are involved. It is for this reason that I have chosen different terms - strategies, factors and styles, rather than practices - for my key conceptual categories.

\section{Focusing on governance strategies}

Chapters 5 through 8 each examine one key governance strategy: creating global standards, fostering ownership, managing risk and vulnerability, and measuring results. These strategies are constellations of practices that are linked by their connection to a concrete problem and a way of defining and tackling it, rather than by their situation in a common field. Focusing on strategies is a particularly effective way of understanding institutional practices because they are in many ways problem-driven machines.

What kinds of problems am I talking about? When we look at recent policies adopted by various organizations and governments involved in financing development, it is clear that many share similar concerns. For example, in the past few years there have been numerous policies that identify risk and vulnerability as key challenges in a more uncertain global environment - including social risk policy at the World Bank, the Organisation 
for Economic Co-operation and Development (OECD) and DFID, and renewed attention to low-income countries' vulnerability to external shocks at the IMF following the recent financial crisis. ${ }^{15}$ Similarly, a wide range of institutional actors became preoccupied with developing and implementing new global standards in the late 1990s and early 2000s, and sought to achieve them through a range of policies including the good governance agenda, the standards and codes initiative, and the MDGs. Standardization, risk and vulnerability are all concepts, but they only really become effective when they are translated into concrete practices that seek to foster or control them. They are thus examples of what I am calling governance strategies.

The term "strategy" has its origin in military planning. In global governance as in warfare, a strategy looks at the medium to long term, while tactics are the more immediate means through which those objectives are pursued. Yet, unlike wartime strategies, governance strategies are not always explicitly articulated, nor are they the source of a central will or intention. My use of "strategy" is therefore quite different from traditional IR use, in which "strategic" interaction refers to individual rationalist action, often in a game-theoretic context. ${ }^{16}$ Governance strategies are social rather than narrowly individual, and are embedded in the day-to-day work of governance.

Governance strategies are defined by a set of assumptions, goals and ways of doing things. Strategies link together several policies, often across more than one institution. In so doing, they work to problematize certain aspects of social, political and economic life: to draw a line between one issue and another, to make an issue visible, to suggest a direction or a point of attack - in brief, to make things governable. ${ }^{17} \mathrm{My}$ concept of governance strategy therefore resembles Foucault's concept of problematization, which he uses in his later work. In the Use of Pleasure, for example, Foucault's goal is to understand how certain sexual practices came to be problematized at a certain moment in history, "becoming an object of concern, an element for reflection, and a material for stylization." ${ }^{18}$ This book examines how such reflexive moments of questioning and contestation or problematization - emerge from, and are translated into, routine everyday forms of practice. In so doing, the concept of strategy links discursive or ideational approaches, like constructivism and post-structuralism, and materialist and pragmatic ones, like Bourdieusian practice theory.

The various strategies that I am studying emerged as certain issues came to be viewed as matters of concern, either for the first time or in new ways. For example, in the debates prior to the development of the strategy of country ownership, key actors began to see the challenge of dealing with a country's domestic politics as both relevant and problematic in new ways. 
As I will discuss in the coming chapters, this problematization of politics was precipitated by contested failures in development and finance, particularly in Africa and Asia. After decades of denying or downplaying the political dimensions of their policies, development policymakers began to see political institutions and a lack of political will, or ownership, as a key determinant of program failure, and thus a legitimate object of policy action. This process of problematization was not limited to elite policymakers or economists but was a wide-ranging debate that included NGOs, critics, state leaders and institutional staff. In the process, these actors brought background assumptions about what counted as success and failure into the foreground, forcing the IFIs to defend and adapt not just their policies but the expert authority on which they were based.

Key IFI and donor actors began to see fostering country ownership as a way of addressing the problem of politics and re-establishing their authority. Yet this was a far from coherent process: there was no singular individual or group responsible, nor a general commanding troops to ensure ownership. While many institutional, intellectual and governmental actors championed the ownership strategy, others resisted it. Nonetheless, over time, the practice of fostering ownership has become an explicitly articulated and generally accepted strategy, one that has been adopted by a whole host of organizations ranging from the IMF to many donors and NGOs and that has had profound effects across a multitude of issue areas.

\section{Examining factors of governance}

Studying specific governance strategies may be more manageable than trying to make sense of broad practices like "the governance of development finance," but strategies are still very complex things. If we want to understand how strategies do the work of governance, we need to break them down further into their constituent parts or governance factors. Even the simplest of practices are complex phenomena made up of many different dimensions. ${ }^{19}$ I want to focus on five dimensions of practice here that are central for understanding governance strategies: the roles of actors, techniques, knowledge, authority and power. The concept of "governance factors" encourages us to look both at and beyond day-today practices: to look not just at what is done, but who is doing it, how they conceptualize their work, what specific techniques they use, how they are authorized, and what kinds of power relations are implicated. By studying these factors we can compare past and present practices, determine whether patterns exist that link policies through a common strategy, and assess whether changes are occurring. 


\section{Actors}

Who is governing? If we are to understand the meaning and import of a particular governance practice, then we need to consider which actors are involved. Agency and practice are intimately connected: practices are always undertaken (practiced) by particular actors; at the same time, those actors can be shaped by the practices in which they participate. This book draws some inspiration from Callon and Latour, who have urged scholars to "follow the actor." ${ }^{20}$ This approach has produced some fascinating analyses of heroic figures, such as Latour's account of Louis Pasteur, as he forged networks that helped to remake the scientific world. ${ }^{21}$ Yet, as Susan Leigh Star has pointed out, it is important to look beyond such heroic figures, to the more ordinary actors involved in the day-to-day work of governance. ${ }^{22}$ Part of our task must involve moving from actor to practice, determining which actors are engaged in both developing particular governance strategies and in the everyday implementing of global development practices. At the same time, we need to also move from practice back to actor, considering how specific governance strategies not only empower certain actors to govern, but also seek to define and constitute them in particular ways - "making up people," to use Ian Hacking's phrase. ${ }^{23}$

How much can a focus on actors tell us when they are enmeshed in a highly technical bureaucratic system? As Latour puts it, those practices that are the most technical are also the most social: it takes a lot of negotiation (and domination) to make something appear beyond contestation. ${ }^{24}$ In global economic governance, we can think of the many scholars, NGO activists, and IO and government staff involved in defining what counts as a problem, framing solutions, and then persuading others to accept their take on these issues. Problematizing governance practice is a dynamic and contested process, defined by major debates, some areas of relative consensus and others of ongoing conflict. Through this process, certain ideas and practices will eventually become dominant, and taken for granted (or black-boxed), although they remain vulnerable to later contestation and revision. Throughout this book, I will examine the roles of a range of different actors in translating, negotiating and producing various governance strategies.

Some of these same actors are involved in the day-to-day work of implementing a given strategy, and were involved in its creation. Yet much of the ongoing work of governance is delegated. That is part of the power of modern governance: once certain rules, routines and procedures have been established, governance can be done through intermediaries - what governmentality scholars call governance at a distance. ${ }^{25}$ In this book, 
I will examine the ways in which IFIs and donors have increasingly sought to delegate the authority for governing to a wider range of actors, including members of civil society, private-sector actors, government leaders and the poor. These new governance strategies are not only designed to enrol new actors in the practice of governance, but also to constitute them as particular kinds of active and responsible actors. By paying attention to these dynamics, we can begin to appreciate the dynamic relationship between those who govern and the practices through which they do so. ${ }^{26}$

\section{Techniques}

Having gained a general idea of who is doing the governing, we then need to figure out what kind of techniques they are using. As I discussed earlier, practices are materially mediated, involving not just individual people but also material actions and, in many cases, concrete objects. When studying global governance, a useful way of understanding these different forms of material mediation is by looking at the specific techniques designed to do the work of governing.

Many governance techniques are designed to make things happen: they may be procedures for implementing a policy, for negotiating an agreement, for consulting with a population or for conducting an evaluation. Sometimes these procedures are highly specific and explicitly articulated: in the case of DFID's good governance policy, or the IMF's streamlined guidelines for conditionality, for example, there are "how to" guides for staff that set out specific steps for applying the policies. ${ }^{27}$ In other cases, these ways of doing things may be unspoken norms and habits, what Bourdieu would view as part of the habitus of everyday practice. Over time, certain kinds of techniques may become more common, while others disappear. Another set of techniques that has become particularly prominent in international development and finance organizations in recent years involves those practices necessary for measuring and evaluating governance practices. They include an ever-expanding repertoire of indicators, risk assessments, impact assessments, stress tests and surveys, as organizations become increasingly caught in a cycle of self-assessment, criticism and justification.

For practices to be effective they must be made visible and useable, so that they can be evaluated and monitored. This often means translating them into documents of some kind. In their research on the scientific process, Bruno Latour and Steve Woolgar revealed the techniques through which scientists work in their laboratories to translate everything from rats to chemicals into paper. ${ }^{28}$ More specifically, they suggest, the objective of the scientist is to turn everything into numbers, graphs and 
reports that they can then use to demonstrate a new fact about the world. Such inscriptions, as Latour calls them, stabilize the messiness of the laboratory (in which objects and animals do not always do what they are expected to do) and render its products into a kind of information that can be taken out of the lab and used to convince others of its truths.

It is not hard to see how the concept of inscription might be applied to an analysis of global economic governance practices. Scientists are not the only ones engaged in efforts of inscription: if anything, modern bureaucratic organizations are even more so machines of inscription that work to translate the complications of the world around them into tidy analyses and reports. Moreover, as I will discuss throughout this book, many of the new IFI and donor policies place increasing emphasis on the production of new kinds of reports and documents, which act as ever more powerful reference points for global action. In fact, each of the four strategies discussed here relies in part on such performative inscriptions for their effectiveness, including reports on observance of standards and codes (ROSCs), PRSPs, debt sustainability analyses (DSAs) and results chains.

Inscriptions are not only material in their form, but also in their effects. As Callon has argued in his study of economists and economic theory, such inscriptions both describe a particular version of reality and also play a role in constituting it: they are, in short, performative. ${ }^{29}$ Inscriptions act as a crucial referent around which different actors can mobilize and through which they can manage things. There are cases where inscriptions can become self-fulfilling, such as when enough actors accept the inscriptions. In others, they may have perverse or even opposite effects. ${ }^{30}$

Throughout the book, I will examine the role played by different techniques of governance, focusing not only on any emerging trends but also on the limits and resistances to their implementation. Bureaucratic techniques have potent effects. Yet the creation and mobilization of particular kinds of techniques is always contingent and contested. Different actors work to produce inscriptions and then use them to develop alliances, to enrol others in their projects, and to ultimately make their representations of the world so authoritative as to appear beyond contestation. Such efforts are always provisional, and ultimately subject to challenge and revision.

\section{Knowledge and ideas}

Techniques are partly but not exclusively material. They involve physical processes, objects, spaces and measurement devices. Yet these material forms cannot be understood without reference to the knowledge that 
underpins and authorizes them. As I discussed above, some IR scholars have emphasized the tacit, habitual and unspoken forms of knowledge that underpin international practices. In this book, I am interested in examining the ways in which tacit and reflexive forms of knowledge interrelate and influence each other - particularly in moments of profound debate, when a new set of issues becomes problematized. ${ }^{3}$

To do so, I focus on two kinds of knowledge involved in governance practice: practical or small " $\mathrm{i}$ " ideas, and more profound ontological and epistemological assumptions. As I will discuss throughout the book, governance actors have developed and used a range of potent ideas over the past few decades, including public choice theory, new public management, new institutionalist economics, and participatory development. Many of the actors who have debated, developed and applied these practical ideas are not exclusively social scientists or practitioners, but a bit of both: many of them are economists who oscillate between IOs like the World Bank and university departments. The ideas they rely on are important, but they are on a smaller scale than many of the large "I" Ideas that have been the subject of global governance studies of the past - such as Keynesianism, Neoliberalism or Marxism. Small "i" ideas are practical in orientation: they operate at a level that is closer to particular techniques and practices, and provide specific guidance as to how to do things.

This does not mean that these ideas are not connected to broader, more ideological assumptions - merely that they operate at their more pragmatic edges. They are the technicians rather than the shock troops of ideational change. Thus, for example, public choice theory relies on a range of free-market assumptions about rational individuals and the efficiency of the market, but presents itself not as a defence of the free market, but rather as a way of analysing and resolving certain kinds of problems with inefficient state services or government corruption. Such practical ideas are thus particularly important guides for directing and authorizing emergent governance strategies over the past few decades.

Underpinning both these practical ideas and the various techniques being deployed are more fundamental assumptions about the ontology and epistemology of governance - assumptions that, I will suggest below, help define the particular style of governance. Results-based measurement, for example, is a kind of epistemological practice that involves efforts to create a new kind of fact - the result. Social risk analysis, on the other hand, is driven by and helps to reproduce a new ontology of poverty. These governance strategies, and the debates or problematizations that have informed them, are thus working to reshape some of the basic foundations of tacit governance knowledge: changing what actors see in the world of development and how they seek to make sense of it. 
It is important to stress that these new forms of knowledge are themselves produced and reproduced through various practices. We therefore need to examine not only the debates that helped to shape these ideas and assumptions, but also the ways in which they are translated into policies, embedded in documents and cultures of practice, and adapted, altered and contested over time. Moreover, the relationship between ideas and the material world is dynamic and contested. Things have a habit of not quite fitting the categories into which we put them. Objects can resist efforts to define and understand them - particularly when actors seek to make sense of complex objects using simplistic, often quantitative metrics. A practice-oriented attention to the role of knowledge and ideas is therefore attentive to the complex and friction-laden relationship between thought and action in global governance.

\section{Authority}

We cannot talk about the actors, techniques and forms of knowledge that make up a particular governance strategy without also considering the role of authority. One of the principal factors that distinguish practices from actions is the fact that a practice occurs within a particular normative context: as philosopher of science Joseph Rouse puts it, "[a] pattern constitutes a practice rather than some other kind of regularity to the extent that it is a pattern of correct or appropriate performance." ${ }^{32}$ Practices must be authorized by someone or - crucially - by related practices, such as those involved in creating "expert" knowledge or in soliciting public participation and support. To understand a particular governance practice, we therefore need to pay attention to the particular forms of authority involved: both what form they take and to what extent they are accepted and taken for granted, or are in the process of being debated and problematized.

Max Weber famously defined three bases for authority: legalbureaucratic, traditional and charismatic. ${ }^{33} \mathrm{He}$ went on to argue that because of the disenchantment of modernity, we have been left largely with the first, legal-bureaucratic form - in which rules, law and bureaucratic procedures are the bases of legitimate institutional practice. While it is hard to dispute the basic intuition behind this claim, Weber's definition of contemporary institutional authority remains too narrow, for it downplays the ways in which modern institutions continue to rely on a variety of forms of authority to lend legitimacy to their practices: not only expert authority, but also moral and popular forms. ${ }^{34}$

As Martha Finnemore and Michael Barnett have pointed out, bureaucratic organizations such as the IMF, the World Bank and nationally based 
aid agencies have traditionally relied on their claims to expertise as the basis of their authority. ${ }^{35}$ IFIs are made up of experts who have been trained to wield the technical knowledge that is central to their work. They are divided into specialist units, each of which is staffed by people schooled in their field and in the technical procedures through which they apply that knowledge to their objects. ${ }^{36}$ Their expertise becomes the fundamental basis of the institution's claim to legitimacy, authorizing governance practices. Why should borrower countries accept the authority of a particular set of conditionality guidelines or risk assessments? It is because they are underpinned by expert knowledge. This brand of authority has served organizations like the World Bank very well over the years. Yet, in their recent efforts to shore up their authority, IFIs and donors have supplemented their claims to expert knowledge with several other forms of authority.

One form of authority that plays a crucial role in much of social life but is often less visible in global governance is that of moral authority: the claim that a particular practice is correct because it serves the greater good. Although organizations like the IMF and World Bank made few appeals to their moral authority during the structural adjustment years, earlier, in the 1970s, Bank President Robert McNamara made countless appeals to the moral imperative of poverty reduction. Recent years have witnessed a return to this kind of moralizing discourse, as Bank and IMF leaders have called for the need to "civilize globalization." ${ }^{37}$ Moreover, as I will discuss in greater detail in Chapter 6, such appeals are not merely rhetorical but are also embedded in particular practices - as the standards and codes initiative and the good governance agenda both seek to give concrete form to a set of universal aspirations.

More interesting still is a form of authority that has been marginal in global governance for many years, but which has recently become more central: that of popular authority. The popular basis for authority is well understood in domestic political contexts, where it is the core of the liberal theory of the state. It has been less studied in the international context, yet is arguably increasingly important as IOs seek to build consent for their practices. Popular authority is premised on the notion that if the public (or their representatives) has consented to certain practices, then they are legitimate.

In the international realm, consent has traditionally been formalized in treaties, articles of agreement or other rules by which state actors generally agree to accept the authority of a given organization in a particular issue area. Yet IOs and others are also beginning to make use of a broader range of practices designed to foster popular authority. These practices generally include making certain information public (e.g. a government's 
compliance with certain standards or its plans for poverty reduction), and consultation with affected communities and the encouragement of their participation. Nikolas Rose has described such practices as "technologies of community," since their goal is to govern through particular communities - encouraging their members to play a more active role in their own self-management. ${ }^{38}$ At the same time, they also clearly play an important role in granting a certain kind of popular authority to donors and IFIs, supplementing their more traditional reliance on expert knowledge as the basis for the authority of governance practices.

Throughout this book I will examine this proliferation in the forms of authority that development organizations have begun to rely on to support their activities, tracing their connections with one another and the tensions that have begun to emerge.

\section{Power}

We cannot discuss authority without also considering the role of power. If we accept Rouse's contention that "practices matter," then we must also recognize that there is always something at stake in a given practice. Practices are not only produced with reference to particular norms and thus forms of authority, he suggests, but they are also "sustained only against resistance and difference, and always engage relations of power." ${ }^{39}$ I will focus on three ways in which power is important to the practice of global governance: as a productive, increasingly indirect and exclusionary force.

Focusing on practices means paying attention to productive forms of power. Traditional or instrumental conceptions of power tend to treat power as an external force that acts on pre-existing subjects or objects, seeking to push them this way or that, and alter their behaviour or direction. ${ }^{40}$ In contrast, a productive conception of power, as Barnett and Duvall point out, tends to see its object as more plastic and mutable: power is a force that actively constitutes, reshapes, differentiates - even invents new objects and subjects. ${ }^{41}$ Practices themselves enact a particular kind of productive power as they work to configure the world - its objects and actors - in particular ways. I have already discussed one of the most potent examples of this kind of power when I considered the ways in which certain global governance strategies seek to constitute or "make up" people, transforming them into risk-managing individuals, active participants or results-oriented bureaucrats.

Although we can often talk about a particular actor, individual or institution exercising certain kinds of power, as soon as we consider productive as well as instrumental power it becomes difficult to separate 
actors from the context that informs and enables them. Such efforts, moreover, become even more difficult as power takes less direct forms. In theory, direct power is exercised by one actor over another, as in the classic formulation in which A gets B to do what B would not otherwise do. ${ }^{42}$ In practice, most forms of power are less easy to identify or trace than this hypothetical situation. This is particularly the case in global governance, in which various institutions, agreements, rules and expectations intervene between the source of power and its object. Even when it is possible to say, for example, that the US Executive Director on the IMF Executive Board exercised American power by insisting on the inclusion of a particular condition on a country's trade policy, the actual connection between American power and the borrower state is complicated by several intermediary institutions, agreements and practices. Many recent IFI and donor practices have been considerably less direct than even this particular example: by choosing to adopt standards and codes in new areas, for example, rather than more formal conditions, IMF and World Bank staff have developed practices that seek to influence intermediary objects, such as the quality of governmental institutions, in the hopes that different economic policies will ultimately result, rather than applying a condition to the specific policy that they seek to change.

In a growing number of instances, IFI staff have taken an even less direct approach, seeking to empower various intermediary actors, such as civil society or market participants, in the hopes that they will put pressure on the government for reform. ${ }^{43}$ This increasing reliance on technologies of community not only signals a shift to more popular forms of authority, as discussed above, but also reveals a change in the distribution of authority and power: these technologies authorize a wider range of actors to share in the practice of global governance. Yet this delegation of authority involves a complex set of power dynamics: it is only those actors deemed "capable" (e.g. those civil society organizations that have learned how to "demand" good governance), that are included in this expansion of governance authority.

Even as some new actors are empowered by being authorized to play a greater role in their own governance, others are excluded. Defining something as competent practice always excludes other possibilities: when low-income governments are told, for example, that this is the right way to govern their economic affairs or manage their debt level, they are also being told that these other actions are not acceptable. When IOs seek to define a set of standards that all countries can aspire towards, they are also developing a means of defining those who do not meet those standards. This is not the straightforward kind of exclusion that instrumental power generally involves, in which you are either included or excluded. 
Instead, it is not unlike what Georgio Agamben has called "inclusive exclusion," in which those who are excluded are still an essential part of the system, as standards of "best practice" are defined in large measure by what they exclude as not meeting that standard. ${ }^{44}$

In many cases the form that this exclusion takes is not all or nothing, but rather a matter of degree: the development of results measurement matrices, good governance standards and debt risk assessments all allow IFIs and donors to rank and sort countries along a continuum, differentiating between better and worse performers. Just because such forms of exclusion are increasingly indirect does not mean that they are ineffective or that they do not have painful consequences: low scores in these rankings have very real costs for poor countries. We can only capture these kinds of productive, indirect and exclusionary power dynamics by looking not just at who is using power and to what end, but by focusing on how power operates: in other words, by examining the practices of governance.

We can gain a much more nuanced appreciation of how a particular strategy does the work of governing by drilling down and examining the various factors of governance that are in play: who is doing the work of governance, using what assumptions and techniques, enacting what forms of power and appealing to what kinds of authority. While these factors play a role in all governance strategies, the particular form that they take varies over time, allowing us to trace broader shifts in the practices of governance.

\section{Recognizing governance styles}

So far, I have focused on the meso-level strategies that give shape to global governance practices as well as the more basic factors, or building blocks, that make them up. I have suggested that this kind of analysis helps us to overcome the limits of focusing narrowly on individual organizations or policies, as well as to avoid the overly broad generalizations of certain global governance approaches. Beginning in the middle, however, does not mean that we cannot examine broader patterns of governance: rather, it means that any such analysis must be inductive - developed through careful study of concrete governance practices. If it becomes apparent that similar kinds of actors, techniques, forms of knowledge and kinds of authority and power keep reappearing across a range of different strategies, this tells us that a broader process is underway.

During my research for this book, I was struck by the ways in which each of the strategies that I identified seemed, despite their differences, to share some marked similarities. As I will discuss at much greater length 
in the coming chapters, I saw in each strategy a tendency to integrate more local actors in the processes of governance while also attempting to constitute them as more active participants; to use increasingly symbolic and performative inscription techniques; to draw on a similar set of small "i" ideas as a way of making politics amenable to economic governance; to deploy more productive and indirect forms of power in order to sort and rank states and individuals; and to redistribute authority while expanding its basis to include popular as well as expert forms.

As I moved back in time and looked at the recent history of financing development (as I do in the next chapter), I found some markedly different patterns at work. During the structural adjustment era of the 1980s and early 1990s, the actors involved were restricted, the techniques of governance more direct and straightforward, the ideas more narrowly economic, the forms of power more coercive, and the authority exclusively expert. By focusing in on these factors, I had uncovered some broad differences in how the work of governance was done then versus now. These differences are not random, nor are they driven by a kind of monolithic logic. Instead, they are subtler, but important, differences in the style of governance. The structural adjustment style was confident and direct: certain of its authority, direct in its techniques, seeing the future as a continuation of the present. More recent governance strategies are defined by a more provisional style: far less certain about its authority or the future, and relying on more complex and indirect techniques and forms of power to achieve its ends. ${ }^{45}$

I have chosen to talk about "styles" rather than "logics" of governance in order to avoid overstating their coherence. ${ }^{46} \mathrm{~A}$ style colours but does not determine governance practices. The two historical moments that I discuss in this book are characterized by the predominance of a particular style of governance. However, this is not true for all periods: sometimes there is more than one style in operation. Today, for example, the more confident style of the structural adjustment era still defines certain aspects of development finance - certain issue areas, institutional units and individual economists - even if the more provisional style has gained considerable influence.

What do different styles of governance actually do? If strategies emerge out of the problematization of given issues and questions and seek to provide particular solutions, then governance styles do the same at a more fundamental level. As I will elaborate in Chapter 4, modern governance practices have had to come to terms with a very basic problem: the inherent fragility of their claims to expert authority. This fragility has methodological, ontological and epistemological aspects. IFI and donor actors are faced with significant methodological challenges: how do they measure 
and translate the complexities of real development problems in narrowly economic terms? In fact, as I have discussed elsewhere, institutional staff will often spend considerable energy debating just how qualitative or quantitative their metrics should be, and how objective or subjective their findings are. ${ }^{47}$ These difficulties often have ontological underpinnings: time passes and situations change, making past methods obsolete; more fundamentally, the world is messy and unpredictable, and exceeds our capacity to represent it. Underpinning these debates about metrics is a more profound epistemological dilemma: given such complexities and contingencies, how can institutional actors know what they know, and act on a given problem with authority? Modern governance practitioners must therefore come to terms with the ever-present possibility of a very basic kind of failure - the failure to know what counts as a failure.

A style of governance is a particular way of defining and resolving these dilemmas of governance. During the structural adjustment era, institutional actors relied on a simplistic ontology, treating the world of development as if it were amenable to straightforward methods of measurement and intervention. This allowed them to govern through a narrowly economistic methodology and a highly confident set of practices. More recent governance strategies reveal a far more provisional attitude to the world and its governability. The ontology of recent governance practices is messier and more fluid as the world seems more volatile and complex. New strategies like ownership and risk management are underpinned in turn by more cautious epistemological claims about what is actually known.

As I will discuss in the chapters ahead, this caution is driven by a greater awareness of and preoccupation with the possibility of failure - failure to tackle the political roots of development pathologies, to measure the achievements of complex programs, to predict the next big shock. This preoccupation has led IFI and donor actors to develop proactive governance strategies as a way of inoculating development programs against failure. Such strategies may mean playing the long game, by fostering a results culture, for example, or promoting certain risk-management capacities among poor people, which will only pay dividends over the long term. IFI actors are also relying increasingly on indirect techniques that operate in the gaps of formal policies, through the proliferation of informal conditions, for example, or through policies that rely on pressure from peers or civil society groups. The new strategies also make use of increasingly symbolic practices in their efforts to govern development practices that depend more on what they represent than on what they are. The value of global standards, for example, lies increasingly in their capacity to signal a country's commitment to reform, making it visible 
and open to evaluation. Such symbolic practices are also performative, as they seek to mobilize market and civil society actors to act on the basis of these signals provided. Finally, many of those engaged in these strategies are not only preoccupied with failure, but also seek to hedge against future failures.

We are therefore witnessing the rise of the kind of "provisional expertise" that Niklas Luhmann pointed towards, in which experts sought to avoid failure by minimizing risks and deflecting responsibility; yet this is a kind of provisional approach to governance that is not limited to riskmanagement techniques, as he suggested, but that is present in a wide range of different governance strategies. ${ }^{48}$ In the coming chapters, I will examine just how this provisional style colours each of the new strategies, and I will reflect on the sustainability of this shift and its implications in the Conclusion.

\section{Understanding change}

My discussion of the strategies, factors and styles of governance all emphasize their dynamic character. The next two chapters provide a more detailed account of the forces driving the recent shift in how IFIs and donors manage the financing of international development. For now, I will just provide a basic outline of how attending to the styles and strategies of governance and the factors that make them possible enables us to appreciate not just how governance is practised, but also how those practices change over time.

The question of what drives changes in governance is one that has recently gained significant attention in IR. Constructivist scholars have followed in Martha Finnemore and Kathryn Sikkink's steps by seeking to understand shifts in governance norms, tracing the various stages in norms' life-cycles from their emergence to their internalization. ${ }^{49} \mathrm{At}$ the same time, a number of critical and post-modernist scholars have sought to explain governance changes through Foucault's notion of governmentality, seeing them as signs of a broader, more epochal shift to a liberal form of self-government. ${ }^{50}$ In spite of their considerable strengths and resonances with my findings, both of these different approaches tend to emphasize the discursive or ideational drivers of change, downplaying its practical dimensions. Although norms, rationalities and the ways that they are materialized are clearly connected, one cannot be reduced to the other: changes in norms can lead to changes in concrete techniques, but innovations or breakdowns in material practices can also lead to changes in governance norms and eventually to broader rationalities. 
The concept of strategies lends itself particularly well to a conception of change that is attuned to both the material and discursive aspects of governance practice. Rather than being tied to a set of functions or a relatively stable field, strategies are organized around particular problems. Those problems change over time - or rather, the way that institutional actors problematize and tackle them changes. For example, although IFIs have always had to develop some kind of implicit conception of policy time and the future, it is only very recently that they have become explicitly preoccupied with the unknowability of the future, seeking to manage these uncertainties through a strategy of risk management. Such strategies come into being in the context of particular moments of problematization, in which those things that were once taken for granted are destabilized and contested: suddenly the unpredictability of the future seem very important. These moments bring part of the tacit background of governance practice into the foreground, making it the subject of a more reflexive debate.

Why do certain things that were taken for granted become open to debate? As the cases that I consider in the next chapters reveal, there can be many different reasons for settled assumptions to become the subject of problematization: particular events, key actors, a change in ideas, innovations or difficulties in techniques - any of these can precipitate these kinds of more profound debates. Yet, lurking behind these more contingent factors is often a concern about the problem of failure.

Given that the question of failure is one that has been discussed before in both global governance and international development literatures, I want to be very clear about how I am using the concept here. Susan Park and Antje Vetterlein have pointed to development policy failure as one of the triggers of change in IOs' policy norms ${ }^{51}$ On the other hand, James Ferguson and Timothy Mitchell have argued that many development ideas and policies persist in the face of very obvious failures in their explicit objectives. ${ }^{52}$ Without getting into the interesting tensions among these analyses, I would simply like to note that they all focus primarily on objective failures. ${ }^{53}$ In contrast, my interest is not just in objective failures but also in the ways in which certain things are subjectively defined as failures at certain moments. The meaning of most failures is subject to contestation - but some failures in particular seem to provoke enormous debate about the very grounds of what counts as success and failure. It is these contested failures that often lead to a problematization of sedimented governance practices.

For example, the growing interest in the political dimensions of development discussed above was underpinned by a new conviction that the success and failure of aid programs hinged on domestic stability and 
ownership. This was a significant departure from previous conceptions of the determinants of policy success or failure. This redefinition was arguably linked to certain objective failures in development financing, notably the "lost decade" of development in sub-Saharan Africa. Yet the failure of development in sub-Saharan Africa had been going on for decades; past World Bank and other reports had acknowledged the problem, but had identified very different causes and solutions. It was only in the 1990s that this problem was defined as a particular kind of failure (of political will and of governance), opening up a wider debate about aid effectiveness, underpinned by key questions about what counted as successful or failed aid.

While changes in more specific policies or norms may sometimes hinge on certain reasonably obvious objective failures, changes in governance strategies often depend instead on more contested debates about what counts as success and failure. Such debates are not merely technical matters for the experts to work out, but are in fact highly political, and often include a wide range of actors including policymakers, academics, NGOs and political leaders. There is a lot at stake in calling a policy a failure (or a success), including potentially the survival of the organizations involved. Debates about success and failure pose significant challenges to institutional authority, since they strike at the heart of claims to expert authority. How can you be an expert on an issue if you are not sure what counts as success? As I noted above, institutional expertise is a fragile thing, depending on a whole host of methodological, ontological and epistemological compromises. Such moments of problematization can unsettle existing compromises, forcing their renegotiation.

Over time, actors develop new strategies as a way of managing these problems and re-establishing their authority: these strategies seek to move what has been problematized into the background, black-boxing their key assumptions and practices as a new kind of tacit understanding. As my discussion of the development of four new governance strategies reveals, this is not a quick or straightforward process, but rather a messy, contingent and contested affair. For, as I suggested above, the particular form taken by the strategies of fostering ownership, developing standards, managing risk and vulnerability, and measuring results is defined by a more provisional style of governance. The most recent solution to the problem of failure is to develop a preoccupation with its ever-present possibility.

The remainder of the book puts this meso-level analytic framework into practice. In the next two chapters, I will trace the path from the structural adjustment era to the present day, examining the differences between the dominant governance strategies then and now, and tracing 
the processes of problematization and contestation that ultimately led to their decline. Chapters 5 through 8 then examine the four new governance strategies, considering how they emerged in response to the erosion of previous practices and assumptions, and how they do the work of governing. In each case, I examine the role of each of the factors of governance and then consider whether we are in fact witnessing the emergence of a more provisional style of governance. The book concludes by pointing to a paradox of sorts: despite the cleverness of this new provisional style of governance in hedging against failure, the various strategies all face a number of their own failures. After exploring in more depth the paradoxical politics of failure, I conclude by examining the sustainability and long-term implications of this move to a more provisional style of governance. 
Part II

\section{History}


The International Monetary Fund (IMF), the World Bank and various donor organizations have introduced a multitude of new policies over the past decade and a half. There is a significant difference, however, between identifying a list of policy changes, and defining them as a series of new governance strategies and as a shift in the overall style of global governance. Since these claims are central to this book, it is necessary to spend some time establishing how these new governances strategies differ from their predecessors.

As I discussed in the last chapter, governance strategies are ways of defining and managing particular kinds of problems. Institutional actors often develop new strategies in the context of debates about perceived failures, such as World Bank President Robert McNamara's claims of the failure of trickle-down development in the late 1960s, mainstream Bank economists' assertions of the failure of McNamara's targeted poverty reduction efforts in the early 1980s, or more recent arguments from non-governmental organizations (NGOs) and economists about the failure of orthodox aid efforts in the 1990s. While these contested failures have things in common - they are all partly defined as failures of expertise the kinds of responses developed have varied considerably. All governance strategies are thus designed at one level to resolve some of the dilemmas of expert authority. At the same time, each also seeks to respond to a particular problem or challenge.

Each of the strategies I examine in this book both defines and seeks to respond to a certain problem of governance. Fostering country ownership is one way of addressing domestic politics and variation between local contexts. Developing global standards is a means of defining and applying a set of universal principles, which international organizations (IOs) can draw on to justify their actions. Efforts to manage risk and vulnerability are a new way of grappling with the perennial challenge of responding to the unknowns of global governance. Results measurement, finally, is one more approach to the institutional imperative to measure and evaluate policy practices. 
Although international financial institutions (IFIs), donors and other international actors have only recently adopted these strategies, they have in the past found other ways of addressing similar problems - through a conception of time that treats the future as more predictable than the current focus on risk and vulnerability, for example. The transition from one set of governance practices to another is neither linear nor inevitable. In some cases, current governance strategies have brought a set of concerns together that were dealt with quite separately in the past. For example, the strategy of fostering ownership brings together previously separate concerns about the relevance of domestic politics, the importance of responding to particular circumstances, and the value of participation. Other strategies have problematized issues that were far less central just a few decades ago: for example, the new emphasis on results makes measurement a far more integral and performative part of economic governance than in the past. The list of governance strategies I examine is far from exhaustive, and these four strategies are not somehow more fundamental than others. ${ }^{1}$ Yet, as I will elaborate throughout this book, they are currently central to development finance.

This chapter tackles the historical question of how these governance practices have changed over time by examining how similar problems were addressed in the past. Given the number of governance practices that I am discussing here - covering as much ground in one chapter as I do in four chapters later in the book - I can only provide a basic overview of the major trends involved. I will also be concentrating on the two major IFIs, the World Bank and the IMF, focusing primarily on their practices during the 1980s when structural adjustment was the dominant approach. This history reveals that institutional actors have been confronted in the past with similar challenges to those addressed by the four governance strategies discussed in this book: how to develop universally applicable principles, address the problems of politics and particularity, conceptualize and manage the unknown, and measure the effects of their work. Yet how they went about doing so was significantly different from today. During the structural adjustment era, the IMF and World Bank relied on technical, rule-like economic universals, sought to separate politics from economics, relied on a more linear and short-term conception of policy time, and used more straightforward and episodic forms of measurement.

While there are important links between development finance in the 1980 s and both earlier and later periods, the structural adjustment era was characterized by a more confident and direct style of governance practice involving specific kinds of actors, ideas, techniques, authority and forms of power. Yet even as that governance style reached its peak in 
the late 1980s at the World Bank and the mid-1990s at the Fund, it was already in the process of unravelling. I will take up the story of this transition in the next chapter.

\section{What came before}

When scholars and practitioners debate whether there has been a sea change in development theory and practice in recent years, the reference point that they generally have in mind is the structural adjustment, or "Washington consensus," era of the 1980s and early 1990s. Hence Joseph Stiglitz talks about a post-Washington consensus era, while certain critics argue that what we are witnessing is really a continuation of structural adjustment under a different name. ${ }^{2}$ If we are to understand what has and has not changed in the global governance of development finance, then it makes sense to spend some time examining this earlier period to tease out the connections and the disjunctions with the present day.

Although the idea of structural adjustment was actually born in the final days of the 1970s under the leadership of then World Bank President, Robert McNamara, the policy came to define both IFIs' approach to financing development in the $1980 \mathrm{~s}^{3}$ What distinguished structural adjustment loans (SALs) from earlier forms of lending at the Bank was the fact that it was program- rather than project-based and that it was conditional. ${ }^{4}$ Although there had been a few examples of program lending before 1979, most notably in India, Pakistan and Bangladesh, the overwhelming majority of World Bank assistance up to this point was in the form of loans for specific projects such as the building of roads, power plants and agricultural development. ${ }^{5}$ Program lending, in contrast, provided broad-based financial support to governments; the strings, or conditions, that came with this financing were not associated with particular projects, but rather with the economic reforms that the Bank wanted borrowing countries to adopt.

In turning to economic conditionality as a key policy practice, the Bank was adopting similar techniques to those used by the IMF, which introduced conditional lending in the 1950s. Yet between then and the late 1970s, the Fund had relied on a narrow set of performance criteria on first monetary, and then fiscal, policy. It was only once the Fund also adopted SAL in the 1980s that its governance techniques also underwent a significant shift, as the organization began to lend increasingly to very poor countries, for extended periods of time and with a wider range of conditions. Although they retained distinct institutional cultures, the two organizations thus converged in their policies towards developing countries, in many cases developing similar governance practices. ${ }^{6}$ 


\section{Before standardization}

Most forms of governance involve some conception of universality - of the things, values or principles that apply to everyone and not just to a few. Many IOs like the IMF or the World Bank view themselves as universal organizations, with virtually all states as members. They must therefore be careful to consider the universality of their principles and policies. Yet even those organizations that are less global in scope, like national aid agencies, would generally like their policies to be seen as a reflection of universal principles rather than particular national interests. ${ }^{7}$ Governance practices rely on universals in two primary ways. Organizations like the IFIs and donors seek to govern in the name of certain values that they deem to be universal - such as good governance, human rights, sound economics or accountability. At the same time, many of these organizations also govern through certain techniques or forms of expertise that they see as universally valid, such as particular economic theories or principles.

While IFIs during both the structural adjustment era and in more recent years have sought to govern in the name of and through certain universals, they have defined those universals very differently. As I will discuss in Chapter 6, the recent strategy of standardization, which underpins the good governance agenda and the standards and codes initiative, relies on a combination of moral and technical principles to justify its universality. This "moralization" of finance and development is reminiscent of a much earlier era: Robert McNamara's war on poverty in the 1970s. ${ }^{8}$ For McNamara, the battle against poverty was a moral imperative, a set of "fundamental obligations accepted by civilized men" that defined the Bank under his leadership. ${ }^{9}$ Yet, not long after McNamara left the Bank in 1981, the organization underwent what Gerald Helleiner acerbically called "another change of religion," rejecting its earlier emphasis on poverty and rediscovering the virtues of a trickle-down approach. ${ }^{10}$ Under the leadership of the former banker and new World Bank President A.W. Clausen, and more importantly under the intellectual direction of the economically conservative Chief Economist Anne Krueger, the Bank redefined its objectives in more narrowly economic terms, focusing on adjustment and efficiency. ${ }^{11}$ In contrast to the 1970 s, the 1980s/early 1990s was an era in which global economic leaders went out of their way to deny moral universals. Some Bank staff even went as far as attacking the moralizing tone of the McNamara years as "imposing foreign concepts of morality" on developing economies. ${ }^{12}$

Although the 1980s was therefore not a decade characterized by much explicit moralizing rhetoric, it was nonetheless underpinned by a set of universalist economic assumptions; these universals simply took 
technical rather than moral form. In fact, as poverty and even growth dropped down the list of priorities and economic adjustment came to the forefront, Bank staff's approach to development arguably became even more universalist, as their toleration for policy diversity declined. ${ }^{13}$ The 1981 Berg Report, an influential Bank-funded analysis of development policy in sub-Saharan Africa, argued for the universal applicability of certain policies, including more export-orientation, a smaller public sector and more agriculture-friendly policies. ${ }^{14}$ Where McNamara had argued that the mix between public and private ownership of key industries was a matter of domestic choice, Berg and Krueger insisted that public ownership was inherently inefficient, and argued for the superiority of private-based alternatives. ${ }^{15}$ The Bank's doctrine became increasingly rigid, internal debate was stifled and the message carefully controlled. ${ }^{16}$

Although the IMF underwent its share of organizational convolutions in the 1970s as the fixed exchange rate regime that it had overseen fell apart, it did not experience a doctrinal volte-face in its relationship with poorer countries like the World Bank. Instead, its policies underwent a more gradual series of changes from the early 1980s onwards. In some ways, the World Bank's rediscovery of trickle-down economics and its embrace of neoclassical principles brought it closer to the path that the IMF had been on for quite some time. The IMF's approach to adjustment had always relied on narrowly economic tools - chief among them the Polak model of monetary adjustment. ${ }^{17}$ The rigidity of this economic approach to policy had been attenuated by two crucial factors. The fact that IMF programs were generally of short duration, primarily aimed at balance of payments adjustment and designed primarily for middleincome and industrialized economies, meant that a simple set of principles could be reasonably effective. ${ }^{18,19}$ At the same time, the universality of the rules was always complicated by a pragmatic approach to their application, which allowed for more variation in practice. ${ }^{20}$

During the 1980s, both of these compensating factors were undermined, creating a more universalist approach to economic policy. The IMF scaled up its lending to low-income countries (LICs) that often had more complex economic situations. To address these challenges, both the IMF's informal conditions (letters of intent, ex-ante conditions and the newly created structural benchmarks) and its formal performance criteria grew in scope and number. ${ }^{21}$ As supply-side economics became increasingly influential at the IMF, what had been a relatively narrow set of policy tools began to expand to cover other economic issues. ${ }^{22}$ Both Bank and IMF staff began to target a much wider array of domestic policies including trade liberalization, tax reform and eventually 
privatization, in the hopes that these more "structural" forms of adjustment would yield longer-term economic stability. ${ }^{23}$ And although Fund staff and the Executive Board retained their pragmatic approach to interpreting the conditionality guidelines, they did so increasingly to enable the expansion of conditionality into these new areas. ${ }^{24,25}$

This gradual but relentless expansion in conditions at both the IMF and the World Bank was underpinned by economic assumptions that were believed to be universally applicable. John Williamson famously labelled them the "Washington Consensus" - a set of policy prescriptions based on a combination of neoclassical and supply-side economic assumptions that was believed to provide a universal recipe for economic reform. ${ }^{26}$ It was in the name of these economic universals that the institutions sought to justify their policies in the 1980 s. Unlike McNamara's attack on poverty a decade earlier, and efforts to "civilize globalization" several decades later, these universals were not articulated in moral terms (although it was of course implicitly normative in its distinction between good and bad economic policies). Instead, trumpeting the wonders of "efficiency," the IMF and World Bank sought to justify their increasingly interventionist and controversial policies through a language of technical universality. At the same time, the universal principles through which IFI actors sought to do the work of governing were highly rigid: they were exclusively economic and took the form of absolute rules, rather than the broader and more flexible standards that have become influential in recent years.

\section{Before ownership}

This rigid technical approach to finance and development also had significant implications for the ways in which the two organizations dealt with the problems of politics and particularity - the chief concerns that the later strategy of country ownership has sought to address. IOs, bilateral donors and NGOs have always confronted the challenge of balancing their claims to universality with a need to respond to different countries and contexts. Over the past decade and a half, this attention to particularity and politics has become a very visible part of the IFIs' rhetoric and policies, as they have focused on ownership as the key determinant of policy success. Yet the concept of country ownership has only become influential since the mid-1990s. In earlier times, the Bank and Fund relied on rather different approaches to address the challenges of domestic politics.

In the 1970 s, both organizations tended to rely on a strategy of separating politics from economics, treating "political" issues as the domestic issues to be decided by borrowing governments and "economic" issues 
as more universal in scope and therefore fair game for IFI action. ${ }^{27}$ Thus McNamara made a clear distinction between what he called economic and political human rights, arguing that the Bank could be active in promoting the first of these, but that it could not get involved in the second. ${ }^{28}$ At the IMF, there was a similar effort to separate politics from economics. In their first formal debate on conditionality guidelines in 1968, for example, staff and many Board members argued that one of the ways of ensuring that the IMF respected member states' political priorities and values was by avoiding imposing conditions on a borrowing country's fiscal policy (e.g. taxation policies and the budget balance), and focusing instead exclusively on monetary policy (e.g. targeting interest and exchange rates). ${ }^{29} \mathrm{~A}$ Fund staff report to the Board noted that:

Budgetary operations as well as the operations of public agencies reflect the social and economic priorities of the member ... If they are made performance criteria and included in performance clauses, the impression may be created that the Fund is making a judgment on the priorities of the member. ${ }^{30}$

The staff thus sought to develop programs that were seen to be as apolitical as possible, and saw their limited focus on monetary policy as a way of ensuring this. ${ }^{31}$

In the 1980s, as both institutions expanded into ever-greater areas of their member countries' policies, it became difficult to sustain such claims about the clear lines separating politics from economics. While the organizations continued to maintain that their policies remained apolitical, they did so increasingly by redrawing the boundaries between politics and economics. Gradually, more and more aspects of a state's activities came to be viewed as economic problems. IMF staff, for example, quickly overcame their hesitation about the political overtones of fiscal conditionality, first allowing conditions on fiscal policy, and then moving onto more structural reforms. The Bank also saw a gradual expansion in both the number and scope of its conditions. While the first SAL, to Senegal in 1980, included thirty-two conditions, by 1990 the average number had risen to fifty-six. ${ }^{32}$ Structural adjustment conditions initially focused on balance-of-payments deficits, seeking to reduce them through export promotion or budget deficit reduction. ${ }^{33}$ By the mid-1980s, however, the programs began to focus on supply-side and microeconomic issues, including prices, taxes, financial regulations, privatization and labour market policies: all of these issues, which not long ago would have been seen as matters of domestic political choice, were now seen as primarily economic. ${ }^{34}$

This shift was widespread. As Gerald Helleiner noted, even Elliot Berg himself, the author of the influential 1981 World Bank report on 
sub-Saharan Africa, went from suggesting in 1963 that it was "not the business of outsiders ... to quarrel about the suitability of the goals set out by socialists in Africa," to arguing that an export-oriented economy and a smaller public sector would benefit just about any African economy. ${ }^{35}$ While the Berg Report did note that some of the proposed reforms were likely to be "politically thorny," and recognized the fragile political context in many African states, one of the central messages of the report was the importance of African countries paying less attention to "political consolidation" and more to "the efficiency of resource use." ${ }^{36}$ This conclusion, in stark contrast to the more recent consensus that political stability and institutional capacity are vital to the success of development programs, points to the tendency of IFI staff to deny the political character of their new interventions even as they moved into new, more fraught domains.

The growing faith in the universality of certain neoclassical economic principles allowed both the IMF and the World Bank to pay less attention to the particular situations faced by individual countries. Although directors from developing countries did raise the issues of domestic political constraints and urged the IFIs to respond, the fact that politics were treated as a separate domain meant that they were rarely taken seriously or integrated directly into policy. The only real place for addressing particular political contexts was in the form of exceptions or exercises of judgment.

One of the dominant strategies of both the Bank and the Fund during the structural adjustment years was thus to colonize new terrain as economic and therefore subject to universal economic principles rather than particular political values. Although IFI actors did recognize that domestic political constraints could be a source of policy failure, it was not a problem that they could address directly, since the political was still viewed as beyond the pale of IFI expert practice.

\section{Before risk and vulnerability}

This tendency to bracket politics or to treat it as an economic issue was also connected to and sustained by a conception of time that focused on the short-term, assumed considerable continuity between present and future, and treated shocks as exceptional events. This conception of the temporality of policies was quite different from the organizations' more recent preoccupation with risk, which involves more attention to the ways in which policies evolve over time, and to the unpredictability of the future. As I have discussed elsewhere, all organizations must find some way of coming to terms with various unknowns. ${ }^{37}$ International 
organizations operate in an uncertain environment, in which the longterm success of their policies depends on factors that are beyond their control. This uncertainty has become a more serious preoccupation of IFIs and donors in recent years than it was during the structural adjustment era. The 1980s' more confident conception of the future was underpinned in part by the narrower focus - and tidier ontology - of IMF and World Bank policies: by denying the messy complexities of the political and social character of economic adjustment and development, focusing on a shorter time horizon and treating shocks as isolated events, staff could ignore many of the complicating factors that might upset their programs' evolution in the future.

From its inception, the IMF was created specifically to address shortterm balance-of-payments problems: in other words, to provide temporary financing to enable member countries to adjust their economy enough to bring their exports back up and into balance with their imports. ${ }^{38}$ In this respect at least, the organization did respect the goals of one of its architects, John Maynard Keynes, who suggested that the IMF should be a kind of "clearing union" (rather like a modern-day credit union) in which countries could obtain temporary overdrafts (or credit lines) when in need. ${ }^{39}$ As the convention of "stand-by arrangements" evolved from the 1950s onwards, countries were able to negotiate access to financing for between one and three years. Following the Polak model, these programs sought to act quickly on borrowing economies by limiting budget deficits and credit creation, rather than tackling longerterm challenges. ${ }^{40}$ Thus, as James Boughton points out, until the creation of the extended financing facilities in the mid-1970s, IMF programs were of a short enough duration that its staff and directors did not need to think through possible tensions between adjustment and growth or consider the long-term sustainability of their prescribed reforms. ${ }^{41}$

The World Bank has always had a longer time horizon than the Fund, given that its mandate was initially to help reconstruct Europe after the Second World War, and thus focused on development rather than on short-term adjustment. Yet in the 1970s and 1980s that time horizon was still quite limited in comparison with present practice. The organization's early emphasis on projects was consciously "bounded" in both time and scope, requiring little thought about the longer-term effects of development efforts. ${ }^{42}$ Even when the Bank first developed SALs in the early 1980 s, it was assumed that this kind of economic reform would be a short-term "big bang" rather than a more gradual, long-term process. Bank staff did recognize that adjustment was painful, often requiring the elimination of certain subsidies, dramatic changes in interest and 
exchange rates, or the liberalization of trade policy - all of which could be politically as well as economically disruptive. Yet it was hoped that this disruption would be brief, with the economy moving back into a growthoriented phase shortly after adjustment. Underlying this short-term approach were some basic neoclassical economic assumptions: although it was generally accepted that the best economy is one without distortions (understood as government constraints on a free market), it was believed that if you removed just some of the distortions, the remaining ones could have unintended consequences, leading to further deterioration. ${ }^{43}$ This so-called problem of the second-best solution led economists and policymakers to opt instead for an "all at once" approach to economic liberalization.

Over time, some serious strains did begin to appear in the IMF and World Bank's optimistic time horizons: as their policies became increasingly ambitious and wide-ranging, and it became clear that adjustment was not working as quickly as had been hoped, both organizations were forced to conceptualize their policies over an increasingly extended time horizon. The global economic system was also becoming more uncertain in the 1970s and 1980s, once the fixed exchange rate system collapsed and the Organization of Petroleum Exporting Countries (OPEC) crises took their toll, forcing both IFIs to address the effects of shocks. The IFIs responded by stretching out the existing set of temporal assumptions rather than reconceptualizing them entirely; staff continued to assume that policies would work as expected, but just take longer than originally anticipated, and with a few extra bumps along the way.

By the mid-1970s, it became clear to IMF staff and directors that short-term loans did not always provide enough time for borrowing members - particularly poorer countries - to make the changes necessary to turn things around. Developing members were particularly supportive of the idea of a longer-term facility; after some deliberation, the Extended Fund Facility (EFF) was created in $1974 .^{44}$ This was followed in the 1980s by the creation of the Structural Adjustment Fund (SAF) and the Enhance Structural Adjustment Fund (ESAF), both of which sought to provide financing over a longer time in order to enable more profound structural economic reforms. Not long after the Fund's staff created such extended facilities, they became concerned about what they termed "prolonged use" of the IMF's resources. By 1987, over thirty developing members were considered prolonged users, given the number of times that they had borrowed from the Fund and the outstanding credit that they owed. ${ }^{45}$ As the organization lent more to developing countries and placed more emphasis on structural 
reforms, it therefore also began to conceptualize the duration of policies over a longer time frame.

IMF Directors also debated and ultimately created a number of facilities designed to respond to potential shocks. The EFF was designed in part to respond to the disruptions caused by the first OPEC crisis. ${ }^{46}$ The Fund also set up two different oil facilities designed specifically to help countries whose balance of payments difficulties were caused by the increase in oil prices and, starting in the 1960s, the IMF also provided emergency disaster relief in certain cases. ${ }^{47,48}$ These facilities recognized the potential for unforeseen shocks to upset economic development, but they did so by treating the problems as very specific and generally isolated events.

At the World Bank, staff found themselves facing some similar dilemmas. Despite their optimistic assumptions about the speed with which structural adjustment policies would take hold, it was becoming increasingly evident that the complex changes they were trying to achieve were taking longer than anticipated. ${ }^{49}$ In response, Bank staff began to extend the time horizon of their policies from the mid-1980s onwards, sometimes distinguishing between quicker "first" and slower "secondgeneration" reforms. ${ }^{50}$ Towards the end of the 1980s, the Bank staff began to restructure their evaluation processes to try to take account of the longevity of their programs' effects. In 1985, the World Bank's Operations Evaluation Department (OED) introduced the category of "sustainability" in its project evaluations, which it defines as the likelihood of a project sustaining its benefits after completion. ${ }^{51}$ The Bank also began expanding its provision of emergency loans for countries whose balance-of-payments difficulties stemmed from various natural shocks, such as the drought that hit Ethiopia and Sudan in the mid-1980s. ${ }^{52}$ In 1984, the Board adopted guidelines on reconstruction, later formalized into an operational directive on "Emergency Recovery Assistance" in 1989. ${ }^{53}$ Yet, as Kapur et al. note, both McNamara and Clausen were resistant to this kind of lending, seeing it as a form of "relief" rather than economic "reconstruction."

Although the Fund and the World Bank thus conceptualized and operationalized the role of time differently, they both found themselves having to integrate a longer time horizon into their policies throughout the 1980s, as they deepened and expanded the structural aspects of their programs. They also began to find ways of addressing the unknown through peripheral policies designed to address certain kinds of shocks. Yet they both continued to see the future as relatively linear and to treat contingency as a matter of isolated shocks rather than as a more profound challenge to policies' success. 


\section{Before results-based measurement}

If there is one defining feature of modern bureaucratic organizations, it is probably the drive to count, measure and evaluate - in short, to translate the world into numbers. As I suggested in the previous chapter, the expert authority that is so crucial to institutional survival relies heavily on such forms of measurement and calculation. Yet, while the urge to quantify has remained constant among IFIs and donors, the form that these measurement practices have taken has changed over time. In fact, processes of evaluation and measurement have become an increasingly important and visible part of the governance of development finance over the past decade. Not only are key IOs and donors paying more attention to their own measurement practices, but they are also pressuring developing countries to adopt new evaluation strategies. The central concept around which many of these new governance practices hinge is that of results.

Although there is a long history of program evaluation at these organizations, particularly at the World Bank, these earlier practices of measurement were quite different from the current emphasis on results. As I discussed above, the policies of the 1970s and 1980s were based on universalist economic principles, with relatively short time horizons. Although, of course, the effects of these policies were far from straightforward, they were nonetheless conceptualized and operationalized in relatively simplistic terms. The metrics used for evaluating the policies, and the definitions of "successful" and "unsuccessful" programs, were also relatively straightforward and short term, focusing, for example, on the economic return to projects. At the same time, however, even in the earliest days of evaluation, IFI staff were aware of some of the dilemmas of expertise, recognizing the difficulties of adequately measuring the more complex dimensions of development financing.

The World Bank's institutional fascination with measurement and evaluation can be traced to the influence of Robert McNamara, who was known for this love of numbers. He put it particularly clearly when he once remarked: "I see quantification as a language to add precision to reasoning about the world." ${ }^{55}$ In his efforts to expand Bank lending and reduce poverty in the 1970s, McNamara introduced a host of measurements and targets for tracking loan volumes and poverty statistics. $\mathrm{He}$ also created the OED in 1973, which published annual reports evaluating Bank projects, a practice that continues today. ${ }^{56}$

These early reports assessed Bank projects as "successful" or "unsuccessful." They did so by applying a straightforward metric based on the volume of lending - a measure of policy inputs - and on the rate of 
economic return - a relatively narrow measure of output. ${ }^{57}$ Fund staff focused almost exclusively on ex-post evaluation, "assessing the results of work already done, rather than trying to second-guess the decisions of those responsible for current work," in the words of Christopher Willoughby, Director of the OED in the early 1970s. ${ }^{58}$ Yet Bank staff and leaders had already begun to recognize the limits of their measurement efforts. McNamara himself made it very clear that he saw discrete projects as means to the end of policy influence: for him, the ultimate goal of the Bank's efforts was to effect the kinds of changes that would ultimately achieve broad-based development and reduce poverty. ${ }^{59}$ Yet he and the OED staff were unable to find a way of measuring that influence.

By the 1980s, the Bank staff had developed techniques to enable them to formalize this effort to influence borrowing countries' policies through structural adjustment loans, but they were still struggling with the problem of measuring their effects. Most of the OED's annual reports continued to focus on projects (rather than policy loans) and to define success primarily in terms of project effectiveness (ability to attain initial objectives) and process efficiency (which takes into account some factors that may have complicated the original goals). ${ }^{60}$ By these relatively narrow measures, Bank programs were quite successful, with most years finding success rates of between 80 per cent and 85 per cent - with the notable exception of sub-Saharan Africa, which continued to suffer from much lower rates of success. ${ }^{61}$

At the same time as they focused on these narrower determinants of policy success, it is clear from these documents that Bank staff were struggling with the question of how to measure the less tangible but important aspects of their loan programs. As I noted above, in an effort to capture the longer time horizon of structural adjustment initiatives, OED staff introduced the idea of sustainability in 1985 in an attempt to measure the likelihood that projects would sustain their benefits after Bank funds had been disbursed. ${ }^{62}$ The evaluations of sustainability consistently found a lower rate of success than the overall assessment, which tended to focus on the project up to the moment of completion. ${ }^{63}$ As they began to try to assess such complex factors, OED staff expressed some frustration that the measures remained subjective and difficult to quantify.$^{64}$ Moreover, as staff noted in their 1990 review, although most projects could be evaluated through a cost-benefit assessment of their economic rate of return, they had to rely on their subjective judgment when evaluating the success of structural adjustment programs. ${ }^{65}$ Bank staff had not yet invented a way of adequately translating these more complex problems in quantitative terms - a challenge that would lie at the heart of the later turn to results measurement. 
The IMF's history of evaluation has been more sporadic than the World Bank's. ${ }^{66}$ The Fund did not create an independent evaluation office until 2001, and generally relied on occasional internal staff evaluations (and the odd external review) until that time. The IMF Executive Board did, however, mandate periodic evaluations of the conditionality policy beginning in $1979 .{ }^{67}$ The Fund's initial reviews focused on formal performance criteria, measuring the degree of compliance with these conditions and assessing the attainment of key objectives, including inflation rates, balance-of-payments changes and growth rates. ${ }^{68}$ Staff also began to use a variety of methodologies in determining program success. ${ }^{69}$

What is striking about these reviews is the fact that they consistently found very low levels of "success" in conditional Fund programs. The 1979 and 1981 reviews found that the achievement of most of the performance criteria objectives was "mixed" at best, while the 1982 report found that performance "fell short of expectations in many cases." 70 In fact, as IMF historian James Boughton summed up the cumulative results of the evaluations in the 1980s, the success rate was somewhere between one quarter and one half of the programs initiated. ${ }^{71}$ Yet, while these relatively low levels of success were a matter of concern, they did not cause the organization to significantly redesign its approach. Instead, both the staff and most of the Board concluded that the problem was not the model of adjustment itself but a wide range of exogenous problems, ${ }^{72}$ including the fact that certain objectives, like growth, took longer to achieve than was allowed for in the evaluation time frame, ${ }^{73}$ the role of domestic factors including a "lack of political commitment," 74 and the effects of external shocks. ${ }^{75}$

Like their peers at the World Bank, IMF staff were also aware of the limitations of their efforts to measure the success of adjustment programs. In their 1979 report they noted the "significant element of judgment" involved in any evaluation and raised some important questions about the difficulty of establishing a clear causal connection between IMF policy instruments and final outcomes in inflation or growth rates. ${ }^{76}$ In their 1979 and 1981 reports, they also noted that the time frame of their evaluations was too short to assess the implications of policies that take longer to take effect. ${ }^{77}$

The cultures of evaluation within the Fund and the World Bank in the 1970s and 1980s were clearly very different from one another. The Bank had adopted a systematic approach to evaluation relatively early on, one focused primarily on simpler metrics such as inputs and easily quantifiable outputs, but which was gradually beginning to tackle more complex metrics like sustainability. The IMF, on the other hand, adopted a more 
ad hoc approach to evaluation and continued to be remarkably sanguine about what appeared to be much lower success rates. Both organizations contented themselves for the most part with relatively straightforward metrics for evaluating policy success and failure. At the same time, both struggled with the limits of their measurement techniques and began to experiment with different ways of measuring less easily quantifiable aspects of their programs.

\section{A confident style of governing}

This brief overview of earlier IMF and World Bank governance practices allows us to see both their stability and their fragility in the 1980s and early 1990s. As both institutions moved into the business of lending to very poor countries for extended periods of time and of imposing increasingly complex and demanding conditions, they developed a range of policies that relied on specific assumptions about universality, particularity and politics, time and uncertainty and measurement. By redefining what had previously been seen as domestic political issues as economic ones, they were able to redraw the boundaries between the political and the economic, as well as between the particular and the universal. Fund and Bank staff saw this policy space of universal economic questions as unfolding in a particularly smooth, linear kind of time. As the objects of governance proved to be less tractable and the environment less certain than initially imagined, they gradually extended their time horizon but did not yet substantially rethink their conceptions of time or the unknown. Finally, while measurement and evaluation became increasingly integrated into organizational practice, it remained focused on relatively straightforward metrics, such as volume of lending, economic return, compliance with conditions and achievement of initial objectives. $^{78}$

Are there any broader conclusions that we can draw about the way that governance was conducted during the structural adjustment era? Over the course of the 1980s, World Bank and IMF policies were never static: they continuously changed, as staff and Board members sought to adapt and respond to various problems or to apply new ideas. The experiences in both organizations differed in important ways. And policies were applied in diverse ways in the many different countries, regions and sectors in which Bank and Fund staff were involved. We must therefore be very cautious about making any broad generalizations about the kinds of governance practices developed and employed during this time. With these caveats in mind, however, it is useful to consider whether any patterns emerged. 
Nikolas Rose has suggested that: "To govern is to cut experience in certain ways, to distribute attractions and repulsions, passions and fears across it, to bring new facets and forces, new intensities and relations into being." 79 This brief overview of the IMF and World Bank's governance practices during the structural adjustment era provides us with some useful insights into the ways that experience was "cut" and distributed how the political was differentiated from the economic, for example, or success from failure. It also provides us with some perspective on the ways that different forces were brought into relation with one another, as new facets of developing countries' experience were made visible - their trade policy, or their public enterprises - and thus amenable to governance.

As I suggested in the previous chapter, we can gain a better understanding of the patterns that inform governance practices if we consider the actors involved, the kinds of techniques that they use, the forms of knowledge involved, and the types of power and authority that they deploy. If we look at who did the actual work of managing the financing of development in the 1970s and 1980s, we find a very limited group of actors involved. There were various powerful leadership figures then, as there are today, such as Robert McNamara and Anne Krueger. There were also a few vocal critical groups, such as the Group of 24 (G-24) and the New International Economic Order, who challenged the IFIs, but they were far fewer in number and influence than today's NGOs. ${ }^{80}$ The most striking difference between the actors involved in governance then and now, however, was the far more limited roles played by borrowing governments. As far as the everyday work of governance was concerned, it was IMF and World Bank staff who largely controlled the process, designing the policies, deciding on the conditions, drafting the reports and measuring policies' success and failure.

The ideas that dominated the structural adjustment era were also considerably narrower and fewer in number than those we find today. There had been some room for intellectual debate and difference at the World Bank under McNamara, with advocates for various approaches to poverty reduction, for example, vying for influence. ${ }^{81}$ Under the influence of his successor, A. W. Clausen, the Bank became a far more orthodox institution. Like his Chief Economist, Anne Krueger, Clausen was convinced of the universal value of the free market and private sector institutions. In a speech at the Brookings Institution in 1982, Clausen articulated his faith in a market-based approach to development, noting that "The private sector is what I know best" and "I know it works," to further economic development in even the poorest economies. ${ }^{82}$ At the IMF, the shift from a more Keynesian-inspired to a more narrowly 
neoclassical approach to economics was a more gradual affair. Yet by the 1980s, the IMF Board and staff had also shifted to embrace supply-side economics and the full list of Washington Consensus principles. At both institutions, these economic ideas became something of an article of faith a set of virtually unquestionable universal principles. In contrast to the small " $\mathrm{i}$ " ideas that I discussed in the last chapter, and which have characterized the past two decades, the 1980s and early 1990s were dominated by big "I" ideas like Neoliberalism: ideas that promised a solution to everything and that wore their ideology plainly on their sleeve. $^{83}$

These neoclassical principles underpinned conditionality as the chief technique that IMF and World Bank staff used to govern economic adjustment. Over the course of the 1980s and into the 1990s, they developed increasingly numerous and diverse forms of conditions directed at different aspects of a country's economy. In contrast with previous and later approaches, the techniques used during the structural adjustment era were direct. Under McNamara, World Bank staff sought to use their funding of projects as a means to obtaining a much broader and diffuse objective - that of influencing borrowing countries' policies. ${ }^{84}$ Under Clausen, in contrast, the Bank began to use program aid, and the conditions associated with it, to more directly shape domestic actions. At the IMF, the advent of structural conditionality also emboldened staff and Directors to target trade, labour and financial policies more explicitly, rather than relying on the blunter tools of credit-ceilings to affect them.

The documents, or inscriptions, used by both the IMF and the World Bank were also narrowly focused: the key document used to coordinate Bank and IMF programs was the policy framework paper (PFP), a relatively short document and a very different kind of inscription than the PRSP that was to replace it, as I will discuss in Chapter 5. Almost entirely absent from these techniques were the kinds of participatory processes that have come to play such a central role in present IFI practices. Finally, measurement techniques were also reasonably direct and straightforward: they sought to count such things as inputs and outputs, economic return and compliance with quantitative conditions. There was much less effort to measure the less tangible aspects of financing development - the actual effects of specific policies on the longer-term goals of political, social and economic development.

As the IFIs' growing ranks of critics were keen to point out, the techniques of structural conditionality in particular involved quite visible forms of power. Staff at both organizations have of course always been careful to argue that no one is ever forced to accept conditions - since 
they always have the choice of turning down the aid. Yet, when that aid is the difference between surviving a balance of payments crisis or not, or when it makes the difference between a crushing recession and a more gradual, if painful, adjustment, then it is not difficult to see just how narrow a government's "choices" become. As the Berg Report itself stated, the goal of structural adjustment was to use aid dollars to achieve "leverage" over countries' domestic policies. ${ }^{85}$ Again, in contrast with earlier attempts to influence borrower policy by buying a seat at the table through project financing, this was a more overt form of power that sought to dictate policies. It was also a particularly instrumental form of power, in which the goal was to change the behaviour of certain actors (government actors in particular) in line with certain economic principles. Of course, structural adjustment policies, and the broader neoclassical economic framework that they rested in, were also in many ways productive: they did make important changes to borrowing countries' governments and markets, changing their character and not just their behaviour. Yet IFI actors were not on the whole particularly reflexive about their productive power, seeing themselves as acting in rather than on the world.

Perhaps most important of all, however, was the form of authority that these governance practices relied on. This was a narrowly expert kind of authority, based on universal economic principles rather than any explicitly moral precepts or popular approval. This expert authority was the source of much of the structural adjustment era's strength: its advocates could present themselves as immune from political squabbles, acting with objectivity to apply the principles of economic efficiency to make a better world. ${ }^{86}$

Does this particular combination of governance factors add up to a broader pattern? I suggested in the previous chapter that historical moments are often characterized by a certain style of economic governance. Each style is a particular resolution of the ontological, methodological and epistemological dilemmas of expert authority - the need of institutional actors to show that they really do know what they know, despite an uncertain world. This brief review of some of the main practices that characterized IFI governance in the structural adjustment era reveals a simplistic ontology in which only economics mattered, and everything that mattered could be understood as economics. This narrow conception of the world of economic development allowed for relatively straightforward methodologies for measuring, assessing and acting in it. It also allowed for a very confident epistemological position, in which there was one singular, knowable solution to each of the problems of finance and development. The 1980s were thus characterized by a particularly confident and direct style of governance. 
I suggested in the previous chapter that governance styles are often closely connected to the question of failure: contestation over what counts as a failure, in particular, can play an important part in enabling changes in expert governance. There were several key ways in which changing definitions of failure played an important role in launching and legitimizing the rise of this structural adjustment style of governance. As I noted earlier in this chapter, shortly after McNamara's tenure at the World Bank ended, the OED began classifying as "failures" many of the direct poverty reduction projects that he had championed. ${ }^{87}$ This claim of failure was part of a broader move to treat poverty reduction as subordinate to the overall efforts to achieve growth through market-based reforms. ${ }^{88}$ The Berg Report itself can also be understood as an attempt to define the problems that the World Bank had faced in sub-Saharan Africa as a particular kind of failure: a failure of the public sectordominated approach to development that had characterized the region up to that point in time. ${ }^{89}$ These were much less public airings of the failures of development than were to emerge in the late 1990s, and they were also less contested, but they did nonetheless play a role in the transition towards the structural adjustment approach.

How did the various governance practices that characterized the structural adjustment era respond to these past failures and re-establish their authority? I will of course provide a much more comprehensive account of the different qualities of the provisional style of governance that was to follow this earlier set of practices in the coming chapters, so any direct comparison is a little premature. It is nonetheless worthwhile spending a moment tracing some of the major differences between these two styles, considering how they sought to respond to the problems and possibilities of failure. I suggested in the last chapter that the provisional style of governance seeks to re-establish institutional authority through practices that are indirect, proactive and symbolic, and that hedge against the possibility of failure.

In contrast, the structural adjustment style of governance was very straightforward in its relationship with its objects, acting directly on the particular problems (e.g. a country's trade policies or price controls) that it sought to fix. These governance practices were not particularly proactive. Time horizons were quite short, and IMF and World Bank staff were more interested in immediate effects than in playing the long game. Although this short-termism began to shift over time, staff remained focused on changing immediate behaviours (such as budget deficits), rather than tackling the underlying motivations (such as bureaucratic cultures or political will). In part because this governance style relied more on direct techniques, it was also better able to conceal the 
constructed and symbolic character of its practices. Conditions, for example, were designed to directly change specific policies rather than being preoccupied with fostering credibility or signalling commitment. The universal principles that defined key policies were narrowly economic, and so were more easily black-boxed than later, more ambiguous, standards of good governance.

Finally, those involved in the practice of governing development financing in the 1980s were not very preoccupied with the possibility of their own failure. Through the OED World Bank staff did engage consciously in the task of differentiating successful and unsuccessful projects, yet they were not particularly concerned with the less successful cases. This was of course in large measure because their success rates were quite high, due in part to the relatively narrow character of the projects and of the criteria for success. At the IMF, the staff's very sanguine approach to the problem of failure is even more striking given that their actual rates of success were quite low. Why this lack of concern with apparent failure? Because these "failures" did not really count as such. They were seen as the product of various exogenous factors, not of the policies themselves, which were based on correct economic assumptions. The certainty of most IFI staff's convictions regarding the universal validity of their prescriptions thus made for a very direct and confident style of governance. ${ }^{90}$

\section{Tensions emerge}

Looking back at this earlier period, it appears in many ways to be the golden era of the IMF and World Bank, when they seemed most certain about their mandate and most ambitious in their efforts. While critics certainly abounded during the 1980 s, they were treated as marginal. Whether they were fighting in the streets of LICs against sudden increases in the price of basic necessities, or working as staff in a small but growing number of NGOs focused on development reform, they were rarely taken seriously by the IFIs themselves. The economic orthodoxy embodied by the IMF and World Bank also held sway in most universities, as economists interested in development, history or (heaven forbid) heterodox theory were a dying breed. ${ }^{91}$ The hegemony of the "Washington Consensus" seemed complete.

As my discussion of the various practices of the structural adjustment era reveals, there were nonetheless some important tensions in this approach to governance. While structural adjustment policy was often presented by its advocates as a natural progression from the Bank and the Fund's earlier policies, it was, like all governance processes, a social artifact that just happened to be particularly well black-boxed, or pushed 
into the background. There was nothing natural or inevitable about the particular set of economic principles that were suddenly deemed universal and timeless (as was made evident by the speed with which they were amended in later years); nor was there anything inevitable about the boundaries drawn between political and economic issues, the assumptions made about how adjustment policies would evolve over time, or the ways in which success and failure were measured. However solid and definitive they might appear, these governance strategies were all in fact rather approximate and potentially fragile constructions, full of gaps and tensions.

By the late 1980s and early 1990s, some of these tensions were already coming to the fore. For example, although throughout much of the $1980 \mathrm{~s}$ it had been a matter of doctrine that economic adjustment did benefit the poor (even if such benefits were not always visible), ${ }^{92}$ by the end of the decade, World Bank staff were more open to the possibility that there might be negative short-term impacts on the poor. ${ }^{93}$ The IMF, too, became more concerned with the problem of poverty, recognizing that the political backlash caused by unpopular policies like reductions in price subsidies for food and fuel could do serious harm to IMF policies. ${ }^{94}$ Old certainties were thus beginning to come into question. In spite of these challenges, however, structural adjustment and structural conditionality continued to be central to both organizations throughout much of the 1990s. Why and how they eventually gave way to a different kind of governance practice is the subject of the next chapter. 
It was in 1997 that a number of events occurred that pointed to a more profound transformation in development finance. This was the year that an external review of the International Monetary Fund's (IMF) Enhanced Structural Adjustment Fund (ESAF) identified a lack of country ownership as a key problem. ${ }^{1}$ It was also the year that the World Bank's Operation Evaluation Department (OED) restructured its annual reports around the concept of "aid effectiveness." ${ }^{2}$ And the year in which the World Development Report's (WDR) central theme was The State in a Changing World. ${ }^{3}$ Each of these actions indicated that something was changing in global development finance. The IMF's review made it clear that country ownership - a concept that had been circulating among Bank staff for some time - was now a central concern, and signalled the beginning of the institution's move towards a more formal culture of evaluation. The issue of aid effectiveness emphasized by the OED soon became a central mantra for the Bank, and the donor community as a whole. Finally, that year's WDR made it clear that the World Bank was once again interested in the state - and hence in politics - even if it was in a very particular form. This is not to suggest that 1997 was a necessary turning point: in fact, many of these shifts and reconfigurations had been in the works for some time, while others only really became institutionalized several years later. Yet each of these reports made these transformations visible in new ways - and in doing so helped make them possible. ${ }^{4}$

This chapter provides a broad overview of the transition from the confident and direct governance style of the structural adjustment era which was in some disarray but still holding sway at the end of the last chapter - to the new, more provisional form of governance that will be examined in the remainder of the book. The structural adjustment era was characterized by its own approach to the challenges of governance. Institutional actors sought to maintain their expert authority through their faith in technical economic universals, their effort to subordinate politics to economics, their linear conception of time and the future, and their narrower approach to measuring success and failure. By the late 
1990s and early 2000s, however, these earlier governance practices had been reorganized and replaced by the strategies of standardization, ownership, risk and vulnerability management, and results measurement, as the confident style of structural adjustment gave way to a more provisional one.

How did this transformation in the practices of economic governance occur? Certain salient events - particularly the failure of development efforts in sub-Saharan Africa, the Asian financial crisis and the more recent global financial crisis - did play a role in fuelling the changes in development financing. Yet it was not so much the events themselves but the ways in which they were taken up, interpreted and responded to that enabled significant changes in global governance practices. These events became contested failures - failures that raised significant questions about the international financial institution's (IFI) claims to expert authority, ultimately provoking hot debates about what counted as success and failure in development finance. These apparent failures became focal points for contestation, intensifying ongoing debates, exacerbating existing tensions, and ultimately fostering several important processes of problematization. These problematizations took the form of both debates about the character and future of development finance and more practical adaptations and innovations in the various techniques of governance. As they faced the erosion of their expert authority, IFI staff and leaders debated, negotiated and ultimately sought to re-establish their authority through several new governance strategies.

This explanation for the shift in governance strategies still leaves us with a puzzle, however: why were the earlier forms of expert authority so fragile? As I discussed in the last chapter, the 1980s and early 1990s were marked by a confident approach to governance, underpinned by a set of universalist techniques for managing economic adjustment. How did this era of confident economic orthodoxy become subject to this kind of widespread problematization? Drawing on Sheldon Wolin's interpretation of Max Weber, as well as the work of Michel Callon and Andrew Barry, I will suggest that this fragility is in fact a central dilemma in modern governance - and one that has become more pressing for international financial institutions in recent years, as they have moved into the more complex terrain of domestic politics.

My goal here is not to develop a testable explanation of this transition, but rather to provide a coherent account of how these changes occurred, focusing in particular on the often-neglected role of expert authority. As I suggested in Chapter 2, a focus on the fragility of expert authority, the contested nature of failure and the politics of problematization enables us to understand changes not only in governance norms, but also in the 
practices that help to sustain them. What this analysis reveals is neither a linear process of evolution, nor a crisis-defined shift in paradigm, but rather a more complex pattern of changes that involves both recombination and innovation in the governance of finance and development.

I begin this chapter with a brief overview of some of the traditional explanations of the recent changes in IMF and World Bank governance practices. I go on to develop an alternative account that hinges on the fragility of expertise and the politics of failure. I then take up where I left off in the previous chapter, tracing the problematization of earlier structural adjustment-era practices and their replacement with the strategies of fostering ownership, developing global standards, managing risk and vulnerability, and measuring results. I conclude by considering the parallels and differences between this most recent transformation of the practices of global governance and those that have occurred in the past.

As I noted in the Introduction to this book, this way of understanding the change of governance practices over time draws on much of the existing literature on institutional change and also provides some important innovations in our thinking about the role of ideas, the form that change takes, and the character of expertise. Ideas remain a central part of the account, but the emphasis is on small " $\mathrm{i}$ " ideas rather than major ideologies. Moreover, what is at least as important as ideas are the techniques that they enable and in which they are embedded, as well as the various actors involved in their day-to-day use. An attention to these smaller-scale, more concrete parts of the process makes it possible to trace the changes taking place in a way that avoids relying on a logic of crisis, rupture and paradigm shift, or on a narrative of linear evolution. In Bruno Latour's words, the idea of a coherent trajectory is replaced with a series of never-perfect translations as policy practices and ideas are borrowed, combined and transformed over time. ${ }^{5}$ Finally, this analysis also takes not just the experts but also the idea of expertise itself down from its pedestal and shows just how fragile and approximate it really is examining how those who participate within the culture of expertise work pragmatically and imperfectly to maintain their authority.

\section{Some traditional accounts}

Before I outline some of the factors that played a role in these policy changes, it is worth considering some of the more traditional ways of making sense of the transformations in global economic governance. Scholars and policymakers alike have tended to focus on either the role of state interests (particularly the United States), a paradigm shift in development ideas, the institutions' learning from past failures, or the 
evolution of advanced capitalism. While each of these answers is partly correct, they are also all somewhat misleading.

There is no question, for example, that states played an important role in pushing for certain kinds of changes in IMF and World Bank policy: the US Congress has been an ardent critic of both organizations, while both Bill Clinton and Tony Blair were leaders whose interest in finding a "Third Way" resonated with some of the changes taking place in IMF and World Bank policies. ${ }^{6}$ Yet, as I will explore in more detail in the coming chapters, while key state actors did play important roles at certain moments, they rarely got exactly what they wanted. ${ }^{7}$ In many cases, there was little overt state disagreement over the policy changes involved: few, for example, were willing to oppose more country ownership or better risk management. The 1990 s and early 2000 s were a moment of at least partial retreat from the usual state-driven politics of development finance. ${ }^{8}$ This does not mean that there were not winners and losers: just that, as I will discuss in later chapters, the dividing lines are more complex than state-based analyses can adequately capture.

Nor were the battle lines primarily those of class. Some have argued that these changes in IFI policy are the logical next step in the evolution of advanced capitalism - whether as a form of accumulation through dispossession, an extension of Northern productivist logics to the global South, or a sophisticated attempt to enhance legitimacy. ${ }^{9}$ There is little question that these new policy strategies continue to support existing capitalist economic relations, even if they do give them a somewhat gentler face. While this insight is an important piece of the puzzle, it does not tell us much about why these particular policies were chosen over a myriad of other possibilities. The actual paths taken indicated a much more contingent set of processes than can be adequately captured by such structuralist narratives. Moreover, those who see this as the latest iteration of advanced capitalism tend to assume that the IMF and the World Bank are relatively coherent agents of capitalism who actively support these changes, when in fact, as I will discuss in the Conclusion, they are actually quite divided internally, with many staff ambivalent about the new direction that development finance has been taking.

Changing ideas and norms also played an important role in this transformation, as some constructivist commentators have pointed out. ${ }^{10}$ Yet to characterize recent changes as a new paradigm in development policy - a phrase coined by Joseph Stiglitz - is to greatly overestimate the magnitude of the ideational changes involved, and to ignore their more complex history. ${ }^{11}$ Many of the norms and ideas that helped give shape to these new governance strategies had been around in one form or another for some time. As I will discuss below, it was their 
recombination and adaptation that made them such a potent force. Moreover, the most important ideas have not been large paradigmatic ideas, but rather smaller, more pragmatic ones. In contrast to John Gerard Ruggie's argument that norm-governed change is more significant than a shift in instruments, in this case, changes in the instruments the practices, techniques and procedures - were in fact crucial drivers behind the more substantial changes in global governance. ${ }^{12}$

Finally, the suggestion that these changes were the product of institutional learning is both correct and misleading. ${ }^{13}$ Such liberal analyses tend to miss two important complications: first, they assume that what occurred was that the organizations learned from a set of objective failures (such as the decades of unsuccessful development in subSaharan Africa) and developed new policies in response, when in fact what occurred in many cases was that results that had previously been acceptable came to be labelled as "failures" as the tools used to evaluate them changed. Second, such liberal analyses generally treat institutional learning as a benign process relatively free from power relations. In doing so, they miss some of the most crucial struggles taking place as institutional actors seek to renegotiate their authority and recalibrate the ways in which they exercise power.

\section{An alternative account}

In contrast with these more traditional explanations, this chapter will propose an alternative account focused on the paradoxical role of expertise as both the foundation and key weakness of institutional authority. As I discussed in the last chapter, the governance practices of the 1980s relied heavily on a particularly narrow and economistic kind of expert authority. Its practitioners were certain of the universal applicability of its principles, defining its objects in narrowly economic terms and largely ignoring the complications of politics. This minimalist ontology allowed them to use relatively straightforward metrics to evaluate their policies and to view the future as a more or less predictable extension of the present.

All was not as straightforward as it seemed, however. As I will discuss below, over the course of the 1990s, existing tensions within the World Bank and the IMF's structural adjustment strategies became more pronounced: the complications of politics continued to intrude, measurement problems multiplied, and the uncertainty and unpredictability of the global environment increased. These tensions did not cause a radical breach in IFI policy, nor did they lead to a coherent process of institutional learning. Although certain key contested failures did play a 
role, they did so by exacerbating existing tensions, accelerating the messy and uneven process of problematization and innovation in governance practices. In the process, the relative coherence of the structural adjustment style of governance was undermined: the institutions' expert authority was attacked, renegotiated and ultimately supplemented.

\section{The fragility of expert authority}

Why was the IFIs' expert authority attacked and, more importantly, undermined? After all, we have generally come to think of expertise as not only the most pervasive but also the most secure basis for authority. We owe this perspective on technocratic authority to Max Weber above all others, for his powerful depiction of modernity as subject to the progressive colonization by the technical-rational authority beloved of bureaucracies. Yet, it is actually through a particular reading of Weber, by the political theorist Sheldon Wolin, that we can also begin to grasp the fragility of expertise. Wolin suggests that if one reads Weber's political theory and methodological work together, it becomes clear that

Methodology, as conceived by Weber, was a type of political theory transferred to the only plane of action available to the theorist at a time when science, bureaucracy, and capitalism had clamped the world with the tightening grid of rationality. Methodology is mind engaged in the legitimation of its own political activity. ${ }^{14}$

So far so good for our IFI actors, who rely so heavily on the methodological certainties of expert authority. Yet Wolin suggests this scientific solution to the problem of authority is only ever temporary: even the factvalue distinction that was at the heart of Weber's methodology was an article of faith. It had to exist in order to ensure that values remained within the realm of choice. ${ }^{15}$ In such a world, the methodologist, like the Calvinist in The Protestant Ethic, or the charismatic leader in Economy and Society, is a heroically moral figure, who must not only have faith but actively foster it at times when belief flags. ${ }^{16,17,18}$ Weber himself lived through such a moment, during the German methodological debates, "when the nature of the social sciences qua science was being contested." ${ }^{19}$ For Weber, Wolin suggests,

The "foundation" for empirical inquiry comes not from empirical data but from "the meta-empirical validity of ultimate final values in which the meaning of our existence is rooted." These foundations, however, tend to shift and even crumble because life itself is "perpetually in flux ... The light which emanates from these highest evaluative ideas falls on an ever changing finite segment of the vast chaotic stream of events which flows away through time."20 
Methodological crises are thus generated by ontological contingency. At moments of crisis, when foundational values no longer seem to fit the changing world, methodologists must act: not only finding new methods, but also grounding them in new epistemological claims. They must challenge out-of-date modes of analysis and establish new ones, thus rebuilding the foundation - and restoring the faith - that makes social scientific analysis possible.

There is much in Wolin's description of potential crises of expert authority that resonates with the experience of development finance actors over the past two decades. We have witnessed the rise of new methodological debates that have sought to challenge and replace the old foundations of development knowledge. Moreover, as I will discuss below, some of the most vigorous and significant debates have been focused on questions about how to measure success and failure, while new policies that have emerged have sought to measure new things in new ways: measuring risk, results, ownership and best practices, rather than compliance with conditions. This is not simply an example of ideational change. It is not just how people frame the world that has changed, but also how they count and calculate and seek to engage with things; a methodological, and ultimately an epistemological, transformation has been underway.

We face methodological and epistemological limits because the finitude of our frameworks and metrics must come face to face with the open-ended character of the world. As Weber points out, the world is "perpetually in flux," posing a constant challenge to our efforts to understand it. Failure, in this sense, is built into all of our efforts to understand and transform a world that resists us. It is a central feature of modern theory and practice. We do not fail simply because we have not recognized the changes that have occurred, as in the classic dilemma of always fighting the last war. We also fail because the contingencies of the world force us to change our metrics and redefine what counts as success and failure. Failures are always contested, as various actors define or deny them in their own ways. Yet some failures are so contested that they raise these more fundamental methodological and epistemological questions about what counts as failure.

In such moments of more profound problematization, we need to rethink basic categories and re-engineer our practices. In the process, we make the tacit background of our everyday lives the subject of reflexive thought and debate, at least for a time, until we re-establish our methodological foundations and forget their fragility. While such gaps between the world and our efforts to make sense of it will always appear eventually, they can also be intensified or accelerated under certain 
circumstances. In the case examined here, both the IMF and the World Bank began in the 1980s to delve into increasingly complex arenas, as they moved into structural adjustment lending. Yet the methodological categories through which they sought to make sense of these more complex objects remained narrow and simplistic, increasing the tensions in their claims to expert authority.

What happens when such gaps grow wider and the fragility of expert claims is exposed? Two other theorists also provide us with some additional clues to such moments. Andrew Barry suggests that agreed practices of measurement and calculation can act to reduce political dispute, by fixing certain decisions and excluding them from the debate; so, for example, if we agree that a development program's success can be measured using a certain set of metrics, then the assumptions underlying those choices are not subject to dispute. ${ }^{21}$ Yet Barry also points out that such depoliticizing effects are not guaranteed: systems of calculation and measurement rely on processes of standardization which are necessarily imperfect when faced with the complexity of the world. ${ }^{22}$ They are therefore inherently fragile, and can themselves be subject to political debate - producing something rather like the kind of methodological crisis that Weber was concerned about - and the kind of problematization that I have pointed towards.

Michel Callon uses the term "cold negotiations" to describe those debates in which the basic parameters of measurement are agreed, and "hot negotiations" to describe those in which the basis of calculations may themselves be subject to debate. ${ }^{23}$ Many of the debates and transformations that I will survey in this chapter were effectively either hot or warm negotiations, in which the basis of calculation was itself up for grabs. ${ }^{24}$ The debates surrounding discussions of the success and failure of development and adjustment clearly constitute this kind of hot negotiation. These debates about what counts as "aid effectiveness" have in turn informed other discussions about the importance of ownership and good governance, the need to manage risks more effectively, and the kinds of measurement techniques required. As I will discuss in later chapters, while many of these discussions were first either relatively cold or warm, over time much of the debate shifted precisely to the question of what counted as ownership, good governance, risk and meaningful measures of success and failure.

\section{The politics of failure}

What provokes these more profound debates? Although there are many potential causes, such hot negotiations often emerge in the context of 
highly contested failures. These are publicly visible failures that are seen as particularly serious and important, but over which there is significant disagreement about their causes and implications. Such contested failures often pose serious challenges for the actors or organizations that are seen as responsible, and can lead to new problematizations and new strategies. While such contested failures do not cause institutional change outright, they can unsettle taken-for-granted assumptions and practices, come to symbolize existing tensions, and help accelerate the processes of erosion and problematization. In the case of the IMF and World Bank, three contested failures in particular had formative effects on IFIs' thinking and practices: the Asian financial crisis, the crisis of development in sub-Saharan Africa in the 1990s, and the more recent 2008 global financial crisis. These failures played important roles in the transformation of IMF and World Bank governance strategies - not so much because of what they objectively revealed, but rather because of how they were taken up and represented within and outside the organizations. $^{25}$

The 1997-8 Asian financial crisis was a serious and publicly visible failure of the international financial system. Yet it was also a very contested failure. On the one hand, critics, including the World Bank Chief Economist, Joseph Stiglitz, argued that the crisis and the IMF's response to it were both failures of IMF orthodoxy: it was because Asian countries went too far in adopting the IFIs' prescriptions of financial liberalization that they were left without the tools necessary to respond effectively. ${ }^{26}$ Yet IMF staff and management saw the crisis as a different kind of failure - one with domestic political and institutional causes. Together with the US Secretary of the Treasury and mainstream economists, IMF staff argued that the domestic economies of the Asian countries were structurally unsound and distorted by "crony capitalism." ${ }^{27}$ Drawing on the increasingly influential small " $\mathrm{i}$ " ideas of institutionalist economics, they argued for the importance of reforming not just economic policies but also economic, legal and political institutions. This reading of the crisis meant that the Fund was not only justified but also required to expand its mandate, and encourage borrowing countries to undertake more profound kinds of institutional reform. ${ }^{28}$

Another important failure that became a focal point for debate around the same time was the recognition of the "decades of despair" (the 1980s and 1990s) in sub-Saharan Africa. ${ }^{29}$ In the 1980s, investment declined in the region, exports fell and real per-capita income and food production both dropped, while African governments took on ever-greater volumes of debt. ${ }^{30}$ For the Bank in particular, the persistence of poverty in the region and failing to achieve sustainable development was a source of 
shame. No matter how brightly they might paint their reports on global and regional development outcomes, the fate of sub-Saharan Africa remained a dark stain. Yet, as with the Asian crisis, the question of what kind of failure this represented was itself the subject of contestation. For critics, it was a clear indictment of the World Bank's heavy-handed structural adjustment policies. For many Bank staff, it was seen as a different kind of failure: above all, the lesson drawn from this experience was that domestic factors, particularly political capacity and institutional development, played a crucial role in determining the success or failure of development programs. ${ }^{3}$

This preoccupation with the failure of development efforts in subSaharan Africa was not new. OED evaluation reports throughout the 1980s noted that the projects in sub-Saharan Africa had consistently high rates of failure in comparison with other regions - without precipitating the kind of radical rethinking that began in the 1990s. ${ }^{32}$ As my brief overview of the World Bank's history in the previous chapter reveals, the 1981 Berg Report had also focused on the region's difficulties and emphasized the importance of domestic factors - yet it drew rather different conclusions: the report downplayed the importance of achieving political consolidation and focused instead on structural economic issues, justifying the structural adjustment approach to economic governance. ${ }^{3}$

More recently, another major crisis has had a destabilizing effect on the IMF, World Bank and donors: the global financial crisis that began in 2007. Whereas the Asian crisis was largely blamed on Asian domestic governments, it was simply not possible to blame this more recent crisis on other countries or on governments alone. Mainstream economists and IFI leaders finally began to see the markets themselves as a source of considerable instability - a sign of the failure of the West to adequately regulate financial practices and to anticipate the potential for devastating shocks. The recent financial crisis was also a contested failure, with critics arguing that it pointed to a profound failure in the global financial system, and IFIs, most Western leaders and many economists suggesting that the failures were more modest, requiring less radical changes to the system. Yet IFIs and donors did conclude that they had to pay more attention to the fundamentally volatile and contingent character of the global economic system. This more recent contested failure has therefore played an important role in precipitating a shift in how mainstream economists and IFI and donor staff conceptualize the world around them, leading them to place greater emphasis on risk, vulnerability and the ever-present possibility of shocks.

These failures precipitated debates not only within the organizations themselves but also among state leaders, non-governmental organizations 
(NGOs) and academics. British and Nordic country leaders seized the opportunity presented to pressure the IFIs to adopt the "aid effectiveness" agenda. In the US, during the final years of the Clinton Administration, Congress was extremely critical of the IMF and World Bank, with the Meltzer Commission proposing a reduction in the role of both organizations. What is most interesting for our analysis is not necessarily the IMF's blunders in Asia, the continued poverty in Africa, or the growing global financial instability, but how and why these failures became important when they did, sparked particular debates, and helped foster new governance practices.

\section{The problematization of structural adjustment practices}

Although these contested failures played an important role in precipitating changes in development finance practices, they did so by amplifying existing tensions and debates. Despite the apparent robustness of the structural adjustment-era governance practices, they were subject to tensions that made them potentially unstable. By tracing these tensions and the processes of problematization that they ultimately enabled, we can begin to understand the dynamics that helped to produce the four governance strategies discussed in this book: ownership, standardization, risk and vulnerability management, and results measurement.

\section{The problems (and possibilities) of politics}

Politics always poses a challenge to bureaucratic institutions' expert authority, given their claim of neutrality and objectivity. ${ }^{34}$ Of course, this claim is always something of a lie, since even the most technical of operations has political implications. Organizations must therefore carefully navigate these tensions. During the structural adjustment era, the IFIs' claims to expert authority depended in part on their ability to redraw the boundary between the political and the economic, redefining issues that had been deemed political as purely technical and economic. Where they did explicitly recognize the role of politics - usually as a problem - they rarely sought to tackle it directly, seeing it as beyond their mandate.

Yet the IMF and World Bank could not ignore politics forever. The deeper both institutions moved into the minutiae of domestic policies and practices throughout the 1980s and 1990s - imposing conditions on public pensions, price controls and privatization - the more vulnerable they became to charges of political interference. Their actions thus ultimately helped to fuel the problematization of the political dimensions 
of development finance. NGOs became increasingly vocal critics of the World Bank and IMF's heavy-handedness, charging them with political interference. ${ }^{35}$ The World Bank was the first to respond, and tried to defuse NGO criticisms through various outreach programs. For most of the 1990s, the IMF largely ignored its critics, as staff and management believed that part of their role was to have the "broad shoulders" needed to take the criticisms of domestic forces when a government instituted painful adjustment policies. The fallout from the Asian crisis changed all that, however, as criticism became damaging enough that the organization began to take it seriously. ${ }^{36}$

Interestingly, although the two organizations' increasing movement into domestic politics was the source of much tension, one of the ways that the staff in both organizations ultimately resolved it was by admitting, and justifying their attention to, domestic issues, rather than by continuing to deny that they were political. Although IMF staff remained coyer than those at the Bank about admitting the political dimensions of their policies, both institutions gradually found ways of tackling more political questions, as did donors such as the United Kingdom's Department for International Development (DFID), the United States' Agency for International Development (USAID) and the Millennium Challenge Corporation (MCC). ${ }^{37}$ They did so in part by drawing on public choice theory and new institutionalist economics, both of which recognize the role of political pressure and institutional dynamics in economic adjustment, making them amenable to economic analysis. As long as it could be shown that a political issue had significant economic consequences, then it was fair game. "Political economy" (defined in public choice terms) became the preferred lens and euphemism for the previously forbidden subject of politics: one Vice President of the World Bank's poverty reduction and economic management (PREM) network, for example, refused to let the staff hold a seminar on politics, but would let them hold one on political economy. ${ }^{38}$

IMF and World Bank staff did not just start focusing more on overtly political problems, such as institutional reform; they also became increasingly interested in integrating political techniques into their governance strategies. Although the idea of participatory development in particular had been quite influential among NGOs and certain World Bank units (particularly the Social Development Group), it was only in the mid-1990s that participation was seen as a technique that could be integrated into just about any development policy - including the Poverty Reduction Strategy Papers (PRSPs) jointly adopted by the IMF and World Bank in 1999 (examined in Chapter 5). ${ }^{39}$ More generally, both organizations and many donors began to rely more on the active 
participation of civil society to achieve their development objectives. They were supported in this shift by key state actors, particularly the British and Nordic country directors, whose home governments had embraced the aid effectiveness agenda. ${ }^{40}$ World Bank and IMF staff sought to mobilize new, more active and responsible public and market actors who could pressure their governments for reform, constituting the "demand side" of good governance policy (see Chapter 6).

If NGOs and other critics could charge the IFIs with failure on the grounds of their political interference, the institutions' staff responded by redefining failure in a different way altogether: studies by Dollar, Svensson and others argued that the failure of programs was linked to political problems in borrowing countries. ${ }^{41}$ The adoption of these new political economy ideas, the development of new participatory techniques and the engagement of new civil society actors enabled the IFIs and donors to respond to criticisms of their interventionism by actually expanding their involvement in domestic policy. While this was a paradoxical response, it was an effective one, for it shored up the institutions' declining authority in several ways. By focusing on the domestic political sources of policy failure, the IFIs deflected responsibility for poor results. IFI staff also had the opportunity to develop expertise in the arena of political economy, and thus to justify their expansion into new terrains. At the same time, by relying more on political techniques such as participation, and (eventually) country ownership, they were able to supplement their expert authority through appeal to popular support within borrowing countries themselves.

\section{The limits of technical universals}

As I discussed in Chapter 3, organizations often seek to govern in the name of certain universal values or principles, and to govern through their use of techniques and practices that they deem to be of universal applicability. IMF and World Bank leaders had largely eschewed any overtly moral framing of the organizations' universalist aspirations in the 1980 s, relying on technical economic principles as the basis of their claim to universality. This was an approach that fitted well with their claim to expert authority. Yet this was also a vulnerable strategy precisely because its authority relied so heavily on the promise that one set of economic principles could be applied universally.

The events of the 1990s and early 2000s were seen by many as a major test of these universal economic ideas - a test that the IFIs were widely viewed as having failed. The Asian crisis provides a particularly stark example of the kind of erosion that began to occur in the foundations 
of economic orthodoxy. In 1993, the World Bank published a report entitled "The East Asian Miracle," which sought to make sense of the remarkable economic growth in this region. ${ }^{42}$ As Robert Wade has so effectively demonstrated, rather than recognizing the positive role played by activist East Asian states in supporting this success, the report's authors instead chose to downplay it: "The result is heavily weighted towards the Bank's established position, and legitimizes the Bank's continuing advice to low-income countries to follow the 'market-friendly' policies apparently vindicated by East Asia's success." ${ }^{23}$ Even in the face of consistent pressure from Japan and significant evidence contradicting the Bank's position, Bank staff and management held onto their singular, universalist conception of sound economic policy.

The IMF responded to the Asian financial crisis of 1997-8 with the same approach, applying policies that had been used to deal with earlier Latin American crises to a radically different policy environment. They also used the crisis as an example of what can go wrong when economies do not fully embrace the strict free-market model, and sought to re-introduce more Anglo-American economic policies to the region. Yet this time, the universalist model came under enormous strain. The IMF's policies were blamed for worsening rather than resolving the crisis. In 1998, the World Bank published a report that largely blamed the intensity of the crisis on the IMF and the US Treasury. ${ }^{44}$ There was no longer a consensus in Washington on economic policy. Many of the same economic assumptions about low inflation and economic liberalization continued to underpin IFI policies, yet they were no longer as universally accepted as they once were. The principles that had been so confidently relied on since the early 1980s were now the subject of widespread debate and problematization both within and outside the IFIs.

As the economic universals of the structural adjustment era began to erode, they were not replaced by a dramatically new paradigm. Instead, two different responses to this dilemma emerged: IMF and World Bank staff began to pay more than lip service to the idea that there was a diversity of different economic situations and began to focus more on particular contexts, leading to the strategy of ownership; and they began to redefine universals in more normative and flexible terms - to include norms of good governance and standards of best practice - producing the strategy of standardization. Although IMF staff had always rejected the claim that they had applied a "one size fits all" approach to adjustment problems, after the backlash from the Asian crisis they were forced to modify their approach. ${ }^{45}$ At the World Bank too, beginning in the late 1990s, there was increasing concern with ensuring that policies on good governance, for example, were carefully tailored to specific local needs and concerns. ${ }^{46}$ 
There had also been a long history of interest in the problem of what Robert McNamara called "political will" - the need for domestic governments to buy in to Bank and Fund programs. By the late 1980s, this had been refined into the concept of "country ownership," $"$ which the OED first attempted to measure in 1992, ${ }^{48}$ and which the IMF adopted as a key concern in $1998 .{ }^{49}$ The strategy of country ownership was double-edged: it promised more attention to local political concerns in order to attain political buy-in, but it also placed greater responsibility for program success on domestic leaders. The practice of fostering ownership thus allowed staff at both organizations to shift much of the blame for policy failure onto domestic political systems; at the same time, it provided techniques for bringing local political leaders and civil society into the programs as more active and responsible participants.

Another major response of the IFIs to the erosion of their technical universals was to supplement them with a different kind of universal. As programs moved increasingly into the business of rebuilding institutions as well as reforming policy, staff sought to redefine the universal principles of the global economic order to include good governance practices as well as macroeconomic policies. As I will discuss in Chapter 6, these new global standards were different from the previous technical universals in several respects: they were broader in scope, explicitly covering political, social and economic issues; they were justified in moral as well as technical terms; and they took a more flexible and visibly constructed form than the economic principles that they supplemented.

The 1990s thus witnessed both the culmination and the decline of the structural adjustment era's economic universals. While the problematization of these universals was a powerful blow to IFI authority, the two new strategies that have emerged in response have both succeeded in re-establishing it in several ways. Renewed attention to particular contexts and local ownership has required the creation of a range of new forms of expertise for applying political economy frameworks to understand and act upon local contexts. Moreover, by framing these new universals in moral as well as technical terms, the IMF and World Bank leadership has also sought to create a more robust basis for their global authority.

\section{Debating success and failure}

Like most international organizations (IOs), the IFIs' claims to expert authority also relied on their ability to demonstrate at least a certain measure of "success" in their programs. As far back as McNamara's time, there had been enormous emphasis on making sure that programs were seen to be successful. ${ }^{50}$ Yet, as I discussed in the previous chapter, 
there were persistent difficulties with measurement and evaluation, as both IMF and Bank staff struggled with the limits of their abilities to calculate and evaluate their programs. Both organizations had always struggled with a paradox of sorts: they could measure those things that were relatively easy to quantify, such as inputs or narrow objectives, and sacrifice measuring less tangible aspects of their programs (in particular the role of influence); or they could focus on these more slippery factors, but in doing so find themselves struggling with measurement challenges.

Fund staff responded by experimenting with different methodologies, while in the 1990s, the OED at the Bank introduced a more sophisticated metric for measuring success, which included an initial assessment of the riskiness, "demandingness" and complexity of the project, and an assessment of sustainability and institutional development. ${ }^{51}$ By the 1990 s, as the Bank began to assess the success of those projects and programs initiated in the 1980s and to use more sophisticated metrics to do so, they found their success rates dropping precipitously - from the 80 to 85 per cent range to below 65 per cent in the early 1990s. ${ }^{52}$ The 1992 Wapenhans Report was particularly critical in its assessment of the poor success rates at the World Bank, and intensified the search among staff and management for ways of improving them. ${ }^{5}$

In the course of the 1990s, discussions of the problem of failure began to grow more prominent at the World Bank and within the aid community. At a popular level, critics from both the left and the right were vigorous in condemning the Bank for what they saw as wholesale failure: NGOs and groups such as " 50 Years is Enough" attacked the IMF and World Bank for inflicting untold damage on the global poor through their neoliberal policies. On the right, there was a growing chorus of critics, many in the US, who argued that aid was no longer necessary in a world of integrated capital markets. ${ }^{54}$ In academic and policy circles, a host of studies examined the causes of success or failure in a development project. $^{55}$

The most influential among them included Dollar and Svennson's "What Explains the Success or Failure of Structural Adjustment Programs?" and the Bank's own report Assessing Aid: What Works, What Doesn't and Why, headed up by David Dollar. ${ }^{56}$ These studies adopted different metrics from the ones then being used by the OED - focusing on whether policies created "sound policy environments" defined in both macroeconomic and institutional terms. ${ }^{57}$ While their conclusions differed in some respects, they both raised serious concerns about the low levels of Bank success and focused on domestic political and institutional factors as the key reasons for program failures. These and other studies also questioned the effectiveness of conditionality - particularly 
structural conditionality, which had been the dominant technique of the structural adjustment era. ${ }^{58}$ They suggested that without local ownership and domestic institutional capacity to implement policies, increasing the number of conditions was at best pointless, and at worst counterproductive. Assessing Aid suggested some significant policy changes, including radically reducing funding to states that did not already possess the right "policy environment." 59

These internal critics proposed a different set of criteria for both operationalizing and evaluating aid, using effectiveness as the central metric - a metric that relied heavily on political economy factors. This was a classic example of a hot rather than a cold debate, since the very question of what counted as evidence of success and failure was open to debate - simply getting loans out the door and obtaining a reasonable rate of return was no longer enough to make a project count as a success. ${ }^{60}$

Did these studies both within and outside of the Bank discover an underlying pattern of objective failures in Bank and donor lending? Yes and no. They certainly did point to some troubling findings, but this does not mean that these were the only conclusions that they could have reached: it was partly because staff and scholars started to change the metrics for evaluating success and failure (focusing on institutional development, sustainability, policy environment, etc.) that they began to discover more failures. ${ }^{61}$ And it was because of the theoretical lenses that they used in these studies that they diagnosed the problems and solutions as they did.

Both of these studies drew heavily on public choice theory to explain program success or failure, and on new institutionalist economics to propose solutions. From a public choice perspective, borrower governments will generally try to "game" the system by promising reforms that they may not intend to undertake. With aid being fungible (aid dollars allocated for one project freeing up government funds for something else), there are few ways for agencies to control the government's actions and ensure "success." Hence, the best way of guaranteeing that the desired outcome is achieved is to lend exclusively to countries that are most likely to use aid effectively - which, these studies suggest, are those that already have "sound" as opposed to "distorted" policy environments. Institutionalist economics, in turn, suggests that sound institutions are also necessary for good policy: hence aid should be directed selectively towards those states that are already in possession of the rule of law, a capable public sector and a low level of corruption. ${ }^{62}$

These debates on aid effectiveness did not reach as deeply into the IMF. Nonetheless, some of the same ideas that were shaking up the World Bank's policies, such as ownership and selectivity, also started to 
take hold at the IMF. In 1997, the IMF embarked on two different reviews of ESAF - the highly conditional and longer-term lending facility that its poorest members relied on. One was an internal review, conducted by the Policy Development and Review Department. ${ }^{63}$ The other was an external review, which included among its members Paul Collier, a major figure in the aid effectiveness debate who became an influential actor at the World Bank when he started working there a year later. ${ }^{64}$ The two reviews had very different mandates. The internal one provided a very neoclassical analysis of the successes and failures of ESAF programs and recommended budget cuts, inflation fighting and other neoliberal staples. The external review considered the social impact of ESAF programs and, most interestingly, their capacity to foster country ownership, recommending more attention to poverty and social impact and more genuine openness to negotiating with borrower governments.

The external report used different criteria for assessing the institution's programs' success or failure - considering its social impact - and asked the IMF to do the same, drawing on the World Bank's expertise to do so. Both reviews, moreover, found that political factors had a considerable effect on the success or failure of ESAF policies, forcing the institution to reconsider the key determinants of policy viability. Both the IMF and the World Bank thus found themselves having to redesign the metrics through which they judged success and failure; both began to pay more attention to political factors as crucial; and both also sought new measurement and evaluation techniques that could better capture these more complex dynamics. At the World Bank and among many donors, this search brought them eventually to the attempt to measure development results.

\section{The problem of contingency}

One of the subtlest but most insidious challenges to the IFIs in the 1990s and 2000s was the problem of contingency. This was not simply because crises in finance and development occurred: crises do happen and can almost always be blamed on exogenous factors. The problem was that the institutions had not factored the possibility of such happenings into their governance strategies: they had been caught napping. Their linear conceptions of policy time did not provide a way of coming to grips with disasters except in the most reactive of ways. Their promises of predictive power - a key part of much economic theory - turned out to be hugely overstated in the face of these unexpected events. ${ }^{65}$ Although in the past, staff might have been able to adapt to unexpected results by further extending the time horizon or creating specialized facilities, the 
recalibrated measures of success and failure seemed to suggest that something more profound was going on: if the problem was institutional capacity or the political environment in borrowing countries, and not just the narrow economic factors the IMF and World Bank had been focusing on, then these organizations would need to find ways of engaging those more complex issues in an increasingly volatile context. The contested failures in African development, and in Asian and later global finance, thus helped to precipitate a series of more profound problematizations about how to do the work of economic governance in a more contingent environment.

It was in the context of their grim assessments of development success in Africa that the World Bank's OED staff first started to make systematic use of the idea of risk. In 1996, their annual report was entirely structured around the idea of a risk-based assessment of project success or failure. ${ }^{66}$ Introducing yet another series of new metrics, they sought to categorize all programs in terms of their level of risk and reward, and then map the patterns of risk across regions, sectors and types of programs. Poverty-oriented, institution-building and structural programs were all deemed to be high-risk (but also potentially high reward). The goal of the report, however, was not simply to measure and map such risks, but ultimately to propose ways of reducing them - in order to increase the Bank's success rate back to 80 per cent. How were they to do so? Here the aid effectiveness literature discussed above became very useful in suggesting that greater selectivity in lending could be the key to reducing the failure rates.

The Bank staff's perception of the Asian financial crisis and the AIDS crisis in Africa also precipitated a related use of the ideas of risk and vulnerability as a way of conceptualizing contingency: part of what was so shocking about both events was the way in which they not only aggravated existing levels of poverty, but also forced people who had climbed out of poverty back into penury. This again upset any conception of poverty reduction as a linear process. As I will discuss in Chapter 7, staff in the social development unit responded by redefining poverty as risk and vulnerability, an idea that ultimately became a central feature of the 2000-1 WDR.

The Asian crisis also forced the issue of risk onto the IMF's agenda, having put into question the organization's capacity to effectively predict and prevent major economic crises. It was in the aftermath of that crisis that the organization introduced its Financial Sector Assessment Program (FSAP), as part of its standards and codes initiative, which was designed to assess a range of different financial risks within participating states and propose ways of mitigating them. Yet, despite much 
discussion of developing better mechanisms for predicting and preventing future crises, the IMF did not really begin to take seriously the challenges of risk and vulnerability, particularly for low-income countries, until after the 2008 financial crisis. It was only in the aftermath of that contested failure that Fund staff began to focus on the growing impact of external shocks on low-income countries, a problem that they sought to address by assessing their vulnerability.

If financial crises and the failures of African development challenged the capacity of IFIs to govern contingency, then risk and vulnerability assessment and management seemed to promise a new more effective way of governing the vicissitudes of financial and development reform.

\section{Conclusions}

Throughout the 1990s, the IMF and World Bank underwent a difficult process of contestation, problematization and redefinition, as IFI staff, political leaders, NGOs and academics debated the meaning of past policies' failure and challenged the basis of the institutions' claims to expert authority. As they sought to build a practical response, the IFIs moved away from many of their earlier structural adjustment policies. Instead of always trying to separate or subordinate politics to economics, they developed a strategy that explicitly recognized and tried to address the political dimensions of development finance. They expanded the universals they relied on beyond narrowly economic principles, and framed them in moral as well as technical terms. They developed new metrics for policy success and struggled to develop increasingly complex forms of measurement. And they began to try to come to terms with the contingency of the future and the pervasive problem of shocks.

Although the politics of failure and the fragility of expert authority were key determinants of the shifts that occurred, the actual drivers of the changes discussed above were many: key events, various actors, small " $\mathrm{i}$ " ideas and concrete techniques all combined in various ways to make the changes possible. As I suggested earlier, it was not the simple facts of the Asian or global financial crises or the persistence of poverty in subSaharan Africa that were instrumental in fostering change, but rather the way in which publicly visible and symbolic failures opened up fundamental debates about the meaning of failure itself. These judgments of failure were themselves partly a product of experimentations in measurement techniques that had produced new ways of seeing the possibilities and limits of structural adjustment programs. Combined with certain practical ideas, like public choice theory, these techniques helped produce competing definitions of success and failure. 
Strategic actors including the growing number of critics, organizational leaders and staff chose as one of the key terrains of their conflict this "hot" question about the success and failure of aid and adjustment some of them putting into doubt the necessity of aid itself. In response, Bank and Fund staff sought to redefine success as "effectiveness," developing a host of new techniques and policies to improve it. They did so by borrowing, recombining and innovating: taking, for example, the old ideas of political will and self-reliance and transforming them into the practice of fostering country ownership - a strategy that worked as both an explanation of past failures and a direction for future change.

Although this transition has taken a particular shape, we can find similar patterns in the past: the erosion of expertise, the problematization of metrics of success and failure, and the attempt to re-establish authority. In the case of the World Bank, this is not the first time that it has undergone such a process of redefining not just its priorities, but also its criteria for development success. There are many parallels with the transition that took place in the late 1960s, when McNamara announced the failure of trickle-down approaches to poverty reduction, and redefined the metrics of Bank success by insisting that poverty reduction, and not just economic returns, be counted. ${ }^{67}$ In fact, much of McNamara's tenure can be seen as an effort to find new ways of defining and measuring development success and failure.

There are also parallels with the transition that occurred in the early 1980s, when Clausen replaced McNamara as Bank President. As I discussed in the previous chapter, in a remarkably short space of time, not only had the Bank's efforts to wage war on poverty through targeted "poverty projects" been condemned as failures, but also new metrics for evaluating projects were introduced and integrated into structural adjustment programs. In both of these earlier instances, significant changes in policy - from trickle-down development, to targeted poverty reduction, to structural adjustment - were made possible by the problematization of definitions of success and failure and a concerted effort by organizational leaders to attack the authority of previous forms of calculation and to propose new ones in their place.

While there are therefore important parallels with the most recent set of transformations discussed in this chapter, there are also some important differences this time around. For one thing, the community of organizations and actors involved in the most recent changes is much larger - including many donor agencies, NGOs and IOs like the OECD. The IMF and World Bank have also grown much closer in the past two decades, in mandate if not in culture. This all means that although the policies adopted by these different organizations are often quite different, 
there has nonetheless been significant convergence towards a relatively coherent set of governance strategies since the mid-1990s.

The attacks on the Bank and the IMF in particular have also been much more widespread and damaging this time around. While there were academics who had criticized trickle-down development in the late 1960s, it was only after McNamara initiated his "war on poverty" that they gained much influence. By the early 1980s, external actors had begun to play a more potent role, but they were generally elite figures, such as the American Secretary of State, James Baker. NGOs only began to have a real impact on the Bank in the 1980s and on the Fund in the mid-1990s. After the Asian crisis, middle-income countries were also able to throw their weight around a little, paying their Fund loans back early and turning to the private markets for financing - leaving both the Bank and the Fund scrambling for clients.

Finally, but crucially, the scope of IFI interventions also grew markedly in the 1980s and early 1990s as both the IMF and World Bank began to accelerate their movement into increasingly complex terrain. As I have noted above, the number of conditions grew enormously over this period; at least as important, however, was the shift in their character, as more straightforward constraints on credit ceilings or budget deficits evolved into highly detailed requirements to privatize certain industries or pass particular labour laws. This was not only more politically contested territory, but also more ontologically complex material to try to manage and measure. The shift into more structural, policy-oriented lending thus created more room for methodological slippage, debate and failure.

With these increased pressures, the organizations desperately needed to regain the authority that they had lost. Over the next four chapters, I will examine the different ways that they have sought to do so. They have worked hard to re-establish the grounds of their expert authority, using some of their practical ideas, like public choice theory, to expand their scope and stake out new arenas of expertise. At the same time, institutional actors have also begun to expand the forms of authority that they rely on - combining their claims to expertise with increasing appeals to moral and popular authority. As organizational actors have sought to renegotiate their authority, they have developed new ways of sorting and organizing, interpreting and blaming, mobilizing and restraining - in short, they are creating new ways of governing. In the process, new policy strategies have begun to emerge: clusters of heterogeneous policy practices and techniques that together begin to form certain patterns and regularities. ${ }^{68}$ In the next four chapters, I will look at these strategies in turn: ownership, standardization, risk and vulnerability management and results measurement. 
While these new strategies have been designed to re-establish IFI and donor authority, I will suggest that they do so in a less confident and direct manner than the structural adjustment practices that they have replaced. This is a less direct form of governance, that works through institutions and civil society to effect changes in economic policy; a more proactive form of governance that aims at the long game; a kind of governance that relies on increasingly symbolic techniques; and one that is more aware of the possibility of failure and that seeks to hedge against it. Together, as I will suggest in the next four chapters, these patterns point towards the emergence of a more provisional form of governance and a more provisional kind of expertise. 
Part III

New governance strategies 


\section{$5 \quad$ Fostering ownership}

In its own internal reviews the World Bank has come to the same conclusion - "ownership," or strong domestic support of reforms, is essential for adjustment lending to succeed. Before 1990 about a third of adjustment loans failed to achieve expected reforms, and the lack of borrower ownership or commitment was a key factor in the failures.

World Bank. Assessing Aid: What Works, What Doesn't and Why, $1998 .{ }^{1}$

One of the principal lessons that the International Monetary Fund (IMF), the World Bank and donors drew from past failures of aid effectiveness was a belief that borrowers' lack of political will was a crucial part of the problem. In response, after considerable debate and disagreement, institutional actors developed the strategy of fostering country ownership. In contrast to earlier eras, in which development policies sought to separate politics from economics or to redefine political questions as economic, the ownership strategy treats the political support for development programs as a legitimate object of international financial institutions (IFIs) and donor action. Four assumptions underpin this strategy: politics (or at least political economy, defined in public choice terms) is relevant to economic development; policies should be tailored to local contexts; borrowing countries must take more responsibility for their own progress; and they must participate more actively in IFI and donor programs. In combining these four assumptions, the strategy of ownership brought together a number of concepts that had existed before, but separately, such as "courageous political leadership," "self-sufficiency," and participation. ${ }^{2}$ It was only once institutional actors and critics began to problematize the role of politics in development and to identify the political sources of policy failure that these problems were brought together and made governable.

In this chapter, I will focus my attention on two key practices that are part of the ownership strategy: the streamlining of conditionality and the introduction of Poverty Reduction Strategy Papers (PRSPs). Although these practices exist in part as specific policies in certain institutions like 
the IMF, the World Bank and various donor agencies, they all exceed any one particular organizational context. I will therefore examine each policy as it functions both within and across several different institutional contexts, and then consider the combined effects of these new practices as they interact and intersect with one another to make up a more provisional kind of governance.

This chapter seeks to answer two questions about the strategy of ownership: why it emerged, and how it works. I will first answer the why question by examining the various pressures that led to the adoption of the ownership strategy, before considering how the strategy of ownership works by applying a meso-level analysis and focusing on the principal governance factors. I will use a number of concepts derived from actor network theory (ANT), examining how actors sought to operationalize ownership by developing inscriptions that could translate a broader range of voices and concerns into a single powerful document. This analysis reveals some significant shifts in how these new policies do the work of governing, including changes in several key factors of governance: the application of small " $\mathrm{i}$ " ideas, the development of increasingly symbolic and informal techniques, the enrolment of new civil society actors, the expansion of the basis of institutional authority and the increasing reliance on productive and indirect kinds of power.

I will conclude by suggesting that efforts to foster ownership provide considerable evidence of the emergence of a new, more provisional style of governance in which governing is done indirectly, often in the gaps in official policy, while governance strategies are increasingly proactive and performative, relying on symbolic techniques for their effectiveness, yet always aware of the possibility of failure.

\section{The evolution of ownership}

Before considering the institutional evolution of the two specific policies that I will examine here, it is worth considering how IFIs and donors ended up with the practice of fostering "ownership" itself. Why this new emphasis on explicitly political strategies, given the donor institutions' long history of trying to appear objective and apolitical? It is tempting to see the strategy of ownership as part of a linear trajectory in the evolution of development policy. Yet the evolution of the strategy and policy was both contingent and contested.

By emphasizing the importance of country ownership, IFIs and donors have sought to respond to two criticisms: to non-governmental organizations (NGOs) and borrowers who charged them with heavy-handedness, ownership promised to shift more control to local communities; and 
to taxpayers who were suffering from aid fatigue, it was part of the "aid effectiveness" agenda that promised to deliver better results. ${ }^{3}$ Much of the impetus behind the ownership push revolved around emerging concerns about what counted as success and failure, as the debate on aid effectiveness began to erode earlier metrics and IFIs and donors found themselves under pressure to demonstrate achievements on the ground. Drawing on public choice theory, researchers at the World Bank argued that one of the crucial reasons for the poor performance of many Bank programs was the lack of a good "policy environment" in borrowing countries, which they defined as poor macroeconomic performance and distorted institutions. This meant that IFIs could not resolve countries' economic problems without also addressing their political context, and that a willingness to reform was essential if programs were to succeed. ${ }^{4}$ Policymakers thus began to view politics as a central part of the problem of development finance, one that was crucially linked to rates of success and failure.

One strand of the ownership strategy's development began in a technical part of the Bank, its Operations Evaluation Department (OED), responsible for in-house evaluation. OED staff first became interested in the promotion of country ownership in the 1990s, as part of their efforts to find new ways of assessing programs in the face of what appeared to be declining success rates: by their 1994 report, success rates as measured by the OED had dropped from 80 per cent (common throughout most of the 1980 s) to 65 per cent. ${ }^{5}$ Of course, such figures are somewhat misleading, as the metrics used also changed over time, as I discussed in Chapter 4. Nonetheless, this vastly increased rate of failure became a matter of concern and debate within the organization. By 1998, Dollar and others in the Development Research Group identified ownership as key to aid effectiveness, and the OED also integrated it as a metric of program success, making it a crucial part of evaluation practices. ${ }^{6}$

Concerned about the apparent decline in success rates, the newly appointed World Bank President, James Wolfensohn, made the improvement of Bank performance a priority. ${ }^{7}$ In January of 1999 he launched his comprehensive development framework (CDF) in a bid to improve aid effectiveness, in part by fostering country ownership. As I will discuss below, NGOs had been pressing for policies that gave borrowing governments more flexibility to adapt policies to their own priorities throughout the 1990s. There was also pressure for reform from major shareholder governments, including the British and the Americans. ${ }^{8}$ Actors within the World Bank sought to use the strategy of ownership to translate critics' concerns about responsiveness and flexibility in a way that would tackle what had become an embarrassing rate of failure in their programs. 
At the IMF, both internal and external actors also played a role in introducing the strategy of ownership. Fund staff and directors began to discuss the issue of ownership in the mid-1990s in the context of discussions about how to ensure that adjustment policies did not negatively affect investment and growth in borrowing countries. ${ }^{9}$ The issue moved to the front of the institution's agenda in 1997, when the IMF commissioned two different reviews of the organization's Enhanced Structural Adjustment Fund (ESAF), one internal and one external. ${ }^{10}$ Despite its orthodox approach to the problem, the internal report identified country leaders' "commitment to reform" and broader political factors as key determinants of program success. ${ }^{11}$ The external review went much further, concluding that one of the failings of ESAF programs was their inability to solicit country ownership. ${ }^{12}$

At about the same time, Masood Ahmed, the senior World Bank manager responsible for the highly indebted poor countries (HIPC) initiative and PRSP policies, moved to the IMF's Policy Development and Review Department (PDR). The ESAF review and the change in personnel played important roles in highlighting the idea of ownership for Fund policy staff at a time when they were looking to reform their lending policies - partly in response to severe external criticism of their handling of the Asian financial crisis. ${ }^{13}$ Michel Camdessus, the Managing Director at the time, remembers being a strong proponent of the policy:

Personally, I felt extremely strongly about requiring ownership. A country that was not ready to publicly state its support for the policies it had agreed to, including the difficult steps it needed to take to fix the economy, didn't deserve to be eligible for funding. ${ }^{14}$

Although IMF staff adopted the practice of fostering ownership rather later than at the Bank, some of them ultimately became quite keen proponents of the strategy - including a group of staff in PDR who played a central role in integrating it into organizational practice. ${ }^{15}$

Both institutions thus embraced the practice of fostering country ownership as a way of responding to what were perceived to be some serious failures in their policies - made visible by the contested failures of the Asian financial crisis and the "lost decade" in sub-Saharan Africa. Rather than admitting wholesale to their responsibility for these past failures, IMF and World Bank staff redefined the terms of the debate by introducing the concept of country ownership. Suggesting that the causes of failure were linked to a lack of political commitment, a subject that they had previously believed to be beyond their control, Fund and Bank staff were able to place a measure of responsibility on low-income countries (LICs) (for their lack of commitment) while promising to improve 
success rates (by building more ownership). In practical terms, this new attention to country ownership translated into the development of several new policies, including the introduction of general budget support, the streamlining of conditionality, and the development of the PRSP. ${ }^{16}$ These last two policies will serve as the basis for this chapter's analysis.

\section{Redesigning conditionality}

Although the number and character of IMF and World Bank conditions has varied significantly over time, the trend in both institutions has been a persistent increase in both their number and scope - at least until recently. ${ }^{17}$ Long gone are the days when the IMF contented itself with credit ceilings and a few monetary targets, as in the $1950 \mathrm{~s}$ and $1960 \mathrm{~s} .{ }^{18}$ Instead, by the mid-1990s, IMF stand-by agreements and extended facility arrangements often included a host of structural conditions on trade policy, privatization of state-owned industries, and financial sector reforms. With the advent of structural adjustment loans (SALs) in the 1980s, the World Bank had got into the business of imposing conditions and had also gradually expanded those conditions to cover a similar range of areas. Donors followed suit for the most part, either imposing their own conditions or linking their aid to a country's successful negotiation of an IMF agreement.

This trend reached its peak in the IMF response to the Asian financial crisis in 1998, as the Fund negotiated some of its most intrusive financing programs. Yet this financial crisis was also a turning point, as it produced a backlash against the continued expansion of conditionality not only among the IMF's critics, but also, to a lesser extent, within the organization itself. ${ }^{19}$ As one IMF staff member put it to me, you only had to look at the reaction caused by the Fund's rigid attitude to Latin America to understand why the various regional departments at the Fund were treading more softly in recent years: no one wanted to end up facing that much criticism again, or losing so many clients. Although the IMF was perhaps the most self-conscious and public in its efforts to reconsider and revise its practices, it was not the only organization engaging in soulsearching about the nature of its conditions. The World Bank and several donor agencies also revised their practice of conditionality in the early part of the new century.

\section{Streamlining at the IMF}

It was just a few years after the Asian financial crisis that Horst Köhler began his leadership of the Fund and revised the IMF's guidelines on 
conditionality as one of his first major initiatives. ${ }^{20}$ Arguing for the importance of "streamlining" conditionality, Köhler sought to reduce the number and scope of IMF conditions.

There are several different stories about what motivated him to call for these revisions. One senior IMF official has suggested that Köhler's earlier role in negotiations on Indonesia's post-crisis financing package had led him to conclude "that the Fund had gone overboard" in demanding conditions. ${ }^{21} \mathrm{~A}$ former member of the Executive Board suggested that Köhler's Africa tour first prompted his concern with the scope of IMF conditionality, after he witnessed the level of Fund conditions on the Mozambique cashew industry. ${ }^{22}$ What is clear is that he acted quickly after his appointment as Managing Director, issuing an interim notice on streamlining conditionality in September 2000, followed by formal guidelines that were approved by the Executive Board in September 2002. ${ }^{23}$

Why did the Fund embark on these reforms? Although Köhler himself clearly played a central role in making them a priority, he was also responding to broader pressures: growing uncertainty and debate about the effectiveness of the IMF's conditions and increasing criticism of its policies. The Fund's concern with achieving country ownership was driven in part by concerns about program effectiveness, particularly after condition-laden programs negotiated in the context of the Asian crisis were deemed by many to be failures. This was a highly contested issue: as one IMF staff paper put it, "The relationship between conditionality, ownership and the implementation of Fund supported programs has been the subject of an extensive debate, both inside and outside the Fund." 24 This paper and several others around this time nonetheless concluded that political support was crucial to program success. ${ }^{25}$ There was also a growing sense that the ever-expanding number of conditions was making things worse. As one senior IMF official noted: "If conditionality is excessive, it leads to unnecessary political fights that are to the detriment of the programs. ${ }^{26}$ Fund staff thus began to use the concept of ownership to identify the causes of program success and failure in both political and economic terms. They also began to explore ways of translating the idea of ownership into a measurable practice - creating a new kind of expertise capable of governing these new challenges. ${ }^{27}$

The bid to reform conditionality and increase ownership was not entirely driven by concerns about re-establishing expert authority: it was also a rather effective way of responding to some of the Fund's critics. On the one side, NGOs critical of the IMF's activities had become increasingly numerous, organized and vocal in the course of the 1990s. They saw a rise in the number of structural conditions as 
the imposition of free-market ideology on developing countries. On the other side were major shareholder governments, who had also been calling for reforms to the IMF. British officials had been pushing for reforms to the IFIs since the election of Tony Blair's government; the United Kingdom government's first White Paper on development in 1997 argued for a shift to a partnership-based approach to lending that "moves beyond the old conditionalities of development assistance and requires political commitment to poverty elimination on both sides." 28 Their Executive Director at the time, Stephen Pickford, was also an advocate for reform. ${ }^{29}$ In the United States, Treasury officials were under pressure from both left and right to push for IMF reform and sought to respond to concerns that they knew the Meltzer Commission report was going to articulate. ${ }^{30}$ In late 1999 and early 2000, Treasury Secretary Lawrence Summers called for more focused conditionality as part of the Fund's overall need to return to its "core competencies" in several speeches. Yet throughout these debates, US representatives remained quite reluctant to reduce the number or scope of conditions. ${ }^{31}$

After a vigorous debate on the Executive Board, the ultimate form that the new guidelines took was based on five new guiding principles: parsimony, tailoring, coordination, clarity and ownership. Fund staff were to use parsimony in determining what conditions are necessary to achieve program objectives, limiting structural conditions to those that are deemed "macro-critical," a formulation introduced by Canadian Executive Director, Thomas Bernes. ${ }^{32}$ Staff must also now carefully tailor programs to the specific contexts of individual countries. The move to redesign conditionality around the idea of country ownership was an effective way for the Fund to both re-establish its expert authority by providing a technical solution to its perceived failures, and to respond to its critics by promising to be more responsive to local contexts.

\section{A more gradual change at the World Bank}

Although the Bank only undertook a formal review in 2004, it had introduced some significant changes in its conditionality policy over the previous few years, driven by similar concerns to the Fund about compliance and ownership as well as external pressure for reform.

In a 2004 retrospective on adjustment lending, Bank staff suggested that both technical and political considerations played an important role in driving changes in conditionality policy at the institution. ${ }^{33}$ The Bank's own research and analysis of the successes and failures of the 1980s and 1990s indicated that overly detailed and complex conditions had little chance of success, that program ownership was key to any 
adjustment program, and that selectivity played a central role in improving program completion. ${ }^{34}$ At the same time, Bank staff were aware of the criticisms that had been directed towards them of late by "the development community," acknowledging that external criticisms helped shape changes in Bank policy. ${ }^{35}$ One of the more influential critiques came from Paul Collier, who announced the "Failure of Conditionality" in a widely-cited essay. ${ }^{36}$ The paper was published in 1997, just one year after he became Director of the Development Research Group at the World Bank.

Although most of these critical voices were from NGOs and academics, some of the more influential critics were actually within the British government, and included the British Executive Director to the World Bank, two successive Secretaries of State for International Development, Claire Short and Hilary Benn, and the Chancellor himself, Gordon Brown. Since the election of the Labour Party under Tony Blair in 1997 and the subsequent creation of the Department for International Development (DFID), the British government had begun to stake out a more critical approach to international development financing, as I will discuss below. The British Executive Director, Tom Scholar, along with Tony Benn, pushed hard for the Bank to undertake a formal review of its conditionality policy. ${ }^{37}$

One important shift in the Bank's conditionality policy came in 2004 with the Board's adoption of a new operational policy and procedure for lending: the World Bank decided to replace adjustment lending with development policy lending. ${ }^{38}$ This involved not simply a change in name - although the symbolic importance of that change should not be underestimated - but also a number of shifts in policy: the new policy document eliminates all reference to privatization as an explicit objective of such programs and places more emphasis on poverty, participation, the environment, fiduciary responsibility and other related governance issues. ${ }^{39,40}$ The World Bank also undertook a formal review of its conditionality policy in 2004, producing a report on its findings in $2005 .{ }^{41}$ The report, dismissed by critics as more of a justification than a critical review of current policy, ultimately argued for a series of "good practice principles" similar to those adopted by the IMF in its streamlining exercise: criticality, transparency and predictability, customization, harmonization and ownership.

\section{More radical shifts in some donor states}

International organizations (IOs) are not the only players that have made significant changes in their approaches to conditionality. Both the 
UK and the US made more radical changes in the 2000s - although they did so in different ways.

In its 2005 policy paper, Partnerships for Poverty Reduction: Rethinking Conditionality, the British government declared that it would no longer impose economic policy conditionality on those states with which it had a bilateral aid relationship. ${ }^{42}$ While the British retained certain conditions to ensure fiduciary responsibility - i.e. ensure that the money is spent transparently - and also introduced some new governance conditions, they committed themselves to stop imposing formal economic conditions. ${ }^{43}$ This placed them in a relatively small minority of donor states, including the northern Europeans, who believe that conditions undermine rather than support development efforts, and demonstrate this conviction in their aid programs. ${ }^{44}$ Although, in the words of one NGO representative, the British were sometimes viewed as "pot smokers" by other donor government for their radical position on conditionality, they did quietly persuade other nations to pay attention to their ideas. ${ }^{45}$

Why this significant shift in development philosophy and policy by the British government? Nearly all of those I interviewed on the subject suggested that it was a logical outcome of the previous twelve years of Labour government policy, consistent with the creation of DFID as a separate department and with a succession of White Papers by that department. Some argued that the first Secretary of State for Development, Clare Short, had been instrumental in changing the overall tone and philosophy of the UK's aid to one based on the principle of partnership. ${ }^{46}$ Others suggested that the more radical shift to eliminate economic conditionality owed more to the second Development Secretary, Hilary Benn, who was willing to take bolder action, ${ }^{47}$ while others suggested that it was the movement of so many NGO staff into DFID offices that explained the shift in policy. Underlying these individual personalities and dynamics was a broad preoccupation with "the failures of existing aid," as one former assistant to Clare Short put it. ${ }^{48}$ As they noted in their first White Paper on development, the British were keenly aware of the costs of the lost decade in sub-Saharan Africa. ${ }^{49}$ Not unlike the World Bank, they traced the source of many of the failures of aid to "two flaws" in thinking about the relationship between politics and economics: the belief that the state is the only solution, and the belief that it is the only problem. ${ }^{50}$

This emphasis on the political economic dimensions of aid failures at both the World Bank and DFID was not a coincidence: DFID, together with the UK think tank, the Overseas Development Institute (ODI), were major actors in the debate on aid effectiveness. Together, they 
produced a significant amount of research in the late 1990s and early 2000 s indicating that excessive conditions were often part of the problem, including Tony Killick's influential work on "the failings of conditionality. ${ }^{" 51}$ Finally, the British government was no more immune than other institutions from political pressure: this took the form of an organized and vocal community of NGOs in the UK, as well as the recognition that, in the words of one Treasury staff member, it is politically very difficult as donors to impose conditions on other nations. ${ }^{52}$

On the other side of the Atlantic, the Americans also made a significant change to their conditionality policy, through the creation of a new donor agency, the Millennium Challenge Corporation (MCC), in 2004. The MCC seeks to promote sustainable economic growth through a different kind of process than that used by the IMF, the World Bank or DFID. Rather than imposing ex-post conditions on countries that must be followed once a timetable of financial assistance is agreed upon, the MCC reverses the process by pre-selecting countries that have already attained certain basic criteria in three broad areas: "good governance, economic freedom and investments in people." $" 53$

The criteria are interesting in the way that they seek to provide a quantitative measure of compliance, even when the objects being measured are extremely complex (like the level of political rights). I will further discuss this effort to measure development results in Chapter 8. For the present, it is worth noting that the MCC transforms these criteria into a "scorecard" for each country, and determines whether the state has passed or failed in each of these different areas, drawing more attention to the question of failure and creating a particularly stark distinction between those eligible and ineligible for assistance. Although in many ways the MCC approach to conditionality is significantly different from those being adopted by the IMF, World Bank and DFID, it does share one important attribute: the MCC places significant emphasis on ensuring - and measuring - the level of country ownership. ${ }^{54}$

\section{Analysing conditionality reform}

In the context of debates about what counts as program success and the move to begin to problematize the political dimensions of policy failure, IOs and donors developed a range of strategies for redesigning conditionality. Despite their differences, they share some significant commonalities in their underlying style of governance, similarly conceptualizing the problem of politics, developing more symbolic techniques to engage the problem, and broadening the basis of authority and informalizing power relations in the process. 
Small " $i$ " ideas

If the experiences of the 1990s had produced some significant debates about the expert authority of the IFIs and donor states, then these new conditionality policies can be understood in part as efforts to respond to those contested failures. ${ }^{55}$ All four institutions' strategies are shaped by their interpretation of the causes of those earlier failures - whether it is the problem of excessive conditions for the World Bank, the IMF and DFID, the importance of selectivity at the Bank and the MCC, or the importance of country ownership at all four.

What all of these policy innovations have in common is the problematization of the "political economy" dimensions of development, using a cluster of public choice assumptions to conceptualize and engage with their objects. A handful of studies are cited over and over again in the policy literature on the subject: analyses by David Dollar, Jakob Svensson, Paul Collier, Tony Killick and Craig Burnside, all of whom draw heavily on public choice theory (and most of whom worked for the World Bank at some point). ${ }^{56}$ What does politics look like from this perspective? It takes two principal forms: first, as the "environment" within which conditions are implemented, an environment made up of existing policies and institutions. ${ }^{57}$ Second, the political appears in somewhat more active guise as the leaders of borrowing countries, who are deemed to be either "reformers" - keen to implement "sound" economic policies or not. ${ }^{58}$ Dollar and Svensson argue that these "political economy variables" play a crucial role in determining whether or not an adjustment loan achieves its intended outcomes, regardless of World Bank efforts. ${ }^{59}$

From the perspective of public choice theory, development financing should therefore be more selective, directed towards "reformers," since "adding more conditions to loans or devoting more resources to manage them does not increase the probability of reform" for poor performers. ${ }^{60}$ What then is the role of conditions, if they are not needed to "buy" or even encourage reform? They become a kind of "commitment technology," in the language of public choice and credibility theory: they are a way for governments to (voluntarily) bind their own hands, in order to show markets and donors that they are credible reformers. ${ }^{61}$ Yet this new logic for conditionality contains a dilemma for donors: markets will only find governments credible if they trust that they will follow through on their promises. Research by Collier and others indicates that many governments state their willingness to undertake reforms in return for financing, and then fail to follow through. ${ }^{62}$ In public choice terms, IFIs and donors thus face the problems of adverse selection and moral hazard: because most World Bank loans are fully disbursed to borrowers even when conditions are not met, governments have considerable incentives 
to misrepresent themselves as reformers. Hence the crucial importance of selectivity: IFIs and donors must not lend to poor candidates, not only because aid is unlikely to foster reforms, but also because they will actually undermine the credibility of good candidates' conditions. ${ }^{63}$

The logic of public choice theory points towards a different kind of conditionality policy - one where the number and scope of conditions matters much less than the credibility of governments' commitment to implement them. Commitment, or ownership, as it eventually came to be called, becomes the key to addressing the "failure of conditionality," as Collier bluntly called it.

\section{Symbolic and informal techniques}

How was this new public choice conception of conditionality translated into practice? There is little question that there has been a culture shift in the IFIs, particularly at the World Bank, around staff's perception of the role of conditionality. A number of staff who I spoke with suggested that conditions were far less important than they had been, one former senior staff member suggesting that in the region that he was involved in, "we do not have conditionality any more." Instead, "government comes up with a plan which we discuss; the plan is put down on paper and discussed, and if it seems to be something worthy of support, we give them the money to help them implement it." ${ }^{64}$ A closer examination of the evolving practices of conditionality, however, suggest that rather than disappearing, conditions have changed in form, becoming increasingly symbolic in character, and informal in application.

As I discussed above, public choice theory proposes a much thinner conception of conditions as commitment technology. Conditions become less about what they are (required reforms) and more about what they represent (signals of "sound" intentions). Their relationship with concrete policy changes therefore becomes increasingly distant and hypothetical - more symbolic than real. Although all conditions today potentially play this symbolic, signalling role, the IMF has gone so far as to introduce a kind of conditionality that is purely about signalling commitment. The policy support instrument (PSI) does not include any financing whatsoever: it is conditionality without the money. To date, seven countries, all of them African, have negotiated a PSI with the IMF. Why would a government agree to conditions without receiving any financing in return? It would be in order to signal to donors and financial markets their willingness to stick to the sound policies that the IMF supports. ${ }^{65}$

At the same time as formal conditions have been pared down and become increasingly symbolic, informal conditions have proliferated. 
At the World Bank, the number of formal conditions has dropped from above thirty-five on average in the late 1980 s, to twelve in $2005 .{ }^{66}$ Yet even as these formal conditions have declined, there has been an increase in those conditions that the Bank does not officially define as such: these include benchmarks and triggers, which are used in programmatic lending, as well as the country policy and institutional assessment (CPIA), which all play a role in determining whether funding will be provided, and at what level. ${ }^{67}$ Thus, while official conditions may have decreased, by 2001 the average number of benchmarks increased from fifteen in the early 1990s to twenty-three or more, and as many as thirty-five for the poorest countries. ${ }^{68}$ Even at the IMF, where one of the objectives of the 2002 streamlining exercise was to rely less on subjective structural benchmarks in order to increase the "clarity" of conditions, the Board reversed course after the 2008 financial crisis and replaced quantitative performance criteria with more subjective reviews, again blurring the boundaries of what counts as conditionality. ${ }^{69}$ Paradoxically, even as IFIs and donors seek to make conditions more transparent, they are becoming less visible.

As donors and IFIs have scaled back formal conditions, they have also been increasing their technical assistance, upping the role of consultants and other sources of policy advice. For example, in the UK, as both DFID staff and NGO critics point out, even as formal conditionality has declined, the agency's budget for technical assistance remains "huge" and has become a crucial means for applying less formal pressure on borrowers. ${ }^{70}$ As ODI researcher, Ruth Driscoll, put it, "In practice, what you get is a bit of a fudge where DFID staff engage in a lot of "policy influencing,."71 Finally, in their studies of "new" or "postconditionality" in Africa, Graham Harrison and Jeremy Gould have both demonstrated an increase in perhaps the most invisible kind of development conditionality: the growing internalization of donor and IFI norms by developing country leaders, particularly by finance ministry officials who have come to accept the imperatives of domestic adjustment. ${ }^{72}$ The combination of this kind of internalization with the persistence of significant aid dependence in many countries makes it difficult to identify the degree of external influence. ${ }^{73}$

\section{Informalizing power}

As public choice theory would have it, the new conditionality avoids power dynamics altogether, since borrowing countries use conditions to tie their own hands and to signal to markets and donors their ownership of policy reforms. Not too surprisingly, this account turns out to be something of a fantasy. Instead of eliminating power dynamics, the 
informalization of conditionality techniques discussed above produces a certain informalization of power relations. Even where formal conditionality has been reduced or eliminated, its ghost lives on at the edges of or in the spaces between formal lending programs - its invisibility lending it a paradoxical kind of power.

There is no question that the reduction in the number of formal conditions by the IMF, World Bank and DFID alters the ways in which the lender can influence the behaviour of the borrower. At the IMF, the attempt to limit step-by-step conditions means that staff have less ability to control how borrowing states comply with conditions, while efforts to focus on their core areas of expertise limit the issues they can address. Yet there is little doubt that the institution retains significant power in its relationship with borrowing states. The very fact that poor African countries would choose to accept the constraints of the PSI without financing suggests that the IMF wields considerable authority through its capacity to decide what counts as sound economic policy.

The fact that the World Bank and DFID have moved even further away from formal conditions suggests that the diminution of lender control will be even more noticeable; yet their increased emphasis on technical assistance, consultants and more flexible benchmarks does not so much reduce as transform their power to influence borrowers' policies. One former senior World Bank staff member I spoke to suggested that conditions have given way to conversations at the institution. In cases where there is considerable evidence that the country is moving in the right direction, that conversation can be reasonably open-ended. On the other hand, "if you have a situation where there is no progress on the poverty reduction front, then you need to ask tougher questions, and it means a tougher dialogue - which can be interpreted as conditions." ${ }^{74}$ This shift towards a policy of conversations is a double-edged sword as it can both complicate and conceal the power relations at work in the aid relationship, evidenced by the fact that surveys have indicated that borrowers do not see much difference between formal and informal conditions. ${ }^{75}$ To put it more succinctly, the difference between a condition and a conversation is not always clear to those on the borrowing side of the relationship.

Even at the MCC, where the practice of relying on quantitative passfail indices appears to be the least ambiguous approach possible, the dynamics of selectivity also work to informalize power. As the then Chief Executive Officer of the MCC, John Danilovich, noted with pride, poorer states that have yet to qualify for MCC assistance have begun to proactively make changes to their governance practices and business regulations in hopes of eventually qualifying. ${ }^{76}$ These changes are no doubt in 
large measure aimed at achieving a better score in the MCC indices; yet they are also a kind of performance of good faith - a demonstration of country ownership. When conditions become increasingly symbolic, power relations also take a representational turn, as borrowing countries seek to signal their willingness to be good political economic players.

This willingness to conform demonstrates the expert authority of the IFIs and donors as they set themselves up as the arbiters of "sound" policies that the markets (and other donors) will view as credible. This expert authority is a particularly productive form of power. Ilene Grabel points out that the discourse of credibility is highly political and performative: the act of declaring a policy as credible (generally by an external, authoritative actor) seeks to create rather than to simply signal credibility. ${ }^{77}$ If the initial performance of the statement of credibility is accepted as authoritative, donors and market actors will follow through with funds and further endorsements that effectively reinforce the initial statement about credibility. Moreover, those policies that are deemed "sound" remain strikingly familiar, focusing on low inflation, financial and trade liberalization, and the creation of a friendly business environment - the stock-in-trade of neoliberalism.

Paradoxically, as conditions become more symbolic, they also become more performative: conditions are designed to do a lot more than simply indicate what policies should be changed; they now also communicate a particular kind of political will. Similar to the standards and codes that I will discuss in the next chapter, these seemingly simple techniques are thus delegated a new kind of power, as conditions take on a life of their own.

These new subtler forms of power can nonetheless be devastatingly effective. We should not forget that underpinning the new conditionality is a belief in the value of selectivity - of only providing financing to those countries with good policy environments and leaders who demonstrate their commitment to reform. The aid effectiveness studies discussed above suggested that those not deemed "genuine reformers" should receive advice and technical assistance but no money; in practice, as one former senior World Bank staff member noted, not only has the allocation of dollars been reduced to countries deemed poor candidates, but so has the time spent on them, which is a serious mistake given that "the whole point was that these countries needed more engagement." Moreover, in the wake of these changes, Bank aid in particular has become more selective. ${ }^{79}$ The cost to poor countries of not complying with informal conditions - of not convincing lenders of their commitment - is therefore very high indeed. Selectivity and the threat of selectivity act as particularly potent forms of exclusionary power, sorting countries into the saved or the potentially savable, and the damned. 


\section{Poverty Reduction Strategy Papers (PRSPs)}

Conditionality policy is not the only policy through which IFIs and donors have sought to foster country ownership: the PRSPs are also key to that strategy. In fact, the PRSPs can be understood as a more active process for generating the country ownership that is needed for streamlined conditionality to work. First introduced in 1999, PRSPs replaced the poverty framework papers (PFPs) that the IMF and World Bank developed in the late 1980 s to coordinate their programs. ${ }^{80} \mathrm{By}$ the late 1990s, institutional actors recognized that "the PFP process was broken": the plans were drafted in Washington, largely by the IMF, with countries signing off but not terribly committed to the program. ${ }^{81}$ PRSPs were first developed by staff at the World Bank and IMF in the context of the debt relief initiatives for "highly indebted poor countries" (HIPC). Staff developed the idea of requiring governments to draft a PRSP before receiving debt relief - developing a "big picture" plan for how the funds would be used. The practice of creating the PRSP was also intended to give borrowing governments more responsibility for setting their own priorities, and at the same time to nudge them towards a more responsive relationship with their population.

Like efforts to streamline conditionality, the development of the PRSP was driven in part by political pressure from states and NGOs, and in part by expert concerns about past policy failures and the belief that country ownership was essential if development finance was to succeed. With the PRSP these institutions went considerably further, however, in their efforts to re-establish their flagging authority by developing techniques designed to foster public involvement in the creation of development plans and thus actively build local ownership. Although its development was contested, the PRSP ultimately became the key mechanism for putting country ownership into practice.

\section{The push for the PRSP}

Karin Christiansen and Ingie Hovland, in their excellent analysis of the dynamics underpinning the development of the PRSP, have described its adoption as the consequence of a "tipping point" in the international development field. ${ }^{82}$ As both internal and external actors began to problematize the political dimensions of policy failure, debates about aid effectiveness, new concerns about poverty and participation, and internal bureaucratic dynamics converged to make the PRSP the crucial practice for operationalizing ownership. 
External actors played an important role in pressuring the IMF and World Bank to adopt a policy that would enable country ownership and poverty reduction. As in the case of conditionality, the UK, under the leadership of Clare Short and Gordon Brown, argued forcefully for a more participatory and country-owned process. ${ }^{83}$ The Clinton administration was less enthusiastic but ultimately supported an instrument that they saw as ensuring that the neediest people and states would benefit from debt relief and additional assistance. ${ }^{84}$ The Development Assistance Committee (DAC) of the Organization for Economic Co-operation and Development (OECD), an organization bringing together major donors, also played an important role in championing the new emphasis on ownership. ${ }^{85}$ NGOs like Jubilee 2000, Oxfam, Christian Aid and ActionAid also pushed for debt reduction and argued for a povertyfocused approach to aid. Finally, although southern actors played a smaller formal role in the development and adoption of the PRSP process, the strategy was modelled in part on several developing states' own earlier poverty reduction plans, including those in Tanzania, Bolivia, Mozambique and, above all, Uganda. ${ }^{86}$

It is impossible to neatly separate out political from expert pressures, however, since all of the main "political" actors, like donors and NGOs, participated in the debates about policy success and failure, and articulated their concerns in these terms. Nevertheless, the public choiceinformed analyses of aid effectiveness discussed above tended to tackle the problem of reform in relatively narrow terms, emphasizing the need for orthodox economic reform, and pointing to political commitment as a crucial determinant of success. These concerns about how to reduce policy failures combined with a growing emphasis on poverty reduction as a central goal of development finance, though there was little consensus on how to best tackle the problem. ${ }^{87}$

These emerging concerns about political commitment and poverty reduction combined with a third debate around participation. The practice of integrating participation into development had been circulating for some time, appearing in a number of different contexts with different meanings. As I will discuss in the next chapter, in the public choice-informed debates on aid effectiveness, local participation was defined as a means to better service delivery. The idea of participation was also popular among the more "critical" units of the World Bank, like Social Development, where it was framed as a way of getting civil society actors to hold government accountable - a conception that would eventually come to underpin the "demand side" of good governance. More broadly, increased emphasis on development finance as a "partnership," in which developing country governments 
must take some responsibility for reform, relied on more active participation from borrowing country actors. ${ }^{88}$

By the late 1990s, there was therefore an emerging consensus about the importance of increasing aid effectiveness, focusing on poverty reduction, and encouraging greater borrower participation and responsibility - even if the actual meaning of the term "ownership" remained contested. This process of debate and problematization helped create a tipping point that meant that some kind of change in policy was needed; what form that policy was to take - the question of how to operationalize ownership - was, however, far from inevitable. Several different possibilities were on the table, including World Bank President James Wolfensohn's proposed CDF.

Although the PRSP has been popularly represented as a brainchild of Wolfensohn and a logical continuation of his CDF, the World Bank President was not actually pleased with the PRSP when it was first developed, seeing it as competing with his framework. ${ }^{89}$ His fears were at least partly vindicated, since the PRSP quickly overshadowed the CDF as the dominant practice for tackling ownership within the broader aid community. Wolfensohn's CDF was defined by four major principles, emphasizing long-term thinking, citizen participation, country ownership and measureable results. ${ }^{90}$ It was therefore very much in tune with the broader shifts in developing thinking that I have discussed, and also consistent with the principles underpinning the PRSP. Yet the CDF remained in the realm of ideas - it was a framework, not a policy - and in an organization as vast and decentralized as the World Bank, frameworks need to be put into practice to have much effect. The PRSP, in contrast, promised a set of concrete practices for achieving these objectives: it was practical, and as such, quickly eclipsed the CDF. The PRSP was eventually represented as a way of putting the CDF into practice. ${ }^{91}$

The IMF's own adoption of the PRSP was actually a matter of chance. Facing pressures from the Asian crisis, and NGO and developing country criticism of conditionality policy, PDR staff sought to restructure their lending relationship with poor countries. The PRSP, which in its earliest form had been developed partly by senior IMF staff member Jack Boorman, ${ }^{92}$ seemed like a policy that might just do the job. ${ }^{93}$ The Fund's transformation of the old ESAF into the poverty reduction and growth fund (PRGF) (which was then tied to the PRSP) was far from automatic, as the very question of whether the Fund should have a presence in LICs was contested at the institution; yet the IMF Managing Director at the time, Michel Camdessus, was a deeply religious man who saw the Fund as having a moral responsibility towards the poor, and ultimately pushed hard to ensure that the institution included poverty 
reduction as a central part of its mandate. ${ }^{94}$ In my interview with him, Camdessus himself noted that focusing on poverty as well as macroeconomic stability required a difficult shift in the culture of the institution one that was resisted by some staff members and stakeholders. ${ }^{95}$ The significance of this shift for the Fund's internal culture should not be underestimated. As one senior IMF staff member put it: "It's now accepted in this building that the IMF ... [is] an instrument of the international community to end poverty. You would have been laughed out of the building if you had said that twenty years ago." 96

Over time, the PRSP's role was expanded, as it came to replace the PFP as the planning document for IMF and World Bank concessional lending. Donor governments also began to use the PRSP for their own aid strategies, making it a lynchpin in the governance of development finance.

\section{Analysing the PRSP}

Perhaps even more clearly than efforts to streamline conditionality, the introduction of the PRSP brought with it a number of important changes to how the IFIs and donors did the work of financing development, including the introduction of new inscriptions and technologies of community, the integration of new actors into the work of governance, and the application of subtler but more productive forms of power.

\section{Engaging new actors}

Those involved in developing and implementing the PRSP have sought to use this policy strategy to engage new actors in the practices of governance. Who has historically been responsible for the day-to-day work of governing international development finance? If we look back to World Bank President Robert McNamara's "war on poverty" in the 1970s, McNamara himself was not only a force behind the adoption of new policies, but also played dual roles as a diplomat working behind the scenes to influence borrowers, and as a technocrat whose measurement techniques ensured that staff were achieving their targets. ${ }^{97}$ As the Bank and Fund became actively involved in structural adjustment in the 1980s, more work was delegated to technical staff. With the shift from one-off projects to more program-based lending, domestic government actors became more important; yet they were conceptualized in passive terms as consumers of policy advice rather than as active participants, as IFI staff often bypassed domestic institutions and actors.

With the introduction of policies like the PRSP, Bank and Fund staff have continued to be key actors. Yet the PRSP's architects hoped that the 
day-to-day practice of governing economic growth, adjustment and poverty reduction would increasingly be undertaken by a new set of actors. Domestic governments were seen as much more active participants in their own governance, preparing their own strategies and taking more responsibility for their successes and failures. The PRSP's creators also sought to integrate civil society actors as active players, participating in the creation of the PRSP and then using it to hold the government to account. In practice, the range of actors involved in the formulation of the PRSPs has varied considerably, but has included religious groups, parliamentarians, worker and peasant organizations, indigenous peoples, women's groups, local government officials and others. Even the poor themselves, who were once deemed unable to organize themselves into an effective political force, are now seen as a group capable of having an effect on government policies. ${ }^{98}$ In the process, developing countries' civil society has come to be viewed as a necessary quasi-political space - a third space, to use Nikolas Rose's term - in between the rent-seeking realm of the state and the self-interested logic of the market. ${ }^{99}$

\section{New techniques}

In order to understand what role these new actors play, we need to consider the techniques through which the PRSP does its work. Two kinds of techniques in particular are crucial: inscription techniques, and what Rose calls "technologies of community." 100 The technique of putting things down on paper has long played an important role in IFI lending to poor countries: the PFP was also designed to translate complex domestic economic factors into practical goals. Both the PRSP and the PFP it replaced can usefully be understood as inscriptions: they each seek to translate the complexities of a country's economic, social and political context, their aspirations and objectives, into a single document capable of enrolling actors and orienting action. Yet they are very different kinds of inscription.

If we compare them, the most obvious difference between the two is the length and scope of the documents. PFPs were relatively short (twenty- to thirty-page) documents that covered a range of areas, from social to monetary policy, viewing them all through the lens of economic efficiency. ${ }^{101}$ The object of the PFPs, and the structural adjustment programs that they facilitated, was economic transformation. The PRSPs, in contrast, are not merely much longer documents - often close to 200 pages long - but also much more ambitious in their objectives. ${ }^{102}$

What is perhaps most interesting about the PRSP is the way that it is produced - a key selling point for its advocates. This is where technologies of community combine with inscription techniques to produce a 
more dynamic and performative document. Whereas the PFP was a report created by Bank and Fund staff in order to coordinate their respective development programs, the PRSP is, at least in theory, prepared by the borrowing government. It is not just the Treasury staff who are involved: many of the affected ministries now play a role, together with a range of civil society groups and individuals. The goal of the PRSP is to engage a myriad of actors in discussing the shape of the country's development policy. By translating some of the past experiences with micro and project-level participation to a macro level, staff involved in implementing the PRSPs seek to engage a range of stakeholders in the process of formulating, implementing and monitoring a country's poverty reduction strategy. In practical terms, techniques include information dissemination strategies, various kinds of consultations, workshops and focus groups, citizen surveys and report cards. ${ }^{103}$

\section{New forms of authority and power}

By linking PRSPs to a wide range of different development practices, the IFIs have sought to both re-establish and expand their institutional authority. They have sought to re-found their economic expertise by putting into practice many of the insights of public choice theory and institutionalist economics. At the same time, IFIs' use of various 'technologies of community" help to enhance their claims to popular authority - allowing them to argue that their programs are based on a wider, more robust kind of ownership than in the past. These more popular technologies also delegate a certain amount of governance authority to a wider range of actors - giving domestic governments and local populations more control over their own economic development.

Given its popular, participatory dynamic and its effort to redistribute authority, the PRSP appears to be less subject to power imbalances than the PFP. Yet this delegation of authority is far from unconditional. Although the instrumental power that was so often visible in SALs has become less prominent, power relations remain in a different guise.

The PRSP has been designed not simply to engage government and civil society actors in governing, but also to help shape them. As Joseph Stiglitz, then Chief Economist at the Bank, put it, "At the heart of development is a change in the way of thinking and individuals cannot be forced to change how they think." ${ }^{104}$ Rather than operating through coercion, the PRSP is designed to work more subtly, fostering change through the document's production and reception. Even after the document is produced, its publication is to have performative effects. One of the "wagers" of this strategy, as one development think-tank member put 
it, is that by giving civil society actors new capacities and tools, they will put pressure on governments to become more responsive. ${ }^{105}$ In the process, PRSPs, as inscriptions, have become increasingly performative, as institutional actors have delegated considerable powers to them powers that continue to operate after their original formulation.

Another wager contained in this policy is that if government actors participate in devising their own programs - and become "selfresponsible" in the words of one IMF Managing Director - they will become better at developing "good" rather than "distorted" policy environments. ${ }^{106}$ This emphasis on fostering an internal will to reform resonates with Foucault's concept of governmentality, in which the objective is to govern by encouraging actors to regulate themselves. ${ }^{107}$ This is also a particularly proactive strategy that seeks to create the conditions necessary for its long-term objectives, rather than simply reacting to ongoing events and challenges.

The power relations enabled by policies like the PRSP are thus not only more productive and proactive, they are also increasingly indirect. Although the goals are economic - development, adjustment, stability and poverty reduction - the means are through various intermediaries. It is only through the roundabout route of mobilizing the poor, encouraging civil society pressure, generating demand for reforms and fostering political will that the ultimate objective is attained.

Like efforts to reform conditionality, the PRSPs have the effect of informalizing power and making it less visible. This is rather ironic, given that one of the central premises of the PRSP is to make development planning more transparent. Although the preparation of the PRSP as inscriptions is a more public process, with many more participants, it is certainly not universally inclusive. In most countries, not all civil society groups are included in the consultation processes: in Uganda, for example, the unions and many other groups seen to be too "political" were excluded from the first PRSP process. ${ }^{108}$ In Bolivia, it was local government officials who played a preponderant role in consultations. ${ }^{109}$ Moreover, studies of the Bolivian, Ghanaian, Ugandan and Nicaraguan PRSPs suggest that donors continued to play a significant role in defining the ultimate form of the PRSP, often undermining the "bottom-up" accountability that the process was intended to create. ${ }^{110}$ Which actors were included in the participatory processes? Which ones were heard? Whose voices were ultimately translated into the PRSP documents? The answers to these questions say a great deal about the power relations reflected in and enabled by this particular poverty reduction strategy. Yet they are obscured as much as they are revealed by the PRSPs themselves. 


\section{A more provisional style of governance}

When we look at the recent revisions to conditionality policy and the introduction of the PRSP together, we find that despite the somewhat different motivations and pressures behind them, they have much in common. Both have been designed to respond to the contested failures of finance and development in the 1990s and are concerned with improving the efficiency of development financing by making specific conditions and entire poverty reduction policy frameworks more responsive to local contexts. Both policies are also motivated by a concern about the flagging authority of the IFIs and donors. By reinventing structural adjustment policies as PRSPs and streamlining or redefining conditionality, IFIs and donors seek to regain expert authority and bolster it through increased popular authority. At the same time, both continue to reinforce power relations - in less formal and often less visible forms.

The turn to ownership represents a shift in how the work of governance is done, as the overall approach to governing has become more provisional. As I discussed in Chapter 2, a provisional style of governance is a particular kind of response to the problem of policy failure and to the fragility of expert authority: rather than seeking to control absolutely, those seeking to govern provisionally apply a less direct, more proactive approach to the task - one that relies crucially on increasingly symbolic techniques, and often hedges against the possibility of future failure.

In the case of the ownership strategy, we can see how governance increasingly occurs indirectly rather than through direct action. Influence is exerted in the spaces where conditions have been cut, in the form of advice, quasi-conditions, conversations or unspoken expectations that must be met to demonstrate "genuine" commitment to reform. The PRSP, in turn, is designed to solicit pressure for reform from civil society actors rather than applying it directly on government actors. This indirect form of governance relies crucially on the increasingly symbolic character of policy techniques. Both loan conditions and inscriptions like the PRSPs are valued for their capacity to signal political commitment. The symbolic nature of these policy techniques is crucial for their performative effectiveness. Paradoxically, it is because conditions and PRSPs are abstract signs of ownership that they work to foster "real" ownership. If the markets believe in the credibility of a country's leaders' commitment to fulfil the conditions, they will reward that country, making it easier for the leaders to stick to their commitments. Similarly, if civil society members see the PRSP as a signal of their government's responsiveness to their concerns, they will begin to take more ownership of the strategy and related aid programs. In theory, at least, the symbolic 
character of these techniques produces a virtuous circle in which the appearance of a thing helps to make it real.

These policies are also highly proactive: the Bank and major donors increasingly recognize and address the temporal dimension of policies, seeking to create the conditions for longer-term reform by not only altering the incentives but also changing thinking. They are therefore seeking to pre-empt failure by changing the context in which policies are developed and implemented. It is not just this more proactive approach to governance that seeks to inoculate the policies against failure: all of these more provisional tactics of governance do the same. The indirect techniques of the PRSP and streamlined conditionality allow the IFIs and donors to step back a bit from the highly politicized fray of more direct conditions, and escape some responsibility. By delegating more responsibility for success and failure to domestic governments and their populations, they further distance themselves from potential failures. Institutional actors' reliance on more symbolic techniques also allows them to hedge their bets: if they are interested less in "real" ownership than in its appearance, then the fact that participatory dynamics are often instrumentalized, and that ownership is not always genuine, is not a sign of failure. ${ }^{111}$

Yet despite these efforts to inoculate themselves against failure, the possibility of failure remains a continual preoccupation of IFI and donor staff - in large measure because the strategy of fostering ownership is fraught with so many of its own problems. I will take up these various failures and their implications in greater detail in the Conclusion to this book. For now, it is just worth noting that these challenges have begun to erode internal and external support for the PRSP, unravelling the initial consensus on the strategy of ownership. Although they have continued to pursue efforts to foster country ownership in various forms, IFI and donor staff have grown increasingly ambivalent about its promise, running into persistent difficulties in quantifying ownership and finding the strategy difficult to put into practice.

One of the challenges that the ownership strategy has had to come to terms with is its complex relationship with a second important governance strategy: the push to develop new global standards in everything from good governance to budgeting practice to infant mortality rates. As I will discuss in the next chapter, even as IFI and donor staff have sought to tailor their policies to particular local contexts, they have also pursued a far more universalist strategy of standardizing global practices. 


\section{Developing global standards}

International institutions seek to govern in the name of and through universals. By claiming to be working on an issue of universal concern such as global poverty, human rights or sound economics - international organizations (IOs), non-governmental organizations (NGOs) and donors seek to gain authority. At the same time, they often represent the kinds of expertise that they use to tackle these problems as universal. World Bank and International Monetary Fund (IMF) staff drew on both of these universalizing strategies during the structural adjustment era: arguing that they were seeking to achieve the universal good of economic development, while simultaneously drawing on what they saw as the timeless universals of economic theory to identify the policies needed to achieve those ends. As I discussed in Chapter 4, the inflexibility of these universals was one of the central reasons for the erosion of the international financial institutions' (IFIs) expert authority in the mid1990s. As a growing number of critics described these rigid economic prescriptions as failures, IFI staff, management and directors sought to respond - not by rejecting universals altogether, but by problematizing and ultimately redesigning them.

If anything, the rhetoric of IFI and donor leaders became more explicitly universalist in the late 1990s and early 2000s, as they sought to build support for their vision of a new global economic order in the wake of the contested failures that they faced. The World Bank President, James Wolfensohn, initiated this new universalism with his famous speech about the "cancer of corruption" at the 1996 Annual Meetings, while the IMF Managing Director, Michel Camdessus, promised in 1999 that the institution would contribute to "civilizing globalization," the UK Minister for Development, Clare Short, argued that "We have a moral duty to reach out to the poor and needy," and Camdessus's successor, Horst Köhler, called in 2002 for a new "global ethics." 1 This is a language that was unashamedly universalist.

Yet the kinds of universalizing strategies being used today by IFIs and donors are very different from those of the structural adjustment era. For 
one thing, their scope has expanded: when Wolfensohn or Camdessus talk about the universal value of their institutions' efforts, they are not just talking about economic development, but also recognizing the social and political underpinnings of economic success. The new global norms of development include standards of political as well as economic transparency, judicial as well as central bank independence, and maternal as well as economic health. ${ }^{2}$ Not only the scope but also the form of these universals has changed. The law-like economic rules of the 1980s and early 1990s have been supplemented and replaced with more flexible standards, often taking the form of best practices and benchmarks. ${ }^{3}$ These new standards seek to define the norm in far more complex and contested arenas than in the past. Despite efforts to black-box them as thoroughly as the economic rules that they replace, more effort is therefore required to justify and maintain them. ${ }^{4}$ As the IFIs in particular move beyond the narrower mandate of the structural adjustment era, they have felt the need to justify the universality of these standards in moral as well as expert terms - which helps to explain the strikingly normative tone of some leaders' rhetoric. ${ }^{5}$

This chapter examines the evolution and logic of this new universalist strategy of standardization by focusing on two policies pursued by the IMF and World Bank: the development of the "good governance" agenda from the 1980s onwards in response to the perceived failures of traditional aid, and the more recent adoption of the standards and codes initiative after the financial crises of the late 1990s. Both initiatives involve a range of other institutions in the process of governance: practices designed to foster good governance have been adopted by many donors, while the standards and codes initiative relies on organizations like the Basel Committee on Banking Supervision, the International Accounting Standards Board, and the Organization for Economic Co-operation and Development (OECD) to develop the standards. While I will focus my attention here on these policies' initial development by the IMF and World Bank, these standardizing practices have thus gone on to become part of a wider community of practice in development finance.

Although the standards and codes initiative has received less attention, the rise of good governance has been widely examined in the academic literature, particularly by those working on the World Bank. ${ }^{6}$ What is gained from revisiting these policies yet again? The simple fact of expanding the discussion from considering just good governance to looking at standards and codes, and of looking beyond the World Bank to the IMF, reveals these changes to be more widespread and profound than the conflicts within and around any single institution or issue area. The focus on the how of governance also reveals the complexity of the 
changes involved, particularly when one looks at the most recent developments in the good governance agenda - the emphasis on the "demand side" of governance - which has been understudied to date. ${ }^{7}$ Finally, I have drawn on verbatim minutes recently made available from the IMF and World Bank archives, which provide additional insight into the debates around these policies.

A meso-level focus enables us to see these new policies as part of a broader strategy of developing global standards, and to understand them as a way of governing in the name of and through universality. In order to grasp the character and significance of these emerging policies, we need to pay attention to how good governance and standards and codes do the work of governance. There are important ways in which standardization acts to foster a new kind of normal, a new kind of norm, as Michel Foucault would suggest. ${ }^{8}$ Yet, such analyses tend to over-generalize contingent, locally driven processes as part of a singular logic of governmentality. ${ }^{9}$ Within sociology, particularly among those working on science and technology studies (STS), there is a growing literature on processes of standardization that I will draw on throughout this chapter, which draws attention to their often local, contingent and socially constructed character. ${ }^{10}$

The good governance agenda and the standards and codes initiative both define new global standards of economic development, and pressure governments to adopt them. In pursuing these policies, IMF and World Bank staff have drawn on small "i" ideas to redefine universals, changing how they go about the business of governance. They seek to enrol a wider range of actors in the processes of governance - not only member governments, but also market and civil society actors. As in the ownership strategy discussed in the previous chapter, institutional staff rely on new, more performative and reflexive techniques, including new ways of measuring and publicizing compliance with standards, and new technologies to encourage popular pressure, thus redistributing a measure of governance authority. They draw on different forms of power in doing so, including more indirect and proactive forms that seek to produce cultural changes aimed at longer-term transformations. As power has become more productive, the forms of exclusion that it generates have become more complex, a matter of degree rather than of absolutes.

Together, I will suggest, these shifting factors of governance once again point towards the emergence of a provisional kind of governance. This form of governance uses indirect but proactive techniques to encourage market and civil society to pressure governments to comply with new standards. Its advocates use techniques that are increasingly symbolic and highly performative to achieve these ends, relying on the 
fiction of credibility to do so. And although all of these various gambits are designed to minimize the possibility of failure, they nonetheless remain aware of its dangers and seek to hedge against them.

\section{Good governance}

In the last half-century we have developed a better understanding of what helps governments function effectively and achieve economic progress. In the development community, we have a phrase for it. We call it good governance. It is essentially the combination of transparent and accountable institutions, strong skills and competence, and a fundamental willingness to do the right thing.

Speech by World Bank President Paul Wolfowitz, April 2006. ${ }^{11}$

Over the past two decades, it has come to seem natural that IFIs and donors would make good governance and limits on corruption part of their development programs. Governance conditions now apply to over 85 per cent of IMF programs. ${ }^{12}$ Governance factors also account for over two-thirds of the country policy and institutional assessment (CPIA), which the World Bank uses to determine how much concessional assistance poor countries are entitled to through the International Development Association (IDA). ${ }^{13}$ Governance is also front and centre in many donor assistance programs, from the United Kingdom's Department for International Development (DFID) to Canadian international development programmes and the United States' Millennium Challenge Corporation (MCC). ${ }^{14}$ When governance was first introduced into the World Bank and IMF, it was politically sensitive and the subject of considerable debate. ${ }^{15}$ Since then, however, good governance and anti-corruption efforts have come to be seen as an essential part of development finance.

\section{The evolution of a governance agenda}

Given that the term "good governance" is ambiguous, it should come as no surprise that it has come to mean different things at the World Bank and the Fund. While there are overlaps in the practices of fostering good governance at the two institutions, it is worth looking at each separately, since the path that each has taken is different.

\section{The World Bank}

The World Bank prides itself on being the first institution to recognize and act on the idea that governance is central to economic development. Although its staff and management have certainly retained that conviction over the past twenty-odd years, they have defined and acted 
on that idea differently. It is possible to define two broad phases in the evolution of the governance agenda at the World Bank: the first phase, from 1989 to 98, was an extension of neoliberalism and defined governance primarily in public choice terms as an effort to avoid rent-seeking by creating a leaner, more effective government. The second phase, dating roughly from 1999, saw a broadening of the governance agenda to include the Bank's new emphasis on poverty reduction and a shift in the theoretical framing from public choice theory to new institutionalism; this phase also saw the development of more experimental policies aimed at fostering the "demand side" of governance.

The term "good governance" first emerged in response to the perceived failures of development in sub-Saharan Africa. In an influential 1989 report on the subject, the authors argued that the principal source of this failure was not external - in declining terms of trade, for example but internal, based on a failure of investment linked to bad public management. ${ }^{16}$ This "crisis of governance," they argued, must be addressed before economic progress can be expected. ${ }^{17}$ The report is framed in neoliberal terms and can be read in part as a neoclassical rebuttal of dependency theorists' claims that the causes of underdevelopment are within the capitalist system. ${ }^{18}$ While the report places some responsibility for failure on the Bank for its inability to recognize the importance of institutions, it also implies that the ultimate blame for underdevelopment rests with poor countries' governments. Although the report was never formally discussed by the Executive Board, nor served as the explicit basis for policy discussions, it framed later discussions on the legality of the Bank's move into the governance area. ${ }^{19}$ In fact, during discussions of the Bank's legal mandate in this area, the Libyan Executive Director, Salem Omeish, went so far as to charge the Bank staff with trying to "sneak" the results of that study into policy discussions. ${ }^{20}$

This report launched a broader process of debate and problematization at the Bank, as the issue of good governance became a central preoccupation, with Bank staff producing several further reports on the subject and Executive Board members debating the emerging policy. ${ }^{21}$ Not surprisingly, those involved in these initial debates about governance drew heavily on economic theory, using a public choice conception of state-market relations that treated all of the players as self-interested and individualistic agents. ${ }^{22}$ Perhaps the most pervasive argument made throughout staff documents at this time is that rent-seeking is the central problem of governance. Rent-seeking is a concept that assumes that the state's ability to make decisions about resource allocation - e.g. the building of a dam in a particular location - can have perverse consequences as it encourages the unproductive use of resources by those 
seeking to affect government decisions. ${ }^{23}$ The most touted solution to rent-seeking in the public choice literature is to reduce the scope of state decision-making by shifting greater responsibility to the markets.

By the mid-1990s, the governance agenda was having a concrete impact on Bank operations: in 1994, a report on the Bank's experience of governance programs noted that the volume of governance-related lending was significant and increasing, with as many as 68 per cent of lending operations containing some kind of governance dimension. ${ }^{24}$ Yet, even as the idea of governance began to take hold within the institution, it was clearly a fraught issue. The Bank's General Counsel, Ibrahim Shihata, was asked to provide a legal opinion on whether the institution's mandate allowed it to address governance issues. Shihata's opinion - which he only provided after significant pressure from management - narrowly reduced the scope of the Bank's involvement to factors that had a direct impact on economic development. ${ }^{25}$ When the Bank's executive directors discussed the legal opinion in an Executive Board seminar, their conversation was intense, with one director noting that the subject was "clearly delicate and perhaps emotive," while another went so far as to charge the institution with attempting to "move into the distinct political arena and dictate [a country's] political agenda and ideology." 26

It was not until James Wolfensohn took the helm of the World Bank in 1995 that the issue of governance - and the related problem of corruption - took centre stage. In a famous speech at the 1996 annual meetings, Wolfensohn called for an end to the "cancer of corruption.",27 It was during his tenure that the 2000-1 World Development Report (WDR), Attacking Poverty, and the 2002 WDR, Building Institutions for Markets were released. ${ }^{28}$ Together, these two reports altered the good governance strategy in several respects. ${ }^{29}$ First, they justified good governance based on its capacity to reduce poverty. Second, they reframed the theoretical justification for good governance in terms of new institutionalist economics. ${ }^{30}$ This shift is significant because although an institutionalist approach remains consistent with much neoclassical economic theory, it emphasizes the problems of market failure - instances in which the state must step in because markets are unable to allocate resources effectively.

The good governance agenda also began to focus more explicitly on the importance of public participation and demand. The role of participation had been controversial in the early 1990s: Shihata's 1991 legal opinion had identified participation as a borderline case that might be viewed as too political, yet a number of directors were vocal in their advocacy for its importance. ${ }^{31}$ By 2000, in the context of the development of the ownership strategy, the idea that governance reform should 
be driven by the "demand" of public and private actors (and not just the "supply" from lenders) had become a defining feature of efforts to foster good governance. ${ }^{32}$ When Wolfowitz took over as Bank President in 2005, he continued this emphasis on the demand side of good governance. As one World Bank staff member put it in 2011,

A lot of Wolfowitz's enthusiasm for governance and anti-corruption has given a real boost to an interest in citizen participation, because - we can have a discussion about neo-conservatism and Strauss and some very interesting philosophical ideas - but a central neoconservative idea is let's support human rights, citizen rights and grassroots democracy... The [World Bank] President loves this stuff. ${ }^{33}$

This focus on local participation was integrated into Wolfowitz's governance and corruption strategy (GAC), which remains the principal framing document for governance activities at the Bank. ${ }^{34}$

\section{International Monetary Fund}

The story of the evolution of the IMF's governance policy is somewhat shorter since the Fund only got on board with the good governance agenda in 1997 and has remained more consistent, broadly in line with the Bank's early public choice-driven approach.

In 1996, following a directive from the IMF's Interim Committee, ${ }^{35}$ the Executive Board sat down to discuss a staff paper on "The Role of the Fund in Governance Issues." ${ }^{36}$ Like the Bank's early governance strategy, Fund staff drew extensively on public choice theory to frame the problem of governance, arguing that the central issues were those of rent-seeking and ad hoc decision-making, which could be best resolved through continued economic liberalization to reduce opportunities for government mismanagement. ${ }^{37}$

Despite Fund staff and management's attempts to define governance issues as consistent with the institution's traditional role, the attention to governance clearly expanded the organization's mandate. A 2001 report on the Executive Board's discussion of governance issues provides a useful overview of the new practices undertaken by the IMF under the rubric of "good governance":

[S] trengthening revenue administration; enhancing financial accountability of state enterprises; improving bankruptcy laws and procedures; consolidating extrabudgetary funds into the budget; enhancing transparency in tax and tariff systems; reinforcing central bank independence; extending prudential bank supervision; and improving economic and financial statistics. ${ }^{38}$

In concrete terms, such governance issues were not only raised in the context of the Fund's usual Article IV consultations with member states, 
but were also integrated into its lending conditions. ${ }^{39}$ Good governance practices therefore had teeth, since program approval could be "suspended or delayed on account of poor governance."

In a 1998 speech on the IMF's role in good governance, Managing Director Michel Camdessus argued that there existed a "universal consensus" on the importance of good governance. ${ }^{41}$ Yet, in truth, this expansion of the Fund's mandate was more contested on the Board than Camdessus suggests. Jack Boorman, then head of the Policy Development and Review (PDR) department, which was responsible for developing the governance policy, has since noted, "the resistance to the governance agenda was amazing in the mid-1990s." 42 Camdessus himself admitted as much in the same speech cited above, suggesting that initially "Some of our shareholders feared that in taking on such issues the [Bretton Woods] institutions would become politicized and lose their effectiveness." 43

Those pushing to broaden the Fund's role to include governance issues ultimately won the day. In fact, as the 2001 review of the IMF's experience noted, engagement on governance had expanded well beyond the staff and Board's initial expectations when they had first approved the Guidance Note on Governance in 1997. The principal reasons for this expansion were the Asian financial crisis in 1997-8, which led to the standards and codes initiative discussed below, and the decision to link governance conditions to debt relief as part of the Highly Indebted Poor Countries (HIPC) initiative. ${ }^{44}$ The emphasis on governance issues also continued to increase in the Fund's bread-and-butter policies - in its Article IV surveillance consultations and lending programs.

\section{Analysing good governance}

\section{$A$ new kind of universal}

The good governance agenda was an effective response to critics' charges of the failure of past efforts at financing development: it allowed the IFIs to shift significant responsibility for those failures onto low-income governments while at the same time developing new forms of expertise to respond to the "problem" of governance. In the process, institutional actors did not so much reject their earlier economic universals, as modify and supplement them through a different kind of universal: one that was broader in scope, more symbolic in character, and that combined technical and moral appeals to its authority.

These new universal standards of good governance are defined partly in technical terms. Through their use of public choice theory, Bank and Fund staff have framed the challenges of governance in universal terms, viewing them as the logical outcomes of human self-interest and the 
difficulties of collective action. The solution for developing states is no different from what (it is assumed) applied to industrialized states many years ago - the development of rules and institutions capable of keeping self-interested tendencies in check. The institutionalist economics literature, which has played a more important role in framing good governance policy in recent years, is somewhat more nuanced, focusing on institutional rather than individual dynamics, and paying more attention to historical and geographical variation. Yet, here as well, the problems of transaction costs and market failure are represented as universal. The 2002 WDR on institutions begins with a discussion of eleventh-century Maghribi trades, suggesting that the challenges that they faced in expanding trade, and the solutions that they found to overcome problems of information and cheating, are parallel to those faced by people everywhere today. ${ }^{45}$

Given the prominence of such technical economic claims in the good governance agenda, how different is this standardizing strategy from that of the structural adjustment era, which also relied on technical economic universals? If we take a closer look at the kinds of universals that are being deployed through good governance policies, we find several significant differences.

The first of these differences is the broader scope of the new universals, which not only define "sound economics" but also explicitly identify the kinds of political and social institutions needed to achieve such economic goals. ${ }^{46}$ This is a much messier and more contestable undertaking - one that runs the risk of overstepping the IFIs' mandate. IMF and World Bank staff have worked hard to police the boundary between "politics" and "economics." By insisting that only those institutional reforms needed to achieve economic stability or development are appropriate, they have managed the policy in such a way as to "protect [the institution's] reputation for technical excellence, professionalism and objectivity." 47 Yet, in practice, the move into governance issues has further blurred these distinctions. As Michel Camdessus noted in an interview,

We had to promote a shift in the mentality of staff members. Many saw the mission of the Fund as technical, and were not comfortable mixing a more technical emphasis on problems such as inflation with other policies focusing on human living standards. The challenge was to bring both together in a new approach.

Eventually, Camdessus suggests, staff grew more accepting of the need to move into this new terrain. ${ }^{48}$ The 1996 IMF staff paper on governance, as well as the later staff guidelines, simultaneously argue for defining the Fund's role in terms of the macroeconomic consequences of governance, 
while also noting the difficulty in clearly separating political from economic dimensions. ${ }^{49}$ World Bank Executive Directors also noted the difficulties in separating politics from economics: as the UK Director, David Peretz, put it, "There is always going to be some ambiguity, some borderline cases." 50

The second major difference from structural adjustment-era universals is the form that good governance standards take. Because good governance is more complex and pushes the boundaries of the IFIs' (formally) apolitical mandates, these standards tend to be more visibly constructed, even arbitrary, and therefore contestable. Of course, the "rules" of sound economic practice are also social constructs, built up over centuries as the institutions of the market economy were developed and propagated and homo economicus was formed. ${ }^{51}$ Yet these economic norms have been black-boxed: naturalized as expert knowledge and integrated into everyday life, so that the principles of low inflation and independent central banks now appear as law-like propositions that are natural facts rather than symbolic constructions.

The principles underpinning good governance, in contrast, are less commonsensical and more obviously Western in their origins. IFI actors advocating their adoption face more vigorous opposition and are more aware of the need to actively define, construct and police the boundaries of these new governance standards. These are standards of good practice, rather than fundamental rules: they are therefore more clearly contingent in their construction, making visible their character as what STS scholars, Timmermans and Berg, describe as "local universals," a term that emphasizes the way that "universality always rests on real-time work, and emerges from localized processes of negotiations and pre-existing institutional, infrastructural, and material relations." ${ }^{52}$ As these specific, localized standards are generalized and universalized, however, they lose contact with the particular Western liberal contexts in which they were produced and become increasingly symbolic, even arbitrary.

The strategies that IFI actors have used to justify these new, more symbolic and visibly constructed standards have taken two different forms: on the one hand, as I discussed above, IFI staff have sought to justify them in technical terms through the use of public choice theory and new institutionalist economics. On the other, they have begun to justify the good governance agenda in explicitly moral terms. This moral turn may appear self-defeating in a context in which actors are supposed to be objective and apolitical. In fact, by framing good governance standards in universal moral terms, the IFIs are working to move these standards into a category that is beyond dispute - not because they are technical, but because they are universal goods. ${ }^{53}$ 
Both Fund and Bank leaders have made strong moral claims for the importance of the good governance agenda. The quotation that begins this section makes that clear: when Wolfowitz claimed in 2006 that good governance requires "a fundamental willingness to do the right thing," he was making an explicitly normative argument regarding the universal "goodness" of the good governance agenda. Although many of the universal moral principles being alluded to are largely drawn from industrialized, Western economies, the claim that the "problems of governance are universal" suggests that this is not a policy directed only at developing economies, but rather at a global challenge. ${ }^{54}$ Executive Board discussions make it clear that it was important to some members that governance not be seen as "a peculiarly African problem," but rather that "the principles and practices are universal or ought to be so."

This combination of moral and technical universalism has several interesting effects: although the technical logic remains the predominant one, it is supplemented by a thicker set of universals, enhancing the basis of the institutions' claims to legitimacy. This thicker set of universalist claims provides a more robust foundation for expanding the institutions' mandate to include increasingly contested and politically charged areas in their programs, thus expanding the basis of their authority.

\section{New actors and sites of authority}

The shift towards broader, messier and more self-consciously constructed universals entailed in the good governance agenda has led to the enrolment of new state, market and civil society actors, and the redrawing of the boundaries that separate them. Although these new standards do intervene more closely into the workings of borrowing states, they do not seek to render local actors "docile," to again borrow a term from Timmermans and Berg. ${ }^{56}$ Instead, IFI staff have sought to encourage the engagement of more proactive, reflexive local actors in the process of governance: citizens and market participants who will demand better governance, and government actors who will respond. This strategy distributes the authority for governing more widely to a range of new actors, while simultaneously reconstituting them in particular terms.

One of the most striking aspects of the changes taking place in IMF and World Bank policies and pronouncements over the past decade has been their renewed interest in the state and government actors - after several decades of denigrating their role. Yet that attention has retained a certain scepticism about state actors, and a belief that their role should remain secondary to that of the market. The 1997 WDR, The State in a Changing World, carefully differentiates the renewed emphasis on the state from earlier state-led development efforts in the 1950s and 1960s. 
In the 1990s, the report argued, developing-country government actors could only become effective if they first pared down the role of the state by shifting some of its "burdens" to the private sector and to local communities, and made "the state's central institutions work better."

These policies seek to redistribute some governance authority by enrolling state functionaries in the development process - but only insofar as those government actors learn to behave in certain ways. The World Bank in particular has expended an enormous amount of energy over the past decades in fostering Western-style public services in borrowing countries. ${ }^{58}$ The goal is not only to change public-sector management practices but also to transform bureaucratic actors by fostering a different kind of culture. As I will discuss in Chapter 8, in the context of results-based management, many of these efforts are inspired by new public management theory, which is based on public choice assumptions and seeks to make bureaucracies work more like markets. Drawing on these ideas, World Bank and donor staff seek to transform developing-country bureaucrats into more efficient, accountable and market-like actors.

One of the key ways of cultivating this new kind of bureaucratic actor is by creating checks on their actions, which reduces the potential for corruption among public officials - a classic concern in public choice theory. ${ }^{59}$ These checks can take the form of rules, procedures and internal audits, but also include other actors: specifically, active citizens and other non-state actors. The World Bank has long been interested in using market actors and forces to check government action - that is part of the logic underpinning decades of privatization and efforts to build up a strong private sector. The logic behind these new initiatives is, however, somewhat different: there is a genuine attempt in the demand-side initiative to encourage both market actors and citizens to press for better governance. Civil society actors are also therefore granted a degree of authority and responsibility in the practice of fostering better governance. Yet these are citizens of a peculiar kind: "citizen-consumers" who are both consumers of basic services, such as water or health care, and citizens of a state responsible for the provision of those services. ${ }^{60}$ Their identity as public actors is linked to their role as private consumers. The architects of the good governance agenda thus seek not only to enrol a range of new actors in the practices of governance, but also to reconstitute them as more responsible and active participants.

\section{New techniques: governing through universals}

Bank and IMF staff use a range of new techniques in their operationalization of good governance practices. Some of these are similar to 
techniques used for structural adjustment programs, while others are far more innovative, experimenting with ways of generating popular support for governance reforms.

Since the mid-1970s, the World Bank has relied on the CPIA to help establish the level of funds that the poorest countries receive from the IDA, the World Bank's concessional financing facility. The CPIA translates countries' performances in a wide range of areas into indices, which it ultimately reduces to a single numerical score: a classic technique for making disparate contexts commensurable with reference to a set of universally applicable criteria. ${ }^{61}$ The CPIA initially focused on macroeconomic criteria, but starting in 1997 the Bank introduced governance criteria into the mix, which now account for 68 per cent of the final score. ${ }^{62}$ At the IMF, more traditional techniques include the inclusion of governance concerns in Article IV consultations and the addition of governance conditions in stand-by agreements and concessional loans.

The good governance agenda has also led to some innovative practices. At the IMF, the chief example of this is the standards and codes initiative, which I will discuss in the second half of this chapter. At the World Bank, this kind of innovation is most apparent in the institution's move to foster the "demand for good governance" (DFGG) at the country level, through the development of new technologies of community. ${ }^{63}$

Bank staff have identified several practices as key to supporting DFGG: transparency and the dissemination of information, consultation and participation, and ongoing monitoring and evaluation. These techniques should be familiar to anyone who has examined liberal conceptions of the public sphere as a site where individuals engage in publicity (typically through a free press) and debate. Bank staff thus seek to mobilize popular support for good governance in a way that combines liberal normative assumptions about publicity and participation with public choice ideas about the need to develop checks on government excess. In the process, deliberation is transformed into a kind of thin participation that is somewhere between consumer feedback and citizen consultation.

If citizen-consumers are to act as checks on government, they need information about what government actors are doing. The Bank's goal is not simply to engage public actors in the initial formulation of policies, but rather to create mechanisms through which they can monitor, evaluate and report on government policies on an ongoing basis. ${ }^{64}$ For this to happen, it is necessary to gather information about the effects of those policies, to assess them against predefined indicators, and to communicate them to the public. This involves the creation of new kinds of inscriptions. These can include Doing Business indicators, a Bank 
initiative that scores countries on how easy it is to set up a business, complaints mechanisms, media investigations, and "citizen report cards," in which civil society organizations grade public services. ${ }^{65}$ Transparency, participation and monitoring thus come together, as information on service performance is transmitted to encourage public actors to "voice" their views, producing data that is in turn used to improve service delivery.

While such thin public practices could potentially spill over into thicker, more genuinely political activities, this possibility is constrained by the tendency to frame civil society actors as consumers of services first and foremost. Narrowly economic forms of consultation such as obtaining customer feedback thus come to redefine and constrain activities that might have produced more political kinds of engagement.

\section{New forms of power and authority}

Any efforts to reshape the policies and institutions of developing-country governments clearly involve power relations, whatever claims the IFIs may make to the contrary. The IMF and World Bank have always relied on a range of forms of power, from the more coercive power of traditional conditional lending to the informal power of technical advice and assistance. The incorporation of governance criteria into the CPIA at the World Bank and of governance conditions into loans at the IMF are examples of how the good governance agenda has extended the IFIs' more traditional coercive forms of power. Yet when World Bank executive directors discussed the institution's initial move into good governance, they were explicit about the importance of using "persuasion" rather than "constraint" as the key tool for achieving objectives. ${ }^{66}$ Efforts to develop new standards of good governance have made the IFIs more reliant on productive, indirect and proactive forms of power.

As Barnett and Finnemore suggest, IOs like the IMF and World Bank have always exerted a kind of productive power that uses their capacity to define and categorize objects of governance in order to give them real meaning and presence. ${ }^{67}$ The idea of good governance is a classic example of a term whose invention has had performative effects by making possible a range of practices and interventions that would not have been possible before. "Good governance" can be seen as an extension of earlier such categories, like "sound economics," which have been used for much longer. Yet whereas calls for sound economics once defined state and market actions in largely negative terms, as a matter of deregulating and liberalizing, the category of good governance seeks to define far more explicitly - and positively - the role of government, civil society and market actors. 
Thus the IFIs aim to create important changes in the organization of low-income governments and their relationship with the market and citizens by creating the conditions in which others (chiefly citizenconsumers) will demand those changes. This is a kind of indirect power that relies on information and transparency to achieve its ends. Not only is the form of this strategy somewhat unusual, but its goal is also novel, at least in the developing world: the attention to market and popular demand together with the emphasis on transparency and accountability makes it clear that the objective is to create what Mitchell Dean, drawing on Peter Miller, has described as a kind of reflexive government:

The imperative of reflexive government is to render governmental institutions and mechanisms ... efficient, accountable, transparent and democratic by the employment of technologies of performance such as the various forms of auditing and the financial instruments of accounting, by the devolution of budgets, and by the establishment of calculating individuals and calculable spaces. ${ }^{68}$

Michel Foucault's discussions of the different forms that power take are useful here: the universalist strategy that underpinned structural adjustment operated both like a juridical rule, dictating orthodox economic practice, and like a form of discipline, differentiating normal economics from abnormal forms. ${ }^{69}$ The standardizing practice that underpins the turn to benchmarks, standards and best practices shares with the structural adjustment era a disciplinary logic, as it sorts economies into normal and abnormal. But it also increasingly relies on a more governmental form of power, focusing on managing circulations around the norm (rather than drawing lines between what is normal and what is not), and seeking to foster a more active, self-disciplining kind of subjectivity among the bureaucratic, market and civil society actors that it enrols.

The form that power takes here is not one of domination, since the goal is not to produce docile subjects, but to enrol a wide range of actors in the process of demanding and providing better governance. Yet these less direct mechanisms still work to generate forms of exclusion and inequality. Standards may appear inclusive but, as Timmermans and Epstein put it, "every standard inevitably implies an evaluation at the expense of some other, often obfuscated, devaluation." ${ }^{70}$ In the case of good governance standards - and even more clearly with the standards and codes initiative, as I will discuss below - those kinds of institutions and practices of governance that have been deemed "good" are almost entirely drawn from Western, liberal, free-market societies. The patterns of inclusion and exclusion enabled by standards are therefore subtle: countries are graded and ranked, rather than simply excluded. Moreover, because their "grade" translates, through the CPIA and 
performance-based conditions, into different levels of funding, this ranking has very real consequences for the poorest in the world. ${ }^{71}$

\section{Standards and codes}

Although the good governance agenda is the most prominent of recent efforts to develop global economic standards, it is not the only such policy. By taking a look at a second, related, policy change - the development of standards and codes - we can gain a more concrete sense of how the IFIs have deployed the strategy of standardization in practice. Whereas the World Bank was the main driver of the good governance policy, here it is the IMF that has been in the driving seat.

\section{Developing the initiative}

The standards and codes initiative ultimately became the centrepiece of the IFIs' response to the financial crises of the 1990s. ${ }^{72}$ Over time, the standards also came to be viewed, particularly by the IMF, as their central contribution to the spread of good governance practices. Yet the first standards were not developed with such grand objectives in mind. In fact, the standards and codes initiative evolved gradually, eventually taking on the central role that it plays today. By tracing the initiative's development, we can also track the evolution of thinking about the role of these standards and recognize the choices that were made in pursuing this path to financial stability and good governance choices that reflected a desire to govern more provisionally.

The standards and codes initiative was developed in two major stages in response to two major crises - the Mexican and Asian financial crises. While external critics saw these two crises as evidence of a profound failure of the IFIs' efforts, IMF staff and management interpreted them rather differently: as evidence of a more modest failure in the information that governments made available to market actors, and of a more serious failure in borrowing countries' institutional quality. It was not markets (or the IMF), but states that were to blame for these failures, they argued, due to their poor institutional capacity and failure to provide the markets with timely and accurate information. In debating the nature of these failures and the appropriate responses, IMF staff and management thus began to problematize the role of information and transparency in domestic governance, both of which played a central role in the global standards that they developed in response.

The first stage in this standardization strategy was the IMF's development of a highly technical and, at least on the surface, unexciting set of 
standards for statistical information: the special data dissemination standard (SDDS). Reacting to G7 calls for action in the wake of the 1994 Mexican crisis, the IMF created the SDDS to encourage member countries to begin publishing statistics on their economies in a standardized and timely manner. ${ }^{73}$ The IMF, the G7 and others saw the poor quality of Mexican data as one of the causes of the crisis, and believed that better data would improve market confidence. Shortly after creating the SDDS, which was designed for countries that were able to borrow from international financial markets, the Fund created a second general data dissemination standard (GDDS), which gave poorer states an incentive to develop their statistical capacities and publish the data that they obtained. Central to both standards is the technique of publicity: the strategy not only seeks to get countries to regularly publish their statistics, but also publicizes countries' compliance with the standards through an electronic bulletin board.

This same preoccupation with transparency and publicity characterized the second stage in the development of this standardizing strategy. In 1997, the IMF Executive Board sat down to discuss two staff papers, one on "Transparency in Government Operations" and the other on "Fiscal Policy Rules." The first of these papers discussed the value of transparency - not only in the provision of statistical information but also in the everyday fiscal activities of a state. ${ }^{74}$ The second document focused on the usefulness of fiscal policy rules - such as balanced budget rules, or a maximum budget deficit threshold such as the 3 per cent of gross domestic product (GDP) limit in the Maastricht treaty. ${ }^{75}$ In their discussions, IMF staff and directors focused on the problems of the kind of "creative accounting" used by some European Union countries in order to meet Maastricht rules. They expressed concerns about unintentional opacities - when a government does not have the capacity to provide the necessary information - and intentional forms, in which a government attempts to "escape public scrutiny of its behaviour - especially in the run-up to elections - in order to avoid or postpone possible adverse reaction from the electorate and from financial markets."

The outcome of these discussions was the next step in the creation of the standards and codes initiative. Although executive board members considered the possibility of integrating fiscal rules into their programs, they decided instead to take a less direct and more flexible approach to transparency. At an October 1997 meeting, the board asked Fund staff to compile current best practices into a manual that would be available to all members. By March of the following year, pressure from the G7 and various government leaders for more explicit guidelines was strong enough that the Fiscal Affairs Department drafted a more comprehensive 
code of conduct on fiscal transparency. The code emphasized the importance of providing timely and accurate information on the budget to the public, ensuring that the budgeting process was open and that there were independent audits of public accounts. ${ }^{77}$ Shortly after the code on fiscal transparency was approved in 1998, a second code on monetary and financial policies was developed.

The IMF Board and staff gradually developed techniques for monitoring compliance with the codes. ${ }^{79}$ This process initially took the form of experimental case studies, but eventually grew into the more standardized reports on observance of standards and codes (ROSCs). Like the SDDS and the GDDS, the ROSCs are based on the principles of voluntary compliance, publicity and market discipline. Both the adoption of the standards and codes and the publication of the ROSCs are voluntary. Staff and directors believed that peer pressure and a desire for market approbation would lead governments to adopt the standards and codes, and publish information on their compliance. They hoped that markets would provide a further crucial incentive by rewarding compliant states with lower borrowing costs.

The list of standards and codes continued to grow, ultimately including twelve different issue areas covering everything from accounting standards to bank supervision and the prevention of money laundering. ${ }^{80}$ The World Bank and the Fund together have responsibility for overseeing their implementation. What initially began as a rather modest effort to reform statistical capacities has thus grown into a vast array of standards covering a wide range of different aspects of political economic life.

\section{An analysis of standards and codes}

\section{$A$ new kind of universal}

The standards and codes initiative, like the good governance agenda, is a universalist strategy that seeks to promote new global standards of good political economic practice. Yet, once again, when we look closely, we find a visibly constructed universal at work, broader and more flexible than the rigid economic rules that defined the structural adjustment era.

As I discussed in the previous chapter, a particular small "i" idea credibility theory - was highly influential when the IMF Board was debating whether and how to develop new standards of economic practice. ${ }^{81}$ Advocates of credibility theory and the time inconsistency problem argue that as long as governments are able to revise the policies that they committed to earlier, they will not be seen as credible by market actors, and will therefore find their efforts at constructive market intervention undermined; in such circumstances, the only credible alternative 
is for the government to relinquish much of its policy discretion and commit to binding rules. ${ }^{82}$ This is seen as a universally applicable axiom, since it is assumed that all rational market participants will recognize good or bad economic policy, and therefore judge the credibility of a government's actions accordingly.

The fiscal rules paper that the IMF Board discussed was particularly explicit in its reliance on both public choice and credibility theory to justify the application of universal rules that would bind governments' hands. ${ }^{83}$ In the end, the Board decided not to adopt fiscal rules as their primary technique for fostering standardization. Yet the logic of credibility remained central even as they developed more flexible techniques for achieving their ends. Staff believed that fiscal transparency and the publication of the ROSCs would have a similar effect on credibility, by providing markets and the public with additional information on fiscal plans, reducing governments' leeway to back-track on policies, and thus increasing their credibility. ${ }^{84}$

Although technical expertise served as the primary grounds for justifying the universality of these new standards, this was a different universal claim from those underpinning the economic rules of the structural adjustment era. Credibility theory relies on a more contingent kind of universal from those in traditional neoclassical theory - or rather, credibility theory makes the symbolic and performative dimensions of economic universals more visible. As I noted in the previous chapter, the very acts by market participants that are supposed to be signals of objectively credible or non-credible policy actually create or undermine policy credibility. ${ }^{85}$ For example, an inward flow of foreign capital, which is often seen as a sign that a government's policies are credible, actually generates that credibility by providing the government with resources that enable it to keep its promises, while an outward flow of capital has the opposite effect. Similarly, the role of external experts who are often imported to play key roles in monetary institutions do not simply verify and communicate a government's latent credibility, but actually help to create it through their presence as symbolic markers of Western economic expertise.

These standards and codes are not only more performative but also far broader in their scope than past economic norms - defining best practices in the fields of auditing and accounting, corporate governance, money laundering and terrorist financing, to name a few. In their effort to justify a move into these new domains, the IMF leadership, like the World Bank, moved beyond a narrowly technical discourse and began to frame the policy in moral terms. Horst Köhler, the managing director of the IMF during the early years of the initiative, suggested "While standards and codes deal with highly technical matters, there is nothing 
narrow or technical about their purposes." 86 Michel Camdessus, Köhler's predecessor, also suggested that universal standards could help to "civilize globalization" by creating new "rules of the game" to tame the wilder excesses of the global economy. Given the interdependent character of that global economy, Camdessus argued, "a duty of universal responsibility is incumbent upon all. Every country, large or small, is responsible for the stability and quality of the entire world growth." 87 These new universals are therefore not only more symbolic and performative than their predecessors, but also more complex in their justification, relying on both technical and moral appeals to their universality.

\section{More performative techniques}

An interesting aspect of the standards and codes initiative is the way in which its creators sought to put the policy into practice through new and innovative techniques. The key technique at the heart of the standards and codes initiative is the ROSC. This technique was developed through an experimental process in which IMF staff undertook several case studies in a range of different countries, published their findings, and solicited public feedback. The IMF Board initially deemed these "experimental ROSCs" a success, but continued to advocate a "gradual and interactive approach" in developing the Fund's involvement in standards. ${ }^{88}$

As their name suggests, ROSCs are reports: they are inscriptions that seek to translate the messiness of a country's strengths and weaknesses into a single document. They were intended to establish "best practices" in a range of areas from corporate governance to banking regulation, and to benchmark individual countries' performance in each of these areas. Part of the goal behind these benchmarks is to enable governments to assess their own progress over time. Once the ROSCs are published, however, their role shifts significantly and credibility becomes key, as an early IMF report notes:

By highlighting actual practices and identifying those in need of improvement, transparency reports could reduce the likelihood that market participants are uninformed or misled, and enhance the credibility of those national authorities following sound practices. ${ }^{89}$

The role of ROSCs as inscriptions is thus not only to translate complex economic and political actions into a single document, but also to signal good (or bad) economic practice to market actors. Like the conditions I discussed in the last chapter, standards and codes are not only important because of what they are (guidelines for best practice) but because of what they signal through the ROSCs. Their value is increasingly symbolic and it is through that symbolic role that they do their most important 
work: IMF staff and management believed that this signalling would have significant material effects, as those interested in buying government bonds would pay attention to ROSCs and reward good economic performers with lower borrowing costs. ${ }^{90}$

Although many policies based on credibility theory, such as fiscal policy rules, ignore or downplay the performative character of the policy, advocates of ROSCs were highly reflexive about the performative nature of this kind of signalling device, seeing the reports not simply as descriptions of an objective reality but as tools for creating the kind of selffulfilling cycle that pushes countries towards more "credible" policies.

\section{New actors and sites of authority}

These new techniques rely for their effectiveness on the active involvement of a range of actors: not only the IFI staff who conduct the evaluations, or the member government actors who are to use the benchmarks established, but also civil society and market actors who, it is hoped, will pay attention to the ROSCs and reward good performers.

As in practices to foster good governance, information, publicity and transparency are the key mechanisms through which these new actors are to be informed and enrolled. As I have discussed elsewhere, although a policy of transparency may appear to be minimalist, its objectives are not. ${ }^{91}$ Take the two data standards discussed earlier: although the SDDS and the GDDS seem highly specialized and technical, they are important for several reasons. They frame the problem of economic governance in terms of the quality of information. They also seek to constitute a particular capacity to obtain and communicate that information, particularly among emerging and developing countries. ${ }^{92}$ And in providing that information they also hope to influence not just the actions of government, but also those of civil society and market actors, by providing them with the information that they need to keep the government in check. This same logic underpins the other standards and codes. As the introduction to an early draft of the code on fiscal transparency put it:

Increased fiscal transparency should lead to better-informed public debate about the design and results of fiscal policy, make governments more accountable for fiscal policy and management, and thereby strengthen credibility as well as mobilized popular support for sound macroeconomic policies. ${ }^{93}$

The standards and codes initiative thus seeks, like the good governance agenda, to redefine the relationship among state, market and public actors. Here again we see a new emphasis on the demand side of governance, and an effort to redistribute some governance authority based on the belief that market and public actors can pressure governments to act 
in certain ways. Although one might argue that these assumptions about the superior rationality of the market and the public are rather naive, it is important to note that the goal of fiscal transparency is not simply to rely on existing public actors but also to educate them about the budget, thus constituting a more informed and active public citizenry. This belief in the importance of external scrutiny is key to the particular form of power that the standard and codes initiative relies on.

\section{More indirect power}

What is perhaps most striking about the standards and codes initiative is its almost exclusive use of indirect forms of power. Although there were wide-ranging debates both within and outside the IMF about whether the new standards and codes should be mandatory or voluntary, those who believed in the power of peer pressure ultimately won the day. ${ }^{94,95}$ Underlying this informal strategy was the assumption that it was in states' interest to adopt the new standards and codes. Thus, Köhler argued, "While it is still early in the game, there is already evidence that meeting standards can pay off," as investors reward good behaviour with lower borrowing costs. ${ }^{96}$ No need for the IMF or World Bank to use the blunter instrument of conditionality to achieve their desired goals.

The forms of power involved in making the standards and codes initiative work are also clearly productive: the goal is not simply to make government actors behave in certain ways, but to give them new tools statistical capacities, best practices and benchmarks - to enable them to see and calculate their actions and objectives in new ways. In Michel Callon's terms, the strategy is one that seeks to generate a particular kind of economic society by fostering new calculative capacities. ${ }^{97}$ This is therefore also a proactive strategy: while transparency is partly an end in itself, more importantly it is a means to encourage market and civil society to pressure governments to achieve longer-term goals of economic policy change.

Who gets to decide what count as "best practices" of fiscal and monetary policy? As the initiative's critics - academics, NGOs and emerging market leaders - were quick to point out, the process for establishing these news standards was exclusive, and largely based on Western, freemarket principles. ${ }^{98}$ Moreover, as Ilene Grabel notes, although scholars and policymakers generally insist that credible policies (low inflation, low taxes, minimal government involvement in the economy) are timeless and universal, they are instead based on neoliberal values, and tend to support a particular set of economic interests. The process of fixing these particular economic values as the standard also devalues alternative forms of political and economic policy as non-credible and therefore not viable. ${ }^{99}$ Although the mechanisms through which these valuations 
of better and worse policy are therefore far subtler than a fiscal rule or strict conditions, their effects are nonetheless to grade and rank country practices according to Western norms.

\section{A more provisional kind of governance}

Both the good governance agenda and the standards and codes initiative involve a significant shift in how the IFIs govern through, and in the name of, universals: the universal economic rules of the structural adjustment era have been supplemented by a more reflexively constructed and justified set of global standards. In the process, universals based on technical expertise have been combined with moral and popular ones, new actors have been enrolled and authorized to play a role in governance, more performative techniques have been developed, and more indirect and productive forms of power deployed.

As standardization has gradually colonized new terrains of global life, so has the influence of technical expertise. Yet the evolution of this new strategy of standardization has been far messier and fragile than a narrow focus on technical expertise would indicate: IFI leaders have had to bolster their technical justifications for the standards with normative claims, changing the character of the standards themselves in the process. ${ }^{100}$ Although we might expect a strategy of standardization to be a classic example of the spread of technical expertise to new areas of social, political and economic life, what we find is a more complex picture, in which governance and the expertise that underpins it have changed in form and become more provisional: more proactive, indirect, symbolic and aware of the possibility of failure.

The IMF and World Bank Executive Boards both considered and rejected the option of enforcing these new standards using more direct techniques, opting instead for an indirect approach that works through the publication of performative inscriptions and the pressure of market actors, civil society and peer states to achieve its ends. The techniques involved are also proactive, playing the long game: both policies seek to use these less direct pressures to change the cultures of borrowing country governments, markets and civil societies, giving them new tools and new incentives to pursue the changes sought by the IFIs.

These standards are not only more flexible than the economic rules that they supplement, but also more visibly constructed and symbolic in form. Because their subject matter is more complex and contested, the assumptions and biases that go into a standard of good governance or transparent fiscal policy are more visible than those that underpin the rules of sound economic policy. They are therefore harder to naturalize 
and black-box. At the same time, the role played by these standards is increasingly symbolic - aimed at signalling credible government intentions, whether to civil society actors or market investors. Whether in the form of the Doing Business Indicators, government "report cards" or ROSCs, these policies all rely on a kind of inscription designed to translate complex on-the-ground realities into a signal of good or bad state behaviour. In a context in which transparency, information and publicity are key techniques, it is this signal that does the real work of encouraging further government compliance: enrolling external actors in the business of pressuring, punishing and rewarding governments.

These new governance practices were developed in response to particular interpretations of the failures of international development and finance. At the same time, the provisional character of the standardization strategy enables IFI staff and leaders to avoid certain kinds of failure. The indirectness of these governance practices creates considerable distance (and thus deniability) between IFI policies and their effects. Moreover, the policies' proactive effort to give more authority to governments for ensuring their own compliance with the standards also transfers to borrowing countries much of the responsibility for failure.

In spite of these pre-emptive tactics, IFI staff and management continue to be aware of and preoccupied with the strategy's limits. I will discuss the challenges faced by the standardization strategy at some length in the Conclusion to this volume. They include the gradual unravelling of the compromise that these standards represent - with some seeking to return to hard and fast rules, while others argue for an even more contextual and flexible interpretation of governance norms. These challenges also include some very real practical difficulties in the operationalization of the inscriptions as, for example, the market actors who were supposed to pay attention to the ROSCs have tended to ignore them entirely, thus eroding their performative effectiveness. These limits have in turn ensured that the strategy's advocates have had a hard time blackboxing these standards, leaving them open to ongoing contestation.

While the standardization strategy remains highly influential today, neither it, nor the strategy of ownership, have managed to fully resolve the problems of institutional authority posed by the contested crises of the 1990s. These two early provisional strategies have been followed, however, by two newer strategies designed to tackle more explicitly the epistemological and ontological problems of earlier governance practices. By measuring results, IFI actors are developing a new epistemological foundation for assessing development financing. And by managing risk and vulnerability, the subject of the next chapter, they are developing a new ontology of poverty, debt and the unknown. 


\section{$7 \quad$ Managing risk and vulnerability}

In the past two decades, international organizations (IOs) and donors have become increasingly aware of the uncertainty of the global environment and the contingency of policy time. All organizations' actions have an implicit temporal logic and a set of assumptions about the unknown. In the early days of development finance, as I discussed in Chapters 3 and 4, institutional actors generally assumed that policy time was relatively linear and uncertainty reasonably manageable, with progress achievable over time. ${ }^{1}$ As the international financial institutions (IFIs) and donors began to pursue more complex and longer-term structural adjustment policies in the 1980s and early 1990s, they encountered more surprises and disappointments and began in response to manage their policies over a longer period of time. Yet these early shifts in the conception and management of policy time were relatively minor, gradually extending time horizons rather than profoundly rethinking the challenges of the unknown.

It is only in the last fifteen years or so that these organizations have really changed the way they manage policy time, treating it as increasingly uncertain and volatile. Why this shift in thinking and practice? The easy answer is that international actors were literally shocked out of their linear conception of time by three key crises: the AIDS crisis in Africa, the Asian financial crisis, and the more recent global financial crisis. Each was a highly visible shock to the system that made it clear that the unexpected could occur with devastating consequences. Yet it was not these events alone that changed how IFIs conceptualized and managed the unknown, but rather how they were interpreted and acted upon. As I have suggested throughout this book, organizational actors are often concerned with the problem of policy failure: what counts as failure, what causes it, and how to resolve it. The shocks of the 1990s raised the spectre of a particular kind of failure: that caused by the sheer unpredictability of the social and physical world. The AIDS crisis and the Asian crisis both forced many people back into poverty after they had just climbed out of it, reversing decades of effort by the World Bank, non-governmental 
organizations (NGOs) and donors. The Asian and global financial crises also put at risk low-income countries' (LICs) efforts to reduce their debt burdens with the help of policies like the highly indebted poor countries (HIPC) initiative. ${ }^{2}$ Policies once deemed successes were suddenly put into doubt, raising questions about the expert authority of the institutional actors behind them.

These unsettling events sparked a process of problematization, as scholars, practitioners and critics debated how to manage these more volatile problems. In the process, IFI and donor actors began to redefine the process of attaining policy goals such as poverty and debt reduction as more dynamic and uncertain. What has been going on is no less than a change in their ontology: they began to view the world with which they were engaging in very different terms, seeing poverty, debt and economic health as more volatile phenomena. Moreover, they began not only to view the objects of their efforts differently, but also to develop new techniques for managing them. Central to these new governance practices were two concepts: risk and vulnerability.

As I have discussed elsewhere, ${ }^{3}$ risk is not as an objective thing but a way of translating the unknown into something calculable. ${ }^{4}$ Risk assessment techniques allow institutional actors to evaluate the likelihood of certain problems, to convert their assessments into numbers, and to reduce those risks (in theory, if not always in practice). ${ }^{5}$ Much has been written in recent years about the increasing prevalence of the idea of risk and risk management in almost every area of modern life, from finance to security to the environment. ${ }^{6}$ It should therefore come as no surprise that the IFIs and donors have also begun to think about the risks of development finance. As I discussed in Chapter 4, staff in the World Bank's Operations Evaluation Department (OED) began to evaluate program risks beginning in the mid-1990s in an effort to increase success rates. ${ }^{7}$ The International Monetary Fund (IMF) also began to pay more attention to the problems of financial risks in the late 1990s, introducing its Financial Sector Assessment Program (FSAP) in the aftermath of the Asian financial crisis.

In the late 1990s and particularly after the 2008 global financial crisis, the IMF, World Bank, Organisation of Economic Co-operation and Development (OECD) and donors like the United Kingdom's Department for International Development (DFID) had also become interested in a second related concept: vulnerability. Whereas many of the initial risk-management policies focused on reducing the risks to the lenders' own programs, the concept of vulnerability shifted the focus to potential difficulties faced by others - both countries and individuals. ${ }^{8}$ It is these two concepts - risk and vulnerability - that I will focus on in this chapter. 
In the mid-2000s, the IMF and World Bank began focusing on LICs' vulnerability to risks associated with excessive debt; a few years later, after the global financial crisis, the IMF started evaluating poor countries' vulnerability to further shocks. The World Bank, followed by DFID and the OECD, also began in the late 1990s focusing on the vulnerabilities faced by poor people. Rather than relying on traditional social welfare policies, World Bank staff adopted a new, more proactive strategy for social protection designed to prepare poor individuals and families to respond more effectively to risks, transforming "safety-nets into springboards." ${ }^{9}$ These policies not only brought together the concepts of risk and vulnerability but also extended them to the country and individual level in order to reduce the likelihood of failure in an increasingly uncertain context.

This new institutional attempt to govern risk and vulnerability is a meso-level phenomenon that cuts across a range of organizations and actors, and is therefore a very appropriate subject for the theoretical framework that I develop in this book. Although the policies that I will examine in this chapter - debt vulnerability assessments, vulnerability assessment exercises, and the social risk approach to social protection are all quite different, they involve similar changes in the ideas, actors, techniques and forms of power and authority involved in governing. These new policies focused on risk and vulnerability emerged out of separate processes of debate and problematization; yet the ideas that ultimately underpinned the new policies have all drawn on institutionalist economics and public choice theory. And although these policies aim to enrol very different actors in governing risk - national governments or poor individuals - they both seek to make those actors more active and selfresponsible, drawing them more deeply into the process of global governance. The techniques involved in both social risk frameworks and vulnerability assessments are designed to be performative, promotive and pre-emptive, preventing rather than simply reacting to shocks. The strategy of managing risk and vulnerability also distributes expert authority more widely and supplements it with more popular forms. Finally, these policies mobilize indirect forms of power to achieve their ends, working to produce particular kinds of actors and behaviours, differentiating among different classes of states and individuals, and excluding those who do not fit.

Increased efforts to manage risk and, above all, vulnerability, point towards the emergence of a more provisional style of global governance. At the heart of this new form of governance is a more reflexive preoccupation with the problem of failure, and increasingly sophisticated strategies for managing it. These strategies for managing risk and vulnerability are both more pre-emptive and indirect in their relationship with 
their objects, seeking to prevent failures before they manifest themselves. It is also provisional in its increasing reliance on more symbolic and therefore contestable techniques, as it seeks to translate increasingly complex phenomena into simple indexes. Finally, this new strategy is provisional because its practitioners are also increasingly cautious: less ambitious than past initiatives in their efforts to predict and respond to crises, thus hedging against the possibility of failure.

\section{Assessing poor countries' vulnerability to shocks}

Once institutional actors began to see the world as a less certain place, they sought new ways of making sense of it by developing new practices for determining the kinds of shocks that might occur and for predicting their likely consequences. Despite a long history of surveillance at the IMF in particular, it was only after the most recent 2008 global financial crisis that serious attention was directed towards assessing the financial risks faced by LICs. ${ }^{10}$ All of the new policies on risk and vulnerability discussed in this next section were designed to better understand the risks facing LICs and the vulnerabilities that are likely to affect their response to shocks.

\section{Understanding the shift}

Why the increased interest in the effects of global economic shocks on low-income countries? While several crises played a role in precipitating this new concern, the particular policies that emerged were the result of a more gradual process of problematization and debate that included economists, institutional actors and external pressures.

Part of this process of problematization was a shift in thinking both within and around the IFIs, as policy-oriented economists began to pay more attention to the problem of economic volatility. ${ }^{11}$ An increasing number of economists and policymakers began to recognize that extreme volatility was not an aberration in an otherwise smooth global economic system, but was increasingly the norm; as Craig Burnside put it in a research paper prepared for the World Bank, "one of the shortcomings of fiscal sustainability analysis is that it often does not take into account the effects of uncertainty." 12 Economists including Burnside and Claudio Raddatz also began to write about the importance of exogenous shocks for LICs' economic development, examining the effects of increased external volatility. Such shocks had become more of a concern in recent years, Raddatz argued, because LICs' macroeconomic and institutional policies had improved significantly, reducing the role of domestic factors, 
but greater integration into the global economy had made them more vulnerable to external pressures. ${ }^{13}$ Economists also began to recognize the very serious consequences of external shocks on LICs, since these governments and their citizens had fewer resources to draw on, making it much harder for them to recover. ${ }^{14}$

In addition to identifying volatility and shocks as universal challenges for low-income countries, policy experts began focusing on a second related problem: the crucial differences among LICs' ability to respond. Whereas in the past, LICs were seen as a relatively homogeneous category with a few exceptions that could be addressed through ad hoc measures, the crises of the 1990s and 2000s made it clear that the same external shock could have very different effects on different countries. Economists like Dani Rodrik, Paul Collier and Daron Acemoglu began to investigate the reasons for these differences. Although their answers varied, they all emphasized structural and institutional (even political) factors as key determinants' of countries' resilience in responding to shocks. ${ }^{15}$ These findings suggested that any attempt to assess countries' vulnerability to shocks and propose ways of reducing them would have to differentiate between stronger and weaker countries. No single approach would be likely to work.

Institutional dynamics and external political pressures also played roles in the debates about how to address risk and uncertainty, revealing some significant differences of opinion among key actors. Several of these new policies sought to determine how much debt LICs could sustain: a low-risk classification meant access to additional non-concessional financing, while a high-risk rating severely limited such options. ${ }^{16}$ During debates about the new policies to manage debt-vulnerability, Executive Directors from low-income countries and NGOs were faced with a dilemma: they wanted the IFIs' policies to be more flexible, to allow poor countries to take on more debt to fund crucial domestic priorities, but they were concerned that donors would use LICs' right to borrow more on non-concessional terms as an excuse to cut back their concessional aid. ${ }^{17}$ There was also considerable ambivalence among some IMF Directors about the very idea of classifying countries based on their debt vulnerability: as one senior IMF staff member put it, one of the mantras of the Board was that "we are not a ratings agency." The staff did manage, however, to slip this policy through. ${ }^{18}$

The crises of the 1990s and 2000s precipitated a process of debate and negotiation that ultimately problematized the effects of shocks and volatility for LICs. These dynamics combined with both institutional and political pressures to set the stage for a series of new policies designed to cope with LICs' vulnerability in an increasingly volatile global economy. 


\section{Three new policies}

As they began to focus more on LICs' vulnerability to external financial shocks, Fund and Bank staff developed or revised a number of their policies. The first serious initiative to address the problem of LIC vulnerability was the World Bank and IMF's development of a joint debt sustainability framework (DSF) in 2005. ${ }^{19}$ This framework was designed to assess the extent to which poor countries are capable of taking on nonconcessional loans without going into debt distress. The key policy technique used is the debt sustainability analysis (DSA), which rates LICs' risk of such distress: low, moderate, high or in debt distress. ${ }^{20}$ Staff analyse countries' projected debt burden over the next twenty years, taking into consideration the possibility of significant shocks. They then use the country policy and institutional assessment (CPIA) as a basis for determining whether the country is likely to be able to manage that level of debt. ${ }^{21}$ As I discussed in Chapter 6, the CPIA was developed by the World Bank to quantify poor countries' economic performance. Today, over two-thirds of the score is based on governance-related criteria, and the IFIs and some donors often use the index as a proxy for institutional capacity - i.e. as a measure of a government's ability to manage economic resources and respond to problems effectively. ${ }^{22}$

This debt sustainability analysis process has several effects on borrowers. IFI staff hope that DSAs will provide borrowing countries with more information so that they can "monitor their debt burden and take early preventive action," and "provide guidance to creditors" so that they will lend in a way that is "consistent with countries' development goals.", More concretely, the ratings are used by the World Bank to determine the mix of loans and grants for International Development Association (IDA) recipients. ${ }^{24}$ In 2009, IMF staff also revised their guidelines on external financing for LICs, making them more consistent with the DSA approach. In the past, the IMF had strictly limited LICs' access to non-concessional financing as a condition for their loans, fearing that they would borrow more funds than they could reasonably pay back. ${ }^{25}$ Fund staff did allow for a measure of flexibility through case-by-case exceptions, but otherwise treated LICs relatively uniformly. The new guidelines are more flexible about external financing by differentiating among different low-income country situations. The main criteria used are the level of countries' debt vulnerability (determined using the DSA discussed above), ${ }^{26}$ and their "macroeconomic and public financial management capacity." 27

A country's capacity is defined in terms of the strength of its institutions, but somewhat more narrowly than the DSA; rather than using 
the full CPIA to assess capacity (an idea that some IMF Directors resisted on the grounds that it was too broad), IMF staff use a "subCPIA" based on five components of the index, together with another index, the public expenditure and financial accountability (PEFA) framework. ${ }^{28}$ The IMF's rating process operates like a matrix, scoring countries as either higher or lower in both debt vulnerability and capacity, and then establishing limits on external borrowing on that basis. The lower a country's vulnerability and the higher its capacity, the more non-concessional funds they are allowed to borrow without losing access to IMF financing.

The IMF has also recently developed a third set of policies aimed at managing risk and vulnerability: "vulnerability assessment exercises" designed to determine how different low-income countries would be affected by different exogenous shocks. The assessments combine both quantitative and qualitative assessments. In the first quantitative stage, staff assess countries based on their analysis of the likely effects of certain kinds of shocks (e.g. financial, commodity price, etc.) combined with a vulnerability index. This vulnerability index once again includes the CPIA as one of its key indicators of countries' vulnerability. ${ }^{29}$ The second, qualitative, stage of the process brings IMF area departments in to provide their judgment on the specific challenges facing individual countries. The goal of these assessments is to identify potential problems "before they materialize" by uncovering underlying vulnerabilities that are likely to amplify the impact of shocks. ${ }^{30}$

The thinking behind the three policies discussed above and the techniques involved in each are somewhat different; yet all are characterized by common conceptions of the volatility of policy environments and of the nature of risk and vulnerability, parallel concerns with evaluating and ranking LICs' vulnerability, and a similar reliance on institutional criteria (chiefly the World Bank's CPIA) to do so.

\section{Changing governance factors}

What is striking about the documents on these new policies is their continual references to the fact that we now live in unsettled times in which volatility, uncertainty and shocks are an ever-present possibility. This new emphasis on risk and vulnerability involves an ontological change: from a conception of the world as relatively stable to one that is far more changeable, and from a conception of policy time that is linear to one that is far more uncertain and unpredictable. It should come as little surprise that the ideas, actors, techniques and forms of power needed to govern such a world are themselves also in the process of changing. 
Small " $i$ " ideas

Economists' and policymakers' attention to the role of external factors in determining poor countries' economic success is in sharp contrast with earlier reports like the 1981 Berg Report discussed in Chapter 3, or the 1989 report on sub-Saharan Africa discussed in Chapter 6, both of which blamed most of LICs' difficulties on their own economic mismanagement and poor governance. ${ }^{31}$ This does not mean that these new policies ignore the role of domestic institutions. Instead, economists and policymakers have begun to study the interaction between internal institutional factors and external economic pressures - hence the continual emphasis on countries' "capacity" to manage risk. Those economists whose work inspired and justified these new policies - including Collier, Acemoglu and Rodrik - all draw on institutionalist economics and public choice theory in order to explain the central role of institutions in determining countries' vulnerability to external shocks. ${ }^{32}$ Acemoglu, for example, draws on a public choice conception of political institutions to argue that weak property rights and rule of law, and lack of social entitlement, allow selfinterested elites to expropriate resources from the economy, producing increased economic volatility. ${ }^{33}$ Both Collier and Rodrik, in different ways, link institutional factors to vulnerability to external shocks, Collier focusing on macroeconomic structural factors, and Rodrik emphasizing the importance of political institutions for managing social conflict. ${ }^{34}$

Several things are worth noting about the influence of these two small "i" ideas - new institutionalist economics and public choice theory - in the development of IFI policies on risk and vulnerability. First, these policies clearly continue the trend that I have discussed throughout this book of bringing institutions into the heart of development thinking and practice at both the World Bank and the IMF. Yet the way that they do so is also distinct from the good governance and ownership strategies discussed in previous chapters. Whereas these other strategies sought explicitly to act on and change institutional practice, the risk and vulnerability assessments have a more minimalist approach - using institutional capacity as a criterion for allowing extra borrowing and only very indirectly seeking to influence institutional quality. This minimalism is reinforced by the reliance on the CPIA as a technical proxy for institutional strength, as the messiness of good-quality institutions gets translated into a single number - the ultimate "black box" in Michel Callon's terms.

The IFIs' increased recognition of the role of institutions and their acknowledgement of the risks and vulnerabilities faced by poor countries indicates a growing awareness of the complexities of governance efforts. Yet the very thin way in which IFI staff have understood these 
concepts works to domesticate the difficult and the unknown, making it tractable, if not fully predictable.

\section{Actors}

All three policies seek to engage LIC actors more fully in managing their own risk and vulnerability, and differentiate more clearly among various categories of low-income countries and their respective capacities. The vulnerability assessment exercises are designed to provide LICs with better information to enable them to take "pre-emptive policy action to reduce vulnerabilities." 35 By increasing the flexibility of the limits on external borrowing by LICs, IMF staff are even more ambitious about encouraging a more active role by low-income governments, noting that "over time, an increasing number of LICs would be expected to move to the more flexible and sophisticated approaches as their macroeconomic and public financial management capacity improves." 36 They thus seek to shift more of the responsibility and authority for managing debt portfolios to "capable" LICs.

This emphasis on different capacities is nonetheless worth noting: lowincome countries are to play a bigger role "as their macroeconomic and public financial management capacity improves." These new policies on risk and vulnerability not only seek to involve some LIC actors in the process of government, but they also seek to sort them according to their capacity to do so. One of the defining features of all three of the policies discussed here is their attention to the question of how to differentiate between low- and high-risk countries, between those who can borrow what they need and those who cannot. Not only do these policies therefore seek to enrol more active participants in financial governance, but they also work to discriminate between those more and less able to take on this new role. This new strategy to govern risk and vulnerability therefore involves a reconceptualization of the ontology not only of the global environment but also of individual actors themselves.

\section{Techniques}

These new policies on vulnerability and risk seek to pre-empt or prevent the worst from occurring, all the while preparing for it, just in case. The debt sustainability framework is "aimed to help countries monitor their debt burden and take early preventive action" before it becomes unsustainable. ${ }^{37}$ The vulnerability exercises are similarly designed to be "pre-emptive," allowing IMF staff and country authorities to address underlying vulnerabilities before they become too serious. ${ }^{38}$

Particular kinds of techniques are required to act pre-emptively in the face of such unknowns. The first set of techniques imagine the possible 
risks that could arise; in both the DSAs and the vulnerability exercises, this is done through "scenario analysis," a process that involves projecting possible futures with a range of different degrees of volatility. The vulnerability exercises in particular include assessments of "tail risks" highly unlikely but extreme events that were largely ignored until the 2008 financial crisis. ${ }^{39}$ As Marieke De Goede has argued, this kind of scenario analysis is a form of "premediation" in which policymakers seek to imagine and prepare for extreme unknowns. ${ }^{40}$ The second set of techniques evaluate countries' vulnerabilities to such shocks and translate these assessments into inscriptions to guide policy, including various scores that identify countries as lower or higher risks (of course, these scores depend in turn on prior inscriptions like the CPIA).

The third set of techniques for managing risk and vulnerability bear important resemblances to ones discussed in earlier chapters: techniques for monitoring and communicating countries' levels of vulnerability. In all three of the policies discussed here vulnerabilities are monitored on an ongoing basis. In the case of the vulnerability exercise, regional assessments are published while country-specific information is shared only between the IFI and the country, for fear that the markets might overreact to a negative assessment. For the two debt assessment policies, on the other hand, the evaluation process is very public: countries' DSA scores are communicated widely to donors, IOs and market actors.

These are highly symbolic practices that parallel both ownership and standardization strategies by emphasizing the signalling power of risk assessment scores. As the IMF's factsheet on the DSA notes, "The effectiveness of the DSF in preventing excessive debt accumulation hinges on its broad use by borrowers and creditors." ${ }^{41}$ The goal is to get as many lenders as possible to use DSA ratings in their decisions about whether and on what terms to lend to LICs. ${ }^{42}$ DSAs are thus performative inscriptions: they not only signal better or worse country conditions, but in doing so mobilize key actors to act on the basis of these signs.

\section{Power and authority}

IFI staff and Directors' efforts to engage LICs more actively in managing their own risks and vulnerability, as well as their attempts to encourage donors and other lenders to use key inscriptions like the DSA, both point to indirect and productive forms of power. As one senior IMF staff member put it, the goal of the IMF's new ranking system is to encourage countries to deal more effectively with their debt through "peer pressure"a technique that mirrors the logic behind the standards and codes initiative. In fact, IMF staff hope that the publication of the IMF's risk ratings will work the same way as the World Bank's "Doing Business" 
index, to which low and middle income countries pay very careful attention, trying to move their way up the rankings. ${ }^{43}$ This is a very indirect form of power: IFI staff seek to change behaviour by publishing information in a highly stylized form, creating a tool - a way of assessing and sorting LIC economies - that others can use. Although the ultimate goal is to foster more responsible behaviour by LICs, the means to that end is through the decisions of other actors who, it is hoped, will lend more to good performers and less to poor ones.

These assessments are a perfect example of expert authority: they are highly technical; they translate complex political and economics realities into a set of simplified ratings; and they are carefully justified through staff's repeated emphasis on the objectivity and neutrality of the processes involved. ${ }^{44}$ These new policies clearly work to re-establish IFI staff authority as experts on risk and vulnerability in the wake of the crises of the late 1990s and 2000s. Yet these new policies also seek to distribute that authority more widely: by enrolling "good" low-income governments in managing their own vulnerabilities and by encouraging donors, IOs and other lenders to use the rankings in their decisions about countries' credit-worthiness.

This is not a zero-sum process where IFIs lose ground to other actors, but rather a more complex way of reorganizing the authority to govern. ${ }^{45}$ For example, although Fund staff and Directors recognize that their new borrowing limits will reduce their more direct influence over many LICs, they also note that "the gate keeping function has led to the perception that the Fund is an obstacle to financing for development;" shifting that function to capable LIC governments will therefore increase the institution's legitimacy. ${ }^{46}$ The staff also note "This is why it is critical that these options be used only in countries with high capacity." ${ }^{47}$ In other words, this authority can only be shared with the "right" actors - those already demonstrating similar priorities and practices as the IFIs themselves. The legitimacy of this strategy for managing risk and vulnerability, like the other governance strategies discussed in this book, thus rests on a particular combination of expert and popular authority. The goal is ultimately to disseminate the expertise embodied in these ratings so that a wide range of non-IFI actors, including the low-income governments themselves, can play a more central role in the governance process.

This less direct form of power is in stark contrast to the institution's traditional "gate keeping" role: in the past, governments were forced to comply with the Fund's determination that they were not in a position to borrow externally if they wanted IMF financing. ${ }^{48}$ Even as the IMF's own resources constituted a smaller proportion of official assistance over time, this gate-keeping role hugely leveraged their influence over 
borrowing countries' financial activities. Yet, the institution has not entirely given up this tool - merely reduced its scope to those countries as yet "incapable" of taking on this role for themselves. A country's rating has some very direct consequences: a higher-risk rating means that the IMF retains its gate-keeping role, limiting the opportunity for a government to borrow, effectively reducing their ability to invest in social and physical infrastructure.

More subtly, these various vulnerability assessment processes are all tools for differentiating - discriminating - among LICs. While this is not a black and white, inside and outside form of exclusion, it nonetheless operates as what Giorgio Agamben has called a form of inclusive exclusion. ${ }^{49}$ Some are excluded from the possibility of additional borrowing by virtue of their location at the very bottom of the ranking system; yet they are still a part of that system - the least capable against whom better performers are compared.

\section{Redefining poverty as social risk and vulnerability}

While some of the IMF's new policies have conceptualized poor countries as vulnerable to the risks of a more volatile global environment, the World Bank has taken this insight even further and began to see poor people in similar terms. Through their reconceptualization of poverty as social risk, key actors in the Bank's Social Protection Unit have redefined poverty as a more dynamic and uncertain phenomenon, and developed provisional governance strategies aimed at pre-empting potential failures in poverty reduction efforts. This risk-based approach to poverty has since been taken up by the OECD and DFID. ${ }^{50}$

\section{Understanding the shift}

Although the World Bank now views poverty reduction as its most important goal, this has not always been the case. In fact, Bank staff and leadership have treated the problem of poverty in a wide variety of ways over the course of the institution's history. ${ }^{51}$ As I discussed in Chapter 3, Robert McNamara was the first Bank President to seriously challenge the trickle-down approach to poverty adjustment, treating poverty reduction as a distinct challenge requiring its own programs. ${ }^{52}$ By the 1980s, however, under the leadership of A. W. Clausen as President and Anne Krueger as Chief Economist, the Bank's focus shifted heavily towards growth, which it sought to achieve through liberalization, privatization and structural adjustment - a triumvirate of policy prescriptions that came to be known as the Washington Consensus. ${ }^{53}$ Poverty 
dropped largely from the agenda. Where it did appear, the assumption was that growth would resolve it: the trickle-down thesis had made a comeback.

In 1987, UNICEF published a highly critical report, Adjustment with a Human Face, detailing the social costs of structural adjustment, sparking a broad debate on the Bank's policies. ${ }^{54}$ It was in this context that the 1990-1 World Development Report (WDR), Poverty, was prepared, a report that sought to outline the Bank's renewed strategy for tackling poverty. ${ }^{55}$ Despite its nod to some of the costs of adjustment for the poor, the 1990-1 WDR remained a product of the structural adjustment era. The report proposed a two-pronged strategy for reducing poverty: enabling the poor to use their principal "asset," labour, more effectively, and increasing the productivity of that asset, through education, primary health care, family planning and nutrition. ${ }^{56}$ As the report points out, these policies are consistent with the objectives of structural adjustment, as they both seek to use labour more efficiently. ${ }^{57}$ The report includes a chapter on transfers and safety nets, but treats them as a peripheral part of the poverty reduction strategy designed primarily for those too ill, old or remote to participate in growth. ${ }^{58}$

This structural adjustment-friendly approach to poverty held sway for some time, but it eventually came to be contested and replaced. The dynamics underpinning this shift were similar to those discussed above, with contested failures leading to a process of problematization and renegotiation, as policy-oriented economists and internal actors struggled to redefine both the problem of poverty and the way to respond to it.

Three key failures played a crucial role in precipitating the shift to a new poverty reduction strategy: the lost decade, the Asian crisis and the AIDS crisis. The persistence of poverty in regions including sub-Saharan Africa, in some cases despite growth in gross domestic product (GDP), challenged Bank economists' assumptions about the straightforward link between growth and poverty reduction. The effects of the Asian crisis, including the sudden immiseration of huge swathes of the population that had achieved a reasonable standard of living, revealed how fragile income security could be. The devastating impact of AIDS in Africa as well as the proliferation of civil conflicts made it increasingly clear that poverty was linked to community-level or even nation-wide shocks. These events forced Bank staff to recognize the potential for unexpected events to disrupt development plans. If shocks played a significant role in people's lives, then Bank staff needed to pay more attention to the vulnerability of poor people and take a closer look at ways of addressing it. ${ }^{59}$

These events did not automatically translate into new poverty reduction strategies, but instead sparked an intense series of debates among 
development practitioners and economists. These were the kinds of debates that might be called "hot" debates, following Michel Callon, as it was not only the question of how to reduce poverty that was up for grabs, but also far more fundamental questions about what counts as poverty, how to measure it, and the nature of the relationship between poverty and growth. ${ }^{60}$ Two debates in particular played a crucial role in redefining poverty at the World Bank and in the wider development community: one set of debates on the relationship between poverty and growth, and another on the social policies needed to respond to poverty.

By the late 1990s, a growing number of economists, at the Bank and elsewhere, were challenging assumptions about the benefits of neoliberal growth-oriented policies for the poor: they included Dani Rodrik, who called the growth versus poverty reduction controversy a "hollow debate," as well as François Bourgignon, Ravi Kanbur, who was lead author on the 2000-1 WDR, and Joseph Stiglitz, then Chief Economist at the Bank. ${ }^{61}$ They pointed to the inconsistent relationship between growth and poverty reduction: as Bourgignon noted, the extent to which poverty could be reduced through growth was highly elastic, depending on domestic factors including the level of inequality. ${ }^{62}$

Ranged against them was a group of economists committed to the belief that, as the title of one controversial article put it, "Growth is Good for the Poor." ${ }^{63}$ Although Dollar and Kraay, the authors of this article, have since argued that they did not intend their paper to be seen as a manifesto for growth alone, they did set out to make a case for the virtues of neoliberal growth. Other Bank economists and a large number of IMF-based economists, as well as leading figures in the US Treasury, supported their position. ${ }^{64}$ Over time, a partial compromise was achieved around the idea of "pro-poor growth" - which became something of a mantra at the OECD and DFID: an approach that focused on the conditions in which growth produced reductions in poverty. ${ }^{65}$

A second, less publicized, debate was also under way around this time among economists interested in social protection. Thinking in this area began to shift in the 1980s and early 1990s, following Amartya Sen's work on famines, which showed that they are often the result of failures of social entitlements to food, rather than in the actual supply of food. ${ }^{66}$ Sen's work influenced the growing literature on hazards and disasters, which focused on individuals' vulnerability to their effects - a literature that also began to influence social policy thinking. ${ }^{67}$ These studies lead to social policy experts beginning to shift from social welfare to social protection as their organizing framework. In the process, they redefined the goals of social protection as more dynamic, not only designed to protect 
individuals from poverty but also to prevent their falling into poverty and to promote their capacity to respond to risks. ${ }^{68}$

Although contested failures and external debates played a necessary role in creating the conditions of possibility for new policies to emerge, the specific shape that they took also depended on the particular dynamics within the World Bank. In the end, the strategy of social risk became a way of moving the social protection agenda ahead without provoking too much opposition from more conservative elements within the Bank, and without straying from a market-oriented approach to development.

Within the World Bank, the Social Protection and Labor unit was the key advocate for redefining poverty as social risk. This unit is one of the newest at the Bank, created in 1996 to bring together pensions, labour market policy and safety nets under one roof. Robert Holzmann was hired as director of this new unit to lead the process of developing a strategy for the sector, and became a powerful driving force behind the idea of defining poverty in terms of social risk. ${ }^{69}$ The concept of social risk allowed its advocates to redefine social transfers as productive investments, increasing the relative importance of social protection within the institution. Although, as I will discuss in the Conclusion, these efforts met with resistance, they also achieved some success. As a later report on the effects of the social protection strategy notes:

Social protection (SP) is moving up on the development agenda. Dismissed as ineffective, expensive or even detrimental to development in developing countries, it is now increasingly understood that assisting individuals, households and communities in dealing with diverse risks is needed for accelerated poverty reduction and sustained economic and human development. ${ }^{70}$

The focus on social risk and vulnerability was also a way of countering certain country representatives' ambivalence about social protection. Many Executive Directors, including those from East Asia, saw pensions and safety nets as expensive luxuries. The focus on social risk and vulnerability reframed these expenses as investments. ${ }^{71}$ As Holzmann, the Director of Social Protection at the time, noted:

Social protection strategies were usually a headache to have to bring to the Board: everybody has an opinion and it tends to be an uphill battle (for every two countries, there are five opinions). We used risk management as an organizing framework to appeal to those not always supportive of social protection - those who focus more on efficiency. On the other hand, those who supported redistribution were okay with this approach. ${ }^{72}$

Emphasizing social risk and vulnerability was a strategy designed to address the problem of poverty without provoking too much opposition. Yet its advocates did face some resistance from within the Bank's 
bureaucracy. Social protection was, after all, a new unit in the Bank; moreover, those economists with the most intellectual capital in the organization were those working for the Research Department and the poverty reduction and economic management (PREM) network, few of whom had any background in social protection. ${ }^{73}$ Holzmann notes that when he first explained the idea of social risk to Martin Ravallion, now the Director of Research at the Bank, he responded "Robert, this is rubbish." ${ }^{74}$ Other staff saw the effort to redefine poverty as vulnerability and social risk as an attempt to take over other units' territory - for example, those in PREM tasked with measuring poverty using other methodologies. ${ }^{75}$ Although the social risk framework ultimately gained influence through its inclusion in the social protection strategy (SPS) and the WDR, it was nonetheless contested within the institution. ${ }^{76}$

\section{The social risk and vulnerability framework}

What form did this new conception of poverty as risk and vulnerability take? Although the fullest statement of the social risk and vulnerability approach is articulated in the SPS, it is useful to examine it together with the 2000-1 WDR, Attacking Poverty, which included social risk as one of its key concepts, because it allows us to compare it with the 1990-1 WDR discussed earlier.

In contrast to the unabashedly neoliberal tone of the 1990-1 WDR, the 2000-1 report is a much subtler document. The three main "pillars" of the WDR strategy are opportunity, empowerment and security. "Opportunity" bears the most resemblance to the earlier report, as it is focused on "making markets work better for poor people." "77 Yet much of the analysis in the more recent WDR, as well as in the SPS, focuses on the ways that markets can fail poor people if they are not managed effectively. ${ }^{78}$

One way of resolving such market failures is by focusing on increasing poor people's "security," which the 2000-1 WDR authors define as reducing their vulnerability and increasing their ability to cope with risks and shocks. The concepts of security, risk and vulnerability are closely related:

In the dimensions of income and health, vulnerability is the risk that a household or individual will experience an episode of income or health poverty over time. But vulnerability also means the probability of being exposed to a number of other risks (violence, crime, national disasters, being pulled out of school). ${ }^{79}$

The report spends a significant amount of time describing the different risks that poor people face. ${ }^{80}$ It maps out the different sources of 
risk - economic, political, environmental, health - as well as the different levels of society that they affect. In both the WDR and the SPS, Bank staff identify two different kinds of risk: idiosyncratic risks that affect individuals or small groups, such as job loss or illness, and covariant risks that affect a larger group simultaneously, such as environmental, political and health crises. ${ }^{81}$ Of course, poor people are not at the mercy of risks and have their own coping mechanisms. In fact, the second pillar of the 2000-1 WDR, "empowerment," focuses on ways of engaging poor people more actively in the management of their economic situation.

Where the 1990-1 WDR did discuss the problem of shocks, it emphasized the importance of informal and market-based mitigation strategies for all but the most vulnerable. ${ }^{82}$ The $2000-1$ report, in contrast, because of its focus on risk in general, and covariant risk in particular, raises doubts about that strategy: large crises tend to undermine informal efforts, since everyone is affected simultaneously. ${ }^{83}$

Reconceptualizing poverty as social risk and vulnerability has had a concrete effect on World Bank development practices: over time, policies in each of the three areas covered by social protection - labour, pensions and safety nets - have been reframed around risk and vulnerability. In the labour market sector, for example, thinking at the Bank has shifted away from the belief that macroeconomic stabilization and liberalization are sufficient to ensure labour market access by the poor. ${ }^{84}$ Bank staff now argue that the various informal and private mechanisms that poorer people use to respond to shocks (e.g. taking children out of school to work), can lead them to under-invest in their human capital: "Thus, public intervention is needed." ${ }^{\prime 5}$ Another new social protection policy initiative with clear affinities with the social risk approach is the conditional cash transfer (CCT) strategy. Although CCTs were not invented by the Bank, they are now seen as a useful way of managing social risk. ${ }^{86}$ CCTs are funds provided to poor households on the basis of certain conditions - usually that they keep their children in school and send them for regular health checkups. The cash transfers thus provide two ways of managing risk: in the short term, they provide funds to help cope with shocks, while in the longer term they seek to foster a population that is healthier and better educated, and thus able to manage future risks more effectively.

\section{Changing governance factors}

Just as we saw in the vulnerability assessment policies discussed above, this new conception of poverty as social risk puts the dynamic and changeable character of its object front and centre. The 2000-1 WDR is illustrative: 
As traditionally defined and measured, poverty is a static concept - a snapshot in time. But insecurity and vulnerability are dynamic - they describe the response to changes over time. ${ }^{87}$

Reconceptualizing poverty as dynamic happened in part because of technical developments: as researchers began to categorize the poor into two groups - the "always poor" and the "sometimes poor" - they rapidly realized that the second group was quite large. ${ }^{88}$ Rather than assuming that the poor and the non-poor were static categories, it therefore made sense to try to measure the movement of people into and out of poverty, as well as to investigate what was driving that movement.

Conceptualizing the poor as mobile transforms poverty from a state of being into a process. This is a new ontology of poverty: it radically transforms the object of development policy. (To borrow a metaphor from physics, this is like changing our image of the electron from a particle into a wave.) This more dynamic conception of poverty also involves a different idea of time. An individual's or a community's vulnerability is something that develops over a long period of time; efforts to reduce it must also take a long view. Coping with risk is a short-term challenge; mitigating and even preventing risks requires longer-term planning. In some ways, this extension of the time horizon merely deepens the trend in development thinking towards focusing on human capital in the form of education and health. Yet the emphasis on risk and vulnerability adds a further dimension to the reconceptualization of time, in its emphasis on the unpredictability of the future: the future becomes an uncertain territory filled with hazards, shocks and risks.

\section{Small " $i$ " ideas}

This new approach to poverty as social risk is underpinned by new institutionalist economics. From the late 1980s until the mid-1990s, more narrowly neoclassical schools of thought dominated macroeconomic thinking at the Bank and the Fund. These theories assumed perfectly efficient markets and rational individuals, and generally concluded that most governmental interventions in the economy were counterproductive. As I discussed in Chapter 4, although institutionalist economists remain within the neoclassical tradition, they focus on what causes market failure. Rather than assuming that market-based solutions are necessarily the most efficient, institutionalist economists emphasize the centrality of institutions in reducing transactions costs and making markets work better.

Both advocates of pro-poor growth and of the new approaches to social protection see poverty as a sign of market failure: the fact that poor people do not have access to the benefits of the market, such as credit 
and jobs, is an indication that the market is not working properly. Even with increased growth, distortions in the market may persist, making it unlikely that growth alone will reduce poverty. Viewing poverty in terms of market failure legitimizes poverty reduction efforts as central to broader economic development: making markets work better for poor people also ensures that markets work. New institutionalist insights thus allow development experts to dig deeper into the causes of poverty without challenging the underlying liberal assumption that the market is the ultimate solution.

\section{Techniques}

Reconceptualizing poverty as a process in time also enables (indeed requires) a new set of proactive governance techniques. It becomes necessary not only to identify those most vulnerable, but also to discover the greatest risks that they face, and develop strategies to deal with shocks long before they have occurred. Those seeking to redefine the Bank's SPS in the late 1990s discovered

that a new conceptual framework was needed which moves SP [social protection] from a definition by instruments (such as social insurance) to a definition by objectives (that is assisting in risk management); from a traditional focus on ex-post poverty to ex-ante vulnerability reduction; from seeing SP in our client countries largely as safety nets to conceptualizing them as spring boards. ${ }^{89}$

This new conception of poverty as risk required new measurement techniques - and new ways of translating those measurements into useful inscriptions for policymakers. Among the key techniques that the Social Protection staff developed for this task were the risk and vulnerability assessments (RVAs). Between 2000 and 2007, World Bank staff undertook 132 country-specific RVAs. ${ }^{90}$ These assessments sought to deliver a comprehensive picture of potential shocks, government, market and community actors' vulnerabilities, and their current risk management strategies. In theory at least, this four-dimensional map (time is also a necessary factor) can be used to develop more nuanced, targeted interventions to alter the movement of people into and out of poverty.

The examples of social protection policies discussed above all seek to engage more proactively with the target populations, to promote the right kind of practices and to pre-empt undesired outcomes. Hence labour-market policy is no longer only focused on reducing barriers to labour-market flexibility (the classic neoliberal strategy), but is also increasingly focused on fostering a better-trained, more work-ready population. $^{91}$ 
Actors

Poor individuals themselves are one key group of actors who are now more directly enrolled in managing risk. The social risk framework not only treats poverty as a more dynamic phenomenon but also views the poor themselves (or at least some of the poor) as more active participants in reducing poverty. ${ }^{92}$ The goal is to provide them with resources and incentives to prepare for and prevent risks (through better education, small accumulations of savings, etc.) and to manage risks more effectively when they do occur (e.g. not remove their children from school).

Poor individuals are not, however, the only actors in this new approach to reducing poverty. The policy also seeks to enrol government, civil society and private sector actors into the process of managing social risk. The prevalence of covariant risks that affect a broader population simultaneously, and the problems of market failure, mean that individual and market-based risk management is not enough. While there is therefore a role for the public sector, the government is seen primarily as a means to "supplement" existing private and individual risk management strategies rather than replace them: ${ }^{93}$

In an ideal world with perfectly symmetrical information and complete markets, all risk management arrangements can and should be market-based (except for the instruments protecting the incapacitated). However, in the real world, all risk management arrangements will play important roles that are likely to change over time. ${ }^{94}$

Who are the actors involved in these various "risk management arrangements"? New institutionalist economics provides a particular lens for understanding and engaging with both institutional and individual actors - one that blurs the boundaries between public and private, state and market, and that sees them largely through the lens of service provision. These actors are both public and private (and sometimes both at once): they are private sector actors providing insurance; they are individuals and families demanding protection and developing new forms of self-insurance; they are actors at various levels of government providing traditional forms of social protection; and they are NGOs, acting as service providers and as advocates for better risk management. What matters is not where they are, but what they do. ${ }^{95}$

The social risk framework reconceptualizes the relationships among these actors through a range of different market-based metaphors, such as competition, supply and demand:

Social protection should contribute to a better match between the supply and the demand of risk management instruments. There are many suppliers of social risk management instruments, such as individuals, households, communities, 
non-governmental organizations, financial markets, governments at different levels, bilateral donors, and international organizations. ${ }^{96}$

As one passage from the 2000-1 WDR notes, "This is not an issue of the state versus the market, but of the use of different agents and mechanisms depending on the type of activity." 97 These heterogeneous social actors are represented in very similar terms as parts in a larger, more social or even political kind of market mechanism, in which individuals, NGOs, communities, IOs and others can act as a source of demand for risk management, as well as being sources of its supply. ${ }^{98}$

\section{Power and authority}

The techniques involved in managing risk and vulnerability rely as much on productive as on exclusionary forms of power. The goal of this kind of policy is not just to reduce poverty, but also to constitute a new kind of low-income individual, better capable of managing risk and thus able to gain and sustain a better quality of life. ${ }^{99}$ Bank staff are themselves keen on the productive and proactive aspects of this new poverty-reduction framework. ${ }^{100}$ In their 2009 review of social protection, staff note, "The productive, as opposed to the redistributive, role of safety nets is becoming more recognized." ${ }^{101}$ Moreover, the concept note and the consultations for the new 2012-22 SPS places even more emphasis on the importance of promoting more resilient communities and individuals. ${ }^{102}$

Risk is a category rather than a thing: it is a way that we make the world calculable in particular kinds of ways. Risks are beyond our control and yet also very much subject to our understanding: a risk by definition is something that can be understood through a logic of probability (as opposed to uncertainty, ambiguity and other kinds of indeterminacy). ${ }^{103}$ Risk-based policies are well suited to the productive application of power, particularly in the context of a market economy, in which risk is never viewed as an entirely bad thing. According to the World Bank, risk is an essential tool for understanding poverty, not only because shocks can wreak havoc with efforts to raise incomes (risk as a bad thing), but also because as poor people find themselves with fewer tools for managing risks, they are less likely to undertake riskier activities, and thus forgo the potential gains that they might make (risk as a good thing). ${ }^{104}$ Risk is thus understood as a double-edged problem: it is not universally bad, but needs to be both mitigated and exploited through careful policy interventions.

As with the policies discussed earlier, the social risk framework relies on a combination of expert and popular authority to underpin its legitimacy. It is not just IFI experts or government bureaucrats who are responsible for applying this new understanding of social risk, but rather 
a range of public and private organizations, and the poor themselves, who are to take on a more active role in reducing their vulnerability and managing risk. We therefore see a similar process of distributing both expert and popular authority to a wider range of "capable" actors as we witnessed in the debt vulnerability assessments discussed above.

The fact that these forms of power are productive does not make them any less exclusionary, however. As a number of social policy analysts have pointed out, even as the social risk framework engages a wider range of poor people in the process of managing risks, it also tends to neglect those less capable of such active self-governance, leading policymakers to downplay the problems of the chronically poor. ${ }^{105}$ The strategy's emphasis on shocks also leads staff to de-emphasize subtler sources of vulnerability, such as those associated with gender, class, ethnicity or other more structural fault-lines. ${ }^{106}$ More fundamentally, the framework's tendency to define poverty in absolute rather than relative terms (downplaying inequality) and to view poverty reduction as a "win-win" policy, means that more politically difficult, structural solutions to poverty tend to get short shrift. ${ }^{107}$ While these new policies on risk and vulnerability may take a less direct approach to their objects, they are therefore no less powerful in their effects - both intended and unintended.

\section{A more provisional kind of governance}

It is not just the increasing emphasis on risk but, more importantly, the new focus on the problem of vulnerability, that indicate the rise of a more provisional style of governance among IFIs today. Many of the patterns that I have discussed in this chapter echo the broader trend towards a risk society or the governmentality of risk that scholars such as Ulrich Beck, Mitchell Dean and Nikolas Rose have explored. My study has revealed an increasing preoccupation among IFI actors with calculating, cataloguing and trying to manage the various dangers and possible unknowns posed by the modern world. It has also revealed the increasing reflexivity of IFI actors about the problem of uncertainty, as Beck and Dean have noted in their work, and a growing reliance on individuals' and communities' responsibility for self-governance, as Rose has discussed.

Why, then, talk about the turn to a more provisional form of governance rather than simply reading this as another example of the governmentality of risk? The two insights are not mutually incompatible. Yet, I want to argue, the shift by IFI actors from risk to vulnerability points to a more equivocal and less confident approach to governance than that suggested by much of the risk literature. Part of what makes risk such an appealing concept for policymakers is its promise to make indeterminacy 
calculable. Risk managers tell us that they may not know what will happen exactly, but they can at least tell us the likelihood of certain things occurring. Confidence in this kind of quantitative risk assessment was challenged in recent years by the failure to predict $9 / 11$ and the global financial crisis. Quantitative risk management techniques remain popular but they have now been supplemented by more imaginative processes, like the scenario analyses discussed in this chapter, which seek to imagine and prepare for various "worst-case" situations. ${ }^{108}$

The new policies examined above point to a second way in which the confidence of traditional risk management has been undermined: through increased focus on vulnerability. Risk and vulnerability are both ontological concepts that encourage their users to see the world differently: as less stable and more prone to shocks and uncertainties. Yet the ontological character of vulnerability is different from that of risk. When IMF and World Bank actors use the concept of risk, they treat it as something "out there" in the form of exogenous shocks or opportunities to be seized. Vulnerabilities, on the other hand, are imagined as lying deep within countries and individuals. They are the inner weaknesses that determine how we react to shocks. The concept of vulnerability is thus both useful and unsettling from the point of view of organizational experts. It is useful, because it allows IFI staff to develop better models of the likely effects of given shocks. But vulnerability is also an unsettling concept because it acknowledges the essential fragility of individuals and countries. Moreover, because it turns out that the various sources of vulnerability are profoundly political and social - linked to institutional quality and social inclusion - such fragilities are difficult to fix through conventional economic expertise.

There is thus an aporia at the heart of these new efforts to govern risk and vulnerability: indeterminacy persists at the very source of the efforts to manage it. ${ }^{109}$ Despite the veneer of confidence that we find in many IFI documents about their capacity to measure and manage these more pervasive unknowns, there exists an underlying sense of unease, a partial if unconscious recognition of the sheer magnitude of the challenges involved. This unease, in turn, underpins a more provisional approach to governance.

This provisional governance strategy is explicitly focused on the problem of failure. The shocks of the 1990s and 2000s led policymakers to recognize that the volatility of the global political economy meant that failure was always a possibility. The best that could be hoped for was the more effective management of risks and vulnerabilities - a strategy that keeps one eye on the possibility of failure, all the while seeking to prevent or mitigate its worst effects. 
One of the key features of these new governance practices is their attempt to act pre-emptively and proactively - to stay one step ahead of this more volatile world. For example, the vulnerability exercises seek "to strengthen the staff's capacity to spot vulnerabilities and flag potential pressure points in LICs arising from external triggers before they materialize." ${ }^{110}$ Similarly, social risk management aims to shift resources towards ex-ante measures focused on preventing and mitigating risks, rather than relying on more costly efforts to cope once the risks have occurred. ${ }^{111}$ The techniques and forms of power that the IFIs use to achieve these ends, moreover, are increasingly indirect in form. There is less emphasis on formal conditionality and more focus on constituting the right kinds of risk-bearing individuals and governments, and of creating the conditions necessary for them to take on governance tasks themselves.

Many of the techniques used to foster this kind of self-governance, moreover, are highly symbolic: the goal is not simply to use risk assessments to inform concrete domestic policies, but also to use the signalling power of various country risk scores, like the debt sustainability analysis ratings, to change investors' and countries' behaviour. Yet these scores are massive oversimplifications of highly complex phenomena. They often rely heavily on other, equally contestable, rankings such as the CPIA. A series of considerable leaps of logic is thus involved in these scores. And while all of these rating systems seek to black-box their many assumptions, they are still vulnerable to criticism. As I will discuss further in the Conclusion, the methodological assumptions underpinning the social risk framework and the various vulnerability assessments remain the subject of considerable contestation within as well as outside the IFIs.

Those involved in developing and defending efforts to manage risk and vulnerability, moreover, are often quite aware of such problems, producing a more cautious kind of governance and a tendency to try to hedge against the possibility of failure. Such an approach is particularly clear in documents on the IMF's vulnerability assessment exercise, which is the most ambitious of the risk-management policies. The staff note:

The exercise does not aim to predict the timing of crises or acute economic distress. Past attempts at crisis prediction have a mixed record at best. The exercise instead strives to flag the underlying vulnerabilities that predispose countries to economic disruption in the event of external shocks. ${ }^{112}$

These policies thus support Niklas Luhmann's contention that risk management is a form of expertise that seeks to inoculate itself against failure; by recognizing the ever-present chance of failure, and by avoiding making any definitive predictions, risk managers are able to promise better chances of success, all the while hedging against the possibility of failure. ${ }^{113}$ 
Together, these efforts to manage risk and vulnerability constitute a more provisional form of governance - one that is always aware of the possibility of failure, that seeks to pre-empt and prevent it, often indirectly, but that is forced in the process onto increasingly symbolic and fragile methodological terrain, and as a result becomes ever more cautious in its governance efforts. Underlying this more provisional approach to governance is the aporia I discussed above: an awareness of the fragility of all claims to knowing such profound unknowns. In fact, all three of the new strategies discussed so far in this book rely on a set of methodological gambles on their ability to measure and evaluate highly complex processes like ownership, good governance, vulnerability and risk. The final strategy that I will examine seeks to tackle this problem of measurement head-on, and to develop a new epistemology of development finance: one that hinges on the possibility of measuring something called "results." 


\section{Measuring results}

Accurate measurement has become something of a holy grail in development finance, viewed as a mythical key to figuring out what works and what does not - and why. The pursuit of better ways of measuring and assessing development successes and failures is not new. Yet the forms measurement takes and the roles it plays have evolved. As the International Monetary Fund (IMF), World Bank and key donors have adopted the new strategies that I have discussed in previous chapters - new standards of governance and transparency, policies aimed at fostering local ownership and reducing vulnerability and riskthey have also developed ever more complex models, indicators and matrixes to try to measure these policies and their effects. In the process, there has emerged a veritable industry surrounding policy measurement and evaluation. These new practices of measurement represent an important new governance strategy - one that not only follows from the other three discussed so far in this book, but which also plays a crucial role in making them possible.

Such efforts to redesign measurement techniques can be seen in a wide range of different international financial institution (IFI) and donor policies - including efforts to define and operationalize ownership, develop new governance indicators, measure compliance with new standards and codes, and assess risk and vulnerability. Different institutions have tackled these challenges in diverse ways. Yet one theme that has been consistent in virtually all of the organizations that I have looked at has been the attempt to reorient measurement around results. ${ }^{1}$ This new results-oriented approach to measurement and evaluation has played an important role in the shift towards the more provisional form of governance that I have been discussing in this book.

This chapter will move beyond the IMF and World Bank and consider various donors, international agreements and organizations in order to trace the spread of the ideas and practices underpinning the current focus on results. Even more than those of standardization, ownership and risk management, the emergence of the results strategy can only be fully 
appreciated by moving beyond individual IFIs, tracing the evolution of new practices within a wider community of organizations, and focusing on the meso-level of analysis - the specific techniques, ideas, actors and forms of power and authority through which these institutions have sought to measure results.

Why does measurement matter? I began this book by suggesting that a decade and a half ago, key players in finance and development faced a serious erosion of their expert authority in the context of several contested failures. These failures precipitated significant debates about what constituted success and failure in development finance - debates that were, at their heart, about questions of measurement: if so many past policies that were once deemed successes had in fact resulted in failure, then clearly something needed to be done not only about how development finance was performed, but also about how its successes and failures were measured. One of the key means of re-founding expert authority has therefore been through the development of new ways of measuring and evaluating policies - not just their inputs and outputs, but also their outcomes, or results, providing a new metric for defining success and failure. The hope of the various organizations adopting these measurement strategies is that by demonstrating successful results they will be able to justify their policies, thus re-legitimizing development efforts by re-establishing them on sound methodological grounds.

As I suggested in Chapter 2, the politics of failure is closely linked to the process of problematization. Debates about failure often lead to the identification of new problems and the development of new ways of governing them. In fact, in the case of the practice of results measurement, its history is long enough that we can actually identify two key moments of problematization, the first and more significant of which was triggered by a belief in the failure of government in the 1980s, leading to the introduction of the practice of results management into Western bureaucracies, and the second of which was triggered by the perceived failure of aid, making results a central element of the aid effectiveness agenda in the 1990s and 2000s.

While demonstrating the results of development policy initiatives may sound relatively straightforward, it is in fact a very ambitious undertaking. This effort to develop new kinds of measurement is both a methodological and an epistemological exercise. As different development practitioners, non-governmental organizations (NGOs) and state leaders have debated whether and how to focus on results, they have also been contesting the basis of development expertise. Drawing on the insights of Michel Callon and Bruno Latour in this chapter, I will examine how these new measurement techniques work to create a new 
kind of fact. While talking about "evidence-based" policies, they have also sought to reconstitute what counts as evidence. ${ }^{2}$ Results-based measurement involves a promise of a new way of knowing not just how to count economic activities, but also what can be counted, and therefore what counts.

Those involved in developing and implementing the strategy of results-based measurement thus not only draw on particular, small "i" ideas - new public management, public choice theory and participatory development - but also seek to transform the epistemological underpinnings of expertise. They do so using two principle techniques: performative inscriptions such as the "results chain," and various technologies of community that reach out to civil society and other affected groups. Advocates of the results agenda seek to enrol a range of new actors in the practices of measurement and evaluation, particularly bureaucrats in both lending agencies and recipient countries. Although by engaging new actors the strategy does redistribute a measure of expert authority to a wider group, it also seeks to reconstitute them into more results-oriented kinds of actors, through the development of a "results culture." Power dynamics thus remain a key dimension of this governance strategy, although they often take less direct forms than in the past.

As measurement techniques have become integrated into the dayto-day work of development policy, international organizations (IOs) and donors are seeking to govern through measurement. They are engaging in a highly provisional form of governance practice: one that seeks proactively to transform the culture of evaluation so profoundly that bureaucratic actors change the way that they develop programs by anticipating their ultimate results. This is an indirect form of governance, operating through the most peripheral and technical of arenas measurement and evaluation - in an effort to transform the assumptions underpinning the management of development finance. And while results may appear like the most concrete of policy objectives, they in fact depend on a highly constructed and symbolic set of techniques - the results chain - in order to be made visible. The symbolic character of the assumptions underpinning the results agenda does occasionally threaten its credibility. Yet, paradoxically, its proponents are able to exploit these leaps of logic in order to deliver good results in often-questionable circumstances, thus hedging against the risk of failure.

\section{Where it came from}

Although results-based measurement has only dominated development lending over the past five years, it has a much longer history. This recent 
reorientation around results can be linked back to two small "i" ideas and an influential technique - new public management thinking, participatory development and evaluation, and the logical framework or "LOGFRAME" approach to development projects. Current resultsbased thinking and practice is increasingly driven by top-down new public management and LOGFRAME-style analysis; however, it has integrated a measure of the more bottom-up participatory approach and language. The potency and appeal of the idea of results owes a great deal to the fact that it can be understood from these rather different starting places, even though in recent years the strategy has moved away from its participatory roots.

\section{The "failure" of government and new public management}

New public management and results-based measurement emerged in response to a widespread - if contested - problematization of the role of the public sector in the 1980s and 1990s in the wake of the purported failure of "big government." The public sector had expanded massively after the Great Depression and the Second World War, in order to provide social and political stability to support the economy. Keynesian economic theory, emphasizing the central role for government in smoothing out the wider swings of the business cycle, played a crucial role in both legitimizing and operationalizing the public sector's role. The oil crises and stagflation of the 1970s seriously undermined elite support for this economic model, and Keynesian economic ideas - and the governments that had sought to implement them - came under increasing attack. Leading the charge were public choice theorists and their supporters in the newly elected conservative governments in the UK and the US, where Margaret Thatcher and Ronald Reagan were now in power. ${ }^{3}$

The theoretical underpinnings of the new public management ideas that began to transform government practice are relatively straightforward: public management gurus such as David Osborne and Ted Gaebler sought to adapt the insights of public choice theory to the practices of government agencies - and in doing so to transform them from bureaucracies into something that resembled the rapidly changing face of private sector organizations. ${ }^{4,5}$ As I have discussed in earlier chapters, public choice theory seeks to apply economic conceptions of humans as essentially rational self-interested maximizers to a wide array of different non-economic contexts. ${ }^{6}$ Doing so leads public choice scholars to the premise that markets are the most effective means for achieving an optimal distribution of goods and economic growth. 
While public choice advocates therefore tend to support the transfer of all possible activities to the private sector, they nonetheless recognize the need for some governmental role - particularly for the provision of public goods that would otherwise be underprovided. Yet they remain deeply suspicious of traditional public bureaucracies, seeing them as a source of inefficient rent-seeking and thus a major drag on growth. In the 1980s and 1990s, new public management scholars sought to solve this dilemma by proposing wide-ranging changes to the public sector (symbolized by the shift from "public administration" to "public management" as the preferred term). ${ }^{7}$ The goal was quite simply to make the public sector operate more like the private sector - by introducing competition, individual responsibility and performance evaluations based on results.

This problematization of results thus emerged out of claims about the failure of government. Amidst the widespread debate about the causes of the economic set-backs of the 1970s and early 1980s, new public management proponents argued that there had been a fundamental failure in how government worked: they saw the traditional public service's emphasis on collective responsibility and accountability as misguided and sought to develop a way of doing government's work that would mimic firms by individualizing responsibility. The key to doing so was to link individuals' or units' actions to results, making them responsible for their own successes and failures - and thus hopefully reducing the prevalence of policy failure.

This new way of managing the public sector soon took off in the United Kingdom, New Zealand, Canada, the United States and Australia. ${ }^{8}$ New Zealand became the poster child for public choice advocates, showcased by the World Bank among others as a model of public sector reform. ${ }^{9}$ Beginning in 1988, the government introduced massive institutional reforms, transforming relationships between government and public service into a series of contractual arrangements in which managers were responsible for the delivery of specific results but had significant discretion over how to meet them. As Alan Schick, a consultant with the World Bank's Public Sector Group, noted in a 1998 paper, "New Zealand has brought its public management much more closely into line with institutionalist economics and with contemporary business practices. $" 10$

The first wave of interest in results-based management was as much neoliberal as it was neoconservative in flavour, driven by a belief in reducing the size of government. Results-based measurement thus survived the end of the Thatcher-Reagan era and, in the mid-1990s, began to take a more widespread hold among Organisation of Economic 
Co-operation and Development (OECD) countries, becoming, for example, the centrepiece of Vice President Al Gore's National Performance Review in the United States and of Paul Martin's Program Review in Canada. ${ }^{11}$ The OECD championed the spread of such policies to all industrialized nations, arguing for "a radical change in the 'culture' of public administration" in order to improve public sector "efficiency and effectiveness." 12

\section{Results in development agencies}

The growing popularity of new public management soon took hold in development organizations, particularly among bilateral donors. Performance management became the watchword, and results the key determinant of success. This new enthusiasm for measuring results combined with two other already-present trends within the aid community - LOGFRAME analysis and participatory development.

Back in 1969, the US Agency for International Development (USAID) had commissioned a group called Practical Concepts to develop the program design framework that became the LOGFRAME. ${ }^{13}$ Although results matrixes have evolved over time, this initial framework established many of their crucial elements. The LOGFRAME (Figure 8.1) encouraged development planners to focus on outputs rather than inputs, and required them to identify "objectively verifiable indicators," the "means of verification" and the "important assumptions" for each step in the process. Within a few years of its development, thirty-five other aid agencies and NGOs had begun to use the LOGFRAME in their work. ${ }^{14}$

Two and a half decades later, as new public management thinking spread across the Western world, the US Government Performance and Results Act, which tied budgetary decisions to measurable results, was passed with bipartisan support and was soon applied to USAID. ${ }^{15}$ If anything, the pressure on development agencies was even more acute than other areas of government policy, since it was believed that financing for development was even less good value for public money than that spent on domestic programs. If the initial focus on the problem of results was a response to the perceived failure of the public sector, the later concern with development results was linked to the more specific belief that development aid in particular was inefficient. Yet, despite these considerable pressures, the move to results-based management was a contested one. In fact, Andrew Natsios notes that the USAID Administrator at the time, Brian Atwood, saw the performance-based legislation as contrary to the needs of his agency. Yet he ultimately decided to accept the lesser of two evils (the first being the abolition 
THE "LOGICAL FRAMEWORK"

\begin{tabular}{|c|c|c|c|}
\hline \multicolumn{3}{|c|}{$\begin{array}{l}\text { PROJECT DESIGN SUMMARY } \\
\text { LOGICAL FRAMEWORK }\end{array}$} & $\begin{array}{l}\text { Life of Project: } \\
\text { From F.y.___ to F.y. }\end{array}$ \\
\hline NARRATIVE SUMMARY & $\begin{array}{l}\text { OBJECTIVELY VERIFIABLE } \\
\text { INDICATORS }\end{array}$ & $\begin{array}{l}\text { MEANS OF } \\
\text { VERIFICATION }\end{array}$ & IMPORTANT ASSUMPTIONS \\
\hline $\begin{array}{l}\text { Programme of Sector } \\
\text { Goal: The broader } \\
\text { objectives to which } \\
\text { this project contributes: }\end{array}$ & $\begin{array}{l}\text { Measures of Goal } \\
\text { Achievement: }\end{array}$ & & $\begin{array}{l}\text { Assumptions for achieving } \\
\text { Goal Targets: }\end{array}$ \\
\hline Project Purpose: & $\begin{array}{l}\text { Conditions that will } \\
\text { indicate Purpose has } \\
\text { been achieved: }\end{array}$ & & $\begin{array}{l}\text { Assumptions for achieving } \\
\text { purpose: }\end{array}$ \\
\hline Outputs: & Magnitude of Outputs: & & $\begin{array}{l}\text { Assumptions for providing } \\
\text { Outputs: }\end{array}$ \\
\hline Inputs: & $\begin{array}{l}\text { Implementation Target: } \\
\text { (Type and Quality) }\end{array}$ & & $\begin{array}{l}\text { Assumptions for providing } \\
\text { Inputs: }\end{array}$ \\
\hline
\end{tabular}

Figure 8.1 The LOGFRAME ${ }^{16}$ 
of the agency, proposed by conservative members of Congress), hoping that "he could prove to USAID's adversaries that foreign aid works and could produce quantitatively measurable program results." 17

The World Bank also began to focus on results management in the 1990 s, championing its spread to low- and middle-income countries. The Bank had a long history of focusing on public-sector reform in borrowing countries. ${ }^{18}$ By the late 1990s, its staff were focusing on its good governance agenda, convinced that institutional reform was vital for policy success. It was in this context that the staff involved in public sector management - now located within the poverty reduction and economic management (PREM) area - began to emphasize the adoption of new public management-inspired reforms in developing countries, including results-based measurement. ${ }^{19}$

The spread of these new public management-inspired ideas into development policy was not entirely smooth, however, for it encountered a second, somewhat different approach to evaluation - one that emphasized local knowledge and participation. Participatory approaches to project evaluation had existed for many years, particularly among NGOs, but became increasingly popular with the publication of Robert Chambers' work on participatory rural appraisals (PRA) in the mid-1990s. ${ }^{20}$ PRAs were a more participatory version of the earlier Rapid Rural Appraisals (RRAs) which emphasized the cost-effectiveness and usefulness of project evaluations that relied on local knowledge (often through interviews) rather than more formal quantitative analyses. ${ }^{21}$ The chief difference of participatory evaluations was that they were to be driven by locals themselves, and organized around their concerns. The objective of participatory appraisals was not simply to extract information from local populations, but to empower them to identify their own needs and assess development programs' success in meeting them. ${ }^{22}$ Here then was another strategy for measuring and evaluating the success of development programs, but one that focused on meeting poor people's needs rather than on ensuring organizational efficiency.

Development organizations struggled with these tensions. At the World Bank, different units adopted different approaches to measurement and evaluation, with the PREM focusing on public-sector reform and public choice-inspired results management, while those involved in social development relied more on participatory approaches inspired by Chambers' work. ${ }^{23}$ At the Canadian International Development Agency (CIDA), which introduced its first results-based management policy around the same time as USAID in the mid-1990s, there were also discussions about how to reconcile different approaches to measurement and evaluation. ${ }^{24}$ One 1996 CIDA paper made a careful distinction 
between top-down, donor-controlled management by results and a more bottom-up, indigenized management for results. ${ }^{25}$ While the first was often focused on more bureaucratic objectives such as reporting back to stakeholders, the second was designed to improve performance in the field. The authors noted that most CIDA policies and practices to that point had been dominated by the first of these approaches. While the paper's authors supported results-based management in principle, they made a strong case for developing a more dynamic, even experimental approach which they felt was better suited to meeting CIDA's increasing concern with institutional development.

\section{Analysing early results-oriented approaches}

Despite their differences, these earlier versions of measurement and evaluation had similarly ambitious objectives: to transform development governance by creating new kinds of facts, enrolling new participants, redistributing expert authority, and using productive power to constitute new, more proactive actors.

The New Zealand-inspired approach to results management required a new kind of counting and accounting to ensure that public sector managers had achieved the targets set out in their contracts. At the heart of resultsbased management is a particular kind of inscription: the causal chain, or logical framework, which seeks to create logical connections between inputs, outputs and outcomes (Figure 8.2) ${ }^{26}$ In creating such a framework, public sector or IO staff must develop a results chain that links each step in the policy process, effectively identifying causal relationships between a particular input (such as training more doctors), an expected output (more doctors in a region), and a range of desired outcomes (a healthier population). At each stage, it is also necessary to identify indicators that will allow for the measurement and monitoring of each step in the causal chain (e.g. counting the number of doctors). The objective of this system is to establish a direct link between bureaucrats' actions and the outcomes that result, in order to make public-sector actors accountable for the services rendered (or not).

PRAs also sought to create a new kind expertise using new techniques. Chambers sought to replace statistical techniques with participatory processes that produced their findings by talking to the local population. It took time for these new fact-producing techniques to be widely accepted; as Chambers notes, the earliest practitioners who used RRA-like techniques felt obliged to do more traditional, quantitative and time-consuming studies after the fact, in order to persuade development agencies that their results were credible. ${ }^{27}$ It was only over time, as Chambers' ideas began to gain momentum, that the kinds of facts that RRAs and PRAs 


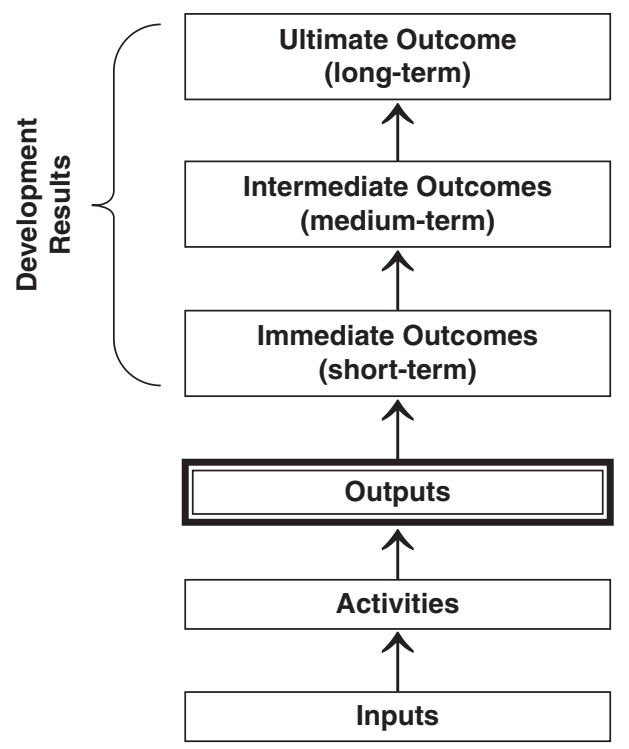

Figure 8.2 CIDA's results chain ${ }^{28}$

collected - interview data, stakeholders' opinions, drawings and other kinds of non-verbal information - began to be viewed as authoritative.

Both policy approaches also sought to enrol new actors in their results-oriented techniques and, in doing so, to transform the culture of development organizations. In the case of the new public managementdriven approach, the goal was to train borrowing-country bureaucrats to use the results chain in their own policy development. The PRAs sought to enrol local community actors in the processes of evaluating and refining development policy, and to change the way in which development professionals interacted with local actors. Both results approaches sought to involve new actors and transform them by changing the culture in which they operated. In both cases, the transformation that they sought to achieve in bureaucratic actors was quite profound: in the first case, bureaucrats were to become more entrepreneurial, driven by rational incentives rather than traditional notions of public service, more adaptive to change and accountable to their political masters. In the second, development agency staff were to renounce their efforts to control the evaluation process and act as facilitators for the voices of others. In both cases, a profound cultural transformation was the goal.

Of course, the forms of expertise that each kind of strategy sought to create and authorize, the actors they sought to enrol and the changes 
in culture that they sought to foster were quite different. Yet some initial points of contact did exist even in the infancy of these two result-oriented approaches; moreover, they were to begin to converge further as time went on and the results agenda came to dominate the global governance of development over the next decade.

\section{Recent developments}

The results-based measurement strategy initiated in the 1990s has gained significant new impetus over the past decade, as the idea of results has been enshrined in three key international agreements: the millennium development goals (MGDs) (2000), the Monterrey Consensus (2002) and the Paris Declaration (2005). As their name suggests, the MDGs establish concrete goals towards which the state signatories agree to work in order to reduce poverty. These goals are not only broadly defined, such as the goal of reducing extreme poverty and hunger, but are also broken down into more concrete targets, such as that of halving the proportion of people who suffer from hunger by 2015 . Moreover, movement towards reaching each of these targets is measured through more specific indicators, such as the prevalence of underweight children. ${ }^{29}$ This kind of practice of linking measurable indicators to intermediate targets and longer-term goals is central to results-based strategies.

If the MDGs established a kind of preliminary methodology for measuring global results on poverty reduction, then the Monterrey Consensus articulated the rationale for integrating results-orientation as a key element of developing country public sector reform. It was at the Monterrey Conference on Financing Development that an agreement was reached on the principles that were to underpin the global governance of development aid: the key principle was mutual responsibility, whereby industrialized countries agreed to bring aid levels closer to the level needed to meet the MDGs in exchange for developing countries' promise to take responsibility for developing "sound policies, good governance at all levels and the rule of law." 30 Three years later, when OECD countries agreed on the Paris Declaration on Aid Effectiveness, results-measurement and evaluation were seen as the central mechanism for achieving these better development outcomes. ${ }^{31}$

If advocates for results-based management in the 1980s justified this radical shift in public sector governance by claiming that big government had failed, those pushing for this more recent problematization of results have pointed to the failure of aid effectiveness. As Patrick Grasso, a member of the World Bank's independent evaluation team, noted in a recent presentation, the Bank's emphasis on results emerged in response to the 
"quality crisis" of the 1980s and 1990s as programs' success rates declined precipitously. ${ }^{32}$ The World Bank President, Paul Wolfensohn, who was preoccupied with the institution's declining success rates, reorganized the Operation Evaluation Department (OED) in the mid-1990s, leading to its identification of results-based management as one of its strategic objectives. ${ }^{33}$ The adoption of results-based management at the Bank and among aid agencies was thus driven in part by fear of increasing rates of policy failure and a desire to demonstrate tangible policy success to their critics. As Grasso notes, "[The] move to results focus and concentration on effectiveness means that evaluation matters more than ever," not only for internal reasons, but also because of external pressures, as "[s]hareholders want to know whether they are getting 'value for money." "34 Aid agencies and IFIs now need to be able to show the effects of their expenditures in order to be able to sell their programs to their leaders and publics.

Who were the external and internal actors pushing for the results strategy? There is little doubt that the US Administration played a major role in demanding that all multilateral development banks including the World Bank be accountable for results. ${ }^{35}$ As Natsios notes, one of President Bush's mantras was that his three priorities were "results, results, results." ${ }^{36}$ Other countries also pushed for results measurement, although with somewhat different objectives in mind: the Nordic countries, for example, were interested in providing more output-based aid in the health sector, ${ }^{37}$ while Latin American countries were keen on assessing the impact of World Bank, IMF and donor policies. ${ }^{38}$ UK representatives were generally supportive of greater focus on results at the World Bank in the early 2000s. Yet they were careful about what was actually achievable in this regard, cautioning against being overly ambitious by seeking "the attribution of success to each agency or to individual projects"; 39 and arguing that "we are focusing on managing 'for' rather than 'by' results," echoing the earlier CIDA working paper discussed above. ${ }^{40}$

States were not the only key actors mobilizing behind the new results agenda. Internal advocates also played an important role in pushing for the results agenda, with not only Wolfensohn but also the Bank's Chief Economist, François Bourgignon, playing leading roles. ${ }^{41}$ NGOs provided another source of support, although in a somewhat tangential way: critical NGOs like Eurodad and Oxfam had long argued that the IFIs should assess the impact of their policies, championing the Poverty and Social Impact Assessment (PSIA) tool at the Bank and the Fund. ${ }^{42}$ Although the goal and form of the PSIA is different from results-based management, its focus is nonetheless on measuring outcomes and relies on similar claims about the value of "evidence-based policy." Although many of these same NGOs have since become more critical of the results 
agenda, their criticisms have been primarily focused on what kinds of results are being measured, rather than on the measurability of results more generally. ${ }^{43}$ Finally, the Washington-based think tank, the Center for Global Development (CGD) has played a crucial role in moving ahead the results agenda through its development and advocacy for a "cash on delivery" (COD) approach that links financing with measurable outcomes. ${ }^{44}$ The COD approach has caught on at the World Bank, and the CGD has been very active in training Bank staff in this policy. ${ }^{45}$

\section{Donors get more quantitative}

As I discussed earlier in this chapter, donor agencies were among the first to integrate results-based measurement and evaluation techniques into their policies as part of broad-based public-sector reforms. Yet in many of these cases, the market-based approach to results was an uncomfortable fit for organizations seeking to achieve more complex, process-oriented and long-term reforms such as institutional development. These organizations were also interested in using more participatory evaluation techniques that were sometimes at odds with the techniques or objectives of the public-choice approaches. The agencies' response in many cases was to try to find a compromise between the donor and recipient-driven approaches and to create more space for flexibility within the resultsframework. In the late 1990s and early 2000s, DFID, for example, relied on more qualitative indicators that better captured the complexities on the ground. ${ }^{46}$ These adaptive strategies helped resolve the tensions in results-based management techniques between the goals of reporting (to the donor government) and of improving policies (for the recipient community). Yet they did so by reducing the clarity of reporting, since numbers were often replaced by more complex accounts of successes and failures.

This particular resolution of the tensions in results management did not, however, provide the kind of shot in the arm to the legitimacy of development governance that key actors had hoped for. Politicians did not just want results, but measurable ones, so that they could take them back to their constituencies and explain why the money had been spent. In 2004, the Bush Administration was the first to translate this desire for quantifiable results into a new kind of development organization: the Millennium Challenge Corporation (MCC). All of this agency's loans were to be tied to borrowers achieving a passing score in several quantitative indicators, including indicators on governance. The assistance in turn was to be linked to clear objectives, and results were to be regularly reported to Congress. While the agency ultimately had to fudge things a little (after almost no country qualified for financing), and 
created a new category of threshold programs designed to help countries meet the minimum targets, it had nonetheless dared to do what no other agency had: to develop quantitative governance-based criteria for aid. In the words of one former advisor to the DFID Minister, Claire Short, the MCC's willingness to create hard quantitative criteria was "the elephant in the room" that all of the other agencies tried to ignore, but could not. ${ }^{47}$ Many other governments also dearly wanted to be able to show results and justify lending through the clarity of numbers.

While no other agency has been willing to tie its aid so strictly to quantitative measures of country results, many have moved towards more rigid kinds of results-based measurement. Both CIDA and DFID, which had been more cautious and conflicted in their application of measurement and evaluation in the 1990s, were asked by their respective ministers to impose a stricter kind of results-based management. At CIDA, a new results-based management policy statement was issued in 2008 that updated the policy adopted twelve years earlier. This new policy makes it very clear that the central objectives of results management are entirely focused on bureaucratic objectives: better "planning, implementation, monitoring and evaluation," together with more transparent reporting to its key stakeholders - Parliament and the Canadian public. ${ }^{48}$ Just six years before, the organization was still struggling with the complexities involved in applying more traditional results-based management approaches to development programs. ${ }^{49}$ By 2008, however, the difficult debates that had earlier preoccupied the organization had gone underground. ${ }^{50}$ What took their place was a very straightforward form of top-down results management, or what CIDA staff earlier called a "donor-oriented" rather than "field-oriented" approach. ${ }^{51}$

DFID was similarly pressured to provide clearer data on results to its political masters, particularly in the context of growing pressure on government budgets. ${ }^{52}$ As the Overseas Development Institute's David Booth noted in an interview conducted before the 2010 election, aid has come to be seen by both Labour and Conservatives as a vote-winner but only if claims about aid making a difference are verifiable. ${ }^{53}$ DFID's 2007 Results Action Plan begins with a mea culpa of sorts:

DFID needs to make a step change in our use of information. We need to use evidence more effectively in order to ensure we are achieving the maximum impact from our development assistance. We also need to be able to demonstrate its effectiveness more clearly. ${ }^{54}$

Demonstrating effectiveness, moreover, means basing more development program decisions on quantitative information: this is the number one priority of the reforms proposed in the action plan. In fact, as Booth 
noted, "senior managers at DFID headquarters adopted a 'results orientation' that placed a strong emphasis on monitoring quantifiable final outcomes, which put a new kind of pressure on program design and delivery in country offices." ${ }^{55}$ The Action Plan is also quite frank about what its authors believe were the reasons for the decline in the use of quantitative information, suggesting that "as our work has moved progressively away from discrete project investments, we have made less use of tools such as cost-benefit analysis. ${ }^{56}$ As DFID moved from projects to program-based, longer-term and more country-owned support, they also lost the ability to easily link causes and effects, and to compare costs and benefits. Decisions were thus no longer easily linked to quantitative evidence and it became more difficult to communicate the results of development assistance to the public. This new results action plan seeks to rectify these perceived failures. As I will discuss further in this book's Conclusion, this attention to "hard" results has only gained ground over the past few years, not only in the UK but also in several other key donor countries with conservative governments, including Canada and the Netherlands.

\section{The World Bank's recent initiatives}

In the past decade, the World Bank has also "mainstreamed" results-based measurement. Before this shift occurred, the results-based approaches of PREM's public-sector teams and the social development groups were not well integrated into the core of Bank operations. Integration first began in the context of the organization's development of Poverty Reduction Strategy Papers (PRSPs) together with the IMF, in 1999. ${ }^{57}$ The PRSP was supposed to include general objectives and more specific targets and indicators that could then be monitored by both the borrowing government and the lending institutions. The idea of results was thus integrated into the PRSP: countries were asked to develop a detailed matrix prioritizing their poverty objectives and outlining the longer-term and shorter-term results that they were seeking to achieve, as well as how they would achieve them. The PRSP thus sought to combine top-down and bottom-up forms of results management, by linking participatory input to more bureaucratic forms of measurement and evaluation.

The results-orientation of PRSPs has had several important effects on development practice for both borrowers and lenders. As I will discuss further in the Conclusion, reviews of the early PRSPs indicated that the prioritization and results orientation of many documents were uneven. ${ }^{58}$ This has lead to increasing pressure on countries to develop more results-oriented poverty reduction strategies. Since the same reviews 
made it clear that many countries do not have the capacity to produce the necessary statistics, nor to integrate results management into their public service, this has also increased emphasis on institutional capacity building and on results-based public-sector reform more generally.

Donors have also pushed for results-based management at the country level, particularly through their role in the World Bank's International Development Association (IDA). IDA funds are provided to low-income countries (LICs) in the form of long-term interest-free loans and grants, and are made possible through contributions (known as fund replenishments) from industrialized states. During the negotiations over IDA13 in 2002, the thirty-nine donors agreed that their support was contingent on borrowers' being able to demonstrate specific results. Outcome indicators were developed to track progress towards achieving targets in areas such as health and private sector development. ${ }^{59}$ Ultimately, the Bank created a system of "performance based allocation" (PBA) that linked the level of IDA funding that each country could receive to a score that was a combination of a country's demonstration of need and its performance as determined through the country policy and institutional assessments indicators (or CPIA - as discussed in Chapters 6 and 7). ${ }^{60}$ Three years later, IDA14 took this results-oriented approach one step further and developed a Results Measurement System at the Bank that monitors broad country-level outcomes, IDA's contribution to those country outcomes and changes in statistical capacity in LICs.

Most recently, the Bank has proposed yet another results-based instrument: the Program for Results (P4R) lending. The P4R, which was adopted by the Board in 2012, is designed to provide a third form of World Bank lending, somewhere between investment lending (for specific projects) and development policy lending (for broader government reforms). Bank management seeks to use this lending instrument to directly tie the disbursements of funds to the achievement of agreed performance indicators, such as a percentage reduction in the mortality rates of children under five, or the length of time that it takes to start a new business. ${ }^{61}$ One of the primary goals of the Bank's new resultsoriented programs is to focus on building country capacity - particularly their capacity for results measurement, fiduciary oversight and risk management (all the technical capacities needed for a results-based approach). ${ }^{62}$ Interestingly, one of the main arguments presented in the Bank's Revised Concept Note in favour of P4R is the fact that other already existing lending instruments cannot be fully tied to results; the document's authors make no attempt to justify the usefulness of focusing on results per se, but rather seek to explain why this particular instrument is needed in order to allow a results focus. Results management is thus 
becoming black-boxed as an operational concept in development assistance: a general good that needs no justification.

\section{Analysing governance factors}

The path towards the current quantitative approach to results-based measurement and management has therefore not been a straight line from public-choice textbooks to the current action plans and results strategies. Instead, it was only after a decade of trying to modify the stricter forms of results-based management to suit the complexities and uncertainties of development programs, to reconcile it with the goals of country ownership and to integrate some of the insights of participatory evaluation, that we have now seen a turn to a more donor-driven kind of measurement strategy. In this final section, I will trace the ways in which the results strategy involves significant changes to the factors of governance.

I have suggested throughout this chapter that results-based management is above all about creating a new kind of knowledge. For if one wants to manage for and by results, one also needs to know those results; this in turn means determining what results are desirable and how to measure them, and deciding what constitutes a result in the first place. This process of creating new kinds of facts called indicators, targets and results is as much material as it is ideational: it involves a new set of measurement and inscription techniques to make them possible. All of these elements - the starting point, the objectives and the indicators - must be translated into facts, of either quantitative or qualitative kind. They have to be made into paper - or more precisely into tables, graphs, charts or, best of all, numbers. Of course, development practices have always had to translate complex information into various kinds of inscriptions chiefly reports. What is different about this kind of inscription is its attempt to make this new slippery object - the result - visible, and to do so in a way that manufactures clear causal connections between specific policy actions on the one hand and a number of concrete development outcomes on the other. Although the promised results appear to be very concrete, they are in fact based on a set of highly symbolic practices that make the links between action and outcome visible.

The development of these new measurement and inscription techniques has concrete effects on how policy is conducted. Results-based measurement involves a shift from focusing on inputs and outputs to emphasizing results. Yet it is also a shift from processes to outcomes, as many of the critics of results-based management have pointed out. ${ }^{63}$ It is easier to count the number of women who show up for participatory evaluation 
sessions than to determine whether their voices carried weight. ${ }^{64}$ The focus on results - and more specifically on results as translated into quantifiable indicators that can be compared and aggregated into appealing reports - thus has specific costs and consequences for the ways in which development is conceptualized and practised.

The contemporary results strategy also relies on a second set of techniques that seek to produce new knowledge through the solicitation of public feedback via various technologies of community. This is where the LOGFRAME meets some of the ideals of participatory development. These techniques seek to connect policymakers to particular publics through the logics of demand and accountability. In some cases, results-based approaches involve direct participation by local groups affected by development policies - either to identify desired outcomes or to evaluate success in meeting them. The PRSP is the most obvious example of this linking of participation and results, since it was designed to funnel broad-based consultation processes into a set of objectives that can be prioritized and set out in a results matrix. ${ }^{65}$

The publication of results links these two techniques through the same kind of symbolic logic that we saw in the strategies of ownership, standardization and risk management: result scorecards make visible the complex (and often highly problematic) links between policy action and outcome, and in the process signal better or worse performance. Such symbolic practices are also performative: the goal here, as in the other strategies, is not only to rank performance but also to mobilize governments and NGOs to pay attention to the results and respond accordingly.

These techniques thus seek to enrol new actors and ultimately to transform them. The first and most obvious group of actors to be enrolled is bureaucratic staff, in both donor organizations and recipient governments. Results-based measurement involves subjecting the calculators themselves - development organization staff - to a new kind of institutional culture. New public management advocates are quite explicit about the fact that one of their central goals is to create a "results culture" in which staff will change not only their behaviour but also their sense of identity as they become more entrepreneurial in their effort to achieve results. One senior World Bank staff member who has run workshops on results measurement suggested that a results focus changes policy, but not in a mechanical way: instead, the process of thinking about results actually changes people's mind-sets. ${ }^{66}$

These workshops and training programs do not only target IFI and donor government staff, but are also oriented towards developing and emerging market bureaucrats. This effort has been underway for a good number of years, in the context of IFI and donor pressures for 
public-sector reform. Yet it is only more recently that developing publicsectors statistical capacity has become a key priority for development efforts - as it is in the Bank's proposed P4R instrument. The goal is ultimately to train people to view their activities through the lens of results measurement, identifying the objective, mechanisms and indicators on their own. Results-based management thus seeks not only to make up facts, but also to "make up people" - transforming the bureaucratic hack of old into a new kind of subject capable of certain kinds of calculation and responsible for his or her specific policy effects. ${ }^{67}$

At the other end of this measurement process, however, these techniques seek to constitute and enrol another kind of new actor in governance activities: the public. This public not only includes the individuals who participate in certain forms of evaluation and measurement, but also refers to a more abstract public invoked by both public choice theorists and development policy documents: the public that demands accountability in the form of visible, measurable results. This public exists in both donor and borrower countries, and plays a crucial role (at least in theory) in demanding better and more clearly demonstrated results. Results-based management thus seeks to involve the public in governing development by creating the kinds of facts that they need to hold donor and borrowing governments to account. Results-based management techniques, like the good governance reforms and risk management strategies that I discussed in earlier chapters, are to be based not just on IO and donor supply but also on country-level demand. Results-based measurement thus seeks to redistribute some of the authority for governing development to domestic government bureaucrats and the wider population through their capacity to hold the government to account for policy results.

These new techniques of creating new kinds of facts, reshaping institutional cultures and encouraging certain kinds of public participation all involve particular forms of power. Some of these are highly exclusionary: performance-based allocation is probably the clearest example of this kind of power, creating as a does a new kind of ex-ante conditionality. The performance-based allocations use CPIA measurements of country performance to determine how much aid a country can receive. A poor score can mean a 40 per cent drop in funding for a country desperately in need of aid. ${ }^{68}$ With the development of results-based P4R lending at the World Bank, more financing will be tied to performance. No matter how it is dressed up, this is a highly exclusive kind of power. Yet even where power appears relatively obvious, as it is in this case, it is also quite indirect. Although results seem to be a very direct object to target, they are always several times removed from those seeking to attain them, and 
may not be entirely within their control. The very fact of focusing on results and outcomes as the basis for allocating aid (e.g. number of days it takes to open a business), rather than on specific policies or efforts (e.g. passing legislation to facilitate new business start-ups), means that it is much harder to determine responsibility for a country's improving or worsening score; the ultimate results may be caused by local inefficiency, cultures of non-compliance, broader economic changes, or any number of other factors not within the direct control of the government. The effect of this kind of performance-based financing is rather similar to the informalization of conditionality that I discussed in Chapter 5: even though the conditions are explicit in this case, it is not at all clear how to ensure compliance.

Why would donors and IOs create conditions without making it clear how to go about complying with them? Why should A tell B what they should achieve without telling them how to do so? Clearly, the object of power in this case is not simply the achieving of the result, but the process of getting there: of having to figure out how to obtain it. By rewarding and punishing specific results, the hope is to encourage a change in the behaviour of those pursuing them. This is a kind of productive power that encourages a new kind of responsibility in developing countries. ${ }^{69}$ Borrowing governments are thus lent a certain degree of authority in determining how to obtain the outcomes, but are not given the right to determine what those outcomes should be. Of course, it is not just borrowing governments who are the objects of this kind of productive power. Organizational staff are also key targets: the goal of results management is quite explicitly to transform bureaucratic cultures both within developing countries and in the agencies that lend to them.

Perhaps most interesting of all, however, are the transformations to expert and popular authority enabled by results-based management techniques. These new techniques are designed to re-found the expert authority of international and domestic development agencies by creating a new kind of fact that promises to show the definitive links between policy actions and their effects. This manoeuvre is absolutely essential for organizations whose internal cultures and external legitimacy have always rested on claims to expertise. Less obvious, but just as important, is the way in which the results strategy also seeks to redistribute authority to a wider group of actors, including the general public, and, in the process, to bolster lenders' expert authority with claims to popular legitimacy. The public choice theory that underpins results-based management has always involved a particular (narrow) conception of the public: as an aggregation of rational maximizing individuals who demand value for money from their civil service. ${ }^{70}$ The gamble then is that the publics in 
both borrowing and donor countries will see their needs and priorities reflected in development targets and results, and thus grant the organizations the legitimacy to continue their work.

\section{A more provisional style of governance}

I have argued throughout this book that the various changes that we are currently witnessing in how development is financed add up to a shift towards a more provisional form of governance - a kind of governance that is more proactive in its engagement with the future, often indirect in its relationship with its object, reliant on increasingly symbolic techniques, and above all aware of and evasive in the face of the possibility of failure. If we believe what many of the advocates of the results agenda say about it, we would have to conclude that results measurement is the least provisional of these new strategies of governance. After all, it promises direct and transparent access to the truth about which development policies succeed and which fail in delivering concrete results. Yet, as my examination of the results strategy in this chapter has shown, the way that results measurement works is far more complex - and provisional - than this straightforward account suggests.

Although those who advocate results-based management focus on the end-point of development finance - its outcomes - they do so in order to change the way that practitioners approach any project, by changing the way that they conceptualize and plan the work at hand. This is a highly proactive form of governance that seeks to inculcate a particular kind of awareness of the future. Whereas in the past, measurement and evaluation was more episodic and often relegated to specialized units, it has now become all-pervasive in space and time. Although some bureaucratic actors and units remain evaluation specialists, all are required to engage in the process of identifying, anticipating and measuring results. Results measurement is thus an indirect form of governance, focusing on gradually altering bureaucratic measurement cultures in order to change their actions over the longer term. When the bureaucracies targeted are in LICs, this effort to transform the culture of development finance becomes a very potent but indirect form of power.

Results measurement is also a strategy that is preoccupied with the problem of failure. In recent years, as development agencies and IFIs have made it a top priority, they have done so in order to respond to their stakeholders' concerns about past failures of aid effectiveness. At the same time, the strategy's strong ties to public-choice theory and its suspicion of the public sector mean that it is always haunted by an awareness of the possibility of yet more failures. It is hard to ignore the 
underlying assumption that if it is not possible to show visible results, then the policy is just another public-sector failure. Hence the importance of making any successes visible by clearly demonstrating the actual results of particular organizations' actions.

Yet in practice, as I will discuss at greater length in the next chapter, the results measurement strategy has encountered some of its own limits and failures. Although the pressure to adopt results management is immense, there is nonetheless significant resistance within many agencies and IFIs - with the IMF being the most notable example. Underlying much of this resistance is an awareness of the fragility of many of the expert claims on which results management is based. This fragility in turn is linked in large measure to the symbolic and highly constructed character of the key inscriptions at the heart of the strategy. In one sense, results are very real: they may involve a certain number of early-childhood deaths, or a particular level of inflation. Yet results are also symbolic insofar as they signal a kind of achievement based on a claim that this particular set of deaths or level of prices is a direct result of specific lender actions - causal links that are often highly questionable given the multitude of lenders, programs and exogenous factors affecting such complex outcomes. We should therefore not be too surprised that there is a growing debate about whether the new "facts" that results strategies promise to create have any validity: a growing number of institutional staff and commentators are questioning the plausibility of efforts to establish causality and attribution - drawing a line between policy input and outcome. ${ }^{71}$ Thus, ironically, even as results measurement appears to be getting more definitive and factual, it is actually becoming more fictitious and symbolic, as claims about results achieved slip further away from reality.

Paradoxically, these methodological and epistemological weaknesses in the results strategy provide an opportunity of sorts for institutional actors creating a certain amount of fuzziness in the results matrixes and therefore some room to hedge against failure. Despite renewed emphasis on hard numbers, because of their often-symbolic character, the careful identification of indicators and elaboration of results chains are subject to a certain amount of fudging, as both borrowers and lenders have significant incentives and opportunities to "game" the numbers and demonstrate positive results. This is particularly the case at the World Bank, where the incentive structure remains focused on the disbursement of as many dollars as possible, regardless of results. ${ }^{72}$ Organizations have clear incentives to publish positive results and can often find ways of making less than perfect results appear satisfactory. For example, as Stephen Brown points out, the Canadian government's document on their aid commitments 
indicates that everything is "on target" even when the evidence suggests that results have slipped in several categories. ${ }^{73}$

However ingenious the attempts to game the system may be, and however ubiquitous the call for results, the strategy remains fragile and subject to considerable tensions. The wager that it is based on - that the demonstration of measurable results will re-establish IFI and donor authority - is thus far from certain to pay off. Yet all of the various strategies' efforts to bolster institutional authority hinge to some extent on their promise of providing measureable results. The uncertain destiny of the results agenda thus raises important questions about the direction and sustainability of the new more provisional logic of global economic governance, as I will discuss in the Conclusion. 
Part IV

Conclusion 


\section{The politics of failure and the future of provisional governance}

How do international financial institutions (IFIs) and donors do the work of financing development today? They do it by developing flexible but ambitious best practices in a wide range of areas, fostering country ownership through increasingly symbolic conditions, anticipating the risks and vulnerabilities faced by poor people and countries, and developing complex metrics for determining the results of these efforts. If we compare these governance practices to those that were central to the structural adjustment policies of the 1980s and early 1990s, it is clear that something important has changed. That change is not so much in the goals of development finance, but in the way that governance works.

In this book, I have sought to understand why this shift occurred and to consider how these new practices do the work of financing development. I have suggested that the fragility of expert authority and the politics of failure both play important roles in explaining this transformation in how global development is financed. Bureaucratic organizations like the IFIs and donor agencies have historically relied heavily on technical expertise as the basis of their authority, a tendency that was particularly strong during the structural adjustment era. Yet as Sheldon Wolin shows us, that expert authority is inherently fragile - as it periodically finds itself out of step with the messy world that it seeks to comprehend. ${ }^{1}$

Institutions can of course go a long time without confronting the limits of expertise: these are periods in which the assumptions and compromises that underpin their truth claims remain tacit and black-boxed. But even the most stable of these periods of certainty remains vulnerable to doubt and debate. I argue that one of the crucial ways that these vulnerabilities come to light is in the context of contested failures. These are failures whose causes and implications are in profound dispute; that are seen as so significant that they put into doubt past metrics of success and failure; and that, through the process of problematization, ultimately foster important changes in how governance is practised. ${ }^{2}$

Each of the four governance strategies that I have discussed in this book - developing global standards, fostering country ownership, 
managing risk and vulnerability, and measuring results - was developed through such processes of contestation and problematization in the context of the failures of the Asian financial crisis, the decades of despair in sub-Saharan Africa, and the recent global financial crisis. IFI and donor staff, political leaders, non-governmental organizations (NGOs) and academics all played their parts in identifying new problems, and debating and developing new ways of governing them.

Each of these strategies has its own history and dynamics, taking diverse forms in each institution. Yet when we dig deeper into the various factors of governance that make up these strategies - the actors, the forms of knowledge, the techniques, and the kinds of power and authority involved - we find patterns. Each of these strategies attempts to enrol a wider range of actors in the daily practice of governance, drawing domestic governments, civil society members, market actors and the poor into the process. They also use a similar set of small "i" ideas, such as public-choice theory, new institutionalist economics and new public management, and make some profound changes to the ontology and epistemology of development governance.

The creators of these strategies make use of increasingly symbolic and performative techniques, delegating to inscriptions like the Poverty Reduction Strategy Papers (PRSPs), Reports on the Observance of Standards and Codes (ROSCs), and debt sustainability analyses (DSAs) the power to inspire and mobilize domestic actors to demand changes from government. They also grant more authority for governing to domestic actors, thus supplementing expert with more popular and moral forms of authority. Finally, they make increasing use of less direct, but more subtly exclusive forms of power: seeking to foster particular kinds of self-governance in those actors to whom authority has been delegated, while using sorting and ranking processes to separate the worthy from the unworthy. Together, these practices constitute a more provisional style of governance: one that is more proactive and preemptive, that is often indirect in its approach to its objects, that relies increasingly on symbolic practices, and that is both aware of and seeks to hedge against the possibility of failure.

I began this study of the rise of this provisional style of governance by identifying two central problems in modern governance: the fragility of expertise and the politics of failure. I return to these two themes once again in this concluding chapter. Although those involved in developing and implementing these new governance practices are more aware than their predecessors of the problem of failure and often better able to avoid it, they nonetheless must come to terms with its persistent place in development finance. I will begin by examining the various limits and 
challenges encountered by each of these new governance strategies, pointing to the particular forms that failure takes in the context of a more provisional style of governance. I will then discuss the implications of these failures for both the institutions themselves and the political communities affected by their policies. I will conclude by considering the future of provisional governance, identifying two possible paths that it might take, each based on a different politics of expertise: while there remains the possibility of pursuing a more open-ended and inclusive kind of governance, the approach that has been gaining strength in recent years is a far more cautious and even cynical form of development finance.

\section{New failures}

The persistence of the problem of failure in recent years should not come as much of a surprise, given that, as James Ferguson has pointed out, failure is the norm in much international development. ${ }^{3}$ It is nonetheless worth asking what kinds of failures these new strategies are facing, and what their likely impact is on the sustainability of this new style of governance. The form that these failures take is not accidental: they are linked to the more provisional character of current governance efforts. The trajectory of failure that we saw towards the end of the structural adjustment era was one of denial, bluffing and ultimate erosion (with a certain amount of ongoing denial among some key actors) as the epistemological certainties underpinning expert governance were undermined by several massive contested failures. In recent years, the pattern of failure has been more complex: because those engaged in practices of governance are now more aware of the possibility of failure, we instead see careful attempts to insulate policies against failure combined with an anxious undercurrent of awareness of the limits of such efforts.

Two kinds of failure in particular confront recent governance strategies. The first of these is a failure of consensus, or a failure to black-box. This is a subjective failure, since it hinges on key actors' perceptions of the strategies' effectiveness. It is also a particularly important kind of failure, since one of the central goals of any governance strategy is to respond to a moment of problematization by returning contested issues back into a set of tacit assumptions. Yet none of the strategies discussed in this book have succeeded in achieving the degree of black-boxing obtained during the structural adjustment era. Many of the main actors involved in the practices of fostering ownership, managing risk, measuring results and developing global standards remain ambivalent about these strategies and the basic assumptions that underpin them. 
These failures to black-box are linked in turn to a second, more objective, form of failure: a failure of performance, or in many cases, of performativity. Governance practices are not simply ideas, frameworks or arguments about how things should be done. For them to gain and maintain support, they must also achieve in practice at least some of what they promise. Although, as I will discuss further below, it is always possible to some extent to explain away performance failures as the result of exogenous circumstances, this becomes particularly difficult where the failures are not simply in achieving long-term goals (e.g. reducing the level of poverty) but in the short-term effectiveness of the techniques themselves. This is particularly important for those strategies that rely on the performativity of their techniques to achieve their ends: as part of the strategy of standardization, for example, ROSCs are supposed to be used by market and civil society actors to hold governments to account. If this technique fails to do what it promises (because key actors ignore the ROSCs), then this crucial aspect of the governance strategy faces a failure of performativity.

In the remainder of this section, I will return to each of the governance strategies and consider what kinds of failure they have been facing in recent years. I will then turn to a secondary, but crucial, question, which is to ask whether or not these failures actually matter.

\section{Fostering ownership}

There have been at least three notable examples of performance failure in efforts to implement the ownership strategy: failures in efforts to reduce the number of structural conditions, to build meaningful participation into the PRSP process, and to operationalize the PRSP. The Independent Evaluation Office (IEO) at the International Monetary Fund (IMF) released a report in November of 2007 on the IMF's streamlining initiative that concluded that although conditions were now more focused on "core" IMF areas, the streamlining initiative had not actually reduced the number of structural conditions. ${ }^{4}$ Moreover, Fund programs still included conditions that were not deemed critical to program objectives. ${ }^{5}$ The streamlining exercise thus largely failed to reign in structural conditionality.

In the case of the PRSP, both external and internal reports suggest that the program has failed to genuinely engage civil society in preparing the crucial document. A number of studies of the Bolivian experience with the PRSP, generally seen by the IFIs as one of their successes, have pointed to the narrow scope of participation. As Nadia Molenars and Robrecht Renard put it, the selection of civil society participants was 
politicized, as it was dominated by local government officials, at the same time as the agenda for debate was depoliticized - focused almost exclusively on social rather than political and economic issues. ${ }^{6}$ Although the context and the mechanisms of participation were different in Uganda, Laure-Hélène Piron and Andy Norton raise similar concerns about the fact that certain groups were included while others (deemed more "political," like unions) were excluded from the process, and that economic and, above all, political questions were kept off the table.

The IMF and World Bank also undertook two major joint reviews of the PRSP process, while the IMF's IEO evaluated the IMF's role in PRSPs. ${ }^{8}$ Not surprisingly, the internal reviews have generally been positive about the overall direction of the programs. Yet despite their optimism, the internal reviews also highlighted some significant concerns about the programs, including limited participation, insufficient policy space, donor-driven processes and inadequate tailoring. While later generations of PRSPs have responded at least in part to such criticisms, the early enthusiasm about the policy both inside and outside the IFIs has faded.

Finally, the PRSP has significant technical limitations. The ingenuity of the PRSP rests in part on its capacity to translate a broad range of concerns into a single inscription designed to coordinate development activity. Yet it is not clear whether the PRSP is a useful inscription at all. As one former senior Bank staff member put it:

You often ended up with one of two problems: if the process was locally driven, it often ended up being mired in domestic politics, and most governments took the easy way out which was letting everyone throw in the kitchen sink: there was no prioritizing or costing, and it risked becoming a useless exercise ... On the other hand, you had cases where the participatory approach was a sham, and the government ownership was limited because we were dealing with a very limited number of people in the government. ${ }^{9}$

The effectiveness of the PRSP depends on the translation of a multitude of voices into a single coherent text, and the enrolment of a much wider range of actors in a common project. Yet in those cases in which a genuine attempt is made to bring a diverse range of people into the conversation, their very multiplicity resists straightforward translation into a tidy bureaucratic document, reducing the PRSP's usefulness as a governance tool.

These practical failures have helped to erode key actors' support for the ownership strategy, and undermined efforts to black-box the strategy. Many of the IFI staff I spoke with expressed frustration with the lack of prioritization in PRSPs and the considerable difficulties of using them as guides for the various lending policies and programs they were supposed 
to inform. ${ }^{10}$ Despite efforts to resolve these tensions and "mind the gaps" between the PRSP and government and donor policies, problems remain. ${ }^{11}$ Over the several years that I undertook these interviews, it was clear that there was less attention and energy being put into the PRSPs, partly because they simply have not been easy to put into practice. Many staff members feel outside of their comfort zone when asked to assess ownership, or to consider the impact of a policy on poverty. ${ }^{12}$ Inside the IMF, in particular, there has been considerable ambivalence about the expansion of the organization's mandate. ${ }^{13}$ Staff at both organizations admit that the PRSP is no longer as important as it once was, and note that ownership has become a less important lens for designing new policies.

\section{Developing global standards}

The universal claims of the strategy of standardization depend on its capacity to sustain a consensus on what counts as a global standard. Yet that consensus - insofar as it was ever achieved - is unravelling. The strategy of standardization has always been a compromise of sorts - an attempt to develop soft universals that fall between a fully contextualist, case-by-case approach, and hard economic rules of the kind that characterized the earlier structural adjustment era. At the same time, these standards are far more ambitious in their scope than earlier economic principles, moving into highly contestable social and political terrain. As a result, these universals are far more obviously subjective and constructed than those economic principles that underpinned the structural adjustment era: they are therefore harder to black-box, leading to ongoing ambivalence about the strategy among the IFIs.

There has always been some disagreement among institutional actors about whether these new standards are truly universal. Even as the idea of "best practices" was gaining ground at the IMF in 1997, some Executive Board members expressed reservations about their appropriateness. ${ }^{14}$ The World Bank's 2000 and 2002 reports on governance also questioned the appropriateness of the "best practices" approach that had dominated discussions to that point. ${ }^{15}$ With the arrival of Paul Wolfowitz as President in 2005, and his increased emphasis on corruption as the centrepiece of the good governance agenda, the universality of the strategy again became a subject of heated debate among Board members as they challenged the appropriateness of translating good governance performance into a set of standardized indicators. ${ }^{16}$

Whereas these challenges have come from those opposed to excessive standardizing, there are also those who would like to return to something closer to universal rules. At the IMF, there have been persistent calls for 
the institution to withdraw from more overtly political issues like governance altogether. It was partly because of such concerns that the Board made the decision to streamline conditionality. Since that time, there have been growing calls from powerful members, particularly the United States, for the Fund to narrow its activities to those areas clearly within its mandate. ${ }^{17}$ There have also always been those, like the British government, who have argued that standards should be mandatory, an argument that re-emerged in the wake of the recent global financial crisis. ${ }^{18}$

Although the idea of global standards has certainly become pervasive and generally accepted in development financing circles, these examples make it clear that the strategy has only ever been partly black-boxed. As Lampland and Star suggest, the seeming neutrality of standards "obscures the enormous amount of work needed to stabilize knowledge, freeze action, delete outliers and residuals, and facilitate use." ${ }^{19}$ In the case of the strategy to develop global standards, this work of stabilizing and purifying is ongoing and continues to be contested.

In addition to these internal debates about the standardization strategy, there is evidence to suggest that these new techniques have not had the productive and performative effects that they were intended to have. As I noted above, the publication of inscriptions like the ROSC or scorecards on government actions is supposed have the performative effect of empowering citizens and market participants to demand government reforms. It is not at all clear, however, that market actors are behaving according to plan. The IMF and World Bank's own evaluations of the standards and codes initiative found that market participants were not using the data on government compliance published in the ROSCs. ${ }^{20}$ Moreover, although the IMF has regularly cited studies that suggest that markets have rewarded economies that are more transparent, even they admit that the evidence remains inconclusive at best. ${ }^{21}$ Despite these setbacks, the IMF has continued with the standards and codes initiative while scaling back expectations that the publication of the ROSCs will mobilize market actors to reward or punish participating governments. ${ }^{22}$

\section{Managing risk and vulnerability}

Attempts to measure and manage risk and vulnerability, in their turn, face methodological difficulties that threaten the fragile expert consensus around the strategy. Fund and World Bank staff have found that a country's or individual's vulnerability to shocks depends in considerable measure on political and social factors that resist easy calculation. While the many acronymic indices produced as part of risk and vulnerability assessments - CPIA, PEFA, DSA and RVA - help to black-box 
the assumptions required to quantify these complex factors, they nonetheless remain vulnerable to criticism. ${ }^{23}$

As I noted in Chapter 7, a number of senior economists at the World Bank were initially critical of the social risk framework. While this resistance has faded as social protection has become integrated into the institution, there is still considerable scepticism about this approach to measuring poverty. ${ }^{24}$ Moreover, although staff have been at pains to emphasize the innovative character of the strategies for measuring vulnerability and risk, they continue to encounter difficulties in obtaining the right kind of data given the poor statistical capacities of many of the countries that they are dealing with. ${ }^{25}$ Debates continue not only about the meaning of different measures but also on their ability to translate into new practices. ${ }^{26}$ In fact, after almost a decade of RVAs, Social Protection staff concluded that they had not taken off and they were therefore dropped as institutional practices. ${ }^{27}$

The IMF's debt sustainability and vulnerability assessments, in their turn, have also faced methodological limits. Staff, Board members and NGOs have expressed doubts about these metrics, challenging the heavy reliance on the CPIA as a proxy for institutional capacity. Although Fund staff have been careful to emphasize the objectivity of the initial stage of the evaluation process, they remain sensitive to the fact that, as one document put it, any evaluation of vulnerability "would depend heavily on assessments of macroeconomic and public financial management capacity, which would inevitably have a subjective element."28

Academic critics have also raised concerns about the accuracy of the Fund's DSA. As Charles Wyplosz notes in an analysis of the problem: "while price stability or full employment can both be measured with a reasonable degree of precision, debt sustainability cannot even be measured directly." ${ }^{29}$ Wyplosz goes on to suggest that the process of assessing debt sustainability is "mission impossible," a fool's errand of sorts that produces more errors even as it seeks to become more attuned to the complexities of the task.

These more methodological problems have also led to failures of performance and performativity. Most of the World Bank staff I spoke with agreed that the social risk framework was a powerful set of ideas - but that ultimately it had not been effectively put into practice. ${ }^{30}$ This is also the conclusion reached in the 2011 concept note prepared as part of the development of a new social protection strategy (SPS), which suggests that while the social risk management framework "has provided intellectual coherence" it has nonetheless "not always provided sufficient guidance to operations." ${ }^{31}$ Even in cases where policies have been adapted to take more account of social risk, the evidence of success is mixed. 
The conditional cash transfers (CCTs), which are generally viewed as one of the biggest success stories of development policy innovation over the past decade, have had significant success in changing medium-term behaviour - e.g. increasing the number of days children stay in school. Yet there is little evidence of real improvement in "final" outcomes - such as educational attainment or better wages. ${ }^{32}$ It is not clear that efforts to "make up" new kinds of risk-managing and long-term thinking individuals - the ultimate goal of these performative policies - have yet succeeded.

\section{Measuring results}

Although the results agenda has come a long way over these past two decades, the shift towards results-driven policy has not been smooth, and the strategy remains far from black-boxed. There is no question that there is significant momentum towards results measurement among donor agencies and the IFIs; in the words of one senior IMF staff member, there has been "huge pressure" on both the Fund and the World Bank (particularly from the UK and the US) to adopt more results-oriented policies. ${ }^{33}$ Yet there has also been some push-back from the IFIs - most notably by the IMF, but also, to a lesser extent, by World Bank staff.

One place where this push-back is particularly evident is at the IMF. Fund staff have actively resisted moving in the direction of measuring results because they see their policy practices as defying straightforward causal analysis of the kind required for results management. The Fund staff members I spoke with argued that the desired results of Fund programs - such as lowering inflation or increasing economic growth in a given country - are so broad and affected by so many factors that it is impossible to pinpoint the effects of a given Fund program. ${ }^{34}$ As one senior staff member put it, the causes of something like economic growth are "somewhat mysterious," making it unlikely that the Fund would ever embrace the results agenda. ${ }^{35}$

This is not the first time that the IMF has considered and ultimately stepped back from placing results evaluation at the heart of their policies. The IMF Executive Board discussed the possibility of integrating results more directly into their lending programs in the context of their 2002 review of conditionality. At that time, they discussed the possibility of introducing outcomes-based conditionality, in which funds would be disbursed once a country met agreed-upon outcomes. ${ }^{36}$ Yet the Board was divided on the issue and the staff ultimately recommended against adopting the measures - partly because they could not see how the Board could walk away from a program if it failed due to external factors. ${ }^{37}$ 
It is not just the IMF, however, that has been resisting the results agenda. Andrew Natsios, who headed up the US Agency for International Development (USAID) from 2001 to 2005, has published a widely read critique of the perverse effects of results-based management and other examples of what he calls "obsessive measurement disorder." 38 Some World Bank staff members have also been pushing back against the pressure to focus on results. Not surprisingly, the Bank staff members' responses have been mixed: those working in the social and human development sectors have been most supportive of the move towards measuring results, while others have been more resistant. As one senior staff member put it, some sectors have a hard time agreeing on the results that they want to obtain. ${ }^{39}$ Moreover, some issues, such as governance and institution-building, are notoriously difficult to quantify, making the results agenda a harder sell. ${ }^{40}$

This resistance on the part of certain staff members to the results agenda is linked to their perception that the strategy has failed to perform as promised. At the heart of the results agenda is the belief that it is possible to accurately identify the outcomes of particular IFI and donor policies. Yet even as staff at the World Bank, the IMF, the Canadian development department (CIDA), the British Department for International Development (DFID) and USAID are exhorted to demonstrate concrete results, many of them are finding it difficult to do so. Although IMF staff justify their resistance to results by arguing that broad macroeconomic factors like inflation levels are impossible to relate back to individual policies, it is just as difficult to determine the impact of a specific World Bank program on infant mortality rates. Both results are over-determined by an array of complex factors. Staff at these institutions are not unaware of these methodological difficulties and their practical implications. A number of Organisation of Economic Co-operation and Development (OECD) staff members I spoke with described this as the crucial problem of attribution: the virtual impossibility of knowing with any certainty to what degree one assistance program among many (in addition to numerous other variables) may have achieved a given outcome. ${ }^{41}$

Another major performative objective of the strategy of results measurement is to foster a results culture among IFI, donor- and borrowingcountry bureaucracies. Yet here again, the results (so to speak) have been far from consistent. Although aid agencies and IFIs are supposed to publish their results and learn from their mistakes, a number of donor and IFI staff suggested to me that there is considerable institutional pressure to show successes rather than to admit failures. Others suggested that, at the World Bank at least, the dominant culture is still one of 
moving funds out of the door, with results assessment being largely treated as a hoop to jump through rather than a meaningful criterion. ${ }^{42}$ There is just too much temptation to massage results matrixes to show that things are going well. As Isaline Bergamaschi shows in the Malian case, developing country governments have also resisted or "appropriated" the resultsbased agenda in various ways, by, for example, setting indicators to relatively easily achieved levels. ${ }^{43}$ Even where Malian officials have had to cede ground to lenders' concerns, they have seen the results strategy as an instrument of control, undermining the kind of entrepreneurial bureaucratic culture that IFIs and donors had hoped to create. ${ }^{44}$

\section{Do these failures matter?}

Before we can assess the full implications of these failures for the future of provisional governance, we need to assess whether they matter and, if so, for whom. In fact, from the point of view of the institutions themselves, many of these failures are either benign or constructive. As Timothy Mitchell has pointed out, the fact that certain theories or policies do not have the effects that they purport to have does not mean that they are not useful. The economic theories that underpinned structural adjustment policies were often simply wrong, but this did not stop them from having significant effects. ${ }^{45}$ In some cases, failures are irrelevant, since the effectiveness of the policies lies elsewhere. Moreover, as Shoshana Magnet has pointed out, some errors can be productive, ${ }^{46}$ and some failures are actually constructive, as the gap between theory and practice is essential to the policy. ${ }^{47}$

Ironically, many of the most obvious failures in performance are the least problematic - at least for the sustainability of the institutions and their policies, if not for the poor countries affected. I discussed above the failure of the PRSPs to enable a genuinely participatory process - a central goal of a policy designed to foster country ownership. While this seems like a serious failure, its effects depend on how institutional actors conceptualize ownership. The OECD's Paris Declaration, in a remarkably circular logic, deems ownership to exist if a country has an IFI-approved PRSP (in other words, ownership is in the eye of the IFIs). ${ }^{48}$ More generally, there is a tendency among IFI and donor staff to define ownership in minimalist terms, as the acceptance by borrowing country actors of the "correct" path to reform, rather than as their meaningful engagement in defining the scope and direction of that reform. ${ }^{49}$ If ownership is defined in such minimalist terms, then the absence of more robust engagement and meaningful ownership will not matter that much. 
Some failures to black-box a strategy are similarly benign as long as the debates do not get too hot. In the case of the social risk policy at the World Bank, while there have been questions about the added value of focusing on risk (rather than more traditional conceptions of poverty), the Social Protection and Labour unit has responded by adapting their framework without actually ceding much ground. In consultations leading up to the revised strategy, risk management remained a key theme, but a less prominent one. At the same time, the focus on the challenges of uncertainty became even more central: the unit's website, concept note and consultation presentation all frame the strategy as a means of responding to increasingly uncertain times. Moreover, the unit wants to place more emphasis on the promotion of social protection reinforcing the emphasis on a more dynamic, proactive approach. ${ }^{50}$ Thus the provisional style of governance underlying the strategy remains unchanged despite some debate and renegotiation.

Some policy failures can even be constructive. Although the failure to significantly reduce the number of structural conditions seems to be a serious blow to efforts to streamline conditionality, in fact, this is not a terribly destructive failure. As I discussed in Chapter 5, the key techniques in this new approach to conditionality involve treating conditions as more symbolic than real - as signals of credibility - while also informalizing much of the effective conditionality. Neither of these techniques, nor the productive forms of power that they enable, is hindered by the failure to reduce the number of structural conditions. In some ways, this tension between rhetoric and reality (or hypocrisy, as Catherine Weaver would call it), is constructive for the institution, since it provides an outlet for differences of opinion within the organization, allowing those staff wedded to traditional conditionality to impose significant numbers, all the while allowing reformers to emphasize the success in narrowing their scope. ${ }^{51}$ Of course, the apparent failure to streamline conditions has provided fuel to the Fund's critics - but they are fewer in number and influence than a decade ago.

The above examples illustrate Ferguson and Mitchell's contention that the performativity of many development policies does not depend on their capacity to accurately describe, explain or predict the world that they seek to affect. Even when a policy predicts one thing - such as genuine ownership - and yet delivers something else, such failures need not lead to the kinds of contestation and problematization that can erode it.

Yet some failures do have some genuinely destructive effects on governance efforts. In such cases, it is not just that institutions get things wrong, or say one thing but do another, but rather that the performativity 
of the techniques themselves fails in some way, undermining their power and authority. For example, the failure of the standards and codes initiative to attract market actors' interest in the ROSC assessments is a blow to the policy, since it undermines the IFIs' capacity to indirectly reward or discipline participating governments. Market actors' failure to pay much attention to governments' compliance with the standards also puts into doubt the credibility of the standards as universal, eroding their expert authority. Because they undermine some of the strategy's key factors - the techniques and forms of power and authority involved these are failures that are likely to be corrosive to the long-term sustainability of the standards and codes initiative.

Similarly, the limits of the PRSP are double-edged. As I noted above, from a technical perspective, thin forms of participation are not particularly destructive and may in fact be constructive, since they are more amenable to expert analysis and evaluation. Yet a dilemma remains: if the ownership produced through such instrumental forms of popular engagement is too thin, it will not achieve the kind of active selfgovernance that is the policy's goal, eroding one of the key forms of power involved in the PRSP. Paradoxically, the failure of participation is thus simultaneously constructive and destructive for the strategy of ownership.

In fact, perhaps the most destructive kinds of failure faced by these various strategies are the most technical: the various methodological challenges that each has encountered as actors try to quantify the complexities of risk, results, ownership and global standards. These may appear like far less significant failures than those more visible ones discussed above. Yet in organizations in which the language of numbers and indicators is king, the fact that these complex realities resist translation has seriously limited their influence, eroding expert authority and making this a particularly destructive form of policy failure.

As Latour wrote about scientific practice, for standardized knowledge to work, the world has to be made to resemble the conditions in the laboratory. ${ }^{52}$ The various performative techniques deployed by institutional actors can be understood as ambitious attempts to reshape the world so that it looks more like the hypothetical world of public-choice theory: through their efforts to change institutional cultures and "make up" new, more proactive kinds of populations, they are trying to instil a set of norms and values - and ultimately of self-regulating behaviours that look a lot like public-choice concepts of rational political action. Yet this is an undertaking that has faced significant challenges, as the world has refused to fit into such tidy categories. For all of the innovations of this new provisional governance style, we are therefore back facing the 
challenges that I discussed at the very beginning of this book: the persistent fragility of expert authority in the face of the sheer messiness of the world.

\section{The future of provisional governance}

Before we can determine what these fragilities and potential failures bode for the future of provisional governance, however, we have to ask ourselves one final question: failures for whom? My discussion so far has focused on the question of what these various failures mean for the sustainability of the institutions and their governance strategies. Yet more is at stake in these practices than the longevity of particular institutions and policies: these new forms of governance also have very real effects on the character of political life at both domestic and global levels.

\section{Two possible directions}

There are two directions that this more provisional style of governance can potentially take in its effects on political life: one is more experimental, democratic and open-ended, while the other is more cautious, instrumentalizing and even cynical. Moreover, although both remain open as possible paths, the particular form that policy failures have taken has tended to reinforce this second, darker form of provisional governance.

One possible definition for the term "provisional" focuses on its temporary and experimental qualities: in contrast with a more confident governance style, a provisional approach is less certain about the outcomes and therefore potentially more open to trying different things. ${ }^{53}$ We can see this more experimental sensibility in the various strategies discussed in this book. In different ways and to different extents, these new strategies are attuned to the complexity of the task at hand, recognizing the political, social and cultural dimensions of economic development. This messier ontology of development finance can lead to a greater awareness, even humility, about the limits of IFIs' expertise - as when the IMF admits that it cannot realistically predict the next crisis but must instead settle for identifying potential underlying vulnerabilities, or when both IFIs and donors recognize the difficulties of defining and operationalizing a concept as subjective as political ownership.

In spite of, or perhaps because of, this greater uncertainty, institutional actors and groups have sometimes taken greater risks by trying new, more experimental ways of achieving their objectives - echoing trends in other fields that have been identified by Charles Sabel, Jonathan 
Zeitlin and Paul Rabinow. ${ }^{54}$ The World Bank's demand for good governance (DFGG) initiative is an excellent example of this trial and error approach, as its advocates move into new terrains and try numerous options, not all of which will necessarily succeed. ${ }^{55}$ On a less ambitious scale, the IMF's Executive Board also developed several experimental case studies to test out its standards and codes initiative before formalizing the policy. This kind of openness is also linked to a willingness to learn from mistakes. For example, in its early days, results-based management (RBM) was all about developing a more responsive and reflexive organization that tried new things and learned from its mistakes. More participatory forms of measurement and evaluation in particular left themselves open to surprises by giving local communities a say in judging success and failure, and early debates about RBM emphasized the importance of maintaining this more experimental and open-ended approach. ${ }^{56}$ In this same spirit, the current World Bank President, Jim Yong Kim, has embraced the practice of "Fail Faires" that encourage NGO and IFI staff to acknowledge, discuss and learn from recent failures. $^{57}$

We can also find this openness to local forms of knowledge and expertise in many of the other governance strategies: techniques like the PRSP and DFGG are designed to shift some of the authority for identifying development priorities to local actors. Insofar as it opens expertise up to a wider range of actors, this more experimental sensibility resonates with what Callon and others have described as a more "technical democracy," in which the division between professionals and lay people is broken down and everyday experimentation supplements more traditional forms of knowledge creation. ${ }^{58}$ There thus exists within this turn to a more provisional kind of governance the potential for a movement towards not just a more experimental kind of expertise, but also a more open-ended form of politics.

Although this more open-ended sensibility has played an important role in shaping the strategies discussed in this book, it exists alongside a narrower, risk-averse kind of governance. Paradoxically, the term "provisional" can suggest both an experimental approach and a far more cautious one. It is this second meaning of "provisional" that Niklas Luhmann draws on when he suggests that those using provisional forms of expertise make claims that can be reversed or revised without losing face. ${ }^{59}$ As I have suggested in my examination of the four new governance strategies, each uses certain techniques to hedge against the possibility of failure - through results matrixes that can be fudged after the fact, risk assessments that refuse to make definitive predictions, and conceptions of ownership and global standards that rely more on 
symbolic appearance (for the sake of credibility) than reality. These techniques are not experimental or open-ended: their goal is to avoid risks by carefully controlling the form and flow of knowledge.

We can see this more cautious side of provisional governance in the persistent desire of IFIs and donor agencies to quantify everything - good governance, ownership, vulnerabilities and results. Numbers provide a sense of epistemological security to bureaucrats whose expertise has traditionally relied on quantitative assessments. Although this desire to quantify is often qualified by recognition of the limits to doing so, we have witnessed an increasing trend towards attempting to quantify the unquantifiable. The results agenda, which is the newest of the four strategies discussed here, epitomizes that tendency, particularly in recent years as donor agencies have been pushed to translate even the most complex of policies into quantitative results in order to have some "hard data" on policy successes. ${ }^{60}$ The current Bank President Jim Yong Kim's recent emphasis on the need to create a "science of delivery" underpinned by "a relentless drive for results" is just one more example of this belief that quantification is the best way of avoiding future failure. ${ }^{61}$

\section{Political implications}

This trend towards the more cautious form of provisional governance has some significant political consequences. Since not everything can be turned into numbers, something has to give. As one OECD staff member put it, "with an extreme focus on bean counting now, there might be a tendency to move away from the more difficult areas like institution building and governance." ${ }^{62}$ Yet these institutions are still engaged in the messy world of political and social transformation through their emphasis on good governance, poverty reduction plans and social risk. How do they make these complex and often-politicized programs consistent with the twin desires to protect their expertise and minimize risk? They do it by simplifying and instrumentalizing politics: translating political ideas such as consent, participation, difference and accountability into concepts that are consistent with economics (or, more specifically, public choice theory).

In Discourses of Power, Barry Hindess draws on Foucault's later work to provide an analysis of the logic of contemporary liberal governance. $\mathrm{He}$ suggests that juridical power in a liberal political system emphasizes the importance of legitimate consent. In contrast, governmental power - or governmentality - works through technical and often non-state mechanisms to achieve its ends. It is a kind of power that avoids the question of consent by depoliticizing its exercise as a technical matter. ${ }^{63}$ Yet if 
government is a form of power that avoids the problem of consent, then why has obtaining popular support become one of the major objectives of many of these new governmental strategies? Perhaps these strategies point to a further evolution in the logic of liberal governance: a move to make consent itself a kind of technique.

This instrumental approach to consent is apparent in policies focused on fostering demand for good governance. The assumption here is that if you provide civil society with enough information about the government's actions, they will demand the same kinds of governance reforms that the World Bank and donors (who are the supply side of this equation) would like to introduce. This is a conception of politics that assumes that there is little variation in the kinds of demands that will be made by an informed and organized public. All will want the same kind of liberal, market-friendly good governance as the IFIs. While policies such as streamlined conditionality and the PRSP seek to respond to the particularities of different national and local contexts, they thus rely on a shallow conception of the scope of that difference. If this is the case, then the scope of political debate can remain quite narrow, involving consultation, report cards and limited participation rather than genuine deliberation. Encouraging local participation need not complicate the imperative to pursue the "correct" development path.

It is not just consent and difference that often end up being instrumentalized in such policies: accountability, one of the watch-words of so many of these new strategies, is often reduced to something akin to a market transaction. When IFI and donor staff encourage governments to publish their compliance with standards and codes or prepare report cards on their development results, it is in order to improve borrowing governments' accountability to market and civil society actors. Although this objective is admirable, too often the accountability relationship between government and citizen is seen through the lens of service provision and understood as equivalent to that between a seller and a consumer. ${ }^{64}$ While there is certainly enormous room in many countries for better "consumer satisfaction" when it comes to government services, this is not the same thing as democratic accountability. Genuine political accountability requires a more robust and wide-ranging kind of dialogue between government representatives and citizens, in which more fundamental priorities are on the table, not just feedback on a narrow set of services or the limited social priorities up for debate in the PRSP consultations.

Instrumental conceptions of consent, difference, participation and accountability allow IFI and donor actors to engage with the complexities of politics while still translating them (more or less) into the 
language of economic expertise. This methodologically cautious approach to governance conceals the power dynamics and inequalities at work - the differential levels of access various groups have to participatory processes in the case of the PRSP consultation processes, the many issues that are not up for discussion, and the forms of exclusion that are enabled through the processes of sorting and ranking borrowing countries that inscriptions like the ROSCs and DSAs make possible. This more cautious approach to provisional governance thus rests on a kind of impoverished fantasy about the nature of political debate. Unfortunately, it is a fantasy that has some potentially serious consequences for those at the receiving end of development finance.

\section{Where are we heading?}

Both experimental and cautious forms of provisional governance remain present in current governance strategies, and there remain a good number of actors - certain groups of IFI and donor staff, NGOs and scholars - who continue to push to have these new governance strategies meet their democratic potential. Yet there are several reasons to be less than optimistic about the direction that this new style of provisional governance is currently taking.

If we look back at the various policy failures discussed above, the future of provisional governance becomes a little less bright. Many of these failures are related to those aspects of governance strategies that are most innovative and potentially experimental, such as the participatory processes that have turned out to be thin and instrumentalized. Moreover, staff often view the difficulties involved in translating these more participatory processes into operational policies as a sign of the limits of such experiments - hence the growing discomfort about long and unprioritized PRSPs. Other policies, like results-based measurement, that were once more experimental have become far more cautious, even cynical, as bureaucrats have found ways of fudging the results.

Even when these more cautious techniques have themselves failed, as in the many methodological problems encountered when institutional actors seek to translate complex issues into tidy numbers, the response by staff and management has rarely been to recognize the limits of quantification. Instead, the recent trend has been to insist even more vigorously on the importance of quantitative data, while also noting possible methodological problems as a hedge against failure. How failures matter, once again, depends on how they are interpreted. To date, IFI and donor actors have tended to interpret recent failures in a way that reinforces the move to more cautious forms of governance. 
This tendency to adopt a more risk-averse style of governance is nowhere clearer than in the new push for "value for money" (VFM), an approach that has become a mantra in the context of the recent global financial crisis. Those seeking VFM demand that aid dollars be rigorously justified in terms of their "efficiency, economy and effectiveness." 65 This ultimately means not only assessing the costs of a given program but also translating its effects into quantitative results. The VFM approach is particularly popular among the recently elected conservative governments in the UK, Canada and Sweden. Once bastions of more progressive approaches to development assistance, many of these countries have begun to place more emphasis on the political dimensions of development finance. ${ }^{66}$ Although we might expect that this increasing politicization of aid would significantly erode the provisional approach to governance, these governments have embraced many of the strategies examined in this book - the pursuit of global standards, risk management and, above all, the results agenda. Their push for VFM has played a key role in moving the results agenda even further towards a fixation on quantitative and standardized measurements. ${ }^{67}$

This obsession with measuring the immeasurable pushes the cautious tendencies of current development governance to their logical extreme, effectively transforming development results from symbolic representations into nearly fictitious inventions. While such inventions are of little use to local populations in low-income countries (LICs) who might be interested in knowing which policies have been working and which have not, they do nonetheless serve the purpose they are increasingly designed for: public relations. After all, the primary audience for many of these quantitative results matrixes and reports is not aid recipients at all, but the donors - or, more specifically, the voting public. This donor-driven approach to results is not particularly good for the quality of political dialogue either in low-income countries or in donor communities. Nor is it good for the lending agencies themselves.

Why would this shift to a more cautious kind of governance endanger the institutions that practice it? As I argued at the very beginning of this book, the authority of global governance institutions relies heavily on their claims to expertise. As this book has demonstrated, that expertise is contestable and malleable, taking different forms in different eras. Yet it is also always fragile, resting on a set of epistemological and ontological assumptions that do not always fit the messiness of the world that it seeks to understand. While the shift to provisional governance has given development institutions a more dynamic ontology and granted them a measure of additional epistemological flexibility, IFIs' and donors' increasing caution paradoxically threatens to undercut their resilience. When the 
deniability of expert claims is pushed towards parody, as staff are pressured to interpret even the most unpromising of results as successes, this kind of caution becomes self-defeating. It is all too easy to realize that the numbers are fudged, that the scores are arbitrary, and that there is no referent behind the signal. If that happens, institutions will once again lose the authority that they sought so carefully to rebuild, and we will find ourselves back where we started: decrying the failure of development finance and trying to figure out where to go next. 


\section{Endnotes}

\section{INTRODUCTION}

1 Joseph Stiglitz. 1998. "Towards a New Paradigm for Development: Strategies, Policies, and Processes." Prebisch Lecture, UNCTAD: Geneva, 19 October; Jim Yong Kim. 2012. "Remarks As Prepared for Delivery." IMF and World Bank Annual Meeting Plenary Session: Tokyo, 11 October.

2 The IMF's Chief Economist first made this admission in a working paper: Olivier Blanchard and Daniel Leigh. 2013. "Growth Forecast Errors and Fiscal Mulipliers." IMF Working Paper (No. WP/13/1).

3 As I will discuss in Chapter 3, structural adjustment lending provided financial support to governments on the condition that they instituted significant reforms such as eliminating price controls and subsidies, reducing tariffs and privatizing government enterprises.

4 Niklas Luhmann. 1998. "Describing the Future." In Observations on Modernity, Stanford University Press, 69. Linsey McGoey considers the implications of this insight for institutional practice in: McGoey. 2007. "On the Will to Ignorance in Bureaucracy." Economy and Society 36 (2): 212-35.

5 Nigel Thrift explores some of these trends in: Thrift. 2009. "A Perfect Innovation Engine: the Rise of the Talent World." In Cultural Political Economy, edited by J. Best and M. Paterson, London and New York: Routledge, 197221. The classic statement of the shift from use to exchange to sign value can be found in: Jean Baudrillard. 1981. For a Critique of the Political Economy of the Sign. New York: Telos Press.

6 In that particular case, the initial estimate of an increase of 171,000 jobs was revised downwards just a month later to 138,000. Bureau of Labor Statistics. 2012. "The Employment Situation: November 2012." Washington, DC: US Department of Labor, 3.

7 World Bank. 1998. Assessing Aid: What Works, What Doesn't, and Why. New York: Oxford University Press, 32.

8 IMF. 2011. "Managing Volatility: A Vulnerability Exercise for Low-Income Countries." Washington, DC: International Monetary Fund, 6.

9 Michel Callon, ed. 1998. The Laws of the Markets. Oxford: Blackwell, 260-61; Andrew Barry. 2002. "The Anti-Political Economy." Economy and Society 31 (2): $268-84$. 
10 Michel Foucault. 1990. The History of Sexuality, Vol. 2: The Use of Pleasure. New York: Vintage, ch.2; Foucault. 1996. Foucault Live: Interviews, 1961-84. New York: Semiotext(e), Ch. 50; Foucault. 1997. "Polemics, Politics and Problematizations." In Ethics: Vol. 1 of Essential Works of Foucault, edited by L. Davis. New York: The New Press, 381-90.

11 Susanne Soederberg. 2002. "On the Contradictions of the New International Financial Architecture: Another Procrustean Bed for Emerging Markets?” Third World Quarterly 23 (4): 607-20; Jean-Pierre Cling, Mireille Razafindrakoto and François Roubaud, eds. 2003. New International Poverty Reduction Strategies. London: Routledge.

12 Sheldon Wolin. 1981. "Max Weber: Legitimation, Method, and the Politics of Theory." Political Theory 9 (3): 419.

13 Max Weber. 1949. The Methodology of the Social Sciences. Glencoe, IL: Free Press, 116. See also: Barry. "Anti-Political Economy" 274-75. I will discuss the fragility of expert authority at greater length in Chapter 4.

14 Some excellent examples of such internal bureaucratic studies include: Susan Park and Antje Vetterlein, eds. 2010. Owning Development: Creating Policy Norms in the IMF and the World Bank. Cambridge University Press; Jeffrey Chwieroth. 2008. "Organizational Change 'From Within': Exploring the World Bank's Early Lending Practices." Review of International Political Economy 15 (4): 481-505; Catherine Weaver. 2008. Hypocrisy Trap: The World Bank and the Poverty of Reform. Princeton University Press.

15 Arne Rückert. 2007. "Producing Neoliberal Hegemony? A Neo-Gramscian Analysis of the Poverty Reduction Strategy Paper (PRSP) in Nicaragua." Studies in Political Economy (79): 91-118; Marcus Taylor. 2005. "Opening the World Bank: International Organisations and the Contradictions of Global Capitalism." Historical Materialism 13 (1): 153-70; Paul Cammack. 2004. "What the World Bank Means by Poverty Reduction, and Why it Matters." New Political Economy 9 (2): 189-211; Cristina Rojas. 2004. "Governing through the Social: Representations of Poverty and Global Governmentality." In Global Governmentality: Governing International Spaces, edited by W. Larner and W. Walters. London: Routledge, 97-115.

16 I provide a fuller definition of the concept of inscription, which I am borrowing from Callon and Latour, below.

17 As I will discuss further in the Conclusion, this more experimental approach to governance has been explored by a number of different scholars recently, including: Charles Sabel and Jonathan Zeitlin. 2012. "Experimentalism in the EU: Common Ground and Persistent Differences." Regulation and Governance 6 (3): 410-26; Paul Rabinow. 2003. Anthropos Today: Reflections on Modern Equipment. Princeton University Press; Michel Callon, Pierre Lascoumes and Yannick Barthe, eds. 2009. Acting in an Uncertain World: An Essay on Technical Democracy. Boston: MIT Press.

18 Rita Abrahamsen. 2000. Disciplining Democracy: Development Discourse and Good Governance in Africa. London: Zed Books.

19 On the importance of neutrality and expertise to IO culture, see: Michael Barnett and Liv Coleman. 2005. "Designing Police: Interpol and the Study of Change in International Organizations." International Studies Quarterly 49 (4): 
593-619; Michael Barnett and Martha Finnemore. 1999. "The Politics, Power, and Pathologies of International Organizations." International Organization 53 (4): 699-732; Bessma Momani. 2005. "Recruiting and Diversifying IMF Technocrats." Global Society 19 (2): 167-87; Jacqueline Best. 2012. “Ambiguity and Uncertainty in International Organizations: A History of Debating IMF Conditionality." International Studies Quarterly 56 (4): 674-88.

20 James Ferguson. 1990. The Anti-Politics Machine: "Development," Depoliticization, and Bureaucratic Power in Lesotho. Cambridge University Press; Timothy Mitchell. 2007. "The Properties of Markets." In Do Economists Make Markets? On the Performativity of Economics, edited by D. MacKenzie, F. Muniesa and L. Siu. Princeton University Press, 244-75.

21 In March 2013, the Canadian conservative government announced plans to merge CIDA with the Foreign Affairs ministry. Since the Canadian policies discussed in this book were initiated while CIDA still existed, I will generally refer to it, rather than to the new Department for Foreign Affairs, International Trade and Development.

22 The IMF has been in the business of development since it began its long-term concessional lending in 1976, and even though its priorities are different, its overlap with the Bank has only grown in the intervening years. Many IMF staff are aware of this fact, particularly those working in the Africa Department. It is those working in the European Department, certain executive directors (particularly the US) and a few NGOs (who hope to get the IMF out of the business of lending to poor countries) who have continued to uphold the idea that the IMF should only engage in managing global finance, and not economic development (as if the two were separable, whether lending to Burkina Faso or Greece).

23 Some excellent examples of studies that examine the impact of recent policy changes on specific countries or regions include: Isaline Bergamaschi. 2011. Le consensus post-Washington au Mali: Trajectoires, usages et processus d'appropriation, $\mathrm{PhD}$ thesis, École Doctorale de Sciences Po, Institut d'Études Politiques de Paris; Rückert. 2004. "Producing Neoliberal Hegemony?”; Graham Harrison. The World Bank and Africa: The Construction of Governance States. London: Routledge; Tim Conway. 2004. "Politics and PRSP Approach: Vietnam Case Study." London: Overseas Development Institute; Geske Dijkstra. 2005. "The PRSP Approach and the Illusion of Improved Aid Effectiveness: Lessons from Bolivia, Honduras and Nicaragua." Development Policy Review 23 (4): 443-64; Nadia Molenaers and Robrecht Renard. 2003. "The World Bank, Participation and PRSP: The Bolivian Case Revisited." The European fournal of Development Research 15 (2): 133-61; Patrick Guillaumont and Jeanneney Sylviane Guillaumont. 2004. "Une expérience Européenne: la conditionnalité de performance au Burkina Faso." Afrique Contemporaine 1 (209): 197-227. Without trying to provide a comprehensive picture of the impact of the policies on the ground, I have drawn on these and other studies throughout the book where appropriate.

$24 \mathrm{My}$ views on the centrality of process have been influenced by the work of Kevin McMillan, Iver Neumann and Ole Jacob Sending: Kevin McMillan. 2008. The Emergence of International Governance: Practices of European Politics, 1700-1848, PhD thesis, Department of Political Science, Columbia University; Iver B. Neumann and Ole Jacob Sending. 2006. "Governance to 
Governmentality: Analyzing NGOs, States and Power." International Studies Quarterly 50 (3): 651-72. See also: Diane Stone. 2003. "The 'Knowledge Bank' and the Global Development Network." Global Governance 9 (1): 43-61.

25 Barnett and Finnemore. "Politics, Power, and Pathologies"; Michael Barnett and Martha Finnemore. 2004. Rules for the World: International Organizations in Global Politics. Ithaca: Cornell University Press. See also: Chwieroth. "Organizational Change"; Antje Vetterlein. 2007. "Economic Growth, Poverty Reduction, and the Role of Social Policies: The Evolution of the World Bank's Social Development Approach." Global Governance 13 (4): 513-33.

26 Key ANT texts used here include: Bruno Latour. 1987. Science In Action. Milton Keynes: Open University; Michel Callon. 1986. "The Sociology of an ActorNetwork: the Case of the Electric Vehicle." In Mapping the Dynamics of Science and Technology: Sociology of Science in the Real World, edited by M. Callon et al. London: Macmillan, 19-34; John Law, ed. 1991. A Sociology of Monsters: Essays on Power, Technology and Domination. London and New York: Routledge; John Law and John Hassard, eds. 1999. Actor Network Theory and After. Oxford: Blackwell. As I discuss in Chapter 2, I am drawing in particular on Foucault's notion of "problematization," and also engage with the wider literature on governmentality. Michel Foucault. Use of Pleasure; Foucault. "Polemics, Politics and Problematizations"; Foucault. 1991. "Governmentality." In The Foucault Effect: Studies in Governmentality, edited by Graham Burchell, Colin Gordon and Peter Miller. London: Harvester Wheatsheaf, 87-104; Foucault. 2004. The Birth of Biopolitics: Lectures at the Collège de France, 1978-1979. New York: Palgrave Macmillan; Peter Miller and Nikolas Rose. 1990. "Governing Economic Life." Economy and Society 19 (1): 1-31. On the practice turn: Theodore Schatzki, Karin Knorr Cetina and Eike von Savigny, eds. 2001. The Practice Turn in Contemporary Theory. London: Routledge; Vincent Pouliot. 2008. "The Logic of Practicality: A Theory of Practice of Security Communities." International Organization 62 (2): 257-88; Emmanuel Adler and Vincent Pouliot. 2011. International Practices. Cambridge University Press. In combining these different approaches, this book shares much with some of my previous work on cultural political economy: Jacqueline Best and Matthew Paterson, eds. 2010. Cultural Political Economy. London: Routledge.

27 Notable exceptions include: William Walters. 2002. "The Power of Inscription: Beyond Social Construction and Deconstruction in European Integration Studies." Millennium 31 (1): 83-108; Tony Porter. 2012. "Making Serious Measures: Numerical Indices, Peer Review, and Transnational Actor-Networks." Fournal of International Relations and Development 15 (4): 532-57; Paul Langley. 2010. "Review Essay: On the Materiality of Markets." Fournal of Cultural Economy 3 (3): 395-402.

28 Bruno Latour and Steve Woolgar. 1986. Laboratory Life: The Construction of Scientific Facts. Princeton University Press; Bruno Latour. 1986. "Visualization and Cognition: Thinking with Eyes and Hands." Knowledge and Society 6: 1-40; Michel Callon. 1986. "Some Elements of a Sociology of Translation: Domestication of the Scallops and the Fishermen of St. Brieuc Bay." In Power, Action, and Belief: A New Sociology of Knowledge?, edited by J. Law. London: Routledge and Kegan Paul, 196-233.

29 Walters. "Power of Inscription." For a similar use of the idea of inscription, see also: Miller and Rose. "Governing Economic Life." 
30 For an interesting discussion of this challenge, see: Mark Blyth. 2002. Great Transformations: The Rise and Decline of Embedded Liberalism. Cambridge University Press, Chs 1 and 2.

31 I am borrowing this critique of the idea of trajectory from Bruno Latour, who describes the limits of this idea as a way of conceptualizing technological change, using as an example the invention of the Kodak camera. Bruno Latour. 1991. "Technology is Society Made Durable." In A Sociology of Monsters: Essays on Power, Technology and Domination, edited by J. Law. London and New York: Routledge, 103-31.

32 Bruno Latour. 1999. Pandora's Hope: Essays on the Reality of Science Studies. Cambridge, MA: Harvard University Press; Michel Callon. 1998. "Introduction: The Embeddedness of Economic Markets in Economics." In The Laws of the Markets, edited by M. Callon. Oxford: Blackwell, 1-57.

33 Barnett and Finnemore. Rules for the World; Nikolas Rose. 1993. "Government, Authority and Expertise in Advanced Liberalism." Economy and Society 22 (3): 283-99; Nikolas Rose. 1999. Powers of Freedom: Reframing Political Thought. Cambridge University Press.

34 This is not always the case in some of the earlier writings of economic sociologies such as Callon and Latour, which do point to the limits of strategies of inscription, translation and mobilization. Yet Callon's later work on the performativity of economics, as well as some of the advocates of ANT, have sometimes overstated the effectiveness of economic theory and technological practice. This also holds true for some of the governmentality and bureaucratic culture literatures, which focus primarily on the effectiveness of various techniques for governing at a distance, and pay less attention to the slippages, resistances and limits of such efforts. One exception to this trend within the IO literature is Broome and Seabrooke's analysis of the ways in which organizations' practices of standardized measurement can ignore more appropriate local forms of knowledge and thus produce policy failures: André Broome and Leonard Seabrooke. 2012. "Seeing like an International Organisation." New Political Economy 17 (1): 1-16.

35 Jeremy Walker and Melinda Cooper. 2011. "Genealogies of Resilience: From Systems Ecology to the Political Economy of Crisis Adaptation." Security Dialogue 42 (2): 143-60; Mitchell Dean. 1999. "Risk, Calculable and Incalculable." In Risk and Sociocultural Theory: New Directions and Perspectives, edited by D. Lupton. Cambridge University Press, 131-60; Henry Rothstein, Michael Huber and George Gaskell. 2006. "A Theory of Risk Colonization: The Spiraling Regulatory Logics of Societal and Institutional Risk." Economy and Society 35 (1): 91-112.

36 I have made other arguments about the need to rethink indeterminacy beyond risk in Jacqueline Best. 2008. "Ambiguity, Uncertainty and Risk: Rethinking Indeterminacy." International Political Sociology 2 (4): 355-74.

\section{A MESO-LEVEL ANALYSIS}

1 Not all governmentality approaches share this tendency towards epochal analysis; yet the tendency remains quite strong, as Collier has pointed out: Stephen J. Collier. 2009. "Topologies of Power: Foucault's Analysis of Political Government beyond 'Governmentality'." Theory Culture and Society 26 (6): 78-108. 
2 The two scholars who have most explicitly defined themselves as practice theorists are Vincent Pouliot and Emanuel Adler: Pouliot. 2008. "The Logic of Practicality: A Theory of Practice of Security Communities." International Organization 62 (2): 257-88; Pouliot. 2010. International Security in Practice: The Politics of NATO-Russian Diplomacy. Cambridge University Press; Adler and Pouliot. 2011. International Practices. Cambridge University Press; Adler and Pouliot. 2011. "International Practices." International Theory 3 (1): 1-36. For other interesting uses of Bourdieu, see, for example: Michael C. Williams. 2007. Culture and Security: Symbolic Power and the Politics of International Security. London: Routledge; Alexandra Gheciu. 2009. Securing Civilization? The EU, NATO and the OSCE in the Post-9/11 World. Oxford University Press; Anna Leander. 2011. "The Promises, Problems and Potentials of a BourdieuInspired Staging of International Relations." International Political Sociology 5 (3): 294-313.

3 Theodore Schatzki, Karin Knorr Cetina and Eike von Savigny, eds. 2001. The Practice Turn in Contemporary Theory. London: Routledge, 2.

4 Unnoticed, everyday practices such as pronouncing words are sometimes described as "coping skills." David Stern. 2003. "The Practical Turn." In Blackwell Guide to the Philosophy of the Sciences, edited by S. P. Turner and P. A. Roth. Oxford: Blackwell, 190-1.

5 Some early uses of the idea of practice include: Iver B. Neumann. 2002. "Returning Practice to the Linguistic Turn: The Case of Diplomacy." Millennium 31 (3): 627-51; William Walters. 2002. "The Power of Inscription: Beyond Social Construction and Decontruction in European Integration Studies." Millennium 31 (1): 83-108.

6 Pouliot. "Logic of Practicality": 275.

7 Ibid.: 274.

8 Ibid.: 270. As Pouliot himself admits (259), he differs here from Bourdieu in defining social practice in such as way as to exclude representational or discursive practices.

9 Although many scholars have pointed to the disjuncture between international organizations' formal policies and their application on the ground, the production of different kinds of (often abstract) knowledge is a practice that is central to both the formulation and application of policy. Layna Mosley. 2000. "Room to Move: International Financial Markets and National Welfare States." International Organization 54 (4): 737-73; Swati Chaudhary and Leonard Seabrooke. 2009. "Pragmatic Numbers: How the IMF Creates Policy Dialogue for Financial Reform." Warwick CSGR Working Paper (No. 261/09).

10 As Craig Calhoun has noted, Bourdieu's use of the metaphor of the game likely owes something to his own experience as a rugby player. Calhoun. 2003. "Pierre Bourdieu." In The Blackwell Companion to the Major Social Theorists, edited by G. Ritzer. Cambridge, MA: Blackwell, 274-309.

11 This problem of the multiplicity of social fields is akin to the problem of the multitude of contexts that J. G. A. Pocock has identified as a challenge for contextualist history. Both historical and sociological traditions draw on Wittgenstein's concept of language games to help understand the meaning and significance of a practice or a historical text, suggesting that it has to be 
interpreted with reference to the game being played. Yet if there are multiple games, fields and contexts, then this shift from the practice or text to the context or field does not necessarily solve the riddle. J. G. A. Pocock. 1971. "Languages and their Implications." In Politics, Language and Time: Essays on Political Thought and History, New York: Atheneum, 3-41.

12 Although I have not therefore used the concept of field here, a looser conception of fields as discursively constituted, such as that used by Didier Bigo would still be consistent with a meso-level approach. Didier Bigo. 2005. "La mondialisation de l'(in)sécurité." Cultures et Conflits 58 (Été): 53-101.

13 Stern. "Practical": 202; William H. Sewell. 1992. "A Theory of Structure: Duality, Agency, and Transformation." American fournal of Sociology 98 (1): 14-15; Anthony King. 2000. "Thinking with Bourdieu Against Bourdieu: A 'Practical' Critique of the Habitus." Sociological Theory 18 (3): 417-33. Nonetheless, there does remain room with Bourdieu's analysis for an attention to contingency, agency and innovation, through his concept of virtuosity, as I have discussed elsewhere: Jacqueline Best. 2012. "Bureaucratic Ambiguity." Economy and Society 41 (1): 84-106.

14 There has been excellent work done on institutional stability by scholars of bureaucratic culture who have demonstrated just how little institutional actors sometimes change in spite of external pressures to do so. Catherine Weaver and Ralf J. Leiteritz. 2005. “'Our Poverty Is a World Full of Dreams': Reforming the World Bank". Global Governance 11 (3): 369-88. Bourdieu's concepts would make a useful contribution to such analyses, supplementing the current focus on norms with his more concrete emphasis on routines and habits.

15 Not to mention the pervasiveness of risk-based analysis in a wide range of other policy areas. Ulrich Beck. 1992. Risk Society: Towards a New Modernity. London: Sage.

16 Classic formulations of this kind of strategic interaction in IR include those by Robert Axelrod and Thomas Schelling. Schelling. 1960. The Strategy of Conflict. Cambridge, MA: Harvard University Press; Axelrod, ed. 1976. Structure of Decision. Princeton University Press. Adler and Pouliot provide an interesting practice-based analysis of Schelling in: Adler and Pouliot. "International Practices."

17 My use of strategy therefore has similarities to de Certeau's; however, whereas de Certeau defines strategies as strictly spatial, and contrasts them with more temporal, contingent tactics, I would tend to resist this dichotomy. Michel De Certeau. 1984. The Practice of Everyday Life. Berkeley and Los Angeles: University of California Press, 34-7. My concept of strategy is also somewhere between Foucault's narrower and more instrumental use of the term in "The Subject and Power," and his much broader concept of rationalities, as used in his work on governmentality. Michel Foucault. 1982. "The Subject and Power." Critical Inquiry 8 (4): 777-95. Foucault. 1981 "Governmentality." In The Foucault Effect: Studies in Governmentality, edited by Graham Burchell, Colin Gordon and Peter Miller. London: Harvester Wheatsheaf, 87-104; Foucault. 2004. The Birth of Biopolitics: Lectures at the Collège de France, 1978-1979. New York: Palgrave Macmillan.

18 Michel Foucault. 1990. The History of Sexuality, Vol. 2: The Use of Pleasure. New York: Vintage, 23-4; Foucault. 1996. Foucault Live: Interviews, 1961-84. 
New York: Semiotext(e), 456-7; Foucault. 1997. "Polemics, Politics and Problematizations." In Ethics: Volume 1 of Essential Works of Foucault, edited by L. Davis. New York: The New Press, 381-90. Where my concept differs from Foucault's, however, is in my stronger emphasis on the concrete manifestations of such problematizations.

19 For a comprehensive analysis of the different dimensions of practice, see: Joseph Rouse. 1996. Engaging Science: How to Understand its Practices Philosophically. Ithaca: Cornell University Press, 134-57.

20 This principle was first elaborated by Bruno Latour in Science in Action, in which he sought to follow scientists and laboratory technicians in their day-today activities in an effort to unravel the practices of science. Bruno Latour. 1987. Science in Action. Milton Keynes: Open University.

21 Bruno Latour. 1993. The Pasteurization of France. Cambridge, MA: Harvard University Press.

22 Susan Leigh Star. 1991. "Power, Technologies and the Phenomenology of Conventions: On Being Allergic to Onions." In A Sociology of Monsters: Essays on Power, Technology and Domination, edited by J. Law. London and New York: Routledge, 28-9.

23 Ian Hacking. 2002. "Making up People." In Historical Ontology, Cambridge, MA: Harvard University Press, 99-114.

24 Latour. Science in Action, 62.

25 Nikolas Rose and Peter Miller. 1992. "Political Power Beyond the State: Problematics of Government." British fournal of Sociology 43 (2): 172-205.

26 One aspect of STS and ANT theory that I am not adopting here is the idea of actants - or the possibility that non-humans (whether Latour's famour doorcloser, Callon's scallops or Woolgar's machines) can also be actors with significant effects on the social world. In the realm of global governance (at least at the level of bureaucratic institutions that I am studying here), the objects to which such forms of agency are delegated tend to be "softer" than door-closers, taking the form of paper or images on computer screens: tables, graphs, reports and other inscriptions. While there is another story to be told about the increasing delegation of agency to such "quasi-objects," to use Latour's term, I do not have the space to tell it here. For three classic STS discussions of non-human agency, see: Michel Callon. 1986. "Some Elements of a Sociology of Translation: Domestication of the Scallops and the Fishermen of St. Brieuc Bay." In Power, Action, and Belief: A New Sociology of Knowledge? edited by J. Law. London: Routledge and Kegan Paul, 196-233; Jim Johnson. 1988. "Mixing Humans and Non-Humans Together: The Sociology of a Door-Closer." Social Problems 35 (3): 298-310; Steve Woolgar. 1991. "Configuring the User: The Case of Usability Trials." In A Sociology of Monsters: Essays on Power, Technology and Domination, edited by J. Law. London: Routledge, 57-102.

27 DFID. 2007. "How to Note: Country Governance Analysis." London: UK Department for International Development; IMF. 2003. "Operational Guidance on the New Conditionality Guidelines." Washington, DC: International Monetary Fund.

28 Bruno Latour and Steve Woolgar. 1986. Laboratory Life: The Construction of Scientific Facts. Princeton University Press. 
29 While it takes many different forms, the concept of performativity comes originally from the pragmatic philosopher Austin, who defined certain kinds of speech act as performative, such as a priest's declaration of marriage, since the enunciation does the very thing that it states. John L. Austin. 1962. How to do Things with Words. Cambridge, MA: Harvard University Press.

30 On the potential for negative performativity, see: Donald MacKenzie. 2006. An Engine, Not a Camera: How Financial Models Shape Markets. Cambridge, MA: MIT Press.

31 In fact, I would argue, it is impossible to separate out the two forms of knowledge: as William Connolly points out in his analysis of the political and philosophical implications of recent neuroscience, thinking, emotion, instinct and embodied habits are all interconnected, layered and interdependent. William Connolly. 2002. Neuropolitics: Thinking, Culture, Speed. Minneapolis: University of Minnesota Press, Ch. 3.

32 Rouse. Engaging Science, 137.

33 Max Weber. 1976. Economy and Society: An Outline of Interpretive Sociology. Vol. 1. Berkeley: University of California Press, 215-16.

34 For another influential typology of forms of authority, see: Rodney Bruce Hall and Thomas J. Biersteker, eds. 2002. The Emergence of Private Authority in Global Governance. Cambridge University Press.

35 Michael Barnett and Martha Finnemore. 2004. Rules for the World: International Organizations in Global Politics. Ithaca: Cornell University Press.

36 In the case of the IMF, most are economists trained in a limited number of universities; at the World Bank and in aid agencies, they are trained in a wider range of social sciences and sciences, but are still predominantly economists. Bessma Momani. 2005. "Recruiting and Diversifying IMF Technocrats." Global Society 19 (2): 167-87; Jeffrey Chwieroth. 2007. "Testing and Measuring the Role of Ideas: The Case of Neoliberalism in the International Monetary Fund." International Studies Quarterly 51 (1): 5-30; Weaver and Leiteritz. "“Our Poverty Is a World'."

37 I have written about this particular trend in global economic governance at greater length elsewhere: Jacqueline Best. 2003. "Moralizing Finance: The New Financial Architecture as Ethical Discourse." Review of International Political Economy 10 (3): 579-603.

38 Nikolas Rose. 1999. Powers of Freedom: Reframing Political Thought. Cambridge University Press, 188-92.

39 Rouse. Engaging Science, 134-5.

40 This conception of power is best captured by Steven Luke's first and second dimensions of power: Lukes. 1974. Power: A Radical View. London: Macmillan.

41 In using the term "productive," I am both borrowing and expanding Barnett and Duvall's very useful term, including practices as well as discourse. Michael Barnett and Raymond Duvall. 2005. "Power in International Politics." International Organization 59 (1): 39-75; Barnett and Duvall, eds. 2005. Power in Global Governance. Cambridge University Press.

42 The classic formulation of this kind of power is: Robert A. Dahl. 1957. "The Concept of Power." Behavioural Scientist 2: 201-5. 
43 This indirect character of power is clearly related to the broader phenomenon of the diffusion of power, as discussed by Stefano Guzzini and Iver Neumann in: Guzzini and Neumann, eds. 2012. The Diffusion of Power in Global Governance. New York: Palgrave Macmillan.

44 Giorgio Agamben. 1998. Homo Sacer: Sovereign Power and Bare Life. Stanford University Press, 6-7.

45 A style often captures the affective dimension of governance: scratch beneath the technical surface of documents and communications from the structural adjustment or contemporary era and you find certain kinds of feelings circulating: confidence (even hubris) in the 1980s and 1990s, and a great measure of caution and uncertainty today. I do not have the time to explore the implications of this affective dimension in this book. For a very thoughtful analysis of affect in IR, see the work of Andrew Ross, including: Ross. 2010. "Why They Don't Hate Us: Emotion, Agency and the Politics of AntiAmericanism." Millennium 39 (1): 109-25; Ross. 2006. "Coming in from the Cold: Constructivism and Emotions." European fournal of International Relations 12 (2): 197-222.

$46 \mathrm{My}$ use of style is therefore not unlike that used by William Walters who in turn is inspired by Ian Hacking's work on "styles of reasoning." William Walters. 2012. Governmentality: Critical Encounters. London: Routledge, Ch. 4; Hacking. 2004. Historical Ontology. Cambridge, MA: Harvard University Press.

47 Jacqueline Best. 2012. "Ambiguity and Uncertainty in International Organizations: A History of Debating IMF Conditionality." International Studies Quarterly 56 (4): 674-88. I also discuss similar concerns about the preference for (but limits of) quantitative metrics in my examination of vulnerability assessments (Chapter 7) and the recent return to results measurement (Chapter 8).

48 Niklas Luhmann. 1998. "Describing the Future." In Observations on Modernity, Stanford University Press, 69.

49 Martha Finnemore and Kathryn Sikkink. 1998. "International Norm Dynamics and Political Change." International Organization 52 (4): 887-917.

50 Iver B. Neumann and Ole Jacob Sending. 2006. "Governance to Governmentality: Analyzing NGOs, States and Power." International Studies Quarterly 50 (3): 651-72; Mark Duffield. 2001. "Governing the Borderlands: Decoding the Power of Aid." Disasters 25 (4): 308-20.

51 Susan Park and Antje Vetterlein, eds. 2010. Owning Development: Creating Policy Norms in the IMF and the World Bank. Cambridge University Press, Ch. 11.

52 James Ferguson. 1990. The Anti-Politics Machine: "Development," Depoliticization, and Bureaucratic Power in Lesotho. Cambridge University Press; Timothy Mitchell. 2007. "The Properties of Markets.” In Do Economists Make Markets? On the Performativity of Economics, edited by Donald MacKenzie, Fabian Muniesa and Lucia Siu. Princeton University Press, 244-75.

53 The answer to this conundrum is to recognize that there are several kinds of failure. As I will discuss in the Conclusion to this book, the role of failure in development governance is complex: some failures are far more damaging to governance practices than others. 


\section{WHAT CAME BEFORE}

1 Transparency, for example, could be understood as a recent strategy for managing the problems of organizational communication and accountability, while decentralization could be seen as a particular way of conceptualizing the problems and possibilities of the spatial logic of policy implementation.

2 Joseph Stiglitz. 1998. "Towards a New Paradigm for Development: Strategies, Policies, and Processes." Prebisch Lecture, UNCTAD: Geneva, 19 October; Stiglitz. 1998. "More Instruments and Broader Goals: Moving Towards the Post-Washington Consensus." WIDER Annual Lecture: Helsinki, 7 January; Jean-Pierre Cling, Mireille Razafindrakoto and François Roubaud, eds. 2003. New International Poverty Reduction Strategies. London: Routledge; Heloise Weber. 2006. "A Political Analysis of the PRSP Initiative: Social Struggles and the Organization of Persistent Relations of Inequality." Globalizations 3 (2): 187-206; Paul Cammack. 2004. "What the World Bank Means by Poverty Reduction, and Why it Matters." New Political Economy 9 (2): 189-211.

3 McNamara wrote a key memorandum outlining the basic elements of this new form of "lending for structural adjustment": World Bank Archives. 1980. P7757. Memorandum to the Executive Directors: Lending for 'Structural Adjustment,' from the President, Robert McNamara. 5 February.

4 For a more detailed discussion of the Bank's movement from project to program-based lending see: David Williams. 2008. The World Bank and Social Transformation in International Politics: Liberalism, Governance and Sovereignty. London: Routledge, Ch. 3.

5 Paul Mosely, Jane Harrigan and John Toye. 1991. Aid and Power: The World Bank and Policy-based Lending. London: Routledge, 27-8.

6 Although more formal collaboration was resisted by both organizations and was always incomplete, this process of convergence was formalized in the IMF's creation of the Structural Adjustment Fund (SAF) in 1986 and the Enhanced Structural Adjustment Fund (ESAF) in 1987, both of which required formal Bank-Fund collaboration through their agreement on the policy framework paper (PFP) that set out the basic objectives of the adjustment program.

7 So, for example, even as the Canadian government has begun to link its aid more directly to national political objectives, it continues to represent its actions as based on universal principles of results-orientation, transparency and accountability. CIDA. 2010. "Development for Results 2010-2011: At the Heart of Canada's Efforts for a Better World." Gatineau: Canadian International Development Agency. On the growing politicization of Canadian development assistance, see: Stephen Brown, ed. 2012. Struggling for Effectiveness: CIDA and Canadian Foreign Aid. Montreal: McGill-Queen's University Press.

8 Jacqueline Best. 2003. "Moralizing Finance: The New Financial Architecture as Ethical Discourse." Review of International Political Economy 10 (3): 579603; Jacqueline Best. 2005. "The Moral Politics of IMF Reforms: Universal Economics, Particular Ethics." Perspectives on Global Development and Technology 4 (3-4): 357-78. 
9 Robert McNamara. 1981. "To the Board of Governors, September 1973." In The McNamara Years at the World Bank, edited by R. McNamara. Baltimore: The Johns Hopkins University Press, 238-9.

10 Gerald Helleiner used this phrase in a very critical review of the Berg Report (discussed below): Helleiner. 1983. "Accelerated Development in SubSaharan Africa, an Agenda for Action: The World Bank." fournal of Development Economics 13 (1-2): 261.

11 Francisco Ferreira and Louise Keely. 2000. "The World Bank and Structural Adjustment: Lessons from the 1980s." In The World Bank: Structure and Policies, edited by C. Gilbert and D. Vines. Cambridge University Press, 175.

12 Devesh Kapur, John P. Lewis and Richard Webb. 1997. The World Bank: Its First Half Century. Vol. 1. Washington, DC: Brookings Institution Press, 336.

13 Discussions of the neoclassical economic assumptions underpinning structural adjustment lending at both the IMF and World Bank can be found in: Williams. World Bank and Social Transformation, 54-59; Bob Milward. 2000. "What is Structural Adjustment?" In Structural Adjustment: Theory, Practice and Impacts, edited by Giles Mohan, Ed Brown, Bob Milward and Alfred B. Zack-Williams. London: Routledge, 24-38; Howard Stein. 2008. Beyond the World Bank Agenda: An Institutional Approach to Development. University of Chicago Press, Ch. 3; Ferreira and Keely. "World Bank and Structural Adjustment," 160-8.

14 World Bank. 1981. Accelerated Development in Sub-Saharan Africa: An Agenda for Action. Washington, DC.

15 Ibid., Ch. 4; Kapur et al. World Bank, 514.

16 Kapur et al. World Bank, 355.

17 The Polak model, developed by Jacques Polak when he was Deputy Director of the IMF Research Department in the 1950s, combined Keynesian fiscal and neoclassical monetary policy and focused on achieving improvements in the balance of payments over the short term. James Boughton. 2004. "The IMF and the Force of History: Ten Events and Ten Ideas That Have Shaped the Institution." IMF Working Paper (No. WP/04/75): 14; Jacques Polak. 1991. "The Changing Nature of IMF Conditionality." Princeton Essays in International Finance (No. 184); Jeffrey Chwieroth. 2010. Capital Ideas: The IMF and the Rise of Financial Liberalization. Princeton University Press, 131.

18 A country's balance of payments is the difference between its economic outflows and inflows. The IMF generally intervenes to help fund countries' balance-of-payments deficits and imposes conditions to move them into a more balanced position.

19 Like the World Bank, the IMF was initially created to address the financial and development needs of the world in the aftermath of the Ssecond World War. In the IMF's case, over half of its lending went to developed countries in the first two decades of its existence. It was really only towards the end of the 1970s that the Fund began to lend most of its resources to low-income countries. Richard Peet. 2005. Unholy Trinity: The IMF, World Bank, and the World Trade Organization. London: Zed Books; James M. Boughton. 2001. Silent Revolution. The International Monetary Fund 1979-1989. 
Washington, DC: International Monetary Fund, 18-19; Margaret De Vries. 1986. The IMF in a Changing World 1945-1985. Washington, DC: International Monetary Fund, 226.

20 I have discussed this phenomenon in: Jacqueline Best. 2005. The Limits of Transparency: Ambiguity and the History of International Finance. Ithaca: Cornell University Press; Best. 2012. "Ambiguity and Uncertainty in International Organizations: A History of Debating IMF Conditionality." International Studies Quarterly 56 (4): 674-88.

21 IMF Archives. 1986. EBS/86/211. Program Design and Performance Criteria. September 8: 15.

22 Boughton. "IMF and the Force of History." The staff prepared a key document outlining the implications of supply-side economics for Fund policy, which was discussed in April of 1981. IMF Archives. 1981. SM/81/78. Supply-oriented Adjusment Policies. 6 April.

23 Polak. "Changing Nature"; Harold James. 1998. "From Grandmotherliness to Governance: The Evolution of IMF Conditionality." Finance and Development 35 (4): 44-7; Joseph Gold. 1979. Conditionality. Washington, DC: International Monetary Fund; Adolfo C. Diz. 1984. "The Conditions Attached to Adjustment Financing; Evolution of the IMF Practice." In The International Monetary System: Forty Years After Bretton Woods. Boston: Federal Reserve Bank of Boston, 214-43; Sidney Dell. 1981. "On Being Grandmotherly: The Evolution of IMF Conditionality." Princeton Essays in International Finance (No. 144).

24 The day-to-day activities of the IMF and the World Bank are managed by their respective Executive Boards, which are made up of Executive Directors representing one or more member countries. The members with the largest quotas (e.g. the United States, the United Kingdom and several others) each have their own Executive Director, whereas many states with smaller quotas are grouped together.

25 Best. "Ambiguity and Uncertainty."

26 John Williamson. 1990. "What Washington Means by Policy Reform." In Latin American Adjustment: How Much Has Happened?, edited by J. Williamson. Washington, DC: Institute for International Economics, 5-20.

27 I am not of course suggesting that the organizations succeeded in separating the two, given that the very attempt to distinguish the political from the economic is itself a political act.

28 As an example of McNamara's efforts to remain apolitical, Kapur et al. note that the Bank staff and leadership never commented, in either internal or external documents, on Indira Ghandi's declaration of a state of emergency in India in 1975. Kapur et al. World Bank, 477.

29 Although in addition to their Executive Boards both the IMF and World Bank have a Board of Governors made up of representatives (usually finance ministers) from all of the member countries, the Board only meets twice a year. For simplicity's sake, I will therefore refer to each institution's Executive Board as "the Board" and the Executive Directors as either "EDs" or "directors."

30 IMF Archives. 1968. SM/68/128. Fund Policy with Respect to the Use of Its Resources and Stand-by Arrangements. 22 July: 23. 
31 This question of whether fiscal policy conditions were in fact too political became the subject of considerable debate on the Board: IMF Archives. 1968. EBM/68/122. Minutes of Executive Board Meeting. 14 August: 20, 27; IMF Archives. 1968. EBM/68/123. Minutes of Executive Board Meeting. 14 August: 7, 10-14; IMF Archives. 1968. EBM/68/127. Minutes of Executive Board Meeting. 6 September: 11, 13, 15-16. I provide an analysis of these debates and the broader shifts in conditionality policy at this time in: Best. "Ambiguity and Uncertainty."

32 Kapur et al. World Bank, 522.

33 McNamara outlines some of the potential reforms to be included in the earliest structural adjustment programs in his 1980 memo on the subject: they include budgetary cutbacks and trade reforms. World Bank Archives. P7757: Memorandum to the Executive Directors. February 5: 3.

34 For a more detailed discussion of structural adjustment economics and policies, see: Ferreira and Keely. "World Bank and Structural Adjustment."

35 Helleiner. "Accelerated Development": 261.

36 World Bank. Accelerated Development, 133, 10-11, 4-5, 24.

37 Jacqueline Best. 2012. "Bureaucratic Ambiguity." Economy and Society 41 (1): 84-106.

38 For an excellent history of the creation of the IMF and the goals that underpinned it, see: Eric Helleiner. 1994. States and the Re-emergence of Global Finance: From Bretton Woods to the 1990s. Ithaca: Cornell University Press.

39 John Maynard Keynes. 1969. "Proposals for an International Clearing Union (April 1943)." In The International Monetary Fund 1945-1965: Documents, edited by J. K. Horsefield. Washington, DC: International Monetary Fund, 19-36.

40 Boughton. "IMF and the Force of History": 14; Polak. "Changing Nature."

41 Boughton. Silent Revolution, 608.

42 Kapur et al. The World Bank, 456.

43 John Toye. 1995. Structural Adjustment and Employment Policy: Issues and Experience. Geneva: International Labour Office, 70-1. Some economic arguments in favour of rapid reform include: Michael Mussa. 1986. "The Adjustment Process and the Timing of Trade Liberalization." In Economic Liberalization in Developing Countries, edited by A. Choks and D. Papageorgiou. Oxford University Press, 68-124; Michael Michaely, Demetrius Papageorgiou and Armend Choks. 1991. "Liberalizing Foreign Trade: Lessons of Experience in the Developing World." In Liberalizing Foreign Trade, edited by Demetrinus Papageorgiou, Michael Michaely and Armeane M. Choksi. Oxford: Basil Blackwell.

44 Margaret De Vries. 1985. The International Monetary Fund, 1972-1978: Cooperation on Trial: Narrative and Analysis. Vol. I. Washington, DC: International Monetary Fund, Ch. 19.

45 Boughton. Silent Revolution, 618-19.

46 De Vries. International Monetary Fund, 481.

47 Ibid., Chs 17 and 18.

48 The IMF provided such financing seventeen times between 1962 and 1989. Boughton. Silent Revolution, 742-5.

49 Kapur et al. World Bank, 525. 
50 Ibid., 516. By the 1990s, this idea of the necessity of second-generation reforms had been widely accepted, with the IMF holding a conference on the subject in 1999.

51 OED. 1985. "Sustainability of Projects: First Review of Experience.” Washington, DC: Operations Evaluation Department, World Bank.

52 Kapur et al. World Bank, 342.

53 Alcira Kreimer, John Eriksson, Robert Muscat, Margaret Arnold and Colin Scott. 1998. The World Bank's Experience With Post-conflict Reconstruction. Washington, DC: World Bank, Operations Evaluation Department, 5.

54 Kapur et al. World Bank, 342-3.

55 Ibid., 220.

56 Patrick Grasso, Sulaiman Wasty and Rachel Weaving. 2003. World Bank Operations Evaluation Department: The First Thirty Years. Washington, DC: World Bank. The OED was renamed the Independent Evaluation Group, or IEG, in 2006.

57 World Bank Archives. 1979. 26815. Operations Evaluation: World Bank Standards and Procedures. August; OED. 1982. "Eighth Annual Review of Project Performance Audit Results." Washington, DC: Operations Evaluation Department, World Bank. The World Bank did experiment with broader social cost-benefit analyses, but ultimately tended to remain focused on narrower measures of economic return. Kapur et al. World Bank, 38-43; Shantayanan Devarajan, Lyn Squire and Sethaput Suthiwart-Narueput. 1997. "Beyond Rate of Return: Reorienting Project Appraisal." The World Bank Research Observer 12 (1): 35-7.

58 Grasso et al. World Bank Operations Evaluation, 13.

59 Kapur et al. World Bank, 271-2.

60 OED. "Eighth Annual Review."

61 These reports looked back on previous years' programs. Given the extended time required for many of these projects to reach completion, most of the projects evaluated in the 1980s had been initiated in the 1970 s.

62 OED. "Sustainability."

63 OED. 1988. "Project Performance Results for 1986." Washington, DC: Operation Evaluation Department, World Bank, 11-12.

64 Ibid., 12; OED. 1990. "Evaluation Results for 1988: Issues in World Bank Lending over Two Decades." Washington, DC: Operations Evaluation Department, World Bank, 2.

65 OED. "Evaluation Results," 2.

66 For this reason, there is very little scholarship on IMF evaluation, with the notable exception of Catherine Weaver's recent writings on the subject: Weaver. 2010. "The Politics of Performance Evaluation: Independent Evaluation at the International Monetary Fund." Review of International Organizations 5 (3): 365-85; Weaver. n.d. "The Evaluation Paradox: The Politics of Independent Evaluation in the World Bank and International Monetary Fund.” Robert S. Strauss Center for International Security and Law, University of Texas at Austin.

67 IMF Archives. 1979. EBM/79/58. Guidelines on Conditionality. March 1: Article 12. 
68 IMF Archives. 1979. EBS/79/635. Adjustment Programs Supported by Upper Credit Tranche Stand-by Arrangements, 1977. 21 December; IMF Archives. 1981. EBS/81/152. Review of Upper Credit Tranche Stand-by Arrangements Approved in 1978-79 and Some Issues Related to Conditionality. 14 July; IMF Archives. 1982. EBS/82/97. Review of Recent Extended and Upper Credit Tranche Stand-by Arrangements, 9 June.

69 In 1984, for example, they undertook a longer-term analysis, allowing for a "more intensive analysis of developments and policies" in a select group of heavy borrowers, a practice that they combined with the broader, shorterterm review in 1985. IMF Archives. 1984. EBS/84/228. Experience with Adjustment Policies. 13 November: 1; IMF Archives. 1985. EBS/85/277. Aspects of Program Design. 17 December.

70 IMF Archives. EBS/79/635: 9; EBS/81/152: 11; EBS/82/97: 36.

71 Boughton. Silent Revolution, 617.

72 Ibid., 570-1.

73 IMF Archives. EBS/79/635: 12.

74 IMF Archives. EBS/82/97: 33.

75 IMF Archives. EBS/81/152: 15; EBS/82/97: 25.

76 IMF Archives. EBS/79/635: 3, 28. This second problem, of attribution, is one that continues to bedevil the IFIs and donors, in spite of their claims of their ability to demonstrate results. Interestingly, as I discuss in Chapter 8 and the Conclusion, the IMF is one of the few organizations whose staff are willing to point to these methodological problems today.

77 Ibid.; EBS/81/152: 11.

78 It is worth noting that not all of these earlier governance practices were fully formed strategies like the ones that emerged later. The practices of separating politics from economics and of viewing the world through certain universal economic principles were both coherent enough, reflexive enough about the problems being addressed, and well-enough institutionalized to be understood as governance strategies. On the other hand, various practices involved in IMF and World Bank efforts to conceptualize policy time and contingency and to measure policy effectiveness were looser and less coherent. It was only later in the 1990s that more coherent governance strategies began to be developed in these two domains of practice.

79 Nikolas Rose. 1999. Powers of Freedom: Reframing Political Thought. Cambridge University Press, 31.

80 The G-24, for example, mounted some vociferous critiques of IMF conditionality in the late 1970s: IMF Archives. 1978. Communiqué of the Intergovernmental Group of Twenty-Four on International Monetary Affairs. 22 September.

81 Robert Ayers. 1983. Banking on the Poor: The World Bank and World Poverty. Cambridge, MA: MIT Press, Ch. 4.

82 Cited in Jochen Kraske. 1996. Bankers with a Mission: The Presidents of the World Bank, 1946-91. Oxford University Press, 223-4.

83 I am not of course suggesting that small "i" ideas like public-choice theory were not influential during this era, but that they functioned as part of a much bigger and more explicitly ideological set of large "I" ideas at that time. 
84 Kapur et al. World Bank, 271-2; McNamara. "Board of Governors," 653.

85 World Bank. 1981. Accelerated Development, 104.

86 As the IFIs moved ever deeper into borrower politics, redrawing the boundaries between the domestic and the international, this narrowly expert form of authority would also prove to be a significant weakness, as I will discuss in the next chapter.

87 Kapur et al. World Bank, 316.

88 I discuss this phenomenon at greater length in: Jacqueline Best. 2013. "Redefining Poverty as Risk and Vulnerability: Shifting Strategies of Liberal Economic Governance." Third World Quarterly 34 (1): 109-29.

89 These failures are described variously as failures of incentives, of capacity, and of the effective use of resources, all of which lead to a prescription of "reducing the widespread administrative overcommitment of the public sector and ... developing and relying more on the managerial capacities of private individuals and firms. World Bank. Accelerated Development, v.

90 It is important to note that while this set of assumptions was dominant among staff at the Bank and Fund, it was not shared by all. For an account of the silent minority of more socially aware staff at the World Bank during this period, see: Antje Vetterlein. 2007. "Economic Growth, Poverty Reduction, and the Role of Social Policies: The Evolution of the World Bank's Social Development Approach." Global Governance 13 (4): 513-33; Catherine Weaver. 2008. Hypocrisy Trap: The World Bank and the Poverty of Reform. Princeton University Press.

91 As Jack Boorman, former Director of the Policy Review and Development Department at the IMF, noted, in economics departments, "the historians and the institutionalists were more or less relegated to the small offices." Interview, Washington, DC, 31 August 2005.

92 Ayers. Banking on the Poor.

93 Barber B. Conable. 1991. The Conable Years at the World Bank: Major Policy Addresses of Barber B. Conable, 1986-91. Washington, DC: World Bank, Chs 1, 15; Kraske. 1990. Bankers with a Mission, 250; World Bank. World Development Report 1990: Poverty. Washington, DC.

94 Boughton. Silent Revolution, 689-90.

\section{TRANSFORMATIONS}

1 IMF Archives. 1997. EBS/97/112. Summary of Internal Review of ESAF. Review of Experience Under ESAF-Supported Arrangements: Summary Report. 20 June; IMF. 1998. "External Evaluation of the ESAF: Report by a Group of Independent Experts.” Washington, DC: International Monetary Fund.

2 OED. 1998. “1997 Annual Review of Development Effectiveness.” Washington, DC: Operations Evaluation Department, World Bank.

3 World Bank. 1997. World Development Report 1997: The State in a Changing World. Washington, DC.

4 As in the previous chapter, I will be focusing here primarily on the IMF and World Bank, rather than attempting to provide a comprehensive history of the evolution of governance strategies among key donors as well - a task that would exceed the scope of this volume. 
5 Bruno Latour. 1991. "Technology is Society Made Durable.” In A Sociology of Monsters: Essays on Power, Technology and Domination, edited by J. Law. London and New York: Routledge, 114.

6 Principal-agent scholars are among those who tend to focus on the centrality of state (principal) actors as one of the key driving forces behind institutional change, including some recent changes in IMF and World Bank policy. See, for example: Erica Gould. 2006. "Delegating IMF Conditionality: Understanding Variations in Control and Conformity." In Delegation and Agency in International Organizations, edited by Darren Hawkins, David Lake, Daniel Nielson and Michael Tierney. Cambridge University Press, 140-64. For a sociological perspective that places considerable emphasis on US interests as a driving force behind the IMF's "mission creep," see: Sarah Babb and Ariel Buira. 2004. "Mission Creep, Mission Push and Discretion in Sociological Perspective: The Case of IMF Conditionality.” G24 Technical Group Meeting: Geneva, 8-9, March.

7 The US, for example, as I will discuss in Chapter 5, actively and unsuccessfully opposed some of the changes involved in streamlining conditionality.

8 A moment that, as I will suggest in the Conclusion to this book, may be in the process of passing, as a growing number of conservative governments are beginning to exercise a more instrumental kind of power over aid financing in recent years.

9 Paul Cammack. 2004. "What the World Bank Means by Poverty Reduction, and Why it Matters." New Political Economy 9 (2): 189-211; Arne Rückert. 2007. "Producing Neoliberal Hegemony? A Neo-Gramscian Analysis of the Poverty Reduction Strategy Paper (PRSP) in Nicaragua." Studies in Political Economy (79): 91-116; Marcus Taylor. 2005. "Opening the World Bank: International Organisations and the Contradictions of Global Capitalism." Historical Materialism 13 (1): 153-70.

10 Susan Park and Antje Vetterlein, eds. 2010. Owning Development: Creating Policy Norms in the IMF and the World Bank.Cambridge University Press; Catherine Weaver and Ralf J. Leiteritz. 2005. "'Our Poverty is a World Full of Dreams': Reforming the World Bank." Global Governance 11 (3): 369-88.

11 Joseph Stiglitz. 1998. "Towards a New Paradigm for Development: Strategies, Policies, and Processes." Prebisch Lecture, UNCTAD: Geneva, 19 October.

12 John Gerard Ruggie. 1982. "International Regimes, Transactions and Change: Embedded Liberalism in the Postwar Economic Order." International Organization 36 (2): 379-415.

13 Swati Chaudhary and Leonard Seabrooke. 2009. "Pragmatic Numbers: How the IMF Creates Policy Dialogue for Financial Reform." Warwick CSGR Working Paper (No. 261/09). Classic works on the role of institutional learning in global governance include: Ernst B. Haas. 1990. When Knowledge Is Power: Three Models of Change in International Organizations. Berkeley, CA: University of California Press; Peter M. Haas and Ernst B. Haas. 1995. "Learning to Learn: Improving International Governance." Global Governance 1 (3): 255-84; Jeffrey T. Checkel. 2001. "Why Comply? Social Learning and European Identity Change." International Organization 55 (3): 553-88. 
14 Sheldon Wolin. 1981. "Max Weber: Legitimation, Method, and the Politics of Theory." Political Theory 9 (3): 406.

15 Ibid.: 414.

16 Max Weber. 1976. The Protestant Ethic and the Spirit of Capitalism. New York: Scribner.

17 Max Weber. 1976. Economy and Society: An Outline of Interpretive Sociology. Vol. 1. Berkeley, CA: University of California Press.

18 Wolin. "Weber": 417.

19 Ibid.: 419.

20 Ibid., citing: Max Weber. 1949. The Methodology of the Social Sciences. Glencoe, IL: Free Press, 116.

21 Andrew Barry. 2002. "The Anti-Political Economy." Economy and Society 31 (2): $272-3$.

22 Ibid.: 272. For a superb discussion of the politics of standardization, see: Martha Lampland and Susan Leigh Star, eds. 2008. Standards and their Stories: How Quantifying, Classifying, and Formalizing Practices Shape Everyday Life. Ithaca: Cornell University Press.

23 Michel Callon, ed. 1998. The Laws of the Markets. Oxford: Blackwell, 260-1.

24 While some of these debates were certainly "hot," others are better characterized as "warm": defined neither by a general agreement on metrics nor an outright debate on what counts as success and failure, but rather by a pervasive sense of unease and ambivalence about the adequacy of existing forms of measurement. In fact, this kind of ambivalence is a central characteristic of provisional forms of governance.

25 There are clear links between what I am calling contested failures and the idea of socially constructed or narrated crises, as articulated by Colin Hay, Mark Blyth and Wesley Widmaier (and in some of my own earlier work). What the focus on failures adds is an attention to the methodological and epistemological character of certain crises, and the broader connections between events, debates around their interpretation, and the fragile foundations of expert authority. On crises, see: Mark Blyth. 2002. Great Transformations: The Rise and Decline of Embedded Liberalism. Cambridge University Press; Colin Hay. 1996. "Narrating Crisis: The Discursive Construction of the 'Winter of Discontent'." Sociology 30 (2): 253-77; Wesley Widmaier, Mark Blyth and Leonard Seabrooke. 2007. "Exogenous Shocks or Endogenous Constructions? The Meanings of Wars and Crises." International Studies Quarterly 51 (4): 747-59; Jacqueline Best. 2005. The Limits of Transparency: Ambiguity and the History of International Finance. Ithaca: Cornell University Press.

26 Joseph Stiglitz. 1998. "Restoring the Asian Miracle." The Wall Street Fournal, 3 February. See also: Ilene Grabel. 1999. "Rejecting Exceptionalism: Reinterpreting the Asian Financial Crises." In Global Instability: The Political Economy of World Economic Governance, edited by J. Michie and J. G. Smith. London: Routledge, 37-67; Jeffrey Sachs. 1997. "Power Unto Itself." Financial Times, 11 December.

27 Michel Camdessus. 1999. "Governments and Economic Development in a Globalized World." 32nd International General Meeting of the Pacific Basin Economic Council, International Monetary Fund: Hong Kong, 17 May; 
Lawrence Summers. 1998. Statement of Deputy Secretary of the Treasury before the Committee on Finance. United States Senate: Washington, DC, 4 February; Alan Greenspan. 1998. Testimony of Chairman of the Reserve Board to the Committee on Banking and Financial Services. US House of Representatives: Washington, DC, 30 January.

28 I provide a much more detailed account of the IMF's response to the Asian crisis in: Jacqueline Best. 2007. The Limits of Transparency. Ch. 7; Best. "Legitimacy Dilemmas: The IMF's Pursuit of Country Ownership." Third World Quarterly 28 (3): 469-88.

29 The UNDP labelled the 1980s a "lost decade" in their 1999 World Development Report, and then labelled the 1990s a "decade of despair" in their 2003 report. UNDP. 1999. Human Development Report 1999. New York: United Nations Development Programme; UNDP. 2003. Human Development Report 2003. New York: United Nations Development Programme; World Bank. 1989. Sub-Saharan Africa: From Crisis to Sustainable Growth. A Long-term Perspective Study. Washington, DC.

30 Howard Stein. 2008. Beyond the World Bank Agenda: An Institutional Approach to Development. University of Chicago Press, 38-9.

31 David Dollar and Jakob Svensson. 1998. "What Explains the Success or Failure of Structural Adjustment Programs?" Washington, DC: World Bank.

32 OED. 1985. "Sustainability of Projects: First Review of Experience." Washington, DC: World Bank Operations Evaluation Department, ii; OED. 1988. "Project Performance Results for 1986." Washington, DC: World Bank Operations Evaluation Department, xiii, 3.

33 World Bank. 1981. Accelerated Development in Sub-Saharan Africa: An Agenda for Action. Washington, DC, 4-5, 24.

34 In addition to Weber, see also: Michael Barnett and Martha Finnemore. 2004. Rules for the World: International Organizations in Global Politics. Ithaca: Cornell University Press.

35 Jan Aart Scholte and Albrecht Schnabel, eds. 2002. Civil Society and Global Finance. London: Routledge; Randall D. Germain. 2004. "Globalising Accountability within the International Organisation of Credit: Financial Governance and the Public Sphere." Global Society 18 (3): 217-42.

36 Interviews with senior IMF staff members, 11 May 2007 and 6 October 2008.

37 On the political turn at the World Bank in particular, see: Christian Chavagneux. 2003. "FMI, Banque mondiale: Le tournant politique." Revue d'économie financiere 70 (1): 209-18; Graham Harrison. 2004. The World Bank and Africa: The Construction of Governance States. London: Routledge; Michelle MillerAdams. 1999. The World Bank: New Agendas. London: Routledge, Ch. 5.

38 Interview with senior World Bank staff member, 11 May 2007.

39 Antje Vetterlein. 2007. "Economic Growth, Poverty Reduction, and the Role of Social Policies: The Evolution of the World Bank's Social Development Approach." Global Governance 13 (4): 513-33; Catherine Weaver. 2008. Hypocrisy Trap: The World Bank and the Poverty of Reform. Princeton University Press.

40 Key British ministers, such as Clare Short and Tony Benn, as well as the then Chancellor of the Exchequer, Gordon Brown, also became personally implicated in moving these agendas forward - both through pressure on the IFIs 
and by enacting their own reforms to aid policy at home. Interviews with Ruth Driscoll, Overseas Development Institute and Jeff Powell, Bretton Woods Project, September 2006.

41 Dollar and Svensson. "What Explains Success."

42 World Bank. 1993. The East Asian Miracle: Economic Growth and Public Policy. Washington, DC.

43 Robert Wade. 1996. "Japan, the World Bank and the Art of Paradigm Maintenance: The East Asian Miracle in Political Perspective." New Left Review (217): 3-36.

44 David Sanger. 1998. "Decisions by US and IMF Worsened Asia's Problems, the World Bank Finds." The New York Times, 3 December.

45 Interview with senior IMF staff member, August 2005.

46 World Bank. 2000. Reforming Public Institutions and Strengthening Governance: A World Bank Strategy. Washington, DC, xii, xv; World Bank. 2002. Reforming Public Institutions and Strengthening Governance: A World Bank Strategy. Implementation Update. Washington, DC, 17-23.

47 Devesh Kapur, John P. Lewis and Richard Webb. 1997. The World Bank: Its First Half Century. Vol. I. Washington, DC: Brookings Institution Press, 539.

48 OED. 1992. "Adjustment Lending: Lessons from a Decade of Experience." OED. Précis 32 (June).

49 Although Fund staff did not use the term much until 1997, they had raised concerns about the importance of domestic "political commitment" as early as 1979. IMF Archives. 1979. EBS/79/635. Adjustment Programs Supported by Upper Credit Tranche Stand-by Assignments. 26 December.

50 Kapur et al. World Bank. 269, 310, 312.

51 OED. 1994. “Annual Review of Evaluation Results 1993.” Washington, DC: Operations Evaluation Department, World Bank.

52 Ibid.

53 Wapenhans, Willi. 1992. "Effective Implementation: Key to Development Impact." Washington, DC: World Bank, Portfolio Management Task Force.

54 The influence of these more conservative attacks is made explicit by Stiglitz in his foreword to the Assessing Aid report. World Bank. 1998. Assessing Aid: What Works, What Doesn't, and Why. New York: Oxford University Press, ix.

55 Tony Killick. 1997. "Principals, Agents and the Failings of Conditionality." fournal of International Development 9 (4): 483-95; Tony Killick, Ramani Gunatilaka and Ana Marr. 1998. Aid and the Political Economy of Policy Change. London: Routledge; Craig Burnside and David Dollar. 1997. "Aid, Policies and Growth: Revisiting the Evidence." World Bank Policy Research Working Paper (No. 3251).

56 Dollar and Svensson. "What Explains Success?"; World Bank. Assessing Aid.

57 World Bank. Assessing Aid, 6, 20.

58 Tony Killick's work (which also applied a public-choice framework, focusing on principal-agent dynamics) was particularly damning in this respect. Killick. "Principals, Agents"; Killick et al. Aid.

59 World Bank. Assessing Aid, 4, 17.

60 Although the emphasis on volume of lending has remained a very significant motivator. Interview with Bruce Rich, Environmental Defense, 8 May 2007. 
61 As Kapur et al. note, it is very difficult to judge the extent to which the quality of Bank projects did in fact decline over this period: "Even trends are difficult to interpret: was it due to poor inputs, the Bank's venturing into more risky terrain (whether by country or sector), changed value judgments or a more

62 Ibid. volatile global environment?" Kapur et al. World Bank, 45.

63 IMF Archives. EBS/97/112.

64 IMF. "External Evaluation."

65 On the limits of recent efforts at financial risk management see: Jacqueline Best. 2010. "The Limits of Financial Risk Management: Or, What We Didn't Learn from the Asian Crisis." New Political Economy 15 (1): 29-49; Paul Langley. 2008. The Everyday Life of Global Finance: Saving and Borrowing in Anglo-America. Oxford University Press; Mark Blyth. 2006. "Great Punctuations: Prediction, Randomness, and the Evolution of Comparative Political Science." American Political Science Review 100 (4): 493-8.

66 OED. 1996. "Annual Review of Evaluation Results 1995." Washington, DC: Operation Evaluation Department, World Bank.

67 Kapur et al. World Bank, 219.

68 What John Law would describe as "patterns that tend to reproduce themselves, and so their various distributive effects." John Law, ed. 1991. A Sociology of Monsters: Essays on Power, Technology and Domination. London and New York: Routledge, 14.

\section{FOSTERING OWNERSHIP}

1 World Bank. 1998. Assessing Aid: What Works, What Doesn't, and Why. New York: Oxford University Press, 52. This report also cites a World Bank study: William Branson and Carl Jayarajah. 1995. "Structural and Sectoral Adjustment: World Bank Experience, 1980-92." Washington, DC: World Bank Operations Evaluation Study.

2 Each of these concepts has its own storied history, as discussed respectively in: Robert McNamara. 1973. Address to the Board of Governors. World Bank: Nairobi, Kenya, 24 September; Rolf H. Sartorius and Vernon W. Ruttan. 1989. "The Sources of the Basic Human Needs Mandate." Fournal of Developing Areas 23 (3): 344-5; Samuel Hickey and Giles Mohan. 2004. Participation: From Tyranny to Transformation? Exploring New Approaches to Participation in Development. London: Zed Books, 5-9.

3 Over time, NGOs have developed a rather mixed assessment of country ownership, challenging IFIs and donors to foster meaningful ownership while also raising questions about what the term really means - and suggesting that it often boils down to asking developing country governments to "own" traditional IFI and donor policies, rather than generating their own solutions.

4 David Dollar and Jakob Svensson. 1998. "What Explains the Success or Failure of Structural Adjustment Programs?" Washington, DC: World Bank; World Bank. Assessing Aid.

5 OED. 1982. "Eighth Annual Review of Project Performance Audit Results." Washington, DC: Operations Evaluation Department, World Bank; OED. 
1988. "Project Performance Results for 1986.” Washington, DC: Operations Evaluation Department, World Bank; OED. 1994. "Annual Review of Evaluation Results 1993." Washington, DC: Operations Evaluation Department, World Bank.

6 OED. 1998. “1997 Annual Review of Development Effectiveness.” Washington, DC: Operations Evaluation Department, World Bank; World Bank. Assessing Aid.

7 A concern that was only intensified by the fact that success rates continued to decline in the early years of Wolfensohn's tenure. Bruce Rich. 2002. "The World Bank under James Wolfensohn." In Reinventing the World Bank, edited by J. Pincus and J. A. Winters. Ithaca: Cornell University Press, 45-6.

8 Because IMF resources are based on the contributions, or shares, of member states, they are referred to as "shareholders." A member's voting power also depends on the size of their quota, or share. Hence industrialized countries have the vast majority of the voting share, while the US, with 17 per cent, has an effective veto on fundamental changes requiring 85 per cent agreement.

9 IMF Archives. 1995. EBM/95/107. Minutes of Executive Board Meeting. November 13: 26-7, 41-2, 48. Support for more "ownership" came from US, UK and Canadian directors, among others, who suggested that more selectivity in lending might foster more ownership. Other directors, particularly those representing developing countries, disagreed with this approach to country ownership.

10 The ESAF was the facility through which the IMF made concessional lending to poor countries. It has since been replaced by the poverty reduction and growth fund (PRGF).

11 IMF Archives. 1997. EBS/97/112 S2. Summary of Internal Review of ESAF. Review of Experience Under ESAF-supported Arrangements: Staff Studies, Vol. 7 July: 161, 186.

12 IMF. 1998. "IMF Releases Report of External Evaluation of ESAF Following Executive Board Review." IMF Survey 27 (6): 81-6; IMF. 1998. "External Evaluation of the ESAF: Report by a Group of Independent Experts." Washington, DC: International Monetary Fund.

13 Interview with senior IMF staff member, Washington, DC, 14 June 2010.

14 Interview with Michel Camdessus, former IMF Managing Director (19872000), 17 May 2011.

15 Interviews with senior IMF staff members, Washington, DC, August 2005, October 2008 and June 2010.

16 When IFIs and donors provide funds through general budget support (GBS), they do not funnel them to individual projects or through ring-fenced units within the borrowing government, but rather provide the funds to the finance ministry directly, allowing the government to use its own internal mechanisms to allocate them. GBS became an increasingly popular form of aid delivery in the early 2000s, as part of the broader emphasis on country ownership and the move to work within domestic government systems. It has since lost some of its popularity and is the subject of considerable debate among donors. For some interesting assessments of GBS, see: Debbie Warrener. 2004. "Current Thinking in the UK on General Budget Support." London: Overseas 
Development Institute; Stefan Koeberle, Stavreski Zoran and Jan Valliser, eds. 2006. Budget Support as More Effective Aid? Recent Experiences and Emerging Lessons. World Bank.

17 For a more detailed discussion of the changing nature of conditionality, see: Sidney Dell. 1981. "On Being Grandmotherly: The Evolution of IMF Conditionality." Princeton Essays in International Finance (No. 144); Adolfo C. Diz. 1984. "The Condition Attached to Adjustment Financing; Evolution of the IMF Practice." In The International Monetary System: Forty Years After Bretton Woods. Boston: Federal Reserve Bank of Boston, 214-43; Jacqueline Best. 2012. "Ambiguity and Uncertainty in International Organizations: A History of Debating IMF Conditionality." International Studies Quarterly 56 (4): 674-88; Harold James. 1998. "From Grandmotherliness to Governance: The Evolution of IMF Conditionality." Finance and Development 35 (4): 44-7.

18 For a discussion of the original IMF model and its evolution, see: Jacques Polak. 1997. "The IMF Monetary Model at Forty." IMF Working Paper (No. WP/07/49).

19 For a more detailed discussion of the reaction to the Asian financial crisis, see: Jacqueline Best. 2005. The Limits of Transparency: Ambiguity and the History of International Finance. Ithaca: Cornell University Press, Chs 6 and 7.

20 Horst Köhler. 2000. "Streamlining Structural Conditionality in Fundsupported Programs: Interim Guidance Note." Washington, DC: International Monetary Fund.

21 Interview with Jack Boorman, Consultant, Office of the Managing Director and Former Director of Policy Development and Review, IMF, Washington, DC, 31 August 2005.

22 Interview with former Executive Board member, IMF, Washington, DC, 29 August 2005.

23 Köhler. 2002. "Streamlining Structural Conditionality"; IMF. "Guidelines on Conditionality." Washington, DC: International Monetary Fund.

24 IMF Archives. 2001. SM/01/60 Sup. 1. Conditionality in Fund Supported Programs - Policy Issues. February 20: 49.

25 James M. Boughton. 2003. "Who's in Charge? Ownership and Conditionality in IMF-Supported Programs." IMF Working Paper (WP/03/191); Susan Schadler et al. 1995. "IMF Conditionality: Experiences under Stand-by and Extended Arrangements, Part I: Key Issues and Findings." IMF Occasional Paper (No. 128).

26 Interview with senior staff member, IMF, Washington, DC, August 2005.

27 For example: James M. Boughton and Alex Mourmouras. 2002. "Is Policy Ownership an Operational Concept?" IMF Working Paper (No. WP/02/72).

28 DFID. 2000. Eliminating World Poverty: Making Globalization Work for the Poor. White Paper on International Development. London: UK Department for International Development: 39.

29 IMF Archives. 2001. EBM/01/23. Minutes of Executive Board Meeting. 7 March; IMF Archives. 2002. EBM/02/9. Minutes of Executive Board Meeting. 28 January.

30 Telephone interview with Edwin M. Truman, former Treasury Assistant Secretary, International Affairs, US Government, 31 October 2006. See also: 
Allan Meltzer. 2000. "Report of the International Financial Institutions Advisory Commission." Washington, DC: US House of Representatives; US Treasury. 2001. "Report on Implementation of Recommendations Made by the International Financial Institutions Advisory Commission." Washington, DC: US Department of Treasury.

31 In interviews, both senior IMF and British officials noted, without attribution, that the US resisted major reforms to conditionality, a claim that is also reflected in the IMF minutes from the Board meetings. EBM/01/23; EBM/ 02/9. I have provided a detailed analysis of these Board debates in: Jacqueline Best. "Ambiguity and Uncertainty."

32 Interviews with former IMF Executive Directors, September 2006 and May 2007.

33 World Bank. 2001. "Adjustment Lending Retrospective: Final Report." Washington, DC: World Bank.

34 Ibid., ix, xv, xvii.

35 Ibid., $x$.

36 Paul Collier. 1997. "The Failure of Conditionality." In Perspectives on Aid and Development, edited by C. Gwyn and J. Nelson. Washington, DC: ODC, 51-77.

37 Interview with NGO staff member, London, September 2006. Bretton Woods Project. 2005. Highlights of Meeting with UK Secretary of State for International Development, Hilary Benn, 5 October. Available from www. brettonwoodsproject.org/art.shtml?x=379085; Bretton Woods Project. 2005. Highlights of Meeting with UK ED to WB/IMF, Tom Scholar, 5 October. Available from www.brettonwoodsproject.org/art.shtml? $\mathrm{x}=379054$.

38 World Bank. 2004. "From Adjustment Lending to Development Policy Lending: Update of World Bank Policy." Washington, DC.

39 Some of the same broad goals of privatization remain, however, reframed in the language of the creation of a good business climate.

40 World Bank. "From Adjustment Lending," 46, 43, 42, 44, 46-9.

41 World Bank. 2005. "Review of World Bank Conditionality." Washington, DC.

42 DFID. 2005. Partnerships for Poverty Reduction: Rethinking Conditionality. London: UK Department for International Development.

43 DFID. 2006. Conditionality. UK Department for International Development. Available from http://web.archive.org/web/20070203154938/http://www.dfid. gov.uk/mdg/conditionality.asp.

44 Interview with Ruth Driscoll, Research Fellow, Overseas Development Institute (ODI) and former aide to Clare Short, London, 11 September 2006.

45 Interview with Jeff Powell, Coordinator, Bretton Woods Update, London, 11 September 2006.

46 Interview with Ruth Driscoll, ODI.

47 Interview with Jeff Powell, Bretton Woods Update and with another NGO staff member, London, September 2006.

48 Interview with Ruth Driscoll, ODI.

49 DFID. Eliminating World Poverty, 8.

50 Ibid., 12. This framing of the problems of development is very similar to that found in speeches by Bank Chief Economist Joseph Stiglitz, and in the 1997 
World Development Report on the state. World Bank. 1997. World Development Report 1997: The State in a Changing World. Washington, DC; Joseph Stiglitz. 1998. "Towards a New Paradigm for Development: Strategies, Policies, and Processes." Prebisch Lecture, UNCTAD: Geneva, 19 October; Stiglitz. 1998. "More Instruments and Broader Goals: Moving Towards the Post-Washington Consensus." WIDER Annual Lecture: Helsinki, 7 January.

51 Tony Killick. 1997. "Principals, Agents and the Failings of Conditionality." Fournal of International Development 9 (4): 483-94.

52 Interview with Senior Staff Member, HM Treasury, British Government, London, 6 September 2006.

53 MCC. 2008. About MCC. Millennium Challenge Corporation. Available from www.mcc.gov/about/index.php.

54 Alicia Phillips-Mandaville. 2009. "MCC's Approach to Country Ownership Working Paper: A Draft for Comment and Revision." Washington, DC: Millennium Challenge Corporation; John Danilovich. 2007. Remarks by MCC CEO at Brown University's Center for Latin American Studies. Providence, RI, 16 April.

55 For a thoughtful overview of the Bank's internal agonies about these failures, see: John Pender. 2001. "From 'Structural Adjustment' to 'Comprehensive Development Framework': Conditionality Transformed?” Third World Quarterly 22 (3): 397-411.

56 Craig Burnside and David Dollar. 1997. "Aid, Policies and Growth." World Bank Policy Research Working Paper (No. 1777); Dollar and Svensson. "What Explains Success"; Collier. "Failure of Conditionality"; Killick. "Principals, Agents"; Tony Killick, Gunatilaka Ramani and Marr Ana. 1998. Aid and the Political Economy of Policy Change. London: Routledge.

57 Burnside and Dollar. "Aid, Policies and Growth"; World Bank. Assessing Aid.

58 Dollar and Svensson. "What Explains Success," 8-10.

59 Ibid., 3-5.

60 Ibid., 2. This point is also made by: Collier. "Failure of Conditionality."

61 Dollar and Svensson. "What Explains Success," 3-5.

62 Collier. "Failure of Conditionality"; Dani Rodrik. 1989. "Promises, Promises: Credible Policy Reform via Signaling." Economic fournal 99 (397): 756-72.

63 Of course this begs the question of how one determines "genuine" reformers.

64 Interview with former senior World Bank staff member, Washington, DC, 9 May 2007.

65 IMF. 2011. "The Policy Support Instrument: Factsheet." Washington, DC: International Monetary Fund. Of course, as I will discuss below, the fact that conditions are increasingly symbolic does not mean that they do not have very real effects.

66 World Bank. "Review of Conditionality," 5, 9.

67 Ibid., 4.

68 World Bank, “Adjustment Lending Retrospective," 9-10. As the 2006 World Bank review notes, there has since been a slight decrease in the average number of benchmarks in IDA-only countries to twenty-seven, although the number remains well above the average for the 1990s. World Bank. 
2006. "Good Practice Principles for the Application of Conditionality: A Progress Report." Washington, DC.

69 Camilla Andersen. 2009. "New Rules of Engagement for IMF Loans." IMF Survey Magazine. Washington, DC: International Monetary Fund.

70 Interviews with UK official and with NGO staff member, London, September 2006.

71 Interview with Ruth Driscoll, ODI.

72 Jeremy Gould, ed. 2005. The New Conditionality: The Politics of Poverty Reduction Strategies. London: Zed Books, 10; Graham Harrison. 2001. "Post-Conditionality Politics and Administrative Reform: Reflections on the Cases of Uganda and Tanzania." Development and Change 32 (4): 669-70. My interviews with many NGO staff also touched on this particular trend, which posed a dilemma for NGOs seeking to pursue both country ownership and opposing many of the neoliberal development norms that some developing country leaders have adopted.

73 Harrison. "Post-Conditionality": 660.

74 Interview with former senior staff member, World Bank, Washington, DC, 9 May 2007.

75 World Bank. "Review of Conditionality," 19.

76 Danilovich. "Remarks by MCC CEO."

77 Ilene Grabel. 2000. "The Political Economy of 'Policy Credibility': The New-Classical Macroeconomics and the Remaking of Emerging Economies." Cambridge fournal of Economics 24 (1): 1-19.

78 Interview with former senior World Bank staff member, 11 June 2010.

79 World Bank. 2003. "The Role of Selectivity in Enhancing IDA Effectiveness: A Progress Report." Washington, DC; World Bank. 2007. "Selectivity and Performance: IDA's Country Assessment and Development Effectiveness," Washington, DC. Selectivity has been increased in part through the Bank's increased use of the CPIA, which I discuss at greater length in Chapters 6 and 7 , as well as its shift towards performance-based allocations of concessional aid, discussed in Chapter 8.

80 PFPs outlined a basic economic development plan that both institutions could support. Such a plan became necessary as IMF and Bank programs began to converge, as the World Bank placed more emphasis on adjustment lending and the IMF created facilities for medium-term concessional lending (the SAF and ESAF). Paul Mosely, Jane Harrigan and John Toye. 1991. Aid and Power: The World Bank and Policy-Based Lending. London: Routledge, 53.

81 Interview with former senior staff member of the World Bank, 9 May 2007.

82 Karin Christiansen and Ingie Hovland. 2003. "The PRSP Initiative: Multilateral Policy Change and the Role of Research." London: Overseas Development Institute, ix.

83 DFID. Eliminating World Poverty.

84 Christiansen and Hovland. "The PRSP Initiative," 19.

85 Interview with senior OECD-DAC staff member, Paris, May 2012. OECD. 1996. "Shaping the 21st Century: The Contribution of Development Co-operation.” Paris: Development Assistance Committee, Organization for Economic Co-operation and Development. 
86 Christiansen and Hovland. 2004. "The PRSP Initiative," 21-3; LaureHélène Piron and Andy Norton. "Politics and the PRSP Approach: Uganda Case Study." London: Overseas Development Institute.

87 I discuss these debates and the changing practices of poverty reduction in Chapter 8 and, at greater length, in: Jacqueline Best. 2013. "Redefining Poverty as Risk and Vulnerability: Shifting Strategies of Liberal Economic Governance." Third World Quarterly 34 (1): 109-29.

88 On the politics of "partnership," see: Rita Abrahamsen. 2004. "The Power of Partnerships in Global Governance." Third World Quarterly 25 (8): 1453-67.

89 The predominant account of the PRSP (including that provided by Wolfensohn in his official accounts of the events) is that it was a way of operationalizing the CDF. My alternate account has been confirmed independently by two different sources familiar with the internal politics around the PRSPs' development.

90 World Bank. Comprehensive Development Framework. Washington, DC.

91 Interviews with senior IMF and World Bank staff, Washington, DC, June 2010.

92 Interview with Camdessus.

93 Interview with senior IMF staff member, Washington, DC, 14 June 2010. It is worth noting that different interviewees provided somewhat different interpretations of the relative influence of IMF and World Bank staff members in the creation of the PRSP.

94 Interview with Jack Boorman, Consultant, Office of the Managing Director and Former Director of Policy Development and Review Department, IMF, Washington, DC, 31 August 2005.

95 Interview with Camdessus.

96 Interview with senior IMF official, 29 August 2005.

97 Devesh Kapur, John P. Lewis and Richard Webb, eds. 1997. The World Bank: Its First Half Century. Vol. 2. Perspectives. Washington, DC: Brookings Institution Press, Ch. 5.

98 For example, whereas the 1990-1 World Development Report is relatively pessimistic about the possibility of mobilizing the poor as an active force, the 2000-1 Report sees them as a vital force for policy change. World Bank. 1990. World Development Report 1990: Poverty. Washington, DC, 50-2; World Bank. 2000. World Development Report 2000/01: Attacking Poverty. New York: Oxford University Press, 99-102.

99 Nikolas Rose. 1999. Powers of Freedom: Reframing Political Thought. Cambridge University Press, Ch. 5.

100 See also: Javier Lezaun and Linda Soneryd. 2007. "Consulting Citizens: Technologies of Elicitation and the Mobility of Publics." Public Understanding of Science 16 (3): 279-97.

101 See, for example: IMF. 1999. "Republic of Mozambique Enhanced Structural Adjustment Facility Policy Framework Paper for April 1999-March 2002." Washington, DC: International Monetary Fund; IMF. 1999. "Ghana Enhanced Structural Adjustment Facility Policy Framework Paper, 1999-2001.” Washington, DC: International Monetary Fund. 
102 See, for example: Republic of Bolivia. 2001. "Poverty Reduction Strategy Paper - PRSP - Estrategia Boliviana de la Reduccion de la Pobreza." Washington, DC: World Bank; Republic of Uganda. 2005. "Uganda: Poverty Reduction Strategy Paper." Washington, DC: IMF; Socialist Republic of Vietnam. 2004. "Vietnam: Poverty Reduction Strategy Paper." Washington, DC: IMF; Government of Mozambique. 2001. "Action Plan for the Reduction of Absolute Poverty (2001-2005) - Strategy Document for the Reduction of Poverty and Promotion of Economic Growth." Maputo, Mozambique.

103 A detailed overview of staff techniques is provided in Chapter 7 of the PRSP Sourcebook: World Bank. 2001. A Sourcebook for Poverty Reduction Strategies. Washington, DC.

104 Stiglitz. "Towards a New Paradigm."

105 Interview with Ruth Driscoll, ODI.

106 Horst Köhler. 2003. "The Challenges of Globalization and the Role of the IMF." Annual Meeting of the Society for Economics and Management, International Monetary Fund: Washington, DC, 15 May.

107 Michel Foucault. 1991. "Governmentality.” In The Foucault Effect: Studies in Governmentality, edited by Graham Burchell, Colin Gordon and Peter Miller. London: Harvester Wheatsheaf, 87-104; Michel Foucault. 2004. Naissance de la Biopolitique: Cours au Collège de France, 1978-79. Paris: Seuil.

108 Piron and Norton. "Politics and PRSP Approach."

109 Nadia Molenaers and Robrecht Renard. 2003. "The World Bank, Participation and PRSP: The Bolivian Case Revisited." The European fournal of Development Research 15 (2): 140.

110 Laure-Helene Piron and Alison Evans. 2004. "Politics and the PRSP Approach: Synthesis Paper." London: Overseas Development Institute; Geske Dijkstra. 2005. "The PRSP Approach and the Illusion of Improved Aid Effectiveness: Lessons from Bolivia, Honduras and Nicaragua." Development Policy Review 23 (4): 443-64; Lindsay Whitfield. 2005. "Trustees of Development from Conditionality to Governance: Poverty Reduction Strategy Papers in Ghana." Fournal of Modern African Studies 43 (4): 641-64.

111 I will discuss this example of what I am calling a "benign failure" in more detail in the Conclusion to this volume.

\section{DEVELOPING GLOBAL STANDARDS}

1 In order, these quotes are from: World Bank. 1996. "World Bank President Outlines a New Agenda - Describes a Bank 'On the Move'." Press Release (No. 97/1153), Washington, DC; Michel Camdessus. 1999. "From the Crises of the 1990s to the New Millennium." International Graduate School of Management, International Monetary Fund: Madrid, 27 November; DFID. 1997. Eliminating World Poverty: A Challenge for the 21st Century. White Paper on International Development, UK Department for International Development, 5; Horst Köhler. 2002. "Strengthening the Framework for the Global Economy." Award Ceremony of the Konrad Adenauer Foundation Social Market Economy Prize, International Monetary Fund: Berlin, 15 November. 
2 This last example of maternal health is one of the many new global norms included in the millennium development goals, which provide another example of a policy that relies on the standardizing strategies discussed in this chapter.

3 These new practices are therefore not the kind of rigid, constitutional strategies characteristic of trade and investment agreements that neo-Gramscians like Stephen Gill have discussed. Gill. 1995. "Globalisation, Market Civilisation, and Disciplinary Neoliberalism." Millennium 24 (3): 399-423; Gill. 2002. "Constitutionalizing Inequality and the Clash of Globalizations." International Studies Review 4 (2): 47-66.

4 On the fragility of expert authority without popular approval, see: Kirstina Tamm Hallström. 2004. Organizing International Standardization: ISA and the IASC in Quest for Authority. Northampton: Edward Elgar.

5 I have written extensively about this moral turn in IFI discourse elsewhere: Jacqueline Best. 2003. "Moralizing Finance: The New Financial Architecture as Ethical Discourse." Review of International Political Economy 10 (3): 579603; Best. 2005. "The Moral Politics of IMF Reforms: Universal Economics, Particular Ethics.” Perspectives on Global Development and Technology 4 (3-4): 357-78; Best. 2006. "Co-opting Cosmopolitanism? The International Monetary Fund's New Global Ethics." Global Society 20 (3): 307-27.

6 Catherine Weaver. 2008. Hypocrisy Trap: The World Bank and the Poverty of Reform. Princeton University Press; Susan Park and Antje Vetterlein, eds. 2010. Owning Development: Creating Policy Norms in the IMF and the World Bank. Cambridge University Press; David Williams. 2008. The World Bank and Social Transformation in International Politics: Liberalism, Governance and Sovereignty. London: Routledge; Rita Abrahamsen. 2000. Disciplining Democracy: Development Discourse and Good Governance in Africa. London: Zed Books; Graham Harrison. 2004. The World Bank and Africa: The Construction of Governance States. London: Routledge.

7 There is a significant literature on the concept of "new" or "postconditionality," which sees recent initiatives such as the good governance agenda and Poverty Reduction Strategies as another, more extensive but less obvious, form of conditionality. My research confirms many of these claims, but because of my focus on how governance is performed rather than simply on the interests or outcomes at stake, this book points to broader and more profound changes in the logic of global development governance than those advanced in this literature. Jeremy Gould, ed. 2005. The New Conditionality: The Politics of Poverty Reduction Strategies. London: Zed Books; John Pender. 2001. "From 'Structural Adjustment' to 'Comprehensive Development Framework': Conditionality Transformed?" Third World Quarterly 22 (3): 397-411.

8 Michel Foucault. 1991. "Governmentality.” In The Foucault Effect: Studies in Governmentality, edited by Graham Burchell, Colin Gordon and Peter Miller. London: Harvester Wheatsheaf, 87-104; Michel Foucault. 2004. Naissance de la biopolitique: Cours au Collège de France, 1978-79. Paris: Seuil.

9 For example, in the field of development studies, Mark Duffield's otherwise excellent work does tend to suffer from such tendencies: Duffield. 2001. "Governing the Borderlands: Decoding the Power of Aid." Disasters 25 (4): 308-20. 
10 Stefan Timmermans and Marc Berg. 1997. "Standardization in Action: Achieving Local Universality through Medical Protocols." Social Studies of Science 27 (2): 273-305; Martha Lampland and Susan Leigh Star, eds. 2008. Standards and their Stories: How Quantifying, Classifying, and Formalizing Practices Shape Everyday Life. Ithaca: Cornell University Press; Stefan Timmermans and Steven Epstein. 2010. "A World of Standards but not a Standard World: Toward a Sociology of Standards and Standardization." Annual Review of Sociology 36: 69-89; Bruno Latour. 1993. The Pasteurization of France. Cambridge, MA: Harvard University Press.

11 Paul Wolfowitz. 2006. "Good Governance and Development - A Time For Action." World Bank: Jakarta, 11 April.

12 IMF. 2001. "Review of the Fund's Experience in Governance Issues." Washington, DC: International Monetary Fund, 29.

13 IEG. 2009. "The World Bank's Country Policy and Institutional Assessment: An Evaluation." Washington, DC: Independent Evaluation Group, World Bank, ix.

14 DFID. 2006. Eliminating World Poverty: Making Governance Work for the Poor. White Paper on International Development London: UK Department for International Development; MCC. 2008. "Building Public Integrity through Positive Incentives: MCC's Role in the Fight against Corruption." Washington, DC: Millennium Challenge Corporation; CIDA. 2011. Governance. Canadian International Development Agency, 2011. Available from www. acdi-cida.gc.ca/acdi-cida/ACDI-CIDA.nsf/En/JUD-111883426-HX4.

15 In some ways, nothing has changed since then: the pursuit of good governance remains a political project, and continues to encounter opposition, as I will discuss in the Conclusion.

16 World Bank. 1989. Sub-Saharan Africa: From Crisis to Sustainable Growth. A Long-Term Perspective Study. Washington, DC, xii, 3. The actual history of the interest in what eventually became known as good governance dates back further to the late 1970s. On this point, see: Weaver. Hypocrisy Trap; Michelle Miller-Adams. 1999. The World Bank: New Agendas. London: Routledge.

17 World Bank. Sub-Saharan Africa, 60.

18 Samir Amin. 1976. Unequal Development: An Essay on the Social Formations of Peripheral Capitalism. New York: Monthly Review Press; Theotonio Dos Santos. 1970. "The Structure of Dependence." The American Economic Review 60 (2): 231-36; Fernando Henrique Cardoso and Enzo Faletto. 1979. Dependency and Development in Latin America. Berkeley, CA: University of California Press.

19 The study was referenced explicitly in the legal opinion on the Bank's mandate as well as in Board discussions of the document, although Shihata was careful to note in those discussions that some issues addressed by the LongTerm Perspective Study did go beyond what he identified as acceptable governance policies for the Bank to undertake. World Bank Archives. 1991. Doc. 64896. Proceedings of a Seminar of Executive Directors to Discuss Issues of "Governance" in Borrowing Members: The Extent of Their Relevance Under the Bank's Articles of Agreement. 11 April: 15, 17, 52-3.

20 Ibid.: $24-5$. 
21 World Bank. 1991. "Managing Development: The Governance Dimension." Washington, DC; World Bank. 1992. "Governance and Development." Washington, DC; World Bank. 1994. "Governance: The World Bank's Experience." Washington, DC. The reports were discussed at Board meetings in April and July 1991 and December 1993: World Bank Archives. 1991. Doc. 64896. Proceedings of a Seminar; World Bank Archives. Doc. 64897. Proceedings of a Meeting of the Executive Board as Committee of the Whole to Discuss 'Managing Development: The Governance Dimension: A Discussion Paper.' 16 July; World Bank Archives. 1993. Doc. 64898. Discussion of Governance: The World Bank's Experience. Proceedings of a Meeting of the Executive Directors. 16 December.

22 Classic public-choice theory works include: Kenneth Arrow. 1951. Social Choice and Individual Values. New York: Wiley; William Niskanen. 1971. Bureaucracy and Representative Government. Chicago: Aldine, Atherton; Mancur Olsen. 1965. The Logic of Collective Action: Public Goods and the Theory of Groups. Cambridge, MA: Harvard University Press.

23 The term was actually coined by Anne Krueger, an economist who later became Chief Economist at the World Bank in the 1980s and Deputy Director of the IMF in the early 2000s. Anne Krueger. 1974. "The Political Economy of the Rent-Seeking Society." American Economic Review 64 (3): 291-303.

24 World Bank. "Governance: World Bank's Experience,” xv.

25 Ibrahim Shihata. 1990. "Issues of 'Governance' in Borrowing Members: The Extent of their Relevance under the Bank's Articles of Agreement." Washington, DC: World Bank. For an interesting discussion of this opinion, see: M. A. Thomas. 2007. "The Governance Bank." International Affairs 83 (4): 733.

26 The two Directors were, respectively, a Canadian Executive Director, Frank Potter, and a Libyan Executive Director, Salem Omeish. World Bank Archives. 1991. Doc 64896. Proceedings of a Seminar of Executive Directors: 13, 27-28.

27 World Bank. "New Agenda."

28 World Bank. 2001. World Development Report 2000/01: Attacking Poverty. Washington, DC; World Bank. 2002. World Development Report 2002: Building Institutions for Markets. Washington, DC.

29 For a discussion of Wolfensohn's contribution to the Bank's governance agenda, see: Williams. World Bank and Social Transformation; Jonathan Pincus and Jeffrey A. Winters. 2002. Reinventing the World Bank. Ithaca: Cornell University Press.

30 Classic institutionalist texts here include: Douglass North. 1990. Institutions, Institutional Change and Economic Performance. Cambridge University Press; Oliver Williamson. 1985. The Economic Institutions of Capitalism. New York: Free Press. Douglass North, in particular, is cited in a number of Bank documents as an inspiration for governance policy, particularly from the 2002 WDR on institutions onwards, in which the first footnote cites North, Williamson and Coase on institutions. World Bank. WDR: Building Institutions, 5 n.1.

31 Some of the more enthusiastic EDs included those from Costa Rica, Iceland and the Netherlands. The ED from Gambia also noted his support for 
participatory approaches, while pointing out that such processes are not new to Africa as Bank documents tended to suggest. World Bank Archives. Doc. 64896. Proceedings of a Seminar: 33-35, 65; World Bank Archives. Doc. 64897. Proceedings of a Meeting: 8, 34, 96-7.

32 World Bank. 2000. Reforming Public Institutions and Strengthening Governance: A World Bank Strategy. Washington, DC; World Bank. 2002. Reforming Public Institutions and Strengthening Governance: A World Bank Strategy. Implementation Update. Washington, DC.

33 Interview with senior World Bank staff member, 10 May 2011.

34 World Bank. 2007. "Strengthening World Bank Group Engagement on Governance and Anticorruption." Washington, DC.

35 IMF. 1996. "Partnership for Sustainable Global Growth." Washington, DC: International Monetary Fund.

36 IMF Archives. 1996. EBS/96/197. The Role of the Fund in Governance Issues. 20 December.

37 Ibid.: 9, 11, 19; IMF Archives. 1996. EB/CW/DC/97/3. Helping Countries Combat Corruption and Improve Governance: A Joint World Bank/IMF Issues Paper Prepared for the Development Committee. 13 August: 2, 5.

38 IMF. 2001. "Executive Board Reviews IMF's Experience in Governance Issues." Washington, DC: International Monetary Fund.

39 The two main policies through which the IMF engages with its members are its Article IV consultations and lending programs. Under Article IV of its Articles of Agreement, the IMF conducts annual consultations with all member states (not just those using its resources) as a part of its ongoing surveillance of the international financial system. These consultations take the form of an assessment of the strengths and weaknesses of the country as well as non-binding recommendations for reform. The Fund also has a number of different facilities through which it lends resources to states in need; these funds come with conditions (discussed in Chapter 5), which are binding on states that wish to receive the funds.

40 IMF. 1997. "The Role of the IMF in Governance Issues: Guidance Note." Washington, DC: International Monetary Fund.

41 Michel Camdessus. 1998. "The IMF and Good Governance." Transparency International: Paris, 21 January.

42 Interview with Jack Boorman, former Director of Policy Development and Review Department, IMF, Washington, DC, 31 August 2005.

43 Camdessus. "IMF and Good Governance."

44 IMF. "Review of Fund's Experience," 3, 11-12.

45 World Bank. WDR: Building Institutions, 3.

46 Of course, the "sound economics" that formed the basis of the economic universals of the structural adjustment era were also profoundly political - but they did not represent themselves as such.

47 Barber Conable. 1991. "Memorandum to Bank Managers. Subject: Managing Development: The Governance Dimension." Washington, DC: World Bank.

48 Interview with Michel Camdessus, former IMF Managing Director (19872000), 17 May 2011. 
49 IMF Archives. 1996. EBS/96/197: 7. In fact, as one senior staff member explained, there was a major debate within the institution about whether the Fund should describe its role as being related to economic governance or just governance. In the end, the PDR Department sent around a memo telling staff not to use the term "economic governance," since the broader forms of governance had significant implications for macroeconomic stability and growth. Interview with Former IMF Executive Board Member, 29 August 2005, Washington, DC. Catherine Weaver has discussed a similar push by internal forces at the World Bank to make governance an acceptable part of the institution's normal mandate. Weaver. Hypocrisy Trap. This claim was confirmed in one of my interviews with a senior former World Bank staff member, Washington, DC, 7 October 2008.

50 World Bank Archives. Doc. 64896. Proceedings of a Seminar: 43.

51 Karl Polanyi and Albert Hirschman both provide masterful analyses of the early history of the liberal market's construction. Karl Polanyi. 1944. The Great Transformation: The Political and Economic Origins of Our Time. Boston: Beacon Press; Albert Hirschman. 1978. The Passions and the Interests: Political Arguments for Capitalism Before its Triumph. Princeton University Press. For a more contemporary analysis of the work involved in creating calculating economic subjects, see: Michel Callon. 1998. "Introduction: The Embeddedness of Economic Markets in Economics." In The Laws of the Markets, edited by M. Callon. Oxford: Blackwell, 1-57.

52 Timmermans and Berg. "Standardization in Action": 275.

53 I elaborate on the way in which the new appeal to moral universals works to depoliticize IFI policies in: Best. "Moralizing Finance"; Best. "Moral Politics."

54 This quote is from a memo from Bank President Barber Conable to Executive Board members. Conable, "Memorandum."

55 World Bank Archives. Doc. 64897. Proceedings of a Meeting: 38.

56 Timmermans and Berg. "Standardization in Action": 292.

57 World Bank. 1997. World Development Report 1997: The State in a Changing World. Washington, DC.

58 IEG. 2008. "Public Sector Reform: What Works and Why?" Washington, DC: Independent Evaluation Group, World Bank. I further discuss the Bank's efforts to reform developing countries' public sectors in Chapter 8.

59 IMF Archives. 1996. EB/CW/DC/97/3: 3.

60 World Bank. 2004. World Development Report 2004: Making Services Work for Poor People. Washington, DC. This blurring of public and private actors is also clear in some Social Development Department documents, including: World Bank. 2011. Demand for Good Governance - Social Development. Available from: http:/go.worldbank.org/09MJLAICW0. I discuss the thin character of this form of participation at greater length in: Jacqueline Best. Forthcoming, 2014 "The 'Demand' Side of Good Governance: the Return of the Public in World Bank Policy." In The Return of the Public in Global Governance, edited by J. Best and A. Gheciu. Cambridge University Press. 
61 Lampland and Star, eds. Standards and their Stories, 9.

62 World Bank. 2010. "Country Policy and Institutional Assessment: Frequently Asked Questions." Washington, DC.

63 Nikolas Rose. 1999. Powers of Freedom: Reframing Political Thought. Cambridge University Press.

64 World Bank. 2007. "The Cambodian Demand for Good Governance (DFGG) Project - An Updated Storyline.” Washington, DC; World Bank. Governance and Anticorruption: DFGG Analytical Framework. Available from http://go.worldbank.org/YQ1WM1P9W0.

65 Robert S. Chase and Anushay Anjum. 2008. "Final Draft: Demand for Good Governance Stocktaking Report.” Washington, DC: World Bank, 14, 19.

66 World Bank Archives. Doc. 64897. Proceedings of a Meeting: 40.

67 Michael Barnett and Martha Finnemore. 2004. Rules for the World: International Organizations in Global Politics. Ithaca: Cornell University Press.

68 Mitchell Dean. 1999. Governmentality: Power and Rule in Modern Society. Thousand Oaks, CA: Sage:193; Peter Miller. 1992. "Accounting and Objectivity: The Invention of Calculating Selves and Calculable Spaces." Annals of Scholarship 9 (1/2): 61-86.

69 Foucault's thoughts on power are distributed among many of his writings. For a particularly thoughtful discussion of the differences among sovereign/ juridical, disciplinary and governmental/security forms of power, see the 11 January lecture in: Michel Foucault. 2004. Sécurité, territoire, population: Cours au Collège de France, 1977-78. Paris: Gallimard.

70 Timmermans and Epstein. "World of Standards": 84. See also: Laurent Thévenot. 2009. "Governing Life by Standards: A View from Engagements." Social Studies of Science 39 (5): 793-813; Susan Leigh Star and Geoffrey Bowker. 1999. Sorting Things Out. Cambridge University Press.

71 On the political consequences of such indices, see: Tony Porter. 2012. "Making Serious Measures: Numerical Indices, Peer Review, and Transnational Actor-Networks." Fournal of International Relations and Development 15 (4): 532-57.

72 Although it was to be just one of three major initiatives to prevent and respond to financial crises, the other two - the Contingent Credit Lines for states who could prequalify for assistance, and the sovereign debt restructuring mechanism (SDRM), which was to act as a kind of international bankruptcy mechanism, both ultimately failed to obtain global support.

73 G7. 1995. "Communiqué of the Halifax Summit of the Heads of State and Government of the Group of Seven and the President of the European Commission." Halifax: Group of Seven; IMF. 1996. "IMF Executive Board Approves the Special Data Dissemination Standard." Washington, DC: International Monetary Fund.

74 IMF Archives. 1997. SM/97/174. Transparency in Government Operations. 2 July.

75 IMF Archives. 1997. SM/97/175. Fiscal Policy Rules. 2 July.

76 IMF Archives. 1997. SM/97/174: 3.

77 IMF Archives. 1998. SM/98/66. Draft Code of Conduct on Fiscal Transparency. 6 March. 
78 IMF. 2000. Code of Good Practices on Transparency in Monetary and Financial Policies. Washington, DC: International Monetary Fund.

79 IMF. 1999. "Summing Up by the Acting Chairman of the IMF Executive Board: International Standards and Fund Surveillance - Progress and Issues." Washington, DC: International Monetary Fund; IMF. 1999. "Experimental IMF Reports on Observance of Standards and Codes: Overview and an Invitation to Comment." Washington, DC: International Monetary Fund.

80 The full list is: "accounting; auditing; anti-money laundering and countering the financing of terrorism (AML/CFT); banking supervision; corporate governance; data dissemination; fiscal transparency; insolvency and creditor rights; insurance supervision; monetary and financial policy transparency; payments systems; and securities regulation." IMF. 2004. Reports on the Observance of Standards and Codes (ROSCs). International Monetary Fund. Available from www.imf.org/external/np/rosc/rosc.asp.

81 IMF Archives. 1997. SM/97/174.

82 Finn Kydland and Edward Prescott. 1977. "Rules Rather than Discretion: The Inconsistency of Optimal Plans." Fournal of Political Economy 85 (3): 473-91.

83 IMF Archives. SM/97/175.

84 IMF Archives. SM/98/66; IMF. "Experimental IMF Reports."

85 Ilene Grabel. 2000. "The Political Economy of 'Policy Credibility': The New-Classical Macroeconomics and the Remaking of Emerging Economies." Cambridge fournal of Economics 24 (1): 1-19.

86 Horst Köhler. 2001. "Standards and Codes: A Tool for Growth and Financial Stability." IMF/World Bank Conference on International Standards and Codes: Washington, DC, 7 March.

87 Camdessus. "From the Crises." Emphasis in original.

88 IMF. "Summing Up."

89 IMF. "Experimental IMF Reports."

90 Köhler. "Standards and Codes"; Charis Christofides, Christian B. Mulder and Andrew J. Tiffin. 2003. "The Link Between Adherence to International Standards of Good Practices, Foreign Exchange Spreads, and Ratings." IMF Working Paper Series (No. WP/03/74); John Cady. 2004. "Does SDDS Subscription Reduce Borrowing Costs for Emerging Market Economies?" IMF Working Papers Series (No. WP/04/58).

91 Jacqueline Best. 2005. The Limits of Transparency: Ambiguity and the History of International Finance. Ithaca: Cornell University Press, Ch. 6.

92 In the case of the GDDS they seek to provide a capacity to measure not only economic factors but also socio-demographic data such as population and public health, enabling, in Foucauldian biopolitical terms, the measurement, constitution and governance of the population.

93 IMF Archives. SM/98/66: 1.

94 The G7 initially advocated more binding rules in 1998, and the UK continued to push for mandatory standards until 2001. Gordon Brown. 2001. Speech by Chancellor of the Exchequer to the Federal Reserve Bank. UK Treasury: London, 16 November; G7. 1998. "Strengthening the Architecture of the Global Financial System.” Report of G7 Finance Ministers to G7 Heads of State or Government for their Meeting in Birmingham, May. 
95 Interview with Jack Boorman, Washington, DC, 31 August 2005.

96 Köhler. "Standards and Codes."

97 Callon. "Introduction."

98 Benu Schneider, ed. 2003. The Road to International Financial Stability: Are Key Financial Standards the Answer? Basingstoke: Palgrave Macmillan; Dani Rodrik. 1999. "Governing the Global Economy: Does One Architectural Style Fit All?" In Brookings Trade Forum, edited by S. Collins and R. Lawrence. Washington, DC: Brookings Institution Press, 105-39. Also, interview with NGO staff member, Washington, DC, 31 August 2005.

99 Grabel. "Political Economy."

100 Moreover, as I will discuss in the Conclusion to this volume, these standards have been contested both within and outside the IFIs, while the techniques used have often failed to achieve their intended effects.

\section{MANAGING RISK AND VULNERABILITY}

1 I have discussed the history of the IMF's conceptualization and management of the unknown in my first book, on the role of ambiguity in international finance. I will not take up these same ideas here, but will focus instead on efforts to manage time and the unknown through particular conceptions of vulnerability and risk. Jacqueline Best. 2005. The Limits of Transparency: Ambiguity and the History of International Finance. Ithaca: Cornell University Press.

2 This policy is discussed briefly in Chapter 6.

3 Jacqueline Best. 2008. "Ambiguity, Uncertainty and Risk: Rethinking Indeterminacy.” International Political Sociology 2 (4): 355-74.

4 While acknowledging the usefulness of Ulrich Beck's early work on the risk society, I am therefore drawing more from the work of Michel Foucault and those scholars, such as Mitchell Dean, who have built on his work: Ulrich Beck. 1992. Risk Society: Towards a New Modernity. London: Sage; Michel Foucault. 2004. Sécurité, territoire, population: Cours au Collège de France, 1977-78. Paris: Gallimard, 57-89; Mitchell Dean. 1999. Governmentality: Power and Rule in Modern Society. Thousand Oaks, CA: Sage.

5 I have written on the limits of risk management in the context of the recent global financial crisis in: Jacqueline Best. 2010. "The Limits of Financial Risk Management: Or, What We Didn't Learn from the Asian Crisis.” New Political Economy 15 (1): 29-49.

6 Mikkel Vedby Rasmussen. 2004. “'It Sounds Like a Riddle': Security Studies, the War on Terror and Risk." Millennium 33 (2): 381-95; Mark Salter. 2008. "Imagining Numbers: Risk, Quantification, and Aviation Security." Security Dialogue 39 (2-3): 243-66; Tony Porter. 2005. Globalization and Finance. Cambridge: Polity Press, Ch. 5; Randall Germain. 2007. "Global Finance, Risk and Governance.” Global Society 21 (1): 71-93; Marieke De Goede. 2004. "Repoliticizing Financial Risk." Economy and Society 33 (2): 197-217; Ulrich Beck. 1992. "From Industrial Society to the Risk Society: Questions of Survival, Social Structure and Ecological Enlightenment." Theory, Culture and Society 9 (1): 97-123. 
7 OED. 1996. “Annual Review of Evaluation Results 1995.” Washington, DC: Operation Evaluation Department, World Bank.

8 These kinds of risk are generally known as "operational" or "institutional" risks, since they are risks to the smooth operation of an institution. Henry Rothstein, Michael Huber and George Gaskell. 2006. "A Theory of Risk Colonization: The Spiraling Regulatory Logics of Societal and Institutional Risk.” Economy and Society 35 (1): 91-112.

9 World Bank. 2001. Social Protection Sector Strategy: From Safety Net to Springboard. Washington, DC.

10 The institution formally adopted this role in 1978 with the Second Amendment to its Articles of Agreement, which, under Article IV, defined surveillance relatively narrowly in relation to member countries' exchange rates. Over time, the scope of Fund surveillance activities expanded considerably to consider first the underlying macroeconomic conditions and then the structural policies that affected countries' balance of payments. James M. Boughton. 2001. Silent Revolution. The International Monetary Fund 19791989. Washington, DC: International Monetary Fund, Ch. 2 and Appendix.

11 The economists discussed here, like those discussed throughout the book, often have close links with the IFIs and donors, particularly the World Bank. Some have worked at one or other of the IFIs at some point, and all have been cited in the key Bank and IMF documents on debt vulnerability and vulnerability assessments as justification for these new policies.

12 Craig Burnside. 2004. "Assessing New Approaches to Fiscal Sustainability Analysis." Washington, DC: World Bank.

13 IMF. 2011. "Managing Volatility: A Vulnerability Exercise for Low-Income Countries." Washington, DC: International Monetary Fund, 26-8; Claudio Raddatz. 2008. "Have External Shocks Become More Important for Output Fluctuations in African Countries?" In Africa at a Turning Point? Growth, Aid, and External Shocks, edited by D. S. Go and J. Page. Washington, DC: World Bank, 343-74; Craig Burnside and Alexandra Tabova. 2009. "Risk, Volatility, and the Global Cross-section of Growth Rates." NBER Working Paper Series (No. 15225).

14 IMF. "Managing Volatility," 29.

15 Daron Acemoglu, Simon Johnson, James Robinson and Yunyong Thaicharoen. 2002. "Institutional Causes, Macroeconomic Symptoms: Volatility, Crises and Growth." Fournal of Monetary Economics 50 (1): 49-123; Paul Collier, Benedikt Goderis and Anke Hoeffler. 2006. "Shocks and Growth: Adaptation, Precaution and Compensation." Department of Economics, Oxford University; Dani Rodrik. 1998. "Where Did All the Growth Go? External Shocks, Social Conflict, and Growth Collapses." NBER Working Paper Series (No. 6350).

16 Most LICs rely almost entirely on concessional borrowing, which is provided at extremely low interest rates, without any interest, or in the form of grants. Nonconcessional borrowing, in contrast, is generally at market rates of interest.

17 IMF. 2009. "Debt Limits in Fund-supported Programs: Proposed New Guidelines." Washington, DC: International Monetary Fund, 19; IMF and World Bank. 2009. "A Review of Some Aspects of the Low-income Country 
Debt Sustainability Framework." Washington, DC: International Monetary Fund and World Bank; Francesco Oddone. 2007. "Debt Sustainability or Defensive Deterrence? The Rise of New Lenders and the Response of the Old." Brussels: Eurodad; Bernhard G. Gunter. 2007. "MDG-consistent Debt Sustainability: How to Ease the Tension between Achieving the MDGs and Maintaining Debt Sustainability." UNDESA/UNDP.

18 Interview with senior IMF staff member, Washington, DC, 14 June 2010.

19 IMF. 2011. "Factsheet: The Joint World Bank-IMF Debt Sustainability Framework for Low-Income Countries." Washington, DC: International Monetary Fund.

20 IMF and World Bank. "Review," 11.

21 IMF. "Debt Sustainability."

22 World Bank. 2010. "Country Policy and Institutional Assessment: Frequently Asked Questions." Washington, DC.

23 IMF and World Bank. "Review," 4.

24 Low-income countries are eligible for concessional financing at the World Bank through the International Development Association (IDA). Ibid., 11.

25 IMF. 2009. "Changing Patterns in Low-income Country Financing and Implications for Fund Policies on External Financing and Debt." Washington, DC: International Monetary Fund, 9.

26 IMF. 2009. "Staff Guidance Note on Debt Limits in Fund-supported Programs." Washington, DC: International Monetary Fund, 5.

27 IMF. 2011. "Concessionality and the Design of Debt Limits in IMFsupported Programs in Low-Income Countries." Washington, DC: International Monetary Fund.

28 IMF. "Debt Limits," 9, 24. The Sub-CPIA includes an assessment of fiscal and debt policy, the quality of budgetary and financial management, and the quality of public administration and transparency, accountability and corruption.

29 In this case staff chose to use the full CPIA, in part because of the strong correlation they found between social inclusion and equity and vulnerability to crisis: the "Managing Volatility" report includes a graph that demonstrates the correlation, with an R2 of .29. IMF. "Managing Volatility," 13.

30 Ibid., 2, 5, 12.

31 World Bank. 1989. Accelerated Development in Sub-Saharan Africa: An Agenda for Action. Washington, DC, 1981; World Bank. Sub-Saharan Africa: From Crisis to Sustainable Growth. A Long-term Perspective Study. Washington, DC.

32 I provide an overview of these two closely related "small i" ideas - public choice theory and new institutionalist economics - in Chapter 4.

33 Acemoglu et al. "Institutional Causes."

34 Collier et al. "Shocks and Growth"; Rodrik. "External Shocks." Collier's conclusions are far more conservative and consistent with traditional neoliberal economics than Rodrik's; nonetheless, they both rely on certain similar institutionalist ideas in their analyses.

35 IMF. "Managing Volatility," 6.

36 IMF. "Changing Patterns," 4. 
37 IMF and Bank. "Review," 4.

38 IMF. "Managing Volatility," 8.

39 Best. "Limits of Financial Risk."

40 Marieke De Goede. 2008. "Beyond Risk: Premediation and the Post-9/11 Security Imagination." Security Dialogue 39 (2-3): 155-76.

41 IMF. "Debt Sustainability."

42 IMF. "Changing Patterns," Annex II.

43 Interview with senior IMF staff member, Washington, DC, 14 June 2010.

44 This is particularly noticeable in the vulnerability exercises, where much attention is placed on the need for an objective and methodologically rigorous evaluation process - in spite, as I will discuss further in the Conclusion, of the difficulties of such an undertaking.

45 Thus, following Foucault, productive power need not be zero-sum. Michel Foucault. 1980. "Two Lectures." In Power/Knowledge: Selected Interviews and Other Writings, 1972-1977, edited by C. Gordon. Brighton: Harvester Press, 92-108. For an excellent application of this argument to international politics, see: Iver B. Neumann and Ole Jacob Sending. 2006. "Governance to Governmentality: Analyzing NGOs, States and Power." International Studies Quarterly 50 (3): 651-72.

46 IMF. "Changing Patterns," 23.

47 Ibid.

48 Ibid.

49 Giorgio Agamben. 1998. Homo Sacer: Sovereign Power and Bare Life. Stanford University Press, 6-7.

50 I do not have the space to discuss the form that this social risk approach has taken in these other institutions, focusing instead on the World Bank, which was the pioneer in both thinking and policy in this area. For some examples of the influence of social risk policy at DFID and the OECD, see: DFID. 2004. "Pro-Poor Growth Briefing Note 2." London: UK Department for International Development; OECD. 2006. "Promoting Pro-poor Growth: Policy Statement." Paris: Organization for Economic Co-operation and Development; Rachel Sabates Wheeler and Lawrence Haddad. 2005. "Reconciling Different Concepts of Risk and Vulnerability: A Review of Donor Documents." Sussex: Institute of Development Studies.

51 I provide a more thorough discussion of the historical evolution of povertyreduction approaches at the Bank in: Jacqueline Best. 2013. "Redefining Poverty as Risk and Vulnerability: Shifting Strategies of Liberal Economic Governance." Third World Quarterly 34 (1): 109-29.

52 Devesh Kapur, John P. Lewis and Richard Webb. 1997. The World Bank: Its First Half Century. Vol. 1. Washington, DC: Brookings Institution Press, 148, 217; Martha Finnemore. 1996. National Interests in International Society. Ithaca: Cornell University Press; Robert McNamara. 1975. "Preface." In The Assault on World Poverty: Problems of Rural Development, Education and Health. Washington, DC; Baltimore: World Bank; Johns Hopkins University Press.

53 John Williamson. 1990. "What Washington Means by Policy Reform." In Latin American Adjustment: How Much Has Happened?, edited by J. Williamson. Institute for International Economics, 5-20. As Antje Vetterlein points 
out, there nonetheless remained a core group of Bank staff committed to advancing the social policy agenda, although they did not have the opportunity to exercise much influence again until the late 1990s. Antje Vetterlein. 2007. "Economic Growth, Poverty Reduction, and the Role of Social Policies: The Evolution of the World Bank's Social Development Approach." Global Governance 13 (4): 513-33.

54 Giovanni Andrea Cornia, Richard Jolly and Frances Stewart, eds. 1987. Adjustment with a Human Face. Oxford University Press for UNICEF.

55 Given the enormous complexity of the World Bank as an organization, the tidy picture that the annual World Development Reports (WDR) present is more than a little misleading. Yet, these reports do serve a useful purpose in outlining major thinking at the Bank at a given moment - particularly the decade-defining reports, which are more central to the Bank's self-definition. Phone interview with former senior World Bank staff member, February 2012.

56 World Bank. 1990. World Development Report 1990: Poverty. Washington, DC, 3.

57 Ibid., 103.

58 Ibid., 90, 100-1. For a discussion of the Bank's safety-net approach to social protection see: Vetterlein. "Economic Growth."

59 World Bank. 2009. Social Protection and Labor at the World Bank, 20002008. Washington, DC, 1, 12; World Bank. 2003. Social Risk Management: The World Bank's Approach to Social Protection in a Globalizing World. Washington, DC, 2.

60 Michel Callon. 1998. "Introduction: The Embeddedness of Economic Markets in Economics." In The Laws of the Markets, edited by M. Callon. Oxford: Blackwell, 1-57; Andrew Barry. 2002. "The Anti-political Economy." Economy and Society 31 (2): 268-84.

61 Dani Rodrik. 2000. "Growth Versus Poverty Reduction: A Hollow Debate." Finance and Development 37 (4); François Bourguignon. 2002. "The Growth Elasticity of Poverty Reduction: Explaining Heterogeneity across Countries and Time Periods." DELTA Working Paper (No. 2002-3); Joseph Stiglitz. 1998. "Towards a New Paradigm for Development: Strategies, Policies, and Processes.” Prebisch Lecture, UNCTAD: Geneva, 19 October. Also, phone interview with former senior World Bank staff member, February 2012.

62 Bourguignon. "Growth Elasticity." While Bourguignon was respected within the Bank before his term as head of the Research Department, his emphasis on equality only came to be widely accepted in the mid to late 2000s. Phone interview with former senior World Bank staff member, 29 February 2012.

63 David Dollar and Art Kraay. 2001. "Growth is Good for the Poor." World Bank Working Paper (No. 2587).

64 Paul Masson. 2001. "Globalization: Facts and Figures." IMF Policy Discussion Paper (No. PDP/01/4); Robert Wade. 2001. "Showdown at the World Bank." New Left Review 7 (Jan-Feb): 124-37.

65 Martin Ravallion. 2004. "Pro-Poor Growth: A Primer." World Bank Policy Research Working Paper (No. WPS3242). 
66 Amartya Sen. 1983. Poverty and Famines: An Essay on Entitlement and Deprivation. Oxford: Clarendon Press.

67 Martin Prowse. 2003. "Towards a Clearer Understanding of 'Vulnerability' in Relation to Chronic Poverty." CPRC Working Paper (No. 24).

68 Frank Ellis, Philip White, Peter Lloyd-Sherlock, Vasudha Chhotray and Janet Seeley. 2008. "Social Protection Research Scoping Study." East Anglia: Governance and Social Development Resource Centre; Naila Kabeer. 2009. "Scoping Study on Social Protection: Evidence on Impacts and Future Research Directions." London: UK Department for International Development.

69 Interviews with senior World Bank staff, June 2010 and May 2011.

70 Robert Holzmann, Lynne Sherburne-Benz and Emil Tesliuc. 2003. "Social Risk Management: The World Bank's Approach to Social Protection in a Globalizing World.” Washington, DC: World Bank, 1.

71 Interviews with senior World Bank staff, June 2010, May 2011 and February 2012.

72 Phone interview with Robert Holzmann, former Director of Social Protection, 15 June 2010.

73 Phone interview with former senior World Bank staff member, February 2012.

74 Phone interview with Robert Holzmann, former Director of Social Protection, 15 June 2010.

75 The PREM and Research Departments tended to support one another in their scepticism about the social risk framework, in opposition to the Social Protection unit. Interviews with senior World Bank staff members, June 2010 and May 2011.

76 In fact, some of the most energetic contestation revolved around the 2000-1 WDR itself. I have discussed these debates and their connection to the social risk framework in: Best. "Redefining Poverty." I do not have the space to repeat them in detail here.

77 World Bank. 2001. World Development Report 2000/01: Attacking Poverty. Washington, DC, Ch. 4. This section was moved to the beginning in later drafts of the report after pressure from conservative economists within the Bank as well as from the US Treasury. Wade. "Showdown."

78 World Bank. Social Protection Strategy.

79 World Bank. WDR: Attacking Poverty, 19.

80 Ibid., 136-41.

81 World Bank. Social Protection Strategy, 12, 23.

82 World Bank. WDR: Poverty, 34-5.

83 World Bank. WDR: Attacking Poverty, 148-50.

84 World Bank. Social Protection and Labor, 45-6.

85 Ibid., 46.

86 Ariel Fiszbein and Norman Schady. 2009. "Conditional Cash Transfers: Reducing Present and Future Poverty." Washington, DC: World Bank; World Bank. 2011. "Building Resilience and Opportunity: Better Livelihoods for the 21st Century: Emerging Ideas for the World Bank's 2012-2022 Social Protection and Labor Strategy." Washington, DC: Social Protection and Labor Unit.

87 World Bank. WDR: Attacking Poverty, 139. 
88 A special issue of the fournal of Development Studies on "Economic Mobility and Poverty Dynamics in Developing Countries" that was particularly influential in shaping the thinking of those at the World Bank working on social risk and vulnerability outlines the main reasons for this shift in measuring poverty: Bob Baulch and John Hoddinott. 2000. "Economic Mobility and Poverty Dynamics in Developing Countries." Fournal of Development Studies 36 (6): 1-24; Holzmann et al. "Social Risk Management."

89 Holzmann et al. "Social Risk Management," 4. In the increased focus on objectives, we can also see the intersection of risk analysis and results-based management, the governance strategy that I will be discussing in the next chapter.

90 World Bank. Social Protection and Labor, Ch. 2.

91 There are clear parallels here with the kind of processes of active economic citizenship described by Nikolas Rose and Ruth Lister: Rose. 1996. "The Death of the Social? Re-figuring the Territory of Government." Economy and Society 25 (3): 327-56; Lister. 2001. "Towards a Citizens' Welfare State: The $3+2$ 'R's of Welfare Reform." Theory, Culture and Society 18 (2-3): 91-111.

92 Andrew Shepherd. 2004. "General Review of Current Social Protection Policies and Programmes." London: UK Department for International Development.

93 World Bank. WDR: Attacking Poverty, 142.

94 Holzmann et al. "Social Risk Management," 9.

95 Together with Alexandra Gheciu, I have provided a more extensive discussion of this transformation of public and private through the logic of practice in: Best and Gheciu, eds. Forthcoming, 2014. The Return of the Public in Global Governance. Cambridge University Press.

96 Holzmann et al. "Social Risk Management," 9.

97 World Bank. WDR: Attacking Poverty, 86.

98 On the "demand side" of good governance, see Chapter 6.

99 Dean. Governmentality.

100 Interviews with senior World Bank staff, 10 and 15 June 2010 and 17 May 2011.

101 World Bank. Social Protection and Labor, 138.

102 World Bank. 2011. "Building Resilience and Opportunity: The World Bank's Social Protection and Labor Strategy 2012-2022 - Concept Note.” Washington, DC: Social Protection and Labor Unit.

103 Best. "Ambiguity, Uncertainty."

104 This is of course a particular financial conception of risk and reward, in which greater risks can be accurately measured, priced and rewarded with greater returns. This kind of conception of risk was at the heart of the recent financial crisis. See also: Best. "Limits of Financial Risk Management."

105 Shepherd. "General Review."

106 Naila Kabeer, Khawar Mumtaz and Asad Sayeed. 2010. "Beyond Risk Management: Vulnerability, Social Protection and Citizenship in Pakistan." fournal of International Development 22 (1): 1-19. 
107 John Farrington. 2005. "Social Protection and Livelihood Promotion in Agriculture: Towards Operational Guidelines.” Paris: Organization for Economic Co-operation and Development Povnet; Kabeer et al. "Beyond Risk."

108 For some other interesting discussions of the new ways in which institutions have recently sought to conceptualize and prepare for the unknown see: Melinda Cooper. 2011. "Complexity Theory after the Financial Crisis." Fournal of Cultural Economy 4 (4): 371-85; Brian Massumi. 2007. "Potential Politics and the Primacy of Preemption." Theory and Event 10 (2); Jeremy Walker and Melinda Cooper. 2011. "Genealogies of Resilience: From Systems Ecology to the Political Economy of Crisis Adaptation." Security Dialogue 42 (2): 143-60.

109 The concept of aporia refers to a puzzle - often in the form of a moment in which a text or speech undermines itself.

110 IMF. "Managing Volatility," 3. Emphasis added.

111 World Bank. Social Protection Strategy.

112 IMF. "Managing Volatility," 6. Emphasis added.

113 Niklas Luhmann. 1998. "The Ecology of Ignorance." In Observations on Modernity, Stanford University Press, 75-111.

\section{MEASURING RESULTS}

1 The notable exception is the IMF, where staff and management have so far largely resisted efforts to get them to adopt a more results-oriented approach, as I will discuss briefly at the end of this chapter and in more depth in the Conclusion to this volume.

2 Michael Power discusses a similar process of making evidence auditable in: Power. 1996. "Making Things Auditable." Accounting, Organizations and Society 21 (2/3): 289-315.

3 For a variety of accounts of this political economic shift, see: David Harvey. 1990. The Condition of Postmodernity: An Enquiry into the Origins of Cultural Change. Cambridge, MA: Blackwell; Eric Helleiner. 1994. States and the Reemergence of Global Finance: From Bretton Woods to the 1990s. Ithaca: Cornell University Press; Mark Blyth. 2002. Great Transformations: The Rise and Decline of Embedded Liberalism. Cambridge University Press; Jacqueline Best. 2005. The Limits of Transparency: Ambiguity and the History of International Finance. Ithaca: Cornell University Press.

4 David Osborne and Ted Gaebler. 1992. Reinventing Government: How the Entrepreneurial Spirit is Transforming the Public Sector. Reading, MA: Addison-Wesley.

5 It is worth noting that the firms that were being mimicked were not the more traditional bureaucratic companies of the pre- and post-war order. Instead, this conception of the firm was based on more recent business thinking coming out of newly developed MBAs and consultant firms (what Nigel Thrfit has called the cultural circuit of capital) who argued for more flexible and performance-based company structures. See: Nigel Thrift. 1997. "The Rise of Soft Capitalism." Cultural Values 1 (1): $29-57$. 
6 See Chapter 6 in particular for a more thorough discussion of public-choice theory.

7 Owen E. Hughes. 2003. Public Management and Administration: An Introduction. Basingstoke: Palgrave Macmillan, Ch. 1.

8 For discussion of the rise of new public management thinking in Thatcher's Britain, see: Christopher Hood. 1991. "A Public Management for All Seasons?" Public Administration 69 (1): 3-19; R. A. W. Rhodes. 1991. "Introduction." Public Administration 69 (1): 1-2.

9 Allen Schick. 1998. "Why Most Developing Countries Should Not Try New Zealand's Reforms." The World Bank Research Observer 13 (1): 123; Beryl Radin. 2007. "Performance Measurement and Global Governance: The Experience of the World Bank." Global Governance 13 (1): 25-33.

10 Interestingly, Schick himself argued against the applicability of the New Zealand model to developing economies. Schick. "Most Developing Countries," 124.

$11 \mathrm{Al}$ Gore. 1993. The Gore Report on Reinventing Government: Creating a Government that Works Better and Costs Less. New York: Times Books. For an overview of the evolution of new public management thinking, see: Hughes. Public Management.

12 OECD. 1990. "Financing Public Expenditures through User Charges." Paris: Organization for Economic Co-operation and Development.

13 Practical Concepts Inc. 1971. "The Logical Framework." Washington, DC: United States Agency for International Development.

14 Andrew Natsios. 2010. "The Clash of the Counter-Bureaucracy and Development." Washington, DC: Center for Global Development, 16-17.

15 USAID. 1994. "Focus on Performance Measurement." USAID Evaluation News 6 (1).

16 Project Analysis and Monitoring Company. 1980. "The Logical Framework." Prepared for the United States Agency for International Development, Document \#PN-AAR-443. Washington, DC. Available from http://pdf. usaid.gov/pdf_docs/PNAAR443.pdf.

17 Natsios. "Counter-Bureaucracy," 21-2.

18 IEG. 2008. "Public Sector Reform: What Works and Why?" Washington, DC: Independent Evaluation Group, World Bank, 13.

19 Radin. "Performance Measurement": 30-2.

20 Robert Chambers. 1994. "The Origins and Practice of Participatory Rural Appraisal." World Development 22 (7): 953-69; Robert Chambers. 1997. Whose Reality Counts? Putting the First Last. London: ITDG Publishing.

21 Chambers. "Origins and Practice": 956.

22 Ibid.: Table 2.

23 For an interesting perspective on these tensions, see: Radin. "Performance Measurement."

24 CIDA. 1994. "A Hitch-Hiker's Guide to Managing for Results.” Gatineau: Canadian International Development Agency; CIDA. 1995. "Draft CIDA Policy for Results-Based Management (RBM)." Gatineau: Canadian International Development Agency.

25 Peter Morgan and Ann Qualman. 1996. "Institutional and Capacity Development: Results-based Management and Organizational Performance." Gatineau: Canadian International Development Agency. 
26 For a discussion of results chains and logical frameworks, see: Jody Z. Kusek and Jay C. Rist. 2004. "Ten Steps to a Results Based Monitoring and Evaluation System." Washington, DC: World Bank; Howard White. 2009. "The Road to Nowhere? Results Based Management in International Cooperation. Available from www.euforic.org/detail_page.phtml?lang=en\&page=resource_ briefing_evaluat_edit3.

27 Chambers. "Origins and Practice": 956.

28 CIDA. 2008. "Results-based Management - 2008 Policy Statement: Amended Terms and Definitions." Gatineau: Canadian International Development Agency. Available from www.acdi-cida.gc.ca/acdi-cida/acdi-cida.nsf/ eng/ANN-102094249-J4B.

29 Kusek and Rist. "Ten Steps," 5.

30 UN. 2002. Report of the International Conference on Financing for Development. Monterrey. Mexico: United Nations, 2. For a later articulation of the US interpretation of the importance of country responsibility and reform in the Monterrey Consensus, see: Andrew Natsios. 2005. "Five Debates on International Development - The US Perspective." Remarks by the USAID Administrator before the House of Lords: London, 12 October.

31 Although "managing for results" is ostensibly only one of the five commitments made under the declaration (along with ownership, harmonization, alignment and mutual accountability), the definition, measurement and evaluation of program and country performance dominates the entire document's discussion of the way forward.

32 Patrick G. Grasso. 2009. "History of Evaluation at the World Bank Group.” American Evaluation Association, World Bank: Orlando, November. On the link between declining success rates and the reform of the OED towards results, see also: Jean-François Baré. 1998. "Of Loans and Results: Elements for a Chronicle of Evaluation at the World Bank." Human Organization 57 (3): 322-23. I discuss the decline in success rates further in Chapter 4.

33 Robert Picciotto. 2002. "The Logic of Renewal: Evaluation at the World Bank (1992-2002).” OED: The First 30 Years Conference. World Bank: Washington, DC, 23 September.

34 Grasso. "History of Evaluation," 11. I will discuss the push for "value for money" in the Conclusion to this book.

35 Interview with IMF Executive Board member, 16 June 2010. Interview with senior World Bank staff member, 15 June 2010.

36 Natsios. "Counter-Bureaucracy," 26.

37 The health sector has the longest history of results-based policy development, and tends to be the easiest to manage along these lines (although there is considerable evidence that certain kinds of results-orientation in the form of waitlist limits, for example, can have perverse effects). As Natsios notes, health has become the dominant sector for many bilateral donors, in part because its outcomes are most easily measured. Ibid., 9.

38 Interviews with senior World Bank staff members, 15 June 2010.

39 British National Archives. 2002. Web archives. Briefing note. UK Objectives at the Annual Meetings of the International Monetary Fund (IMF) and 
World Bank. Available from http://webarchive.nationalarchives.gov.uk/+/ http://www.dfid.gov.uk/News/Consultations/files/briefing_imf_wb.htm.

40 Development Committee. 2003. "Statements Submitted to the Sixty-seventh Meeting of the Development Committee." Washington, DC: IMF and World Bank Development Committee, 95.

41 Baré. "Of Loans and Results." Interview with Ariel Fiszbein, advisor to the Bank's Chief Economist and Senior Vice President for Development Economics, Washington, DC, 15 June 2010.

42 Lucy Hayes. 2005. "Open on Impact? Slow Progress in World Bank and IMF Poverty Analysis." Eurodad, Christian Aid, Save the Children Fund UK and Trócaire, 5.

43 Nora Honkaniemi. 2010. Eurodad Response: Draft Report of the 16th Replenishment of the World Bank International Development Association. Eurodad. Available from www.eurodad.org/4334.

44 Nancy Birdsall and William D. Savedoff. 2010. "Cash on Delivery: A New Approach to Foreign Aid." Washington, DC: Center for Global Development.

45 Interview with former World Bank staff member, May 2011.

46 DFID. 2007. "Results Action Plan." London: UK Department for International Development. Also interviews with UK Government officials, September 2006 and February 2010.

47 Interview with Ruth Driscoll, Research Fellow, Overseas Development Institute and former aide to Development Minister, Clare Short, London, 11 September 2006.

48 CIDA. 2008. "2008 Results-based Management Policy Statement.” Gatineau: Canadian International Development Agency. As the new Performance Measurement Framework table that CIDA officers must fill out makes clear, all development practices must be linked explicitly to the outcomes specified in the logic model, with indicators, baseline data and targets all clearly specified. CIDA. 2009. "Performance Measurement Framework." Gatineau: Canadian International Development Agency.

49 Réal Lavergne. 2002. "Results-based Management and Accountability for Enhanced Aid Effectiveness: A Reference Paper for CIDA Officers Engaged in Capacity Development and Program-based Approaches such as SWAPs." Gatineau: Canadian International Development Agency.

50 I had informal conversations with members of CIDA staff who raised concerns about the direction of the current results-based management framework, but there is little evidence of any public debate on the issue.

51 Lavergne. "Results-Based Management," 15.

52 Interview with UK official, London, 15 February 2010.

53 Interview with David Booth, Overseas Development Institute, London, 9 February 2010.

54 DFID. "Results Action Plan," 1.

55 Interview with Booth.

56 DFID. "Results Action Plan," 10.

57 See Chapter 5 for a more comprehensive discussion of the PRSP.

58 World Bank. 2005. "Result Focus in Country Assistance Strategies: A Stocktaking of Results-based CASs." Washington, DC, 23; World Bank and IMF. 
2005. "Synthesis 2005 Review of the PRSP Approach: Balancing Accountabilities and Scaling Up Results." Washington, DC: World Bank and International Monetary Fund, 17-19. Similar concerns were articulated in interviews with senior IMF staff members, 6 October 2008 and 14 June 2010, and former senior World Bank staff members, 9 May 2007.

59 World Bank. 2003. "Allocating IDA Funds Based on Performance: Fourth Annual Report on IDA's Country Assessment and Allocation Process." Washington, DC: International Development Association.

60 The CPIA, in turn, is based on measuring performance in a range of areas, with over 60 per cent derived from governance indicators. IEG. 2009. "The World Bank's Country Policy and Institutional Assessment: An Evaluation." Washington, DC: Independent Evaluation Group, World Bank.

61 World Bank. 2011. "A New Instrument to Advance Development Effectiveness: Program-for-results Lending. Revised Concept Note.” Washington, DC, 15.

62 Ibid., 8, 11, 25.

63 Simon Maxwell. 2003. "Heaven or Hubris: Reflections on the New 'New Poverty Agenda'.” Development Policy Review 21 (1): 5-25; Rosalind Eyben. 2005. "Donors' Learning Difficulties: Results, Relationships and Responsibilities." IDS Bulletin 36 (3): 98-107.

64 Ilan Kapoor. 2004. "Donor Participatory Governance Evaluation: Initial Trends, Implications, Opportunities, Constraints." Fournal of International Development 16 (2): 157-70.

65 Most of the other recent policies that I have discussed in this chapter from the World Bank's RBCAS and P4R to the new results-oriented CIDA and DFID strategies involve some reference to a participatory process.

66 Interview with senior World Bank staff member, 15 June 2010.

67 Ian Hacking. 2002. "Making up People." In Historical Ontology, Cambridge MA: Harvard University Press, 99-114.

68 For example, Mali's base scenario for $2008-11$ is $\$ 390$ million, which drops to $\$ 237$ million under a low scenario if it fails to meet CPIA targets. This kind of difference between low and base case scenarios also applies for countries receiving regular World Bank as well as concessional IDA loans - such as Ecuador's country assistance strategy (CAS), in which the low scenario involves half the funding of the base scenario. World Bank. 2007. "Country Assistance Strategy for the Republic of Mali for the Period FY08-FY11." Washington, DC, 12 December; World Bank. 2003. "25817 EC. Report and Recommendation of the President of the International Bank for Reconstruction and Development and the International Finance Corporation to the Executive Directors on a Country Assistance Strategy for Ecuador." Washington, DC, 29 April.

69 Peter Miller and Nikolas Rose. 1990. "Governing Economic Life." Economy and Society 19 (1): 1-31; Mitchell Dean. 1999. Governmentality: Power and Rule in Modern Society. Thousand Oaks, CA: Sage.

70 I will discuss further the problems posed by this thin conception of accountability in the Conclusion.

71 Examples include past and present figures within the OECD, USAID, the World Bank and the IMF. Natsios. "Counter-Bureaucracy." Interviews with senior World Bank, IMF and OECD staff members, June 2010 and May 2011. 
72 Interviews with a former senior World Bank staff member and an OECD staff member, May 2011. For an excellent discussion of the pressures to game results indicators in developing countries, Isaline Bergamaschi provides a detailed study of the case of Mali: Isaline Bergamaschi. 2011. Le consensus post-Washington au Mali: Trajectoires, usages et processus d'appropriation, $\mathrm{PhD}$ thesis, École Doctorale de Sciences Po, Institut d'Études Politiques de Paris.

73 Stephen Brown and John Sinclair. 2011. "Transparency and Canadian Foreign Aid." Huffington Post, 1 August; CIDA. 2011. "Key Government of Canada Commitments for the Allocation of the Aid Budget." Gatineau: Canadian International Development Agency.

\section{THE POLITICS OF FAILURE AND THE FUTURE OF} PROVISIONAL GOVERNANCE

1 See Chapter 4 for a full elaboration of Wolin's interpretation of the politics of Weber's methodology.

2 In other words, a "hot negotiation" in Michel Callon's terms.

3 James Ferguson. 1990. The Anti-Politics Machine: "Development," Depoliticization, and Bureaucratic Power in Lesotho. Cambridge University Press, 251-4.

4 Core areas include taxation, trade, exchange rate, monetary policy, public expenditure management and financial sector reform. IEO. 2007. "Structural Conditionality in IMF-Supported Programs." Washington, DC: Independent Evaluation Office, International Monetary Fund, 8.

5 Ibid., 4, 29.

6 Nadia Molenaers and Robrecht Renard. 2003. "The World Bank, Participation and PRSP: The Bolivian Case Revisited." The European fournal of Development Research 15 (2): 140. On the Bolivian case, see also: David Booth and Laure-Helene Piron. 2004. "Politics and the PRSP Approach: Bolivia Case Study." London: Overseas Development Institute; Geske Dijkstra. 2005. "The PRSP Approach and the Illusion of Improved Aid Effectiveness: Lessons from Bolivia, Honduras and Nicaragua." Development Policy Review 23 (4): 443-64; Göran Holmqvist and Karin Metell Cueva. 2006. "If the PRS Experience in Latin America is a Disappointment, What is the Alternative?" Development Policy Review 24 (4): 477-80; Heloise Weber. 2006. "A Political Analysis of the PRSP Initiative: Social Struggles and the Organization of Persistent Relations of Inequality." Globalizations 3 (2): 187-206; Heloise Weber. 2004. "Reconstituting the 'Third World'? Poverty Reduction and Territoriality in the Global Politics of Development." Third World Quarterly 25 (1): 187-206.

7 Laure-Hélène Piron and Andy Norton. 2004. "Politics and the PRSP Approach: Uganda Case Study." London: Overseas Development Institute.

8 IEO. 2004. "Evaluation of the IMF's Role in Poverty Reduction Strategy Papers and the Poverty Reduction and Growth Facility." Washington, DC: Independent Evaluation Office, International Monetary Fund; IMF. 2005. Poverty Reduction Strategy Papers (PRSPs). International Monetary Fund. Available from www.imf.org/external/np/exr/facts/prsp.htm. 
9 Interview with former senior World Bank staff member, Washington, DC, 9 May 2007.

10 Interviews with former senior World Bank staff member, Washington, DC, 9 May 2007, and with senior IMF staff member, Washington, DC, 14 June 2010.

11 After the initial experience with early PRSPs, IFIs introduced the Mediumterm Expenditure Framework in an attempt to link PRSP priorities with specific spending decisions, again with mixed success. For an overview see: Malcolm Holmes and Alison Evans. 2003. "A Review of Experience in Implementing Medium Term Expenditure Frameworks in a PRSP Context: A Synthesis of Eight Country Studies." London: Overseas Development Institute. Minding the Gaps was a World Bank assessment of the domestic challenges of operationalizing PRSPs: World Bank. "Linking the PRS with National Budgets. A Guidance Note." Washington, DC, 2008.

12 Interviews with two senior IMF staff members, Washington, DC, August 2005.

13 Pedro Malan. 2007. "Report of the External Review Committee on BankFund Collaboration." Washington, DC: International Monetary Fund and World Bank. Also, interview with Executive Board member, Washington, DC, 8 May 2007.

14 IMF Archives. 1997. SUR/97/116. Summing-up by the Acting Chairman: Transparency in Government Operations and Fiscal Policy Rules, Executive Board Meeting 97/102, 15 October.

15 World Bank. 2000. Reforming Public Institutions and Strengthening Governance: A World Bank Strategy. Washington, DC, xii, xv; World Bank. 2002. Reforming Public Institutions and Strengthening Governance: A World Bank Strategy. Implementation Update. Washington, DC: World Bank, 17-23.

16 Arguably the Bank already quantifies governance performance through its use of the CPIA, as discussed in Chapter 6.

17 John B. Taylor. 2002. "International Financial Crises: What Is the Role For Government? Increasing Economic Growth and Stability in Emerging Markets." 20th Annual Monetary Conference, Cato Institute: New York, 17 October; Taylor. 2002. "Improving the Bretton Woods Financial Institutions." Annual Midwinter Strategic Issues Conference, Bankers Association for Finance and Trade: Washington, DC, 7 February.

18 Gordon Brown. 2001. "Globalisation.” Press Club: Washington, DC, 17 December; Gordon Brown. "Out of the Ashes." The Washington Post, 17 October 2008.

19 Martha Lampland and Susan Leigh Star, eds. 2008. Standards and their Stories: How Quantifying, Classifying, and Formalizing Practices Shape Everyday Life. Ithaca: Cornell University Press, 13.

20 IMF and World Bank. 2005. "The Standards and Codes Initiative - Is It Effective? And How Can It Be Improved?” Washington, DC: International Monetary Fund and World Bank, 24. See also: Layna Mosley. 2003. "Attempting Global Standards: National Governments, International Finance and the IMF's Data Regime." Review of International Political Economy 10 (2): 331-62. 
21 IMF and World Bank. 2005. "Standards and Codes Initiative"; IMF and World Bank. "The Standards and Codes Initiative - Is it Effective? And How Can it Be Improved? Background Paper." Washington, DC: International Monetary Fund and World Bank. I have discussed this dilemma further in: Jacqueline Best. 2012. "The Limits of Financial Risk Management: Or, What We Didn't Learn from the Asian Crisis." New Political Economy 15 (1): 29-49.

22 IMF and World Bank. "Standards and Codes Initiative," 27.

23 The acronyms stand for: country policy and institutional assessment, public expenditure and financial accountability, debt sustainability analysis and risk and vulnerability assessment.

24 Interview with former senior World Bank staff member, February 2012.

25 World Bank. 2009. Social Protection and Labor at the World Bank, 2000-2008. Washington, DC, 18; Valerie Kozel, Pierre Fallavier and Reena Badiani. 2008. "Risk and Vulnerability Analysis in World Bank Analytic Work FY2000-FY2007." SP Discussion Paper (No. 0812): 27.

26 Kozel et al. "Risk and Vulnerability Analysis," 21.

27 Discussion at a World Bank consultation session on the concept note for the Social Protection and Labor Strategy, Ottawa, 1 June 2011.

28 IMF. 2009. "Changing Patterns in Low-income Country Financing and Implications for Fund Policies on External Financing and Debt." Washington, DC: International Monetary Fund, 21.

29 Charles Wyplosz. 2007. "Debt Sustainability Assessment: The IMF Approach and Alternatives." HEI Working Paper (No. 03/2007).

30 Interviews with World Bank staff, June 2010 and May 2011.

31 World Bank. 2011. "Building Resilience and Opportunity: The World Bank's Social Protection and Labor Strategy 2012-2022 - Concept Note.” Washington, DC: Social Protection and Labor Unit, 7.

32 Ariel Fiszbein and Norman Schady. 2009. "Conditional Cash Transfers: Reducing Present and Future Poverty.” Washington, DC: World Bank, 20-2.

33 Interview with senior IMF staff member, Washington, DC, 14 June 2010.

34 Interviews with senior IMF staff members, 11 and 14 June 2010.

35 Interview with senior IMF staff member, Washington, DC, 14 June 2010.

36 IMF Archives. 2001. SM/01/60 Sup. 1. Conditionality in Fund Supported Programs - Policy Issues. 20 February; IMF Archives. 2001. SM/01/60. Conditionality in Fund Supported Programs - Overview. 20 February.

37 Phone interview with senior IMF staff member, 11 June 2010.

38 Andrew Natsios. 2010. "The Clash of the Counter-bureaucracy and Development." Washington, DC: Center for Global Development.

39 Interview with senior World Bank staff member, 17 June, 2010.

40 Interview with former World Bank staff member, May 2011.

41 Interviews with OECD staff members, May 2011.

42 Interviews with donor and World Bank staff members, Washington, DC, June 2010.

43 The term "appropriate" is a translation from the French, appropriation, which Bergamaschi uses to describe the various strategies through which borrowing governments adapt donor and IFI policies to their own needs. 
Isaline Bergamaschi. 2011. Le consensus post-Washington au Mali: Trajectoires, usages et processus d'appropriation, $\mathrm{PhD}$ thesis, École Doctorale de Sciences Po, Institut d'Études Politiques de Paris.

44 Ibid., 322, 323. For a discussion of some similar findings in Burkina Faso, see: Patrick Guillaumont and Jeanneney Sylviane Guillaumont. 2004. "Une expérience européenne: la conditionnalité de performance au Burkina Faso." Afrique Contemporaine 1 (209): 197-227.

45 Ferguson. Anti-Politics Machine; Timothy Mitchell. 2007. "The Properties of Markets." In Do Economists Make Markets? On the Performativity of Economics, edited by Donald MacKenzie, Fabian Muniesa and Lucia Siu. Princeton University Press, 244-75.

46 Shoshana Magnet. 2011. When Biometrics Fail: Gender, Race and the Technology of Identity. Durham: Duke University Press, 13.

47 This second kind of constructive failure bears significant resemblances to the kinds of institutional hypocrisies that Catherine Weaver examines in her book. Weaver. 2008. Hypocrisy Trap: The World Bank and the Poverty of Reform. Princeton University Press.

48 OECD. 2005. Paris Declaration on Aid Effectiveness. Paris: Organization for Co-operation and Development. The Accra Agenda sought to broaden the conception of ownership somewhat, with some limited effectiveness. Interviews with OECD staff members, Paris, 2 and 4 May 2011.

49 For an excellent overview of such criticisms, see: Bergamaschi. Consensus postWashington.

50 World Bank. "Concept Note," 7.

51 Weaver. Hypocrisy Trap.

52 Bruno Latour. 1993. The Pasteurization of France. Cambridge, MA: Harvard University Press.

53 A number of readers of earlier versions of this manuscript helped me to recognize this open-ended dimension of provisional governance and its implications for how we conceptualize expertise. These helpful readers include Michael Orsini, Paul Langley and Tony Porter.

54 There has been considerable interest in the possibility of a more "trial and error" approach to policy in a number of fields. In the context of the IMF, Phillip Abbott et al. argue for the value of a "policy trailing" approach that incorporates more "flexibility and adaptability" into policymaking. More broadly, there is an emerging literature in the fields of regulation and social theory on the possibility of more experimental forms of knowledge and governance. Philip Abbott et al. 2010. "IMF and Economic Reform in Developing Countries." Quarterly Review of Economics and Finance 50 (1): 17-26; Charles Sabel and Jonathan Zeitlin. 2012. "Experimentalism in the EU: Common Ground and Persistent Differences." Regulation and Governance 6 (3): 410-26; Paul Rabinow. 2003. Anthropos Today: Reflections on Modern Equipment. Princeton University Press.

55 This spirit of experimentation is particularly evident in the discussion of the Cambodian DFGG project, which has since been modified based on lessons learned about which "components" worked best: World Bank. 2007. "The Cambodian Demand for Good Governance (DFGG) Project - An Updated 
Storyline." Washington, DC; World Bank. "Building Resilience"; World Bank, 2012. Demand for Good Governance Project, 2011. Available from www.worldbank.org/projects/P101156/demand-good-governance-project? lang=en.

56 As I discuss in Chapter 8, some early Canadian International Development Agency (CIDA) reports argued strongly for more responsive forms of results management. CIDA. 1994. "A Hitch-Hiker's Guide to Managing for Results." Gatineau: Canadian International Development Agency.

57 These "Fail Faires" were first introduced by an NGO, Mobile Active, and have been expanded to include a wider network of organizations working in information and communications technology and international development. Several Fail Faires have been hosted by the World Bank since 2011. Fail Faire DC. 2012. "Fail Faire: Where It's OK to Talk about Failure." Available from http://failfairedc.com/about; Sarika Bansal. 2012. "The Power of Failure," The New York Times, 28 November. Available at: http://opinionator.blogs. nytimes.com/2012/11/28/the-power-of-failure-2.

58 Michel Callon, Pierre Lascoumes and Yannick Barthe, eds. 2009. Acting in an Uncertain World: An Essay on Technical Democracy. Boston: MIT Press. There are also wider debates in STS about the role of "lay" or popular expertise: Stephen P. Turner. 2001. "What is the Problem with Experts?" Social Studies of Science 31 (1): 123-49; H. M. Collins and Robert Evans. 2002. "The Third Wave of Science Studies: Studies of Expertise and Experience.” Social Studies of Science 32 (2): 235-96; H. M. Collins and Robert Evans. 2007. Rethinking Expertise. University of Chicago Press.

59 Niklas Luhmann. 1998. "Describing the Future." In Observations on Modernity, Stanford University Press, 69.

60 DFID. 2007. "Results Action Plan.” London: UK Department for International Development; CIDA. 2008. "2008 Results-based Management Policy Statement.” Gatineau: Canadian International Development Agency.

61 Jim Yong Kim. 2012. "Remarks As Prepared for Delivery." IMF and World Bank Annual Meeting Plenary Session, Tokyo: 11 October.

62 Interview with OECD-DAC staff member, Paris, 4 May 2011.

63 Barry Hindess. 1996. Discourses of Power: From Hobbes to Foucault. Oxford: Blackwell, 97.

64 As I discuss further in Chapter 6, this approach to accountability appears in many Bank documents and emerged in several of my interviews. The clearest articulation of this market-based conception of accountability (and the one often cited in other documents) can be found in: World Bank. 2004. World Development Report 2004: Making Services Work for Poor People. Washington, DC.

65 Penny Jackson. 2012. "Value for Money and International Development: Deconstructing Myths to Promote a More Constructive Discussion.” Paris: Organization for Economic Co-operation and Development; DFID. 2010. "Mitchell: Aid Agencies to Focus on Value for Money." London: UK Department for International Development; Alistair Scrutton. 2012. "Interview - 'Broken' Multilaterals Need Aid Transparency - Swedish Minister." AlertNet, 2 July. 
66 The UK's increasing focus on development as a way of meeting security objectives has come under fire from Oxfam in recent years: Oxfam. 2011. "Whose Aid is it Anyway? Politicizing Aid in Conflicts and Crises." London: Oxfam UK. For discussion of the politicization of aid in Canada, see: Nilima Gulrajani. 2012. "How Politicization Has Been Silently Killing CIDA's Effectiveness." The Globe and Mail, 6 September; Stephen Brown. 2008. "CIDA under the Gun." In Canada Among Nations 2007: What Room for Manoeuvre, edited by J. Daudelin and D. Schwanen. Montreal: McGill-Queen's University Press, 91-107; Stephen Brown, ed. 2012. Struggling for Effectiveness: CIDA and Canadian Foreign Aid. McGill-Queen's University Press.

67 Interviews with two OECD-DAC staff members, Paris, 4 May 2012. 


\section{People interviewed}

MASOOD AHMED, Director of the Middle East and Central Asia Department, IMF, formerly Director General for Policy at DFID, Deputy Director of Policy Development and Review, IMF, and Vice President for Poverty Reduction and Economic Management (PREM), World Bank

MARK ALlEN, Former Director of Policy Development and Review Department, IMF

THOMAS BERNES, IMF Executive Director (Canada, Ireland and the Caribbean), 1996-2001, and Director, IMF Independent Evaluation Office, 2005-9

GORDON BETCHERMAN, Lead Economist in the Social Protection Unit, World Bank, 1998-2005

JACK Boorman, Former Director of Policy Development and Review, and Special Advisor to the Managing Director, IMF

DAvid воотн, Research Fellow, Politics and Governance, Overseas Development Institute

HUgh BReDenkamp, Deputy Director, Strategy, Policy and Review Department, IMF

ARIEL BUIRA, Former Director of the G-24 Secretariat

MiChel CAMDessus, Former Managing Director (1987-2000), IMF

Ro B CHASE, Lead Social Development Specialist, Social Development Department of the World Bank

JEFF CHELSKY, Senior Economist, PREM, World Bank, and former staff member in the IMF Independent Evaluation Office

JEAN-JACQUES DETHIER, Manager of the Research Services unit in Development Economics, World Bank

RUTH DRISCOLL, Research Officer, Overseas Development Institute and former Special Advisor to Clare Short, UK Secretary of State for International Development 
ARIEL FISZBEIN, Chief Economist for the Human Development Network, World Bank

DAvid Goldsbrough, Former Deputy Director of the IMF's Independent Evaluation Office (2001-6)

eduardo gonzalez, Development Co-operation Directorate, Organisation for Cooperation and Development

Jo MARIE GRIESGRABer, Executive Director, New Rules for Global Finance

KJETIL hansen, Development Co-operation Directorate, Organization for Economic Co-operation and Development

Robert holzmann, Former Sector Director, Human Development Network, World Bank.

emmanuel Jiminez, Sector Director, Human Development, East Asia Region, World Bank

homi kharas, Former Chief Economist, East Asia and Pacific Region, World Bank

Willy kiekens, Former Executive Director (Belgium), IMF

hetty kovach, Aid Policy Advisor, Oxfam UK

Johannes LinN, Former Vice President, Europe and Central Asia, and Vice President, Financial Policy and Resource Mobilization, World Bank

Meg Lundsager, Executive Director (United States), IMF

ABBAS MIRAKHoR, Executive Director and former Dean of the Executive Board, IMF

ALEXandros mourmouras, Chief of the European Division of the IMF Institute and former member of the Policy Development and Review Department, IMF

TOM NEYLAN, Former senior staff member, HM Treasury, United Kingdom

marjolaine nicod, Development Co-operation Directorate, Organization for Economic Co-operation and Development

MARK Plant, Former Deputy Director, African Department, IMF

JACQUES POLAK, Former member of the Netherlands delegation to the Bretton Woods conference and senior IMF staff member and Executive Director, 1947-86

JEFF POWELL, Former Coordinator, Bretton Woods Project

BRUCE RICH, Attorney, Environmental Defense 
RICK ROWDEN, Senior Policy Analyst, ActionAid International US TOM SCHOLAR, Former Executive Director (United Kingdom), IMF and World Bank.

SUNIL SHARMA, Director, IMF Singapore Regional Training Institute and Former Chief, Asian Division, IMF Institute

TED TRUMAN, Assistant Secretary of the US Treasury for International Affairs, 1998-2001

lisa Williams, Development Co-operation Directorate, Organization for Economic Co-operation and Development

Felix zimmerman, Development Co-operation Directorate, Organization for Economic Co-operation and Development

And thirteen other individuals, including senior staff and Executive Directors from the IMF and the World Bank, NGO staff, and US and UK government officials. 


\section{Index}

accountability 205

Acemoglu, Daron 143, 146

ActionAid 107

actors

as factors of governance 28-9

and power $34-6$

adjustment problems, one size fits all approach 79

Adjustment With a Human Face 151

Adler, Emmanuel 23

Agamben, Giorgio 36, 150

Ahmed, Masood 94

aid effectiveness 7, 73, 76, 81-2, 91, 93, aid failure $40-1$ 99-100, 105, 107-8

AIDS crisis 84, 139-40, 151-2

ANT (actor network theory) 13, 22, 92

Asian financial crisis 73-6, 78-9, 84, 95, 139-40, 151-2, 189-90

Assessing Aid: What Works, What Doesn't and Why 81-2

Attacking Poverty 120-1, 154-5

Atwood, Brian 169-71

austerity, and IMF 3

authority

charismatic 32

in governance 32-4, 61-2

and power $34-6,148-50$

Baker, James 87

Barnett, Michael 14, 34, 128

Barry, Andrew 67, 73

Basel Committee on Banking Supervision 116-17

Beck, Ulrich 160

Benn, Hilary 98-9

Benn, Tony 98

Berg, Elliot 49, 51-2

Berg, Marc 125

Berg Report (1981) 49, 51-2, 62-3, 75, 146

Bergamaschi, Isaline 199

Bernes, Thomas 97 best practices 194

black-boxing 15, 41, 138, 146, 191, 193-6, 200

Blair, Tony 69, 97

Boorman, Jack 108, 122

Booth, David 177-8

Bourdieu, Pierre 22-4

Bourgignon, François 152, 175-6

Broughton, James 53, 58

Brown, Gordon 98, 107

Brown, Stephen 185-6

Building Institutions for Markets 120-1

bureaucratic techniques 30

Burnside, Craig 101, 142-3

Callon, Michel 6, 14, 22, 28, 30, 67, 73, 136, 146, 152, 165-6, 203

Camdessus, Michel 94, 108-9, 115, 122-4, 133-4

Canadian International Development Agency see CIDA

cancer of corruption speech 115, 120-1

CCT (conditional cash transfer) strategy 155, 197

CDF (comprehensive development framework) 93, 108

CGD (Centre for Global Development) 176

Chambers, Robert 171-3

change, understanding 15, 39-42

charismatic authority 32

Christian Aid 107

Christiansen, Karin 106

CIDA 3-4

development policies 11-12

governance factors 118

results measurement difficulties 198

results-based management $171-2,177$, 185-6

citizen report cards $127-8,138$

citizen-consumers $126-8$

civilizing globalization 33, 50, 115 
Clausen, A.W. 48, 60-1, 86, 150-1

Clinton, Bill 69

COD (cash on delivery) approach 176

cold negotiations 73

Collier, Paul 83, 98, 101, 143, 146

commitment technology 101

conditional fund programs 58

conditional lending 101-2

conditionality

and commitment 102

informalizing power $103-5$

policies 20-1, 58, 95-6, 101-2, 197

and political will 105

post-conditionality 103

redesigning 95-105

and selectivity 105

small "i" ideas 101-2

streamlined 205

technical assistance 103

techniques in 102-3, 200

consent, instrumental approach to 205

constructivist theory 39

contested failures $6,40,67$

contingency, and structural adjustment 83-5

Cooper, Melinda 16

corruption 115, 120-1, 194

country ownership see ownership strategies

CPIA (country policy and institutional assessment) 103, 118, 127-8, 144-6, 162, 196

creative accounting 131

credibility theory 101-2, 132-3

crisis of governance 119

crony capitalism 74

Danilovich, John 104-5

De Goede, Marieke 148

Dean, Mitchell 16, 129, 160

debt sustainability see DSA; DSF

debt vulnerability 143

demand-side see governance

demandingness 81

deniability 138

Department for International Development (UK) see DFID

developing global standards strategy 4, 8-9, 45, 115-38, 189-90, 194-7

development and partnership 107-8

Development Research Group 93

DFGG (demand for good governance)

DFID

$$
\text { 127, } 203
$$

and aid effectiveness 99-100

conditionality policies $20-1,99$ criticism of World Bank 98

development policies 3-4, 11-12

governance factors 118

informalizing power $103-5$

political issues 77

and poverty risk 150

qualitative/quantatitive evaluation $176-8$

Results Action Plan 177-8

results feedback by $177-8$

results measurement difficulties 198

and risk and vulnerability 140-2

social risk policy $25-6$

step-by-step conditions 104

diplomacy 23

Discourses of Power 204-5

Doing Business indicators 127-8, 138, 148-9

Dollar, David 67, 78, 93, 101, 152

domestic policy intervention 78

domestic stability and aid failure 40-1

donor agencies 8

qualitative/quantatitive results measurement $176-8$

see also DFID; IMF; MCC; World Bank

donor state policies 98-100, 114

donor-oriented management 177

Driscoll, Ruth 103

DSA (debt sustainability analysis) 144-5, 147-8, 162, 190, 196

DSF (debt sustainability framework) $144-5,147-8$

duty of universal responsibility 133-4

Duvall, Raymond 34

The East Asian Miracle 78-9

economic adjustment see governance, adjustment

economic conditionality 47

economic volatility $142-3$

economic/political distinctions 50-2

EFF (Extended Fund Facility) 54-5

Emergency Recovery Assistance 55

empirical contributions 11-12

Epstein, Steven 129

ESAF (Enhanced Structural Adjustment

Fund) see IMF

estimated economic statistics 5

evaluation and measurement 56-9

evidence-based policies 165-6

experimental policies 202-3

expert authority 16, 32-3, 56, 62

centrality of 13

and conformity 105

doubts on 140

fragility of $71-3,85,189-91,195-6$ 
expert authority (cont.)

IMF limitations 202

and results measurement 165

and results-based management 183-4

role of 70

extended financing facilities 53

external financing guidelines 144-5

factors of governance see governance

Fail Faires 203, 261

The Failings of Conditionality 99-100

failure

as benign/constructive 199-200

deniability 138

destructive effects 200-1

and governance 38-41, 72, 200-1

and government strategies 41

new failures 191-9

of performance 192-4, 196-7

of performativity 196-7

politics of 5-6, 73-6, 85, 190-1

and results measurement 165, 184-5

significance of 199-202

in structural adjustment era 191

to black-box 191, see also black-boxing

Failure of Conditionality 98

failure of government, and new public management 167-9

Ferguson, James 11, 40, 191, 200

field-oriented management 177

fields concept 24

financing development 37

Finnemore, Martha 14, 32-3, 39, 128

fiscal policy, best practices 136-7

Fiscal Policy Rules 131, 133, 135-6

fostering ownership see ownership strategies

Foucault, Michel 6, 14, 22, 26-7, 39, 112, 117, 129-30, 204-5

fragility of expertise see expert authority

FSAP (Financial Sector Assessment Program) 84-5, 140

Gaebler, Ted 167

GDDS (general data dissemination standard) 130-2, 135-6

global financial crisis (2008) 73-6, 139-40, 189-90

global standards development 4, 8-9, 45, 115-38, 189-90, 194-7

Gore, Al 168-9

Gould, Jeremy 103

governance

actors excluded from 35-6

actors in 28-9, 125-6

at a distance 28 authority in $32-4,63,128-30$

changes in 13, 24-5, 145-50

and corruption 115, 120-1, 194

crisis of 119

delegated authority 35

demand-side $78,107-8,117,119-21$

direct 66-8

epistemological assumptions $31-2$

evaluation 29

expertise and authority 32-3, 62

expertise and failure 15-16, see also expert authority

factors of $9,17,21,27-36,145-50$

and failure 15-16, 38-41, 161

global 8, 20, 68-70

traditional accounts of transformations 68-70

good governance 116-30

form of standards 124

moral claims for 70-1

principles 124

universals $122-5$

ideas in 30-2

IMF policy $121-2$

implications of 10-11

inscription 14, 29-30, 37, 112, 127-8

causal chain inscription 172

performance and consensus 11

performative inscriptions 166, 190

ROSC role as 134-5, 195

techniques 110-11, 180-3

and institutional economics 120-1

knowledge and ideas in 30-2

measurement 29

new actors in 125-6

new techniques in 126-8

ontological assumptions 31-2, 38

politicization of 10-11

and power $32-4,61-2,111-12,128-30$

practices $13-14,22-5,37-8,46$

proactive strategies 38-9

proactive/pre-emptive action 162

problematization $6,26-8,37,40$

provisional 4-5, 13, 16-17, 37-8, 63, 113-14, 137-8, 160-3, 184-6, 190-1

alternative directions 202-4

future of 202-8

political implications 204-6

rent-seeking 119-20

and results measurement analysis 180-4

results-oriented approach 164, 172-4, $180-4$

risk-averse 207

standards and codes $20,116-17,130-7$ 
analysis of 132-7

enforcement of 137

performative techniques 134-5

strategies $4,6,8-9,17-18,21,25-7$, $36-9,41,45-6,64-5,86-7$

standardization of $137-8$

see also ownership; results; risk; standardization

structural adjustment see structural adjustment

styles 10, 17, 36-9, 63

supply-side 49-50, 61, 205

techniques in 29-30, 38, 126-8

universality 48-50, 122-5

World Bank legality 120

see also IMF; poverty; risk and vulnerability; World Bank

governing through measurement 166 government accountability 205

government strategies and failure 41

Grabel, Ilene 136

Grasso, Patrick 174-5

Group of 2460

Growth is Good for the Poor 152

growth policy debate 152

Guidance Note on Governance 122

habitus 23

Hacking, Ian 28

Harrison, Graham 103

Helleiner, Gerald 48, 51-2

Hindess, Barry 204-5

HIPC (highly indebted poor countries)

Holzmann, Robert 153-4 initiative 94, 106, 122, 139-40

hot negotiations 6,73

Hovland, Ingie 106

"how to" guides 29

\section{IDA (International Development} Association) 118, 144-5, 179

ideas in governance 30-2, see also governance

IFI policy, and capitalism 69

IMF

Article IV consultations 121, 127

and austerity 3

authority sites in governance 125-6

best practices 194

and capitalism 69

as Clearing Union 53

conditional fund programs 58

conditional lending 47

conditionality policies 20-1, 58, 95, 102, 197 contested failures 73-6

and CPIA 196

development policies 3-4, 11-12, 17

disaster relief 55

and domestic policies 49-50

DSA (debt sustainability analysis) 144-5, 147-8, 162, 190, 196

economic/political distinctions 50-2

EFF (Extended Fund Facility) 54-5

ESAF (Enhanced Structural Adjustment Fund) 54-5, 66, 82-3, 94

evaluation and measurement 56-9

experimental policies 202-3

expertise and authority 32-3, 62

extended financing facilities 53-5

extended loans 59

fields of development finance 24

FSAP (Financial Sector Assessment Program) 84-5

GDDS (general data dissemination standard) 130-2, 135-6

global standards development 115-38

good governance

agenda $116-17$

moral claims for 70-1

policy 121-2

universals $122-8$

influential practices 35

informalizing power 103-5

Interim Committee directive 121

interventionism 50

lending to LICs 49-50

macro-critical program objectives 97

moral authority 33

moral policies 133-4

neoclassical principles $60-1$

new actors in governance 125-6

new powers and authority 128-30

new techniques in governance 126-8

OPEC crisis $54-5$

ownership strategies see ownership strategies

PFP (policy framework paper) 61

and Polak model 49, 53

policies 20, 45, 49, 69

policy uncertainties $52-3$

and politics $76-8$

politics/economics boundary 123

and poverty 65

practices 46, 68

pressures to reform 97

provisional estimates 5

PRSPs 106-9

reviews 193

uncertainty about 193-4 
IMF (cont.)

ranking system $148-9$

remit issues $194-5$

resistance to results measurement 185

results measurement difficulties 198

results-oriented policies 197-9

risk and vulnerability 84-5, 140-2

SAF (Structural Adjustment Fund) 54-5

SDDS (special data dissemination standard) 130-2, 135-6

shock/vulnerability policies $144-5$

and short-term balance-of-payments problems 53

and short-term loans 54-5

stand-by arrangements 53

standards and codes initiative 20, 116-17, 127, 130-7

step-by-step conditions 104

streamlining at $95-7$

streamlining report 192

and structural adjustment $46-8,52$, 59-64, 70-1, 73, 76

success/failure evaluation 7, 64, 80-3, 86

supply-side economics 49-50, 61

time horizon 54-5, 59, 63

universality $48-50$

vulnerability assessment exercise 162

inclusive exclusion 36

indirect power $136-7$

indirect techniques 38

informal techniques 102-3

informalizing power $103-5$

inscription see governance

institutional learning 70

institutionalist economics 146-7, 156, 189-90

International Accounting Standards Board 116-17

International Monetary Fund see IMF

international organizations see IOs

IOs $7-8,14$

IPE (international political economy) 12

IPE (international political economy) literature 13

IR (international relations) 13, 22

Jim Yong Kim 203-4

Jubilee 2000107

Kanbur, Ravi 152

Keynes, John Maynard 53

Keynesian ideas 167

Killick, Tony 99-101

Kim Jong Kim 3

King, Anthony 24 knowledge in governance $30-2$

knowledge-making practices 23

Köhler, Horst 95-6, 115, 133-4, 136

Kraay, Art 152

Kreuger, Anne 48-9, 60-1, 150-1

Lampland, Martha 195

Latour, Bruno 14, 22, 28-30, 68, 165-6, 201

legal-bureaucratic authority 32

LICs (low-income countries)

active role by 147

actors in 147

debt vulnerability 143

differentiation among 150

economic policies/outcomes 4

and economic volatility $142-3$

financial risks to 142

and global crises 139-40

IDA lending to 179

IMF lending to 49-50

internal mismanagement 146

internal/external factors $146-7$

non-concessional finance controls 144

organizational changes 129

poor countries, vulnerability to shock 142-50

power and authority $148-50$

responsibilities of $94-5$

LOGFRAME (logical framework) analysis see results measurement

low-income countries see LICs

Luhmann, Niklas 16, 162, 203

McNamara, Robert 33, 45, 47-51, 56-7, 60-1, 63, 80, 86-7, 109, 150-1

macro-critical program objectives 97

Magnet, Shoshana 199

making up people 28

managing risk and vulnerability see risk and vulnerability

market failure 120

market-friendly policies 79

Martin, Paul 168-9

material/discursive link 13

MCC (Millennium Challenge Corporation)

11-12, 77, 100, 104-5, 118, $176-7$

MDGs (millennium development goals) 20-1

measuring results see results measurement

Meltzer Commission 97

meso-level analysis 21-2, 117

methodological innovations 12-13

methodology (Weber) 71-2 
Miller, Peter 129

Mitchell, Timothy 11, 40, 200

Molenars, Nadia 192-3

Monterrey Consensus (2002) 174

monetary policy, best practices $136-7$

moral authority 33

moralization, of finance and development 48

Natsios, Andrew 169-71, 175, 198

neoclassical principles $60-1$

neutrality of standards 195

new institutionalist economics 146-7, 156, $189-90$

New International Economic Order 60

new public choice theory $82,87,101-2$, $146-7,167-8,189-90$

new public management 166-9, 189-90

in development agencies 169-72

practices 126

NGOs $7-8$

policy trends 8-9

non-concessional finance controls 144

non-governmental organizations see NGOs

Norton, Andy 192-3

objective failures 40

obsessive measurement disorder 198

ODI (Overseas Development Institute) 99-100

OECD (Organization for Economic Co-operation and Development) 25-6, 107, 116-17, 140-2, 150, 168-9, 199, 204

oil crisis (1970s) 167

Omeish, Salem 119

OPEC crisis $54-5$

open-ended character of world 72

Organization for Economic Co-operation amd Development see OECD

Osborne, David 167

ownership strategies $4,8-9,21,27,45,76$, $79,87-8,91-114,192-4$

assumptions 91

country ownership $27,80,92-3,100$, 106, 189-90

evolution of $92-5$

IMF policy 94

policy environment 93

World Bank performance 93

Oxfam 107

\section{P4R (Program for Results Lending) $179-80$}

Paris Declaration (2005) 174, 199
Park, Susan 40

participation 107-8, 120-1, 192-4

participatory development and evaluation 166-7, 171-3

Partnerships for Poverty Reduction: Rethinking Conditionality 99

PBA (performance-based allocation) 179

Peretz, David 123-4

performance failure 192-4, 196-7

performance-based allocation 182-3

performance-based legislation 169-71

performative inscriptions 166

performativity failure $196-7,200$

PFPs (policy framework papers) 61

Pickford, Stephen 97

Piron, Laure-Hélène 192-3

Polak model 49, 53

policy clusters $20-1$

policy environment 93

policy uncertainties $52-3$

political economy 77,101

political implications, of political governance 204-6

political will 80

politics of failure 5-6, 73-6, 85, 190-1

politics/economics boundary 123

poor countries, vulnerability to shock 142-50, see also LICs

popular authority 33-4

post-conditionality 103

postmodernist theory 39

Pouliot, Vincent 23-4

Poverty 151

poverty

conceptual frameworks 157

as dynamic 156

and empowerment 155

growth policy debate 152

and market failure 156-7

and opportunity 154

poverty projects 86

poverty reduction $107,150-60$

reconceptualizing techniques 157

risk/vulnerability 150-60

and security 154

small "i" ideas 156-7

World Development Report strategy 151

see also risk and vulnerability

power

and authority 34-6, 148-50

and governance $32-4,61-2,111-12$, 128-30

indirect $129,136-7$

juridical 204-5

types of 129-30 
PRA (participatory rural appraisals) 171-3 practical knowledge 23-4

practice theory $22-5,34$

predictive power 83

PREM (poverty reduction and economic management) 77, 154, 171, 178

pro-poor growth 152

proactive/pre-emptive action, in governance 162

problematization $6,26-8,37,40$

productive conception of power 34

program lending 47

provisional governance see governance

PRSPs (Poverty Reduction Strategy Papers) 9, 12-13, 17-18, 20-1, 30, 77, 91, 106-12, 190, 205-6

authority forms 111-12, 203

and donor strategies 114

excluded groups 112

failures in 192-4, 199, 201

goal of 111

limits of 201

new techniques $110-11$

and ownership strategies 113-14

power 111-12, 201

informalization 112

relations 112

results-orientation of 178-9, 181

and structural adjustment 113

technical limits 193

PSIA (Poverty and Social Impact

Assessment) 175-6

public management see new public management

public participation 120-1, 182-3

public sector expansion 167

qualitative/quantitative results indicators 176-8, 204

Rabinow, Paul 202

Raddatz, Claudio 142-3

Ravallion, Martin 154

RBM (results-based management) 203

reflexive government 129

Renard, Robrecht 192-3

rent-seeking 119-20

report cards $127-8,138$

results chain 166

results matrix 25

results measurement

actors 181-2

causal chain 172

in development agencies 169-72

difficulties with 198 donor agencies qualitative/quantatitive evaluation $176-8$

and failure $165,184-5$

governance analysis 180-4

governing through measurement 166

history of 166-72

international agreements 174

LOGFRAME (logical framework)

analysis $166-7,169,181$

massaged published results 185-6, 199

need for $165-6$

negative aspects of 185-6

new public management thinking 166-9

New Zealand approach 172

in OECD countries 168-9

participatory development and evaluation $166-7,171$

pervasiveness of 184-5

PREM (poverty reduction and economic management) $77,154,171$

recent developments $174-80$

resistance to 185

results culture 145

strategies $4,8-9,18,21,45,76,87-8$, 189-90

World Bank initiatives 178-80, see also World Bank

results-oriented approaches 164, 197-9

analysis of 172-4

risk and vulnerability $18,21,26,76,84-5$, $87-8,140-2$

actors in risk management 158-9

debt sustainability 144-5, see also DSA; DSF

debt vulnerability 143

framework 154-5

governance factors 155-6, 207

individuals' roles 158-9

internal/external factors $146-7$

managing 4, 8-9, 45, 189-90, 195-7

minimalist approach 146

monitoring and communicating 148

poverty $150-60$

power and authority 159-60

provisional governance 160-3

risk-averse governance 207

risk/vulnerability conceptual differences 160-1

RVAs (risk and vulnerability assessments) 157

scenario analysis 148

shock vulnerability $142-50$

tail risks 148

techniques 147-8 
vulnerability assessment exercises 145 , 147

World Bank assessments 196

Rodrik, Dani 143, 146, 152

ROSC (reports on observance of standards and codes) 30, 132-5, 138, 190, 195, 201

Rose, Nikolas 34, 60, 110-11, 160

Rothstein, Henry 16

Rouse, Joseph 32, 34

RRA (rapid rural appraisals) 171-3

Ruggie, John Gerard 70

RVAs (risk and vulnerability assessments) see risk and vulnerability

Sabel, Charles 202

SAF (Structural Adjustment Fund) 54-5

SALS see structural adjustment

scenario analysis 148

Schatzki, Theodore 22

Schick, Alan 168

Scholar, Tom 98

science of delivery 204

SDDS (special data dissemination

Sen, Amartya 152 standard) 130-2, 135-6

Sewell, William 24

Shihata, Ibrahim 120-1

shock

different effects of 143

policies 144-5

poor countries vulnerability to $142-50$

Short, Clare 98-9, 107, 115, 176-7

Sikkink, Kathryn 39

small “i” ideas 101-2, 146-7, 156-7, 166-7, 189-90

Social Protection and Labor unit 153

social protection policies 157

social risk framework, criticisms of 196

social risk policy 25-6, 159-60, 200

CCT (conditional cash transfer) strategy 155,197

social theory 22

social welfare/protection debate 152-4

sound economics 123, 128

SPS (social protection strategy) 196-7

stand-by arrangements 53

standardization concept 26

standardization era 48

standardization strategies $21,76,87-8$

standards and codes see governance

Star, Susan Leigh 195

The State in a Changing World 66, 125-6

step-by-step conditions 104

Stern, David 24
Stiglitz, Joseph 3, 47, 69, 74, 111, 152

strategy of ownership see ownership strategies

structural adjustment 7, 37, 41-2, 46-8, 52, 59-68, 70-1, 73, 86

contingency 83-5

problematization of practices 76-85

problems/possibilities of politics 76-8

as PRSPs 113

SALs (structural adjustment loans) 47, 51, 53, 95, 111

success/failure debate $80-3$

technical universals 78-80

WDR reports 151

structural conditionality 61-2

structure and agency 23

STS (science and technology studies) 13, 22, 117

Sub-Saharan Africa: From Crisis to Sustainable Growth 119

sub-Saharan development crisis 73-6, 151-2, 189-90

Summers, Lawrence 97

supply-side see governance

sustainability 57

Svensson, Jakob 78, 81-2, 101

symbolic practices 38

symbolic techniques $102-3$

tacit knowledge 23-4

tail risks 148

targeted poverty reduction 86

technical assistance, by donors 103

technical democracy 203

technical expertise, influence of 137

technical universals $78-80$

technologies of community 34, 110-11, 181

theoretical insights $13-17$

Timmermans, Stefan 125, 129

traditional authority 32

Transparency in Government Operations 131 trickle-down development 86-7

understanding change 15, 39-42

UNICEF 151

universal responsibility 133-4

universality 48-50

of good governance 48-50, 122-5

of standards 115-38

US Government Performance and Results Act 169-71

USAID 169-71, 198

political issues 77

Use of Pleasure 26-7 
Vetterlein, Antje 40

VFM (value for money) approach 207

vulnerability see risk and vulnerability

Wade, Robert 78-9

Walker, Jeremy 16

Walters, William 14

Wapenhans Report (1992) 81

Washington Consensus 47, 50, 64, 150-1

WDR (World Development Report) 66, 154-5

Weaver, Catherine 200

Weber, Max 7, 32, 71-2

What Explains the Success or Failure of Structural Adjustment Programs? 81-2

Willoughby, Christopher 57

Wolfensohn, James 93, 108, 115, 120-1, 175-6

Wolfowitz, Paul 118, 125, 175, 194

Wolin, Sheldon 7, 67, 71-2

Woolgar, Steve 14, 29-30

World Bank

authority sites in governance 125-6

Berg Report (1981) 49, 51-2

best practices 194

and capitalism 69

CDF (comprehensive development framework) 93

changes at $97-8$

COD (cash on delivery) approach 176

conditionality policies $20-1,95,97-8$, 102-3

contested failures 73-6

debt ratings $144-5$

development policies 11-12, 17

DFGG (demand for good governance) 127

Doing Business indicators 127-8, 138, 148-9

and domestic policies 49-50

economic conditionality 47

economic/political distinctions 50-2

emergency loans 55

Emergency Recovery Assistance 55

and ESAF 82-3

evaluation and measurement 56-9

experimental policies $202-3$

expertise and authority 32-3, 62

extended loans 59

fields of development finance 24

global standards development 115-38

governance

and corruption $120-1$

good governance 118-21 agenda $116-17$

moral claims for $70-1$

universals $122-8$

legality 120

see also governance

IDA (International Development

Association) 118, 144-5, 179

influential practices 35

informal conditions 102-3

informalizing power $103-5$

interventionism 50

market-friendly policies 79

moral authority 33

moral policies 133-4

neoclassical principles $60-1$

new actors in governance 125-6

new powers and authority $128-30$

new techniques in governance $126-8$

OED (Operations Evaluation

Department) 55-7, 64, 66, 93, 140, 175

orthodoxy of 60-1

ownership strategies see ownership strategies

P4R (Program for Results Lending) 179-80, 182

PBA (performance-based allocation) 179

performance of 93

PFP (Policy Framework Paper) 61

policies 45, 48-9, 69

policy uncertainties $52-3$

and politics $76-8$

politics/economics boundary 123

and poverty 65

poverty projects $86-7$

practices 46,68

PREM (poverty reduction and economic management) $77,143,154,171$, 178

program lending 47

provisional estimates 5

PRSPs 106-9

reviews 193

uncertainty about 193-4

and public sector management practices 126

results management $171,175-6$

results measurement difficulties 198

results-based initiatives $178-80$

results-oriented policies 197-9

risk and vulnerability $84,140-2$

RVAs (risk and vulnerability assessments) 157

SALs 53

shock/vulnerability policies $144-5$ 
short-term economic reform 53

Social Protection and Labor unit 153 social protection policy $152-4$

social risk policy $25-6$

standards and codes initiative $116-17$

step-by-step conditions 104

and structural adjustment $46-8,52$, 59-64, 70-1, 73, 76 and sub-Saharan Africa 40-1, 63

success/failure evaluation $7,64,80-3$, 86

sustainability 57

time horizon 53-5, 59, 63

universality $48-50,126-8$

Wyplosz, Charles 196

Zeitlin, Jonathan 203 
